DOUGLAS FABICHAK JUNIOR

ARQUITETURAS DE DISTRIBUIÇÃO DE AR EM CABINES DE AERONAVES: ANÁLISE EXPERIMENTAL DA DISPERSÃO DE PARTÍCULAS EXPIRATÓRIAS

São Paulo

2014 
DOUGLAS FABICHAK JUNIOR

\section{ARQUITETURAS DE DISTRIBUIÇÃO DE AR EM CABINES DE AERONAVES: ANÁLISE EXPERIMENTAL DA DISPERSÃO DE PARTÍCULAS EXPIRATÓRIAS}

Dissertação apresentada à Escola Politécnica da Universidade de São Paulo para obtenção do título de Mestre em Engenharia

Área de concentração:

Engenharia Mecânica

Orientador:

Prof. Dr. Arlindo Tribess

São Paulo

2014 
Este exemplar foi revisado e alterado em relação à versão original, sob responsabilidade única do autor e com a anuência de seu orientador.

São Paulo, 24 de janeiro de 2014

Assinatura do Autor

Assinatura do Orientador

\section{FICHA CATALOGRÁFICA}

Fabichak Jr., Douglas

Arquiteturas de distribuição de ar em cabines de aeronaves: Análise experimental da dispersão de partículas expiratórias. Douglas Fabichak Jr. - ed. rev. - São Paulo, 2014. $126 p$.

Dissertação (Mestrado) - Escola Politécnica da Universidade de São Paulo. Departamento de Engenharia Mecânica.

1. Ventilação 2. Qualidade do ar 3. Dispersão de partículas 4. Cabines 5. Aeronaves I. Universidade de São Paulo. Escola Politécnica. Departamento de Engenharia Mecânica II. t 
À memória de meu pai. 


\section{AGRADECIMENTOS}

Ao meu orientador, Prof. Dr. Arlindo Tribess, primeira pessoa que encontrei na Universidade e que me ajudou em todos os caminhos que percorri, fundamental para o desenvolvimento deste trabalho.

Aos meus pais, especialmente minha mãe que me educou, orientou e com amor me ensinou conceitos de caráter e bondade, que sempre fizeram parte de sua postura como mãe e mulher. Às minhas irmãs Alexandra e Flávia, aos meus cunhados Leonardo e Luís Henrique, e a minha sobrinha Helena, agradeço por me apoiar nos piores e por estar presente sempre nos melhores momentos da minha vida.

Aos amigos do laboratório de Conforto Térmico e Qualidade do $\mathrm{Ar}$ do Departamento de Engenharia Mecânica da Escola Politécnica da USP, que me apoiaram fortemente na realização deste trabalho, dentre eles, agradeço ao Físico José Carlos Orsi Morel, ao Técnico Sidney Castilho Alves, ao Técnico Vilson Ribeiro dos Santos, à Arquiteta Adriana Camargo de Brito, ao Eng. Sandro Tavares Conceição, e em especial ao Eng. Rogério Vilain, que me auxiliou em todas as etapas na realização desse trabalho.

Ao meu amigo Eng. Evandro Souza da Silva, pelo grande apoio na realização dos ensaios deste trabalho.

Ao Prof. Dr. Jurandir Itizo Yanagihara que, em conjunto com o Prof. Dr. Arlindo Tribess, viabilizou a montagem do Laboratório para a realização dos ensaios.

Aos membros da Banca do Exame de Qualificação, Prof. Dr. Marcelo Luiz Pereira, e Dra. Cristiane Degobbi Coelho, que muito contribuíram com comentários e sugestões de melhorias.

À economista Lívia Menezes, pela elaboração das tabelas e pelo apoio moral nos momentos difíceis.

Aos funcionários Benedito Fragoso e ao saudoso Wilson da Costa Neves (in memoriam), pelos conhecimentos a mim transmitidos em marcenaria e técnicas mecânicas.

Agradecimento especial ao Conselho Nacional de Desenvolvimento Científico e Tecnológico (CNPq), pela bolsa de Mestrado concedida. 


\section{SUMÁRIO}

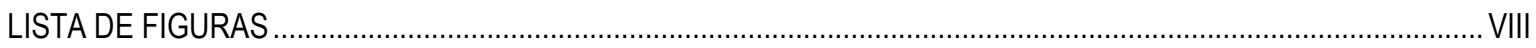

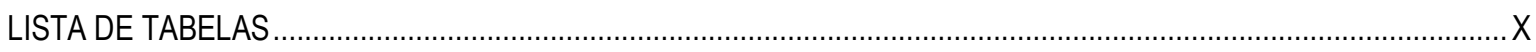

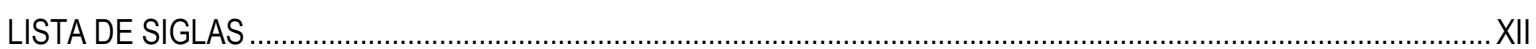

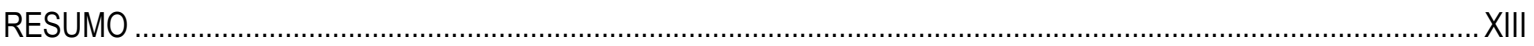

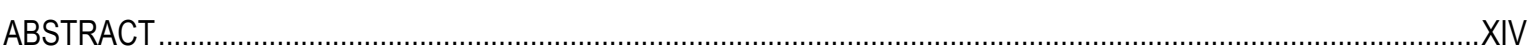

1. Introdução

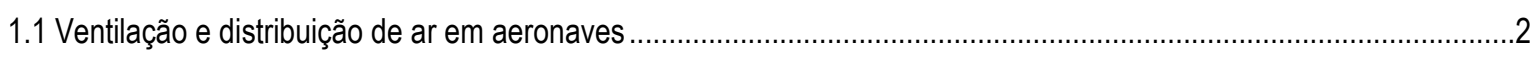

1.2 Estudos de ventilação e de dispersão de partículas em aeronaves.........................................................................

1.3 Motivação

1.4 Objetivo

1.5 Organização do trabalho.

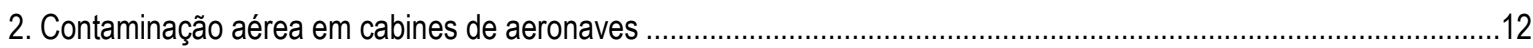

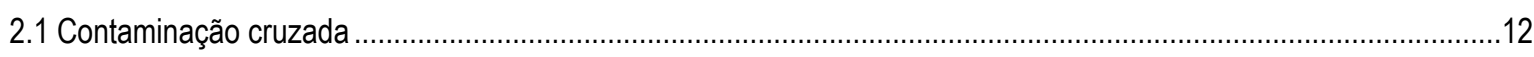

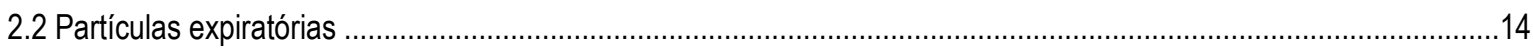

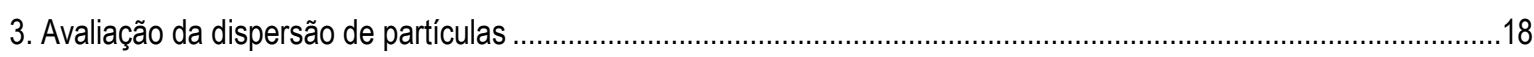

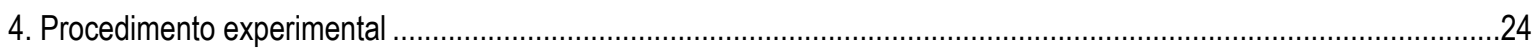

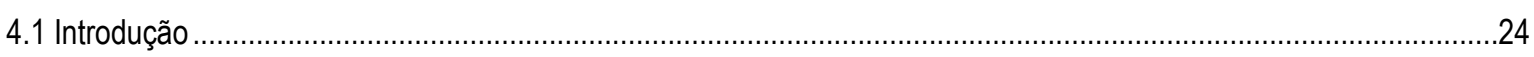

4.20 laboratório

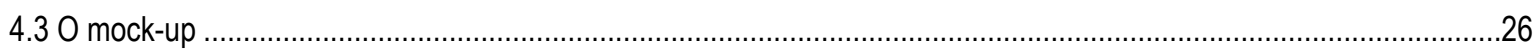

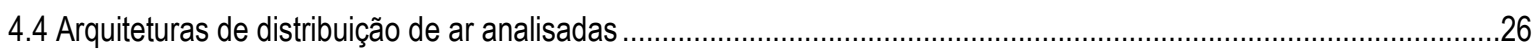

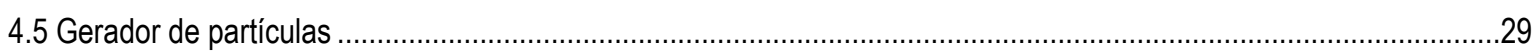

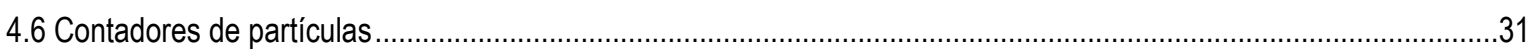

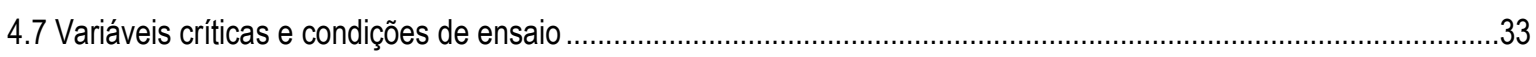

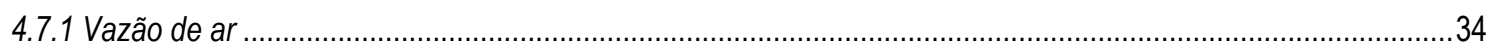

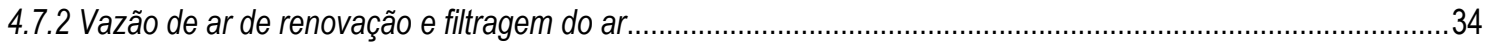

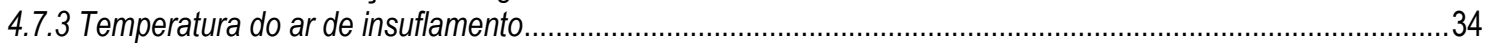

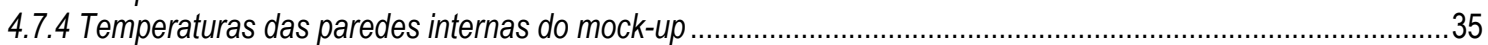

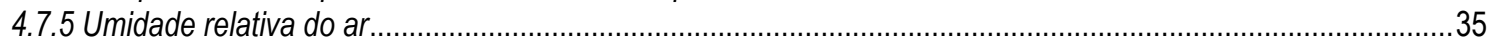

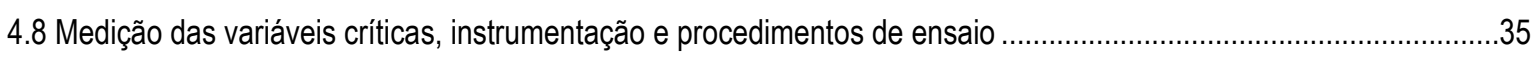

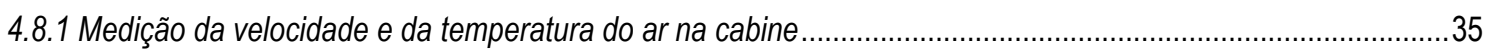

4.8.2 Medição da temperatura superficial das paredes e do ar de insuflamento ......................................................38

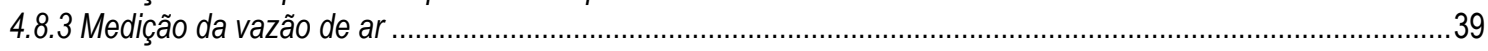

4.9 Processo de geração e de medição da concentração de partículas .......................................................................40

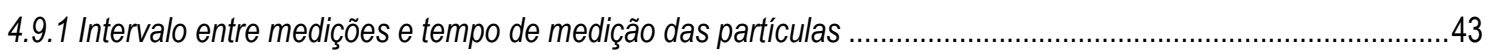

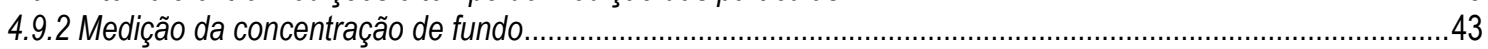

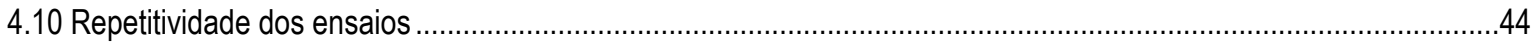

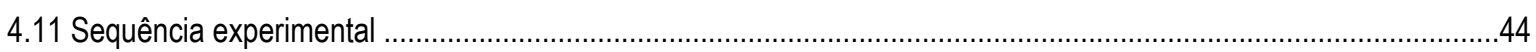

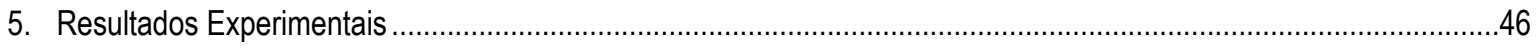

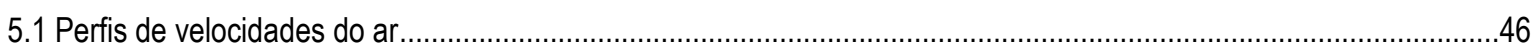

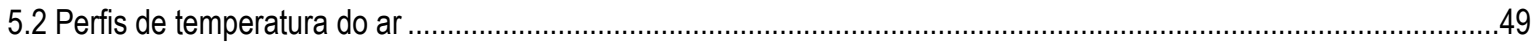

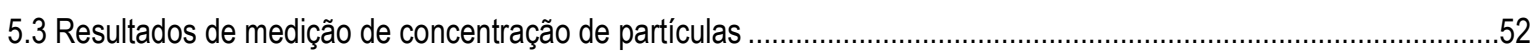

5.3.1 Análise da concentração de partículas com relação à temperatura do ar insuflado .........................................52

5.3.2 Análise da concentração de partículas com relação ao local de injeção/geração ............................................57 
5.3.3 Análise da concentração de partículas com relação às arquiteturas de distribuição de ar testadas .58

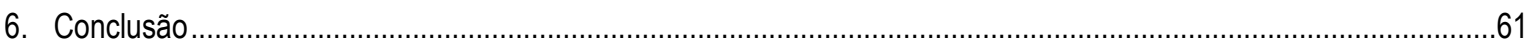

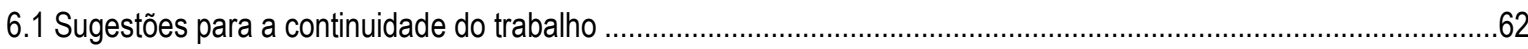

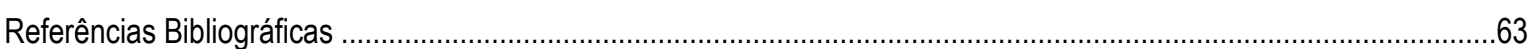

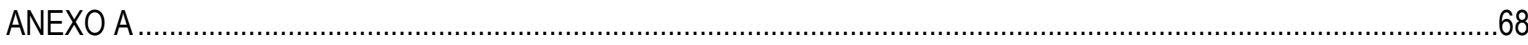

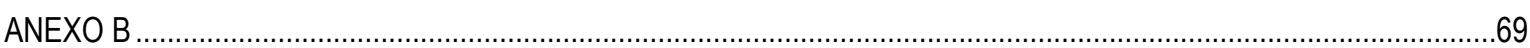

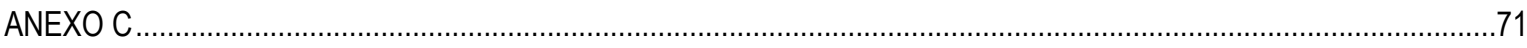

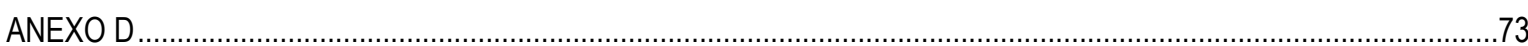




\section{LISTA DE FIGURAS}

Figura 1-1. Sistema de distribuição com mistura de ar na cabine, MV (Hunt e Space, 1994)

Figura 1-2. Sistema de ventilação por deslocamento - DV

Figura 1-3. Sistema de ventilação pelo piso - UFAD

Figura 1-4.Pontos de injeção e de medição de gotículas para diferentes vazões de ar de cabine (Wan et al., 2005) .

Figura 1-5. Mock-up de cabine de aeronave e planos de medição (Zhang et al., 2007).

Figura 1-6. Estudo da dispersão de contaminantes em mock-up do Boeing 767-300 (Yan et al., 2009)

Figura 1-7. Figura 1-7. Linhas de corrente (a) sistema MV, (b) sistema UFAD e (c) sistema UFAD + ventilação personalizada (Zhang e Chen, 2007).

Figura 1-8. Mock-up de 20 lugares utilizado no desenvolvimento do trabalho de Conceição, 2012

Figura 2-1. Gotículas expiratórias, baseado nas medições de Duguid, 1946. a) quantidade absoluta de partículas. b) distribuição do tamanho de partículas normalizada pelo intervalo de medição. c) distribuição acumulada (adaptado por Conceição, 2012)

Figura 3-1. Fluxograma I: Processo de avaliação de dispersão de partículas em cabines climatizadas (Conceição, 2012)

Figura 3-2. Fluxograma II: processo para definição do gerador de partículas (Conceição, 2012)

Figura 4-1. Representação esquemática do sistema de cabine (em azul claro) e personalizado (em amarelo) do mock-up

Figura 4-2. a) Esquema interno do mock-up, b) Acesso e vista externa do mock-up

Figura 4-3. Vista interna do mock-up com os manequins aquecidos

Figura 4-4. Arquitetura 1: sistema de ventilação por mistura (MV)

Figura 4-5. Arquitetura 2: Sistema de distribuição de ar pelo piso (UFAD)

Figura 4-6. Arquitetura 3: Sistema UFAD modificado

Figura 4-7. Gerador aerossol TSI modelo 3475 (TSI, 2010) - imagem de catálogo

Figura 4-8. Concentração de partículas em função do tamanho da gotícula gerada (gráfico do catálogo do gerador TSI modelo 3475)

Figura 4-9. Contadores de partículas da MetOne, modelo HHPC6 (MetOne HHPC-6, 2010), utilizados nos experimentos (Conceição, 2012)

Figura 4-10. Sensor de anemômetro onmidirecional (elemento sensor livre)

Figura 4-11. Pontos de medição de velocidade e temperatura

Figura 4-12. Posicionamento das sondas para medição de temperatura e velocidade do ar na altura de $0,60 \mathrm{~m}$ e de $1,10 \mathrm{~m}$ a partir do piso 
Figura 4-13.Posicionamento da sonda para medição de temperatura do ar após perturbação

Figura 4-14. Tempo de estabilização de temperatura do ar após perturbação

Figura 4-15. Vistas do tubo de Pitot antes e após a instalação

Figura 4-16. Manômetro diferencial para determinação e monitoramento da vazão de ar

Figura 4-17. a) Gerador de aerossol TSI modelo 3475 e monitor PAM 3475 posicionados externamente ao mock-up b) Detalhe dos tubos e mangueiras

Figura 4-18. Pontos de injeção e medição de partículas no mock-up (a) injeção de partículas na poltrona 3D, (b) injeção de partículas na poltrona 3E

Figura 4-19. Posição dos contadores de partículas

Figura 5-1. Perfis de velocidade do ar para insuflamento na cabine a $18^{\circ} \mathrm{C}$

Figura 5-2. Perfis de velocidade do ar para insuflamento na cabine a $22^{\circ} \mathrm{C}$

Figura 5-3. Perfis de temperatura do ar para insuflamento na cabine a $18^{\circ} \mathrm{C}$

Figura 5-4. Perfis de temperatura do ar para insuflamento na cabine a $22^{\circ} \mathrm{C}$

Figura 5-5. Concentração de partículas para temperatura de insuflamento de $18^{\circ} \mathrm{C}$, injeção de partículas no assento 3D

Figura 5-6. Concentração de partículas para temperatura de insuflamento de $18^{\circ} \mathrm{C}$, injeção de partículas no assento $3 \mathrm{E}$

Figura 5-7. Concentração de partículas para temperatura de insuflamento de $22^{\circ} \mathrm{C}$, injeção de partículas no assento 3D

Figura 5-8. Concentração de partículas para temperatura de insuflamento de $22^{\circ} \mathrm{C}$, injeção de partículas no assento 3E

Figura 5-9. Concentração de partículas com relação à temperatura do ar insuflado no assento 1D

Figura 5-10. Concentração de partículas entre 3,0 e 5um no assento 1a , função do ponto de injeção/geração de partículas

Figura 5-11. Concentração de partículas no sistema UFAD modificado (reprodução da parte de baixo da Figura 5.5)

Figura 5-12. Movimento do ar no sistema UFAD modificado

Figura A-1 - Os manequins aquecidos e suas respectivas dimensões 


\section{LISTA DE TABELAS}

Tabela 2-1. Infecções relatadas transmitidas em voos de companhias aéreas comerciais (adaptado de Mangili e Geandreau, 2005).

Tabela 2-2. Características de contaminantes liberados em atividades expiratórias (Conceição, 2012).

Tabela C-1. Resultados das velocidades e temperaturas do ar para temperatura de insuflamento de $18^{\circ} \mathrm{C}$, região inferior. $(0,10 \mathrm{~m})$

Tabela C-2. Resultados das velocidades e temperaturas do ar para temperatura de insuflamento de $18^{\circ} \mathrm{C}$, região inferior. $(0,60 \mathrm{~m})$

Tabela C-3. Resultados das velocidades e temperaturas do ar para temperatura de insuflamento de $18{ }^{\circ} \mathrm{C}$, região inferior. $(1,10 \mathrm{~m}$ ou $1,60 \mathrm{~m})$

Tabela C-4. Resultados das velocidades e temperaturas do ar para temperatura de insuflamento de $22^{\circ} \mathrm{C}$, região inferior. $(0,10 \mathrm{~m})$

Tabela C-5. Resultados das velocidades e temperaturas do ar para temperatura de insuflamento de $22^{\circ} \mathrm{C}$, região inferior. $(0,60 \mathrm{~m})$

Tabela C-6. Resultados das velocidades e temperaturas do ar para temperatura de insuflamento de $22{ }^{\circ} \mathrm{C}$, região inferior. $(1,10 \mathrm{~m}$ ou $1,60 \mathrm{~m})$

Tabela D-1. Resultados das medições de partículas no assento (Sistema MV à $18^{\circ} \mathrm{C}-$ injeção pelo assento $3 \mathrm{D}$ )

Tabela D-2. Resultados das medições de partículas no assento (Sistema UFAD à $18^{\circ} \mathrm{C}-$ injeção pelo assento $3 \mathrm{D}$ )

Tabela D-3. Resultados das medições de partículas no assento (Sistema UFAD modificado à $18^{\circ} \mathrm{C}$ - injeção pelo assento $3 \mathrm{D}$ )

Tabela D-4. Resultados das medições de partículas no assento (Sistema MV à $18^{\circ} \mathrm{C}-$ injeção pelo assento $3 \mathrm{E}$ )

Tabela D-5. Resultados das medições de partículas no assento (Sistema UFAD à $18^{\circ} \mathrm{C}-$ injeção pelo assento $3 \mathrm{E}$ )

Tabela D-6. Resultados das medições de partículas no assento (Sistema UFAD modificado à $18^{\circ} \mathrm{C}$ - injeção pelo assento $3 \mathrm{E}$ )

Tabela D-7. Resultados das medições de partículas no assento (Sistema MV à $22^{\circ} \mathrm{C}-$ injeção pelo assento $3 \mathrm{D}$ )

Tabela D-8. Resultados das medições de partículas no assento (Sistema UFAD à $22^{\circ} \mathrm{C}-$ injeção pelo assento $3 \mathrm{D}$ )

Tabela D-9. Resultados das medições de partículas no assento (Sistema UFAD modificado à $22^{\circ} \mathrm{C}$ - injeção pelo assento $3 \mathrm{D}$ ) 
Tabela D-10. Resultados das medições de partículas no assento (Sistema MV à $22^{\circ} \mathrm{C}-$ injeção pelo assento $3 \mathrm{E}$ )

Tabela D-11. Resultados das medições de partículas no assento (Sistema UFAD à $22^{\circ} \mathrm{C}$ - injeção pelo assento $3 \mathrm{E}$ )

Tabela D-12. Resultados das medições de partículas no assento (Sistema UFAD modificado à $22^{\circ} \mathrm{C}$ - injeção pelo assento $3 \mathrm{E}$ ) 


\section{LISTA DE SIGLAS}

\begin{tabular}{|c|c|}
\hline ASHRAE & $\begin{array}{l}\text { American Society of Heating, Refrigerating and Air-Conditioning } \\
\text { Engineers }\end{array}$ \\
\hline CDF & Computational Fluid Dynamics \\
\hline cfm & $\begin{array}{l}\text { Cubic feet per minute }\left(\mathrm{ft}^{3} / \mathrm{min}\right) \text { - pés cúbicos por minuto } \\
\left(\mathrm{pe}^{3} / \mathrm{min}\right)\end{array}$ \\
\hline $\mathrm{CO}_{2}$ & Controlador Lógico Programável \\
\hline DEHS & Gás carbônico \\
\hline & Di-Etil-Hexil-Sebacato \\
\hline DV & Displacement Ventilation \\
\hline Exp & Experimental \\
\hline f.m.e & Força Eletromotriz \\
\hline H1N1 & Subtipo do vírus influenza $A$ \\
\hline HEPA & High Efficiency Particulate Air \\
\hline ICEE & International Centre for Indoor Environment and Energy \\
\hline IMI & Interferometric Mie Imaging \\
\hline MV & Mixing Ventilation \\
\hline Num & Numérico \\
\hline $\mathrm{N} / \mathrm{A}$ & Não Aplicável \\
\hline OMS & Organização Mundial da Saúde \\
\hline $\mathrm{P}$ & Partículas \\
\hline PM & Particulate matter \\
\hline PPM & Partículas per minute \\
\hline PSL & Polystirene Latex Spheres \\
\hline SARS & Severe Acute Respiratory Syndrome \\
\hline $\mathrm{SF}_{6}$ & Gás Hexafluoreto de enxofre \\
\hline UFAD & UnderFloor Air Distribution \\
\hline UR & Umidade Relativa \\
\hline
\end{tabular}




\section{RESUMO}

O sistema de distribuição de ar comumente utilizado em cabines de aeronaves consiste no insuflamento de ar na parte superior e retorno na parte inferior, com mistura do ar na cabine. Devido à sua característica de mistura, este sistema pode dispersar doenças infecciosas pelo ar na cabine. A eclosão mundial do vírus SARS (Severe Acute Respiratory Syndrome) em 2003 demonstrou que a disseminação de contaminantes aéreos ainda é um evento não controlável, uma vez que foi rapidamente difundido mundo afora, principalmente porque pessoas infectadas viajaram de avião para cidades distantes. Fatos como esses têm motivado governos, empresas e instituições de pesquisa a investirem fortemente em pesquisa e desenvolvimento. Novos sistemas de ventilação e distribuição de ar em aeronaves, baseados em sistemas de ventilação por deslocamento e de distribuição de ar pelo piso, estão começando a ser testados. Neste contexto, no presente trabalho foi realizada análise experimental da dispersão de partículas expiratórias em cabine de aeronave, considerando diferentes arquiteturas de distribuição de ar, em mock-up de 12 lugares, utilizando gerador e contadores de partículas. Os ensaios foram realizados para três arquiteturas de distribuição de ar: sistema de ventilação por mistura (MV), sistema de distribuição de ar pelo piso (UFAD) e sistema pelo piso modificado (UFAD modificado), com a mesma vazão de ar de insuflamento em duas condições de temperatura do ar insuflado na cabine: 18 e $22{ }^{\circ} \mathrm{C}$. E com geração de partículas em dois pontos da cabine: perto da fuselagem e perto do corredor. As partículas foram geradas e medidas na altura da zona de respiração, a $1,10 \mathrm{~m}$ do piso. Os resultados mostram que o ponto de geração de partículas, bem como a temperatura do ar insuflado na cabine, tem grande influência na dispersão e na concentração de partículas ao longo da cabine. Uma menor temperatura do ar na cabine favorece a formação de plumas térmicas junto aos passageiros, aumentando a eficiência na remoção de partículas da cabine. O sistema UFAD apresentou a menor dispersão e a maior eficiência na remoção de partículas expiratórias da cabine, mostrando-se promissor para utilização também em cabines de aeronaves. $O$ aumento na remoção de partículas expiratórias de 3 a $5 \mu \mathrm{m}$, do sistema UFAD com relação ao sistema convencional MV, foi de até $63,4 \%$. 


\section{ABSTRACT}

The air distribution system commonly used in aircraft cabins consists the air insufflations at the top of the cabin with return of the air at the bottom, with mixing air within the cabin. Due to this mixing characteristic, this system can disperse infectious diseases through the cabin air. The global outbreak of SARS virus (Severe Acute Respiratory Syndrome) in 2003 showed that the spread of airborne contaminants is still an uncontrollable event, since it was quickly spread around the world, mainly because infected people who traveled by plane to distant cities. Facts like these have motivated governments, companies and research institutions to invest heavily in research and development. New ventilation systems and air distribution aircraft based on displacement ventilation systems and underfloor air distribution are beginning to be tested. In this context, the present work was made an experimental analysis of the expiratory particles dispersion in aircraft cabins considering different air distribution architectures in a mock- up containing 12 seats, using a generator and a particle counter. The experiments were performed in three architectures air distribution: mixing ventilation system (MV), underfloor air distribution (UFAD) and the underfloor air distribution modified (UFAD modified), all of them with the same air supply rate, considering two air supply temperature conditions: 18 and $22{ }^{\circ} \mathrm{C}$. And particle generation at two points of the cabin: near the fuselage and near the aisle. The particles were generated and measured in the breathing zone, $1,10 \mathrm{~m}$ from the floor. The results show that the point of generation of particles, and the air supply temperature, have great influence on the dispersion and particle concentration throughout the cabin. A lower air temperature in the cab favors the formation of thermal plumes within the passengers, increasing the efficiency in removing particles from the cabin. The UFAD system had the lowest dispersion and greater efficiency in removing expiratory particles from the cabin, being promising also for its use in aircraft cabins. The increase in expiratory removal of particles from 3 to 5 microns UFAD system with respect to conventional MV was up to $63.4 \%$. 


\section{Capitulo 1.}

\section{Introdução}

São muitas as dificuldades encontradas quando se trata da qualidade do ar em cabines de aeronaves, sendo necessários grandes esforços para propiciar aos passageiros um ambiente saudável e confortável.

O ambiente de cabine de aeronaves é único quando comparado com outros tipos de veículos automotivos e de edificações, com exposição dos passageiros a um ambiente com umidade relativa muito baixa, por longo tempo, e sem possibilidade de sair da cabine.

Em cabines de aeronaves comerciais a elevada densidade de ocupação resulta em taxas de ventilação por pessoa relativamente baixas, o que pode levar a uma redução na taxa de diluição de contaminantes potencialmente patogênicos exalados pelas pessoas. Além disso, o espaço interno limitado com elevado número de ocupantes faz com que os passageiros fiquem muito próximos uns aos outros (Fiser e Miroslav, 2013, Volavý et al., 2013).

Neste ambiente complexo, a troca de calor dos passageiros é resultado da convecção natural e forçada, com a geração de plumas térmicas ao redor dos passageiros, e da radiação térmica, que também desempenha um papel importante, porque os passageiros estão ocupando espaços relativamente pequenos e diferentes temperaturas das superfícies interagem com a superfície do corpo humano (Volavý et al., 2013).

A proximidade dos passageiros, aliada a baixas taxas de ventilação por pessoa e ao longo tempo de exposição, podem prover um ambiente favorável para a transmissão de doenças infecciosas por contato e por partículas aéreas (Wan et al., 2009).

A eclosão mundial do vírus SARS (Severe Acute Respiratory Syndrome) em 2003 demonstrou que a disseminação de contaminantes aéreos ainda é um evento não controlável, uma vez que foi rapidamente difundido mundo afora, principalmente porque pessoas infectadas viajaram de avião para cidades distantes (Olsen et al., 2003). 
Em função disso, estudos de contaminação em cabines de aeronaves tem sido focados na contaminação aérea resultante da dispersão de poluentes expiratórios gerados (Wan et al., 2005; Zhang et al., 2008; Wan et al., 2009, Sze To et al., 2009, Yan et al., 2009; Gupta et al., 2011; Conceição, 2012, Bosbach et al., 2012, Chen et al., 2012, Pang et al., 2013).

Mas, embora o entendimento sobre a contaminação aérea em aeronaves e em outros tipos de ambientes tenha evoluído bastante, pouco ainda se conhece sobre a dinâmica das partículas e a influência de novos sistemas de ventilação na dispersão de partículas para controlar e prevenir a sua disseminação (Morawska, 2005; Li et al., 2007; Yang, 2007; Nielsen, 2007; Nielsen, 2008, Müller et al., 2011, Bosbach et al., 2012).

\subsection{Ventilação e distribuição de ar em aeronaves}

O ambiente de cabine de aeronaves é regulado por um sistema de controle ambiental que controla a pressurização, a temperatura, a ventilação e a filtração do ar da aeronave.

Segundo a norma ASHRAE 161 (2007), a vazão total de ar (recirculação + ar externo de renovação) deve ser de $20 \mathrm{CFM} /$ pessoa (9,5 l/s / pessoa). Na maioria das aeronaves comerciais $50 \%$ do ar insuflado na cabine é recirculado como forma de melhorar o controle da umidade do ar e da eficiência no consumo de combustível (House of Lords, 2000).

Embora os filtros HEPA (High Efficiency Particulate Air) utilizados em aeronaves sejam eficazes na remoção de vírus e bactérias, os contaminantes gerados por um passageiro podem ser inalados por outros passageiros antes de serem coletados por estes filtros, que se encontram instalados nos dutos de ar de recirculação (Conceição et al., 2011).

O sistema de distribuição de ar mais utilizado em cabines de aeronaves consiste no insuflamento de ar na parte superior e retorno na parte inferior com mistura do ar na cabine, Mixing Ventilation - MV, Figura 1-1. O resultado é uma temperatura quase uniforme na cabine e a dispersão de contaminantes. 


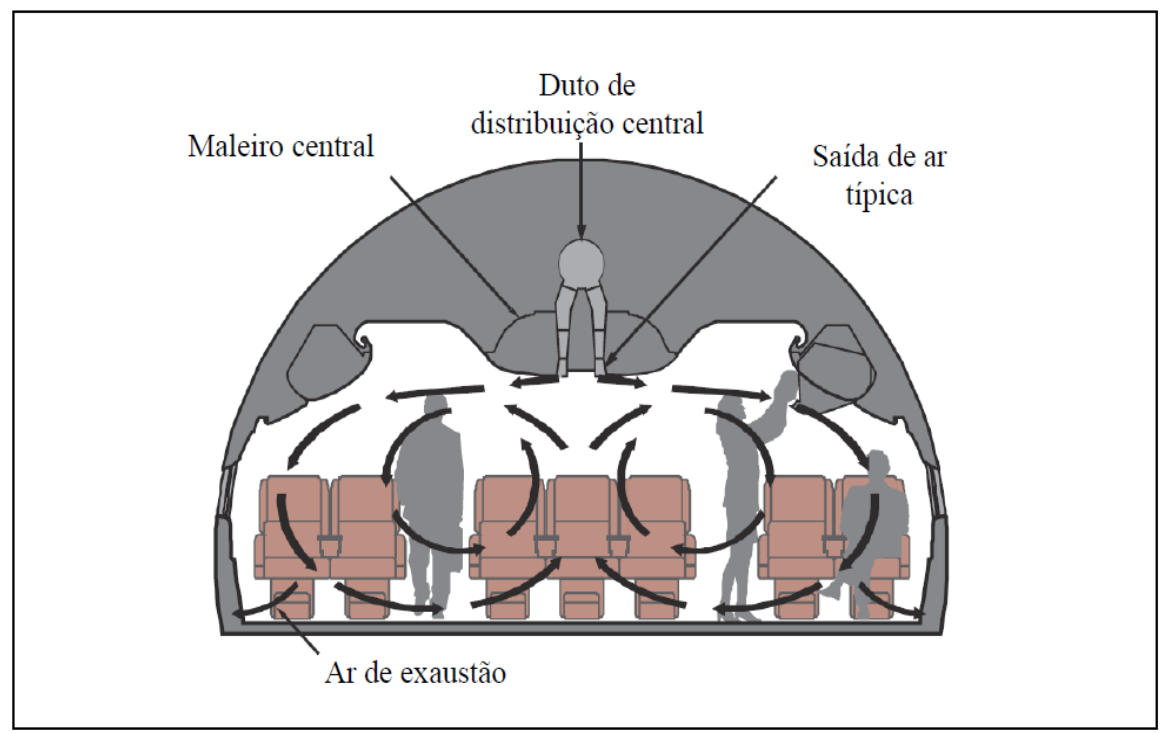

Figura 1-1. Sistema de distribuição com mistura de ar na cabine, MV (Hunt e Space, 1994)

Embora, o sistema MV, normalmente, proporcione um ambiente com baixa estratificação de temperatura, problemas de conforto térmico têm sido verificados. Além disso, devido à sua característica de mistura, pode dispersar mais facilmente contaminantes pelo ar na cabine (Gao e Niu, 2007, Zhang et al. 2007).

Para tentar resolver os problemas de conforto térmico e de qualidade do ar novos sistemas de ventilação e distribuição de ar em aeronaves estão começando a ser estudados numericamente (Zhang e Chen, 2007) e testados (DLR, 2011). Estes novos sistemas são baseados em sistemas já aplicados em edificações como, por exemplo, o sistema de ventilação por deslocamento, Displacement Ventilation - DV (Chen e Glicksman, 2003) e o sistema de distribuição de ar pelo piso, UnderFloor Air Distribution - UFAD (Bauman e Daily, 2003).

No sistema DV o ar é introduzido no ambiente com baixa velocidade por difusores de ar montados na parede próximos ao piso, e o retorno de ar é feito normalmente pelo teto, de maneira que o escoamento de ar acompanhe o sentido natural da pluma térmica dos ocupantes e arraste os contaminantes por eles gerados (Fig. 1-2). Como resultado, o sistema de ventilação por deslocamento pode melhorar a qualidade do ar na zona de respiração se comparado com a ventilação por mistura. Por outro lado, como o ar é insuflado na altura dos pés dos ocupantes, aumenta-se o risco de desconforto por correntes de ar (Fanger et al., 1988). 


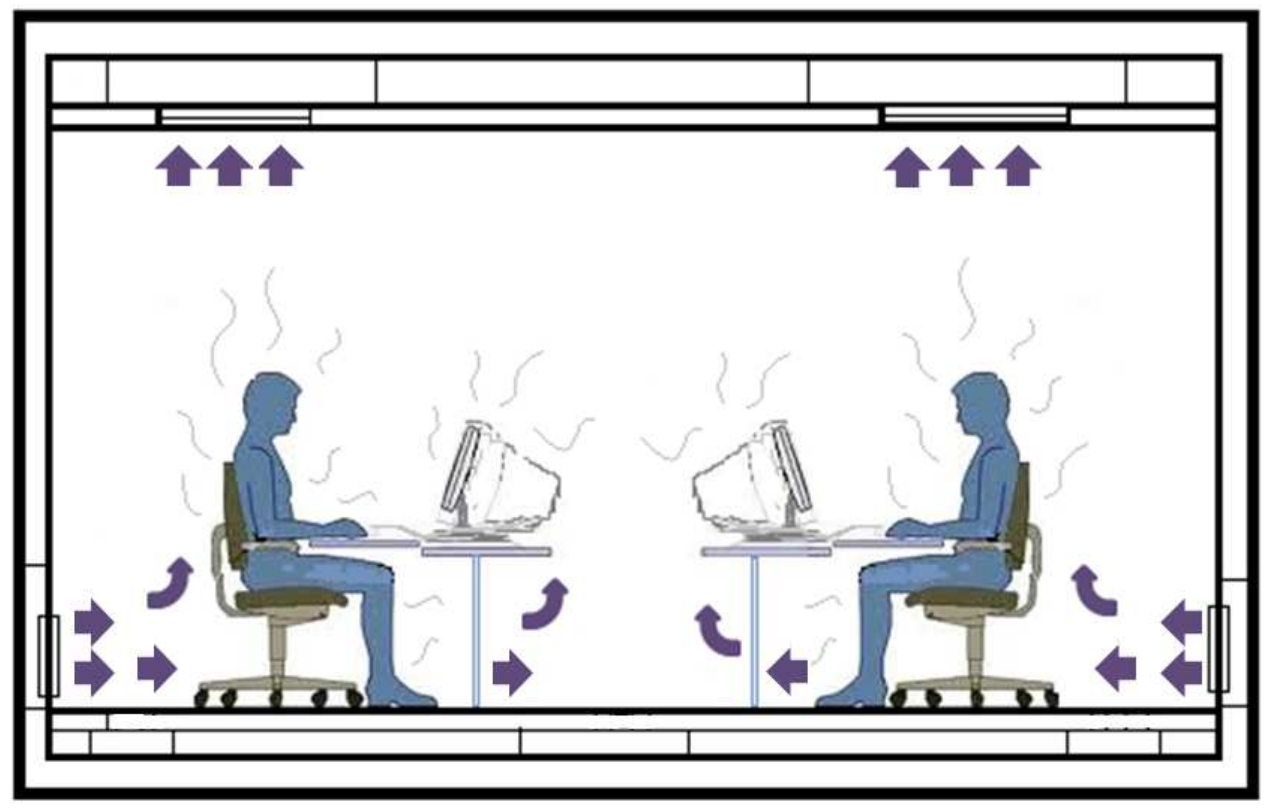

Figura 1-2. Sistema de ventilação por deslocamento - DV

No sistema UFAD, o ar é insuflado no ambiente a partir do piso (Fig. 1-3) e, de maneira semelhante ao sistema DV, o escoamento se soma à pluma térmica dos ocupantes levando os contaminantes até a exaustão pelo teto (Leite e Tribess, 2006, Pereira et al., 2009).

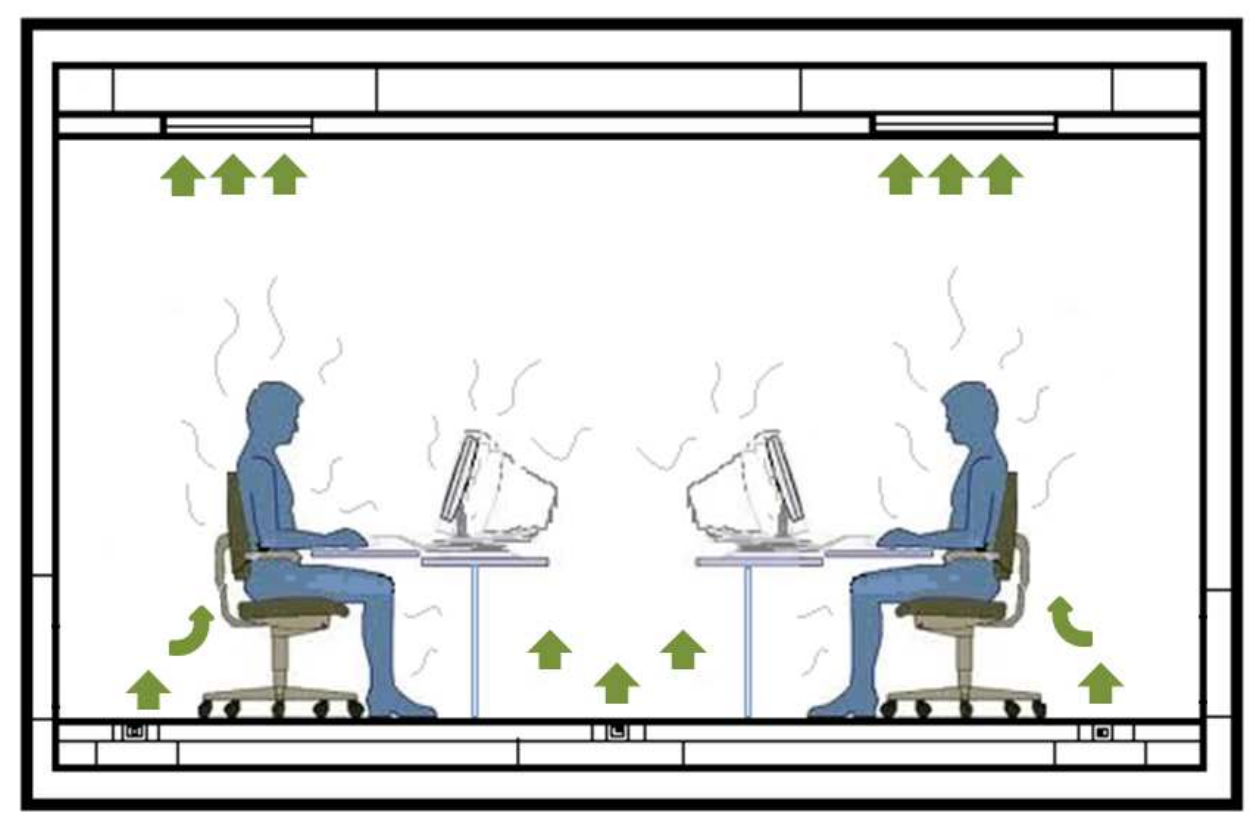

Figura 1-3. Sistema de ventilação pelo piso - UFAD

Embora os sistemas DV e UFAD possam promover melhor qualidade do ar que o sistema MV (Zhang e Chen, 2006), estes podem causar estratificação de temperatura não desejável (Bauman e Daily, 2003; Leite e Tribess, 2006), que 
pode ser potencializada em cabines de aeronaves, onde o volume ocupado por passageiro e a altura da cabine são bastante menores do que em edificações (Wan et al., 2009).

\subsection{Estudos de ventilação e de dispersão de partículas em aeronaves}

Embora ainda em número bastante reduzido, nos últimos anos tem aumentado o número de trabalhos relativos a estudos de ventilação e dispersão de partículas em aeronaves.

Estudos experimentais têm sido realizados em mock-ups de aeronaves de uma seção da cabine ou em aeronaves paradas simulando condições de escoamento em voo. Isto ocorre porque estudos experimentais em condições reais de voo são extremamente caros (Zhang e Chen, 2007).

Wan et al., 2005, realizaram estudo experimental de dispersão de gotículas expiratórias em mock-up com 21 assentos (três fileiras de sete assentos). $\mathrm{O}$ mock-up, instalado no International Center for Indoor Environment and Energy, da Dinamarca, é dotado de sistema de ventilação convencional, sistema MV, com a utilização de manequins aquecidos simulando a presença de pessoas. No trabalho de Wan et al., 2005, foi utilizado gerador de partículas para a simulação de uma pessoa tossindo, desenvolvido pelos próprios pesquisadores. A Figura 1-4 mostra os pontos de injeção e de medição de partículas para duas vazões de ar de cabine de $100 \mathrm{~L} / \mathrm{s}$ e de $200 \mathrm{~L} / \mathrm{s}$, com medições realizadas a 1,10 $\mathrm{m}$ do piso (zona de respiração).

Contaminantes expiratórios foram simulados com gás traçador $\mathrm{SF}_{6}$, e partículas monodispersas de Di-etil-hexil-sebacato (DEHS) com tamanho médio de $0,7 \mu \mathrm{m}$, produzidas com gerador de aerossol TSI modelo 3475. Tanto as partículas gasosas como as líquidas foram geradas e injetadas mediante tubos metálicos e monitoradas em 48 pontos distintos, distribuídos em dois planos de medição, conforme apresentado na Figura 1-4. Cada medição levava 30 segundos e era repetida 10 vezes utilizando analisador multi-gás foto-acústico e um contador de partículas óptico.

Os resultados mostraram que um menor número de partículas foi disperso para outros assentos quando a injeção das partículas foi feita simulando 
passageiro junto à fuselagem em comparação com passageiro sentado em um assento no centro do mock-up. Segundo os autores, isso sugere que o fluxo de ar descendente junto à fuselagem tenha suprimido a dispersão de partículas, enquanto o fluxo ascendente no centro do mock-up tenha aumentado a dispersão.
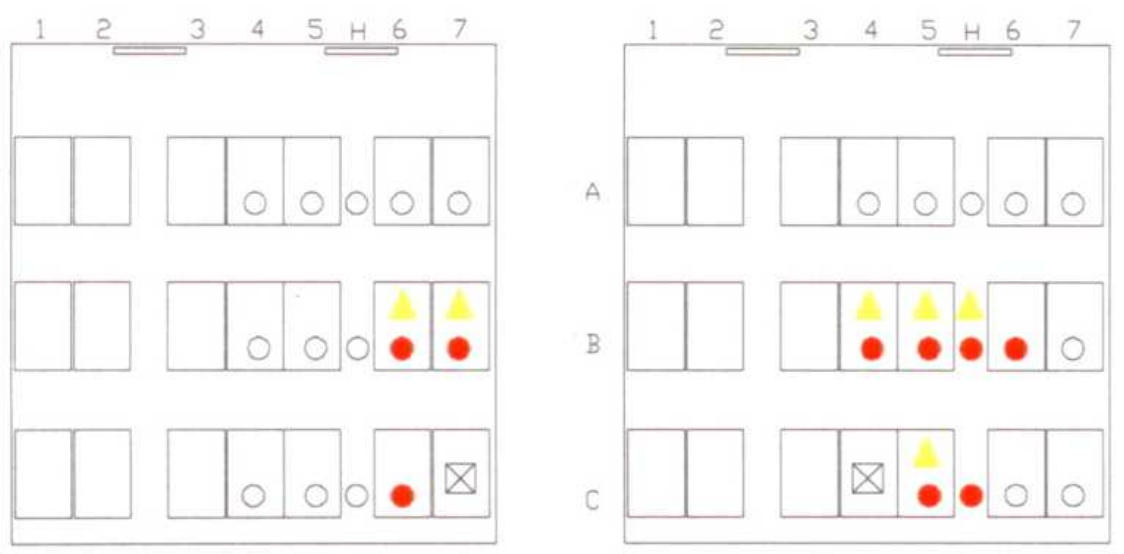

Medição para 200 L/s

Medição para 100 L/s

Pontos de Medição

Pontos de Injeção

Figura 1-4. Pontos de injeção e de medição de gotículas para diferentes vazões de ar de cabine (Wan et al., 2005).

Zhang et al., 2007, também estudaram a dispersão de partículas em mock-up de avião, com manequins aquecidos do tipo caixa (Fig. 1-5) e sistema de ventilação convencional - sistema MV, focando nos campos de velocidade, temperatura e concentração de contaminantes. $O$ objetivo do trabalho foi à validação e avaliação de modelos numéricos.

Yan et al., 2009, estudaram a transmissão de contaminantes simulando atividades expiratórias em mock-up de Boeing 737-300 (Fig. 1-6), também dotado de sistema convencional de ventilação, sistema MV, empregando gás traçador $\left(\mathrm{CO}_{2}\right)$, focando também partículas menores. Os pesquisadores injetaram $4,5 \mathrm{~L} / \mathrm{min}$ do gás traçador durante 5 minutos nas proximidades da zona de respiração, simulando um passageiro infectado, e a partir deste momento, monitoraram a concentração de $\mathrm{CO}_{2}$ na zona de respiração dos outros passageiros, mediante a utilização de 14 sensores de $\mathrm{CO}_{2}$ por infravermelho não dispersivo. 


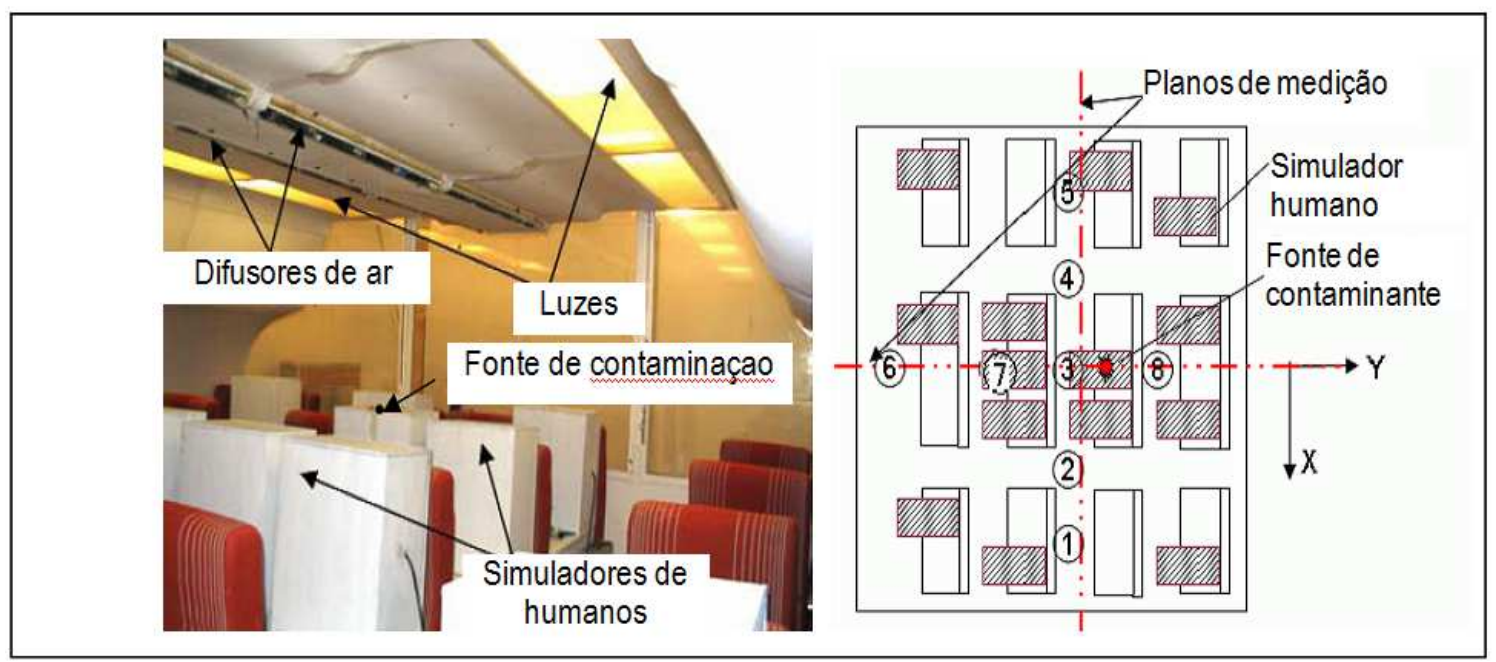

Figura 1-5. Mock-up de cabine de aeronave e planos de medição (Zhang et al., 2007).

Yan et al., 2009, também realizaram simulação utilizando dinâmica dos fluidos computacional - CFD (Computational Fluid Dynamics). De maneira geral, os autores concluíram que o sistema de ventilação influencia significativamente no campo de distribuição de partículas na cabine.

$\mathrm{Na}$ mesma linha de trabalho proposto por Wan et al., 2005, e utilizando as mesmas instalações e equipamentos, Sze To et al., 2009, tiveram por objetivo caracterizar a dispersão e deposição de gotículas provenientes de atividades expiratórias em cabine de aeronaves, bem como identificar os efeitos do sistema de ventilação, sistema MV, na diluição e remoção dessas partículas.

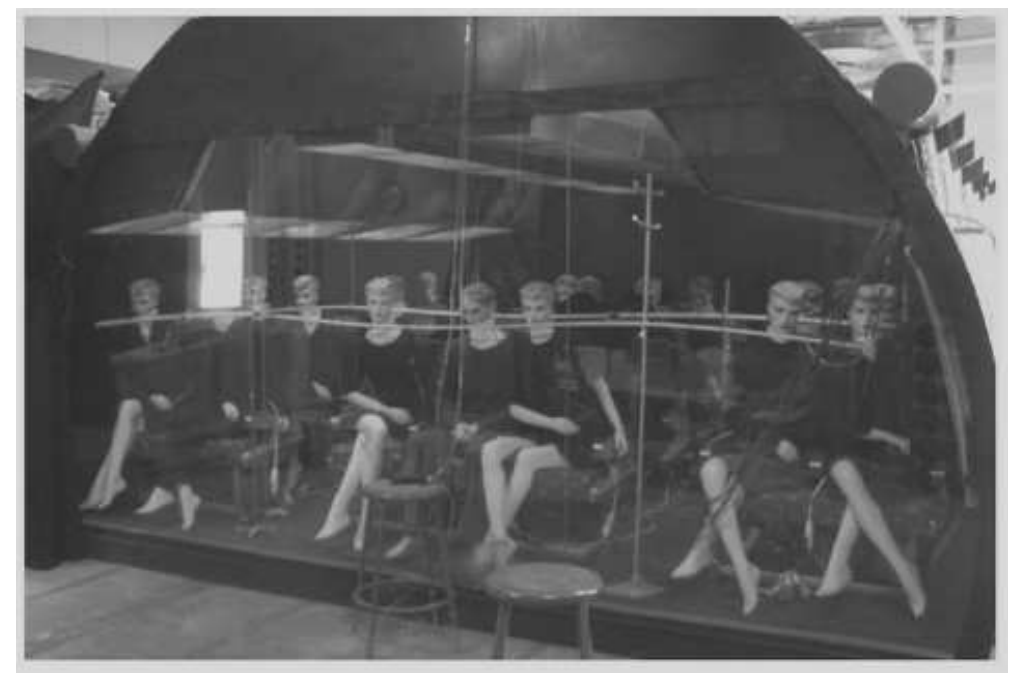

Figura 1-6. Estudo da dispersão de contaminantes em mock-up do Boeing 767-300 (Yan et al., 2009) 
Os resultados obtidos por Sze To et al., 2009, mostraram que o aumento da vazão de ar de renovação (maior vazão) provoca redução na concentração de partículas nas proximidades do ponto de injeção, devido ao efeito de diluição. Porém, a dispersão de partículas aumentou, o que provocou uma elevação da concentração de contaminantes nos assentos mais distantes do ponto de geração. Foi observado também que a dispersão das partículas depende do seu tamanho médio, tendo sido obtidas taxas de deposição de partículas da ordem de 60 a $70 \%$ do total de partículas. Neste estudo não foi investigada a influência de diferentes formas de ventilação na dispersão dos contaminantes na cabine.

Observa-se nos estudos até aqui apresentados que todos tratam da análise experimental da contaminação aérea em sistema de ventilação por mistura, sistema MV, que é o sistema utilizado nas aeronaves comerciais. Não foram encontrados na literatura aberta estudos experimentais com outros sistemas de ventilação e distribuição de ar.

Foi encontrado somente um trabalho de simulação CFD, o trabalho de Zhang e Chen, 2007, que realizaram estudos da dispersão de $\mathrm{CO}_{2}$ simulado pela respiração de passageiros em cabine de B767-300, com três formas de insuflamento de ar: ventilação por mistura - MV, ventilação pelo piso - UFAD, e ventilação pelo piso juntamente com ventilação personalizada.

A partir dos resultados obtidos com a simulação numérica (Fig. 1-7), os autores verificaram que o sistema convencional, sistema MV, Fig.1-7a, proporciona temperatura mais homogênea do ar. Porém, esse sistema oferece um risco maior de dispersar a contaminação gerada de um local para os demais. No sistema com insuflamento pelo piso, sistema UFAD, Fig. 1-7b, o risco de contaminação diminui, pois as velocidades são baixas e o ar segue um fluxo ascendente, mais regular.

O sistema de insuflamento pelo piso, dotado de sistema de ventilação personalizada, Fig.1-7c, proporcionou os melhores resultados de qualidade do ar, apresentando uma concentração média de $\mathrm{CO}_{2}$ na zona de respiração de 600 ppm, contra 1400 ppm do sistema convencional, sistema MV, e 900 ppm do sistema de distribuição pelo piso, sistema UFAD. 


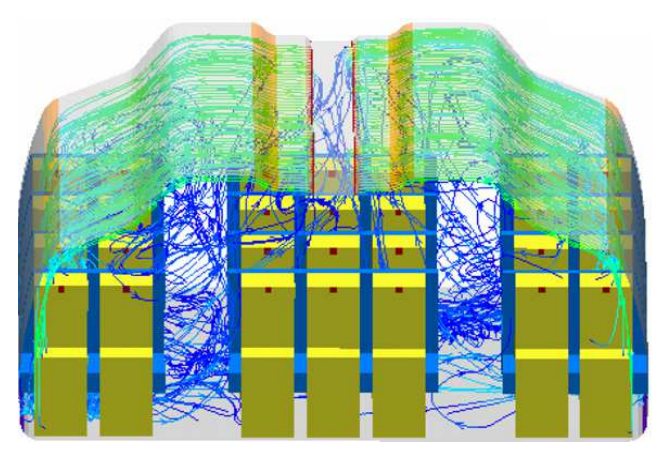

(a)

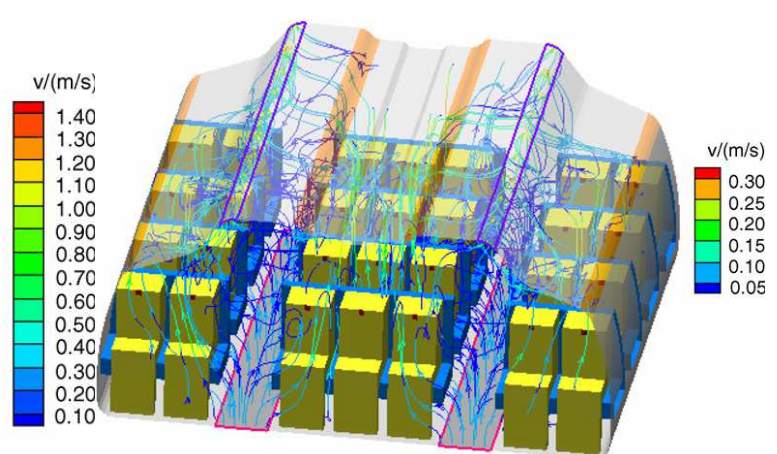

(b)

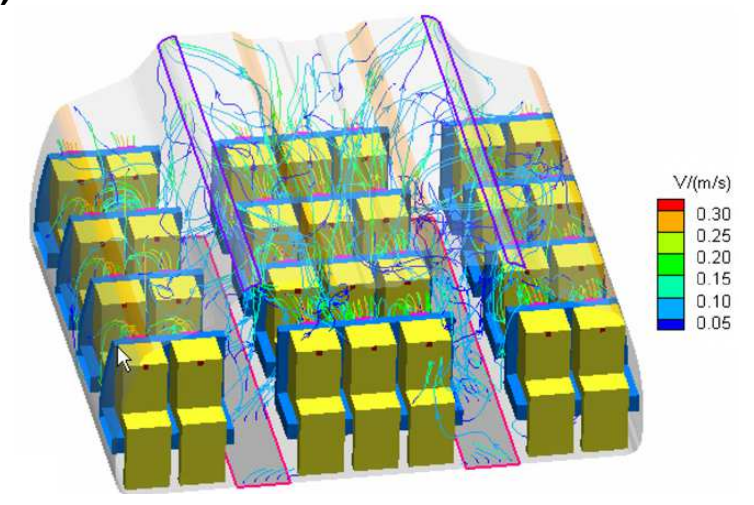

(c)

Figura 1-7. Linhas de corrente (a) sistema MV, (b) sistema UFAD e (c) sistema UFAD ventilação personalizada (Zhang e Chen, 2007).

Outros trabalhos importantes utilizando CFD foram desenvolvidos, como por exemplo, estudos utilizando CFD na análise da contaminação cruzada em aeronaves (Zhang et al., 2008; Wan et al., 2009, Sze To et al., 2009, Yan et al., 2009; Gupta et al. 2011), cujo detalhamento dos trabalhos pode ser encontrado em Conceição, 2012.

Conceição, 2012, desenvolveu trabalho de doutorado realizando análise experimental e numérica (CFD) de contaminação cruzada em mock-up de aeronave de 20 lugares (Fig. 1-8), utilizando sistema convencional MV. Nesse trabalho foi desenvolvido um processo de avaliação de dispersão de partículas em cabines climatizadas, que foi utilizado na análise da influência de sistema de ventilação personalizada (válvula gasper) como uma possível barreira contra a contaminação cruzada. O processo desenvolvido por Conceição, 2012, foi utilizado no presente trabalho, e é apresentado no Capítulo 3. 


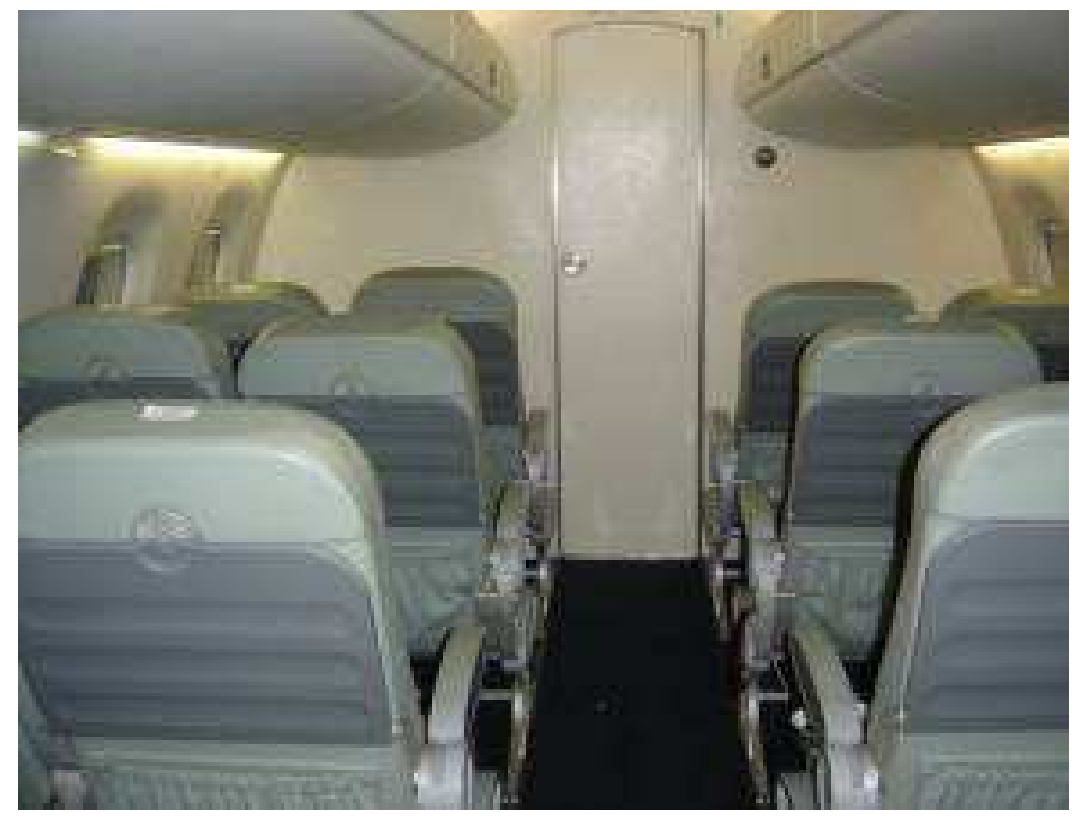

Figura 1-8. Mock-up de 20 lugares utilizado no desenvolvimento do trabalho de Conceição, 2012.

\subsection{Motivação}

Estudos recentes mostram uma real preocupação com relação à saúde dos ocupantes de aeronaves, o que está diretamente relacionada à contaminação cruzada entre os passageiros, sobretudo depois dos surtos do vírus SARS, gripe suína (H1N1), gripe aviária, etc (Mangili e Geandreau, 2005, Booker, 2007, Walkinshaw, 2010), e que tem motivado governos, empresas e instituições de pesquisa a investirem fortemente em pesquisa e desenvolvimento (NRC, 1986, NRC, 2002, COT, 2006; ACER, 2010, HEACE, 2010, ICE, 2010, Possou et al., 2010, Gupta et al., 2011).

Adicionalmente, conforme destacado no início do presente trabalho, novos sistemas de ventilação e de distribuição de ar em aeronaves estão começando a ser estudados numericamente (Zhang e Chen, 2007) e testados (DLR, 2011), baseados em sistema de ventilação por deslocamento, Displacement Ventilation DV (Chen e Glicksman, 2003) e sistema de distribuição de ar pelo piso, UnderFloor Air Distribution - UFAD (Bauman e Daily, 2003), já aplicados em edificações. 
E é justamente neste contexto que se insere o presente trabalho. $O$ de testar novos sistemas de ventilação e distribuição de ar e avaliar a sua influência na dispersão de partículas em cabines de aeronaves.

\subsection{Objetivo}

O objetivo deste trabalho consiste na realização de análise experimental de dispersão de partículas expiratórias em cabine de aeronave, considerando diferentes arquiteturas de distribuição de ar, em mock-up de 12 lugares, utilizando gerador e contadores de partículas.

\subsection{Organização do trabalho}

No Capítulo 1 foi feita uma breve introdução do assunto com ênfase nos estudos de ventilação e contaminação aérea em aeronaves.

No Capítulo 2 são apresentados aspectos gerais sobre contaminação cruzada em cabines de aeronaves e algumas características relevantes sobre as partículas liberadas em atividades expiratórias.

No capítulo 3 é apresentado o processo de análise da dispersão de partículas que foi utilizado no presente trabalho, baseado na proposta de Conceição, 2012.

No capítulo 4 é apresentado o método experimental, com a descrição do laboratório, em especial o mock-up e os instrumentos utilizados para a realização do trabalho, as arquiteturas de distribuição de ar analisadas, bem como o procedimento experimental e as condições de ensaio.

O capítulo 5 apresenta os resultados e discussões sobre a dispersão de partículas no interior do mock-up para as arquiteturas de distribuição de ar propostas.

O capítulo 6 apresenta as conclusões e as sugestões para a realização de trabalhos futuros. Por fim, no capítulo 7 são apresentadas as referências bibliográficas. 


\section{Capitulo 2.}

\section{Contaminação aérea em cabines de aeronaves}

Conforme apresentado no Capítulo 1, estudos de contaminação em cabines de aeronaves têm sido focados na contaminação aérea resultante da dispersão de poluentes expiratórios gerados por pessoas infectadas contaminando outras pessoas - a contaminação cruzada (Wan et al., 2005; Zhang et al., 2008; Wan et al., 2009, Sze To et al., 2009, Yan et al., 2009; Gupta et al. 2011; Conceição, 2012). E este é também o foco do presente trabalho, isto é, o de avaliar a dispersão de partículas expiratórias em mock-up de cabine de aeronave.

Assim, neste Capítulo são apresentados aspectos gerais sobre contaminação cruzada em cabines de aeronaves e algumas características relevantes sobre os contaminantes liberados em atividades expiratórias, protagonistas nos eventos de contaminação cruzada em cabines de aeronaves.

\subsection{Contaminação cruzada}

Em cabines de aeronaves o risco de contaminação cruzada é potencializado tendo em vista os longos períodos de voo em espaços confinados, a alta densidade de passageiros, bem como as características de mistura do sistema de ventilação empregado em aeronaves comerciais.

Além disso, existe um crescimento ascendente no número de pessoas que se utilizam do transporte aéreo no mundo. Enquanto em 1950 o número de passageiros ficava na faixa de 30 milhões, em 2006 estava na faixa de 3,2 bilhões (Cupa, 2009), aumentando o risco de contaminação entre pessoas de diferentes regiões de um mesmo país e de diferentes países.

Uma outra preocupação atual é que a transmissão de doenças em voos seja bem maior do que aquela efetivamente registrada, já que algumas enfermidades possuem um tempo de incubação maior do que aquele do voo, com os sintomas aparecendo somente alguns dias ou semanas depois (Connor, 2009). A Tabela 2-1 apresenta relação de infecções relatadas transmitidas em voos de 
companhias aéreas comerciais. Segundo Wagner et al., 2009, a capacidade de um passageiro infectado com H1N1 transmitir a doença em voo de 17 horas na classe econômica quando esta está lotada, com 309 passageiros, pode chegar ao número de 17 pessoas infectadas, e de 2 a 5 pessoas em voo de 5 horas.

Tabela 2-1. Infecções relatadas transmitidas em voos de companhias aéreas comerciais (adaptado de Mangili e Geandreau, 2005).

\begin{tabular}{|c|c|c|}
\hline \multicolumn{3}{|c|}{ Infecções relatadas transmitidas em voos de companhias aéreas comerciais } \\
\hline & $\begin{array}{l}\text { Número de } \\
\text { relatórios }\end{array}$ & Comentários \\
\hline \multicolumn{3}{|c|}{ Transportadas pelo ar } \\
\hline Tuberculose & 2 & $\begin{array}{l}\text { Teste de pele positivo para a tuberculose, } \\
\text { porém tuberculose não ativa }\end{array}$ \\
\hline SARS & 4 & Nenhum caso desde orientações da OMS \\
\hline Resfriado comum & 0 & Difícil de investigar \\
\hline Influenza & 2 & Nenhum desde regulamentos de ventilação \\
\hline Doença meningocócica & 0 & $\begin{array}{l}21 \text { relatos de passageiros doentes, nenhum } \\
\text { caso secundário }\end{array}$ \\
\hline Sarampo & 3 & Casos internacionais \\
\hline \multicolumn{3}{|l|}{ De origem alimentar } \\
\hline Salmonelose & 15 & Não surtos recentes \\
\hline Estafilococos & 8 & Não surtos recentes \\
\hline \multicolumn{3}{|l|}{ Envenenamento } \\
\hline Shigelose & 3 & Não surtos recentes \\
\hline Cólera & 3 & Durante epidemia de cólera \\
\hline Enterite viral & 1 & Comum em outros tipos de transporte \\
\hline \multicolumn{3}{|l|}{ Vetor-borne } \\
\hline Malaria & 7 & Provavelmente subestimado \\
\hline Dengue & 1 & $\begin{array}{l}\text { Provavelmente aeroporto não, aviões, } \\
\text { transmissão }\end{array}$ \\
\hline Febre amarela & 0 & $\begin{array}{l}\text { Quaisquer focos, desde desinfecção de } \\
\text { aeronaves }\end{array}$ \\
\hline \multicolumn{3}{|c|}{ Agentes do bioterrorismo } \\
\hline Varíola & 1 & Antes da erradicação \\
\hline
\end{tabular}




\subsection{Partículas expiratórias}

Durante as atividades expiratórias, tais como respiração, fala, tosse e espirro, os seres humanos produzem gotículas líquidas geradas pela passagem de meios gasosos, com uma dada velocidade, sobre a superfície de uma substância líquida (Morawska, 2005). Quando essas gotículas são produzidas por uma pessoa infectada, contaminantes patogênicos presentes no seu trato respiratório podem ser carreados e expelidos. Esses contaminantes dispersos podem ser transmitidos diretamente para outras pessoas via inalação, ou indiretamente pelo contato sobre superfícies contaminadas (Mangili e Geandreau, 2005).

Pesquisas realizadas em cabines de aeronaves mostraram que, de uma forma geral, o nível médio de bioaerossóis na cabine é baixo. Contudo, elevados picos de concentração foram observadas devido a espirros, tosse ou outras ações respiratórias dos passageiros. Este fato sugere que o maior risco de infecção é a transmissão de pessoa para a pessoa via dispersão de gotículas exaladas dentro da cabine (Dechow et al.,1997).

Essas gotículas, uma vez dispersas no ar, sofrem processos químicos e físicos que modificam a sua composição química, características físicas e a concentração, influenciando na dinâmica desse tipo de partícula. De acordo com Morawska, 2005, os processos mais relevantes que ocorrem com partículas suspensas no ar são a coagulação, onde partículas de tamanhos semelhantes colidem umas com as outras formando partículas maiores; a deposição de partículas menores na superfície de partículas maiores; mudanças no tamanho das partículas devido a mudanças no seu conteúdo de umidade (crescimento higroscópico ou redução por evaporação); a sedimentação; e a deposição em superfícies.

Devido à força peso, as gotículas maiores do que $5 \mu \mathrm{m}$, em geral, depositamse em superfícies mais rapidamente (Connor, 2009). Já as gotículas menores são carreadas mais facilmente pelo escoamento, pois possuem coeficiente de transporte por difusão similar ao coeficiente de difusão dos gases (Bémer et al., 2000). Por este motivo, podem permanecer em suspensão por longos períodos de tempo e transportar os biocontaminantes por distâncias maiores (Tang et al., 2006) e evaporar formando os resíduos de gotículas ou núcleos de gotículas (droplet nuclei). 
Embora as partículas líquidas ou sólidas menores sigam o escoamento como se fossem partículas gasosas, são normalmente depositados nas superfícies quando encontram obstáculos, diferentemente das partículas gasosas, que depois do choque são normalmente refletidas (Bémer et al., 2000).

Para determinar o tamanho e a quantidade de partículas geradas durante a fala, tosse e espirro, Duguid, 1946, fez a coleta das gotículas em placas oleosas posicionadas nas proximidades da boca das pessoas e as contou e mediu com 0 auxílio de microscópio e micrômetro.

Segundo Duguid, 1946, as atividades expiratórias podem gerar milhares de partículas polidispersas, sendo que $95 \%$ delas possuem tamanho médio entre $2 \mathrm{e}$ $100 \mu \mathrm{m}$, e a maior quantidade está entre 4 e $8 \mu \mathrm{m}$ (Fig. 2-1).

Contagens mais recentes do tamanho e da quantidade de partículas geradas durante atividades expiratórias foram realizadas, com técnicas mais apuradas (Tab. 2-2). Papineni e Rosenthal, 1997, aplicaram contadores de partículas ópticos, reportando que a maior parte das gotículas geradas em atividades expiratórias seria menor do que $1 \mu \mathrm{m}$. Nicas et al., 2005, revisaram esse estudo, dentre outros, e concluíram que os estudos originais de Duguid, 1946, são mais consistentes. Na mesma direção, ainda mais recentemente, Chao et al., 2009, utilizaram o método óptico IMI - Interferometric Mie Imaging - para medir gotículas expiratórias liberadas na tosse e fala, e obtiveram certa concordância com os resultados obtidos por Duguid, 1946.

Finalmente, com base na literatura consultada, observa-se que os dados de Duguid, 1946 continuam sendo referenciados em estudos recentes da dispersão de biocontaminantes em ambientes interiores (Chao e Wan, 2006, Wan et al., 2007, Sze To et al., 2009, Wan et al., 2010), e serão considerados como referência no desenvolvimento do presente estudo. 


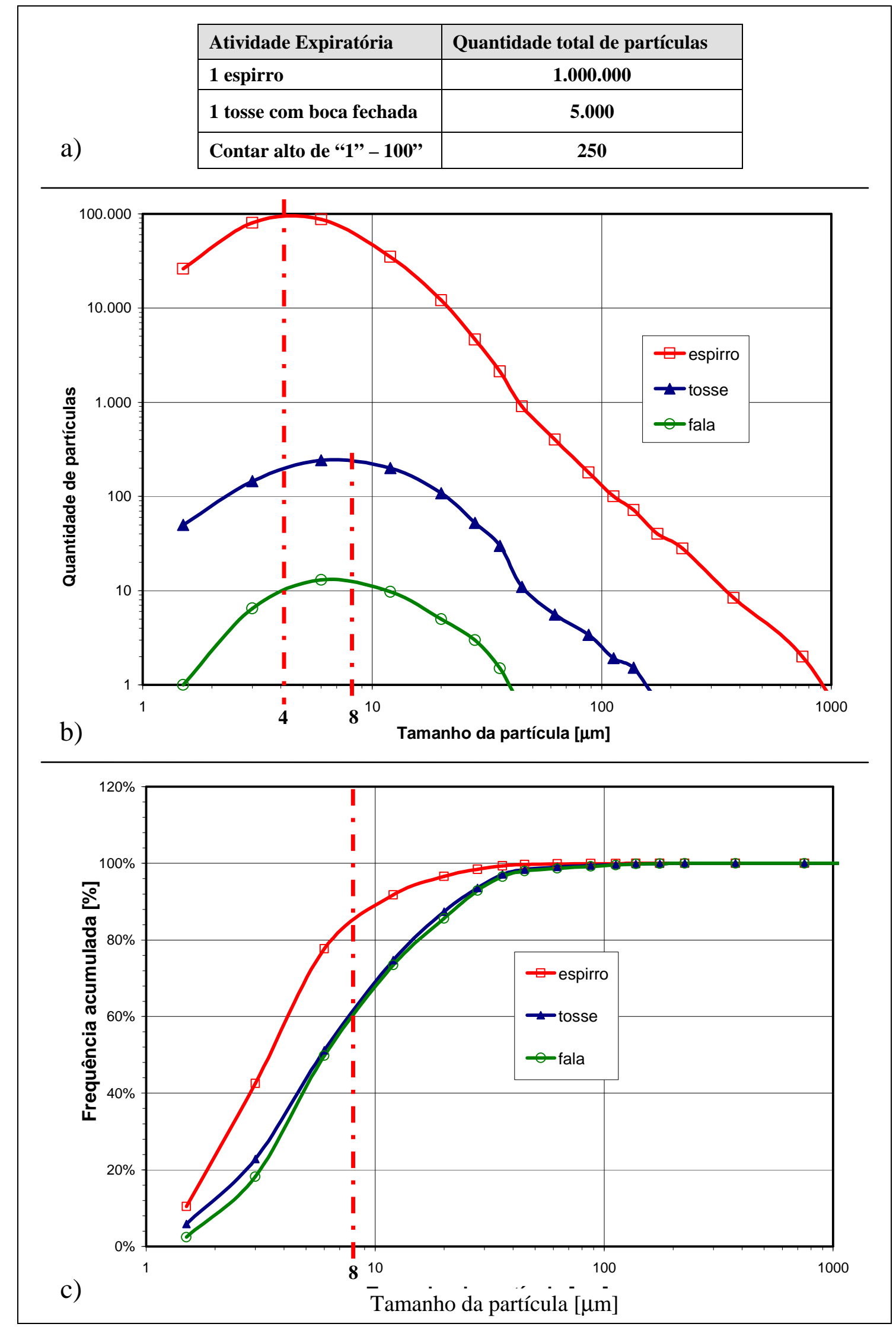

Figura 2-1. Gotículas expiratórias, baseado nas medições de Duguid, 1946. a) quantidade absoluta de partículas. b) distribuição do tamanho de partículas normalizada pelo intervalo de medição. c) distribuição acumulada (adaptado por Conceição, 2012) 
Tabela 2-2. Características de contaminantes liberados em atividades expiratórias (Conceição, 2012)

\begin{tabular}{|c|c|c|c|c|c|c|c|}
\hline Referência & $\begin{array}{l}\text { Tipo de } \\
\text { estudo }\end{array}$ & \begin{tabular}{|c|} 
Atividade \\
expiratória
\end{tabular} & Gás / aerossol & $\begin{array}{l}\text { Quantidade de } \\
\text { partículas/gás }\end{array}$ & Concentração & $\begin{array}{c}\text { Tamanho } \\
{\left[10^{-6} \mathrm{~m}\right]}\end{array}$ & $\begin{array}{c}\text { Velocidade } \\
{[\mathrm{m} / \mathrm{s}]}\end{array}$ \\
\hline $\begin{array}{c}\text { Yan et al., } \\
2009\end{array}$ & $\begin{array}{l}\text { Num e } \\
\text { Exp }\end{array}$ & $\begin{array}{c}\text { Não } \\
\text { específico }\end{array}$ & $\mathrm{CO}_{2}$ & $4.5 \mathrm{~L} / \mathrm{min}$ & $100 \%$ & $\mathrm{~N} / \mathrm{A}$ & ? \\
\hline $\begin{array}{c}\text { Zhang e } \\
\text { Chen, } \\
2007\end{array}$ & Num & Respiração & $\mathrm{CO}_{2}$ & $0,3 \mathrm{~L} / \mathrm{min}$ & $100 \%$ & $\mathrm{~N} / \mathrm{A}$ & ? \\
\hline $\begin{array}{c}\text { Gao e Niu, } \\
2007\end{array}$ & Num & Espirro & $\begin{array}{c}\text { água, } \\
\text { monodisperso } \\
\end{array}$ & 9600 / espirro & $\mathrm{N} / \mathrm{A}$ & 1 & 20 \\
\hline \multirow{3}{*}{$\begin{array}{l}\text { Duguid, } \\
1946\end{array}$} & \multirow{3}{*}{ Medição } & $\begin{array}{c}\text { Fala } \\
\text { (contar de } \\
1-100)\end{array}$ & \multirow{3}{*}{$\begin{array}{l}\text { Saliva, } \\
\text { polidisperso }\end{array}$} & 250 & \multirow{3}{*}{ N/A } & \multirow{3}{*}{$\begin{array}{c}\text { 4-8 (mais } \\
\text { comum) }\end{array}$} & \multirow{3}{*}{$N / A$} \\
\hline & & Tosse & & $5.000 /$ tosse & & & \\
\hline & & Espirro & & $\begin{array}{c}1.000 .000 / \\
\text { espirro }\end{array}$ & & & \\
\hline $\begin{array}{c}\text { Wan et al., } \\
2010\end{array}$ & $\begin{array}{c}\text { Num e } \\
\text { Exp }\end{array}$ & Tosse & $\begin{array}{c}\text { água, } \\
\text { polidisperso }\end{array}$ & $\mathrm{N} / \mathrm{A}$ & $2,5.10^{6} / \mathrm{L}$ & $\begin{array}{c}6,75 \\
\text { (média) }\end{array}$ & 10 \\
\hline \multirow{2}{*}{$\begin{array}{l}\text { Zhang et } \\
\text { al., } 2008\end{array}$} & \multirow{2}{*}{$\begin{array}{c}\text { Num } \\
\text { and Exp }\end{array}$} & \multirow{2}{*}{$\begin{array}{c}\text { Não } \\
\text { específico }\end{array}$} & $\begin{array}{c}\text { DEHS, } \\
\text { monodisperso }\end{array}$ & $4,5 \mathrm{~L} / \mathrm{min}$ & $10^{6} / \mathrm{cm}^{3}$ & 0,7 & $?$ \\
\hline & & & $\mathrm{SF}_{6}$ & $5 \times 10^{-8} \mathrm{~m} 3 / \mathrm{s}$ & $100 \%$ & $\mathrm{~N} / \mathrm{A}$ & $?$ \\
\hline $\begin{array}{c}\text { Shimada, } \\
\text { et al., } \\
1996 \\
\end{array}$ & $\underset{\text { Exp }}{\operatorname{Num} e}$ & $\begin{array}{c}\text { Não } \\
\text { específico }\end{array}$ & $\begin{array}{l}\text { Poliestireno } \\
\text { de Latex, } \\
\text { polidisperso }\end{array}$ & $1 \mathrm{~L} / \mathrm{min}$ & $3.10^{\wedge} 10$ & 0,14 & ? \\
\hline \multirow{3}{*}{$\begin{array}{l}\text { Gupta et } \\
\text { al., } 2011\end{array}$} & \multirow{3}{*}{$\underset{\operatorname{Exp}}{\operatorname{Num} e}$} & Tosse & \multirow{3}{*}{$\begin{array}{c}\text { água } \\
\text { monodisperso }\end{array}$} & $10^{6} /$ tosse & \multirow{3}{*}{$\mathrm{N} / \mathrm{A}$} & 8,5 & 9 (max) \\
\hline & & Respiração & & $\begin{array}{c}525 / \\
\text { respiração }\end{array}$ & & 0,4 & $4(\max )$ \\
\hline & & Fala 15s & & 2250 / fala & & 30 & $?$ \\
\hline \multirow{2}{*}{$\begin{array}{l}\text { Chao et } \\
\text { al., } 2009\end{array}$} & \multirow[b]{2}{*}{ Medição } & Tosse & \multirow{2}{*}{$\begin{array}{c}\text { Saliva, } \\
\text { polidisperso }\end{array}$} & $\begin{array}{c}2085(\max ) / \\
\text { tosse }\end{array}$ & $5.2 / \mathrm{cm}^{3}(\max )$ & $4-8$ & 11.7 \\
\hline & & $\begin{array}{c}\text { Fala } \\
\text { (contar de } \\
1-100)\end{array}$ & & $\begin{array}{c}6720 / \text { tosse } \\
(\max )\end{array}$ & $\begin{array}{l}0.223 / \mathrm{cm}^{3} \\
\quad(\max )\end{array}$ & $\begin{array}{c}\text { 4-8 (mais } \\
\text { comum) }\end{array}$ & 3.1 \\
\hline $\begin{array}{l}\text { Yang, et } \\
\text { al., } 2007\end{array}$ & Medição & Tosse & $\begin{array}{c}\text { Saliva, } \\
\text { polidisperso }\end{array}$ & $0,9 \mathrm{~L} / \mathrm{s}(\max )$ & $\begin{array}{c}2355 / \mathrm{cm}^{3} \\
(\max )\end{array}$ & $\begin{array}{c}\text { Picos em } \\
1,4 \text { e } 8\end{array}$ & $?$ \\
\hline $\begin{array}{l}\text { Fabian et } \\
\text { al., } 2008\end{array}$ & Medição & Respiração & $\begin{array}{c}\text { Saliva, } \\
\text { polidisperso }\end{array}$ & $\mathrm{N} / \mathrm{A}$ & $\begin{array}{c}\text { 8500/litro } \\
\text { (max) }\end{array}$ & $0,3-0,5$ & $\mathrm{~N} / \mathrm{A}$ \\
\hline \multirow{2}{*}{$\begin{array}{c}\text { Fairchild e } \\
\text { Stampfer, } \\
1987\end{array}$} & \multirow[b]{2}{*}{ Medição } & Respiração & \multirow{2}{*}{$\begin{array}{c}\text { Saliva, } \\
\text { polidisperso }\end{array}$} & \multirow[b]{2}{*}{ N/A } & $10^{3} /$ /itro & \multirow[b]{2}{*}{$\mathrm{N} / \mathrm{A}$} & \multirow[b]{2}{*}{$\mathrm{N} / \mathrm{A}$} \\
\hline & & Fala & & & $10^{3} /$ litro & & \\
\hline
\end{tabular}

Nota: Num=numérico; Exp=experimental; Max=máximo; N/A=Não aplicável ?=não informado. 
Capitulo 3.

\section{Avaliação da dispersão de partículas}

Neste Capítulo é apresentado o processo de avaliação de dispersão de partículas em cabines de aeronaves baseado na proposta de Conceição, 2012 (Fig. 3-1), aplicado à análise da influência de diferentes sistemas de distribuição de ar na dispersão de partículas expiratórias na cabine do mock-up do presente trabalho.

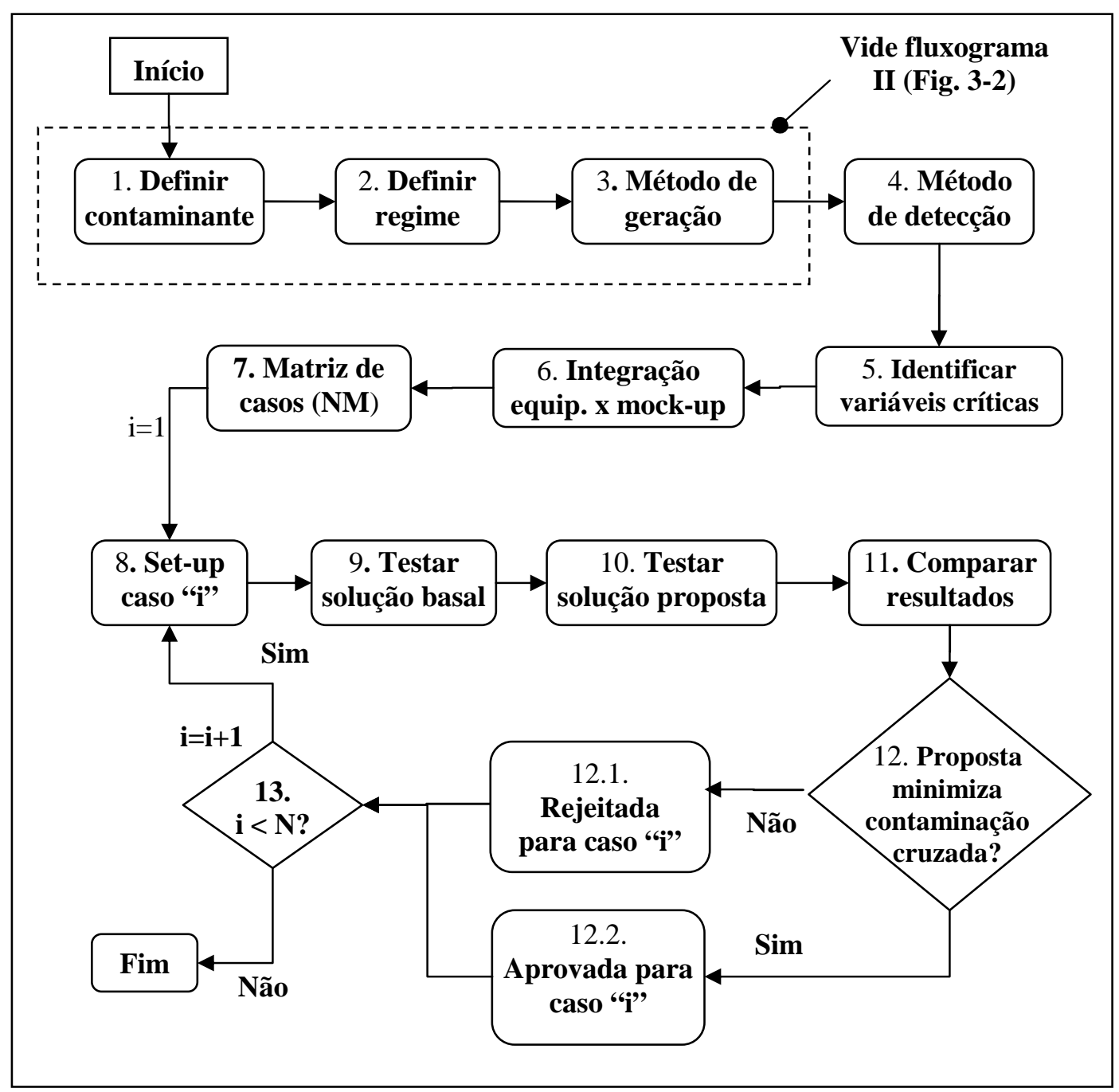

Figura 3-1. Fluxograma I: Processo de avaliação de dispersão de partículas em cabines climatizadas (Conceição, 2012) 
Do processo de análise proposto por Conceição, 2012, são de especial interesse para o desenvolvimento do presente trabalho os passos de 1 a 6 , detalhados a seguir:

\section{Passo 1: Definir o tipo de partículas}

O ponto de partida do processo é definir o tipo de partículas que se deseja avaliar, bem como o processo físico pelo qual estas são geradas (passo 1, Fig. 31). Com isto, é possível especificar o método mais adequado para a geração dessas partículas em laboratório.

A exemplo do trabalho de Conceição, 2012, o foco do presente trabalho também está nas partículas provenientes de atividades expiratórias (ex. espirro, tosse, fala ou respiração), protagonistas nos eventos de contaminação cruzada em cabines de avião.

Pela sua confiabilidade e uso em trabalhos recentes, também foi considerada como referência a curva de distribuição de partículas determinada por Duguid, 1946. Em função disso, considera-se que a maior quantidade de gotículas expiratórias possui tamanho médio entre 4 e $8 \mu \mathrm{m}$, e concentração da ordem de $10^{11} \mathrm{~m}^{-3}$.

\section{Passo 2: Definir o regime}

Dependendo do interesse específico de cada estudo, o fenômeno pode ser tratado como regime permanente ou transiente. A definição por regime transiente ou permanente deve ser feita no começo (passo 2, Fig. 3-1), pois pode influenciar no método de geração/detecção de partículas, definidos na sequência.

Observando o fenômeno físico da tosse ou espirro, logo após a injeção (geração) das partículas no ambiente, as partículas são liberadas em forma de jato e aos poucos vão se dispersando, com as partículas maiores depositando-se mais rapidamente nas superfícies próximas ao ponto de injeção, e as partículas menores arrastadas pelo escoamento alcançando regiões mais distantes.

Segundo Conceição, 2012, se um dado sistema de distribuição de ar é capaz de barrar os contaminantes dispersos neste cenário real e efetivamente transitório, parece adequado considerar que o mesmo seja efetivo para barrar infinitos "disparos" realizados continuamente (ou seja, um jato contínuo de 
aerossol) desde que a quantidade de movimento do jato de aerossol e a distribuição do tamanho de partículas nas duas situações sejam semelhantes. Além disso, depois da injeção pulsada de partículas em um ambiente interior, a sua concentração em um dado local do espaço começa a se reduzir continuamente até que a instabilidade e a incerteza na contagem alcançam níveis inadequados, conforme mostrado experimentalmente por Wan et al., 2009.

Portanto, no presente trabalho também foi efetuada a geração contínua de partículas, simulando a geração de aerossóis durante atividades expiratórias (tosse, espirro, fala, etc), mediante gerador de aerossol disponível no mercado. Com isto, reduziu-se a complexidade dos experimentos e aumentou-se a precisão das medições, sem comprometer o objetivo do experimento, que é comparar a resposta de diferentes arquiteturas de distribuição de ar quanto à qualidade do ar na cabine.

\section{Passo 3: Método de geração}

Uma vez definido o tipo de contaminante, o processo físico de geração que se deseja representar e o regime de operação, parte-se para a definição do método de geração das partículas (passo 3, Fig. 3-1). Como as etapas de definição do tipo de partículas e do método de geração destas partículas são cruciais (etapas 1 a 3, Figura 3-1), estas etapas foram desdobradas por Conceição, 2012, em um segundo fluxograma, apresentado na Figura 3-2.

No processo de escolha do método de geração, Conceição, 2012, partiu de dois argumentos que direcionam à utilização de gerador de partículas ao invés de gás traçador: $1^{\circ}$ ) a maior parte das partículas expiratórias possuem tamanho entre 4 e $8 \mu \mathrm{m}$ (Duguid, 1946), e não podem ser caracterizadas como "aerossóis menores"; $2^{\circ}$ ) as gotículas expiratórias depositam-se nas superfícies dos obstáculos depois do choque, ao passo que as partículas gasosas são refletidas. Além disso, é característico as cabines de avião possuírem a razão "área superficial $x$ volume" maior do que os ambientes de escritório, o que potencializa as taxas de deposição de partículas nas suas superfícies internas (Wan et al., 2009).

$\mathrm{Na}$ escolha do gerador de partículas os principais requisitos considerados por Conceição, 2012, foram: $1^{\circ}$ ) faixa de tamanho das partículas geradas; $2^{\circ}$ ) vazão e 
concentração das partículas; $3^{\circ}$ ) disponibilidade no mercado; $4^{\circ}$ ) custo do equipamento. Com base nesses requisitos, foi escolhido o gerador de aerossol da TSI Modelo 3475, que também foi utilizado no presente trabalho, descrito no Capítulo 4 - Procedimento experimental, item 4.5.

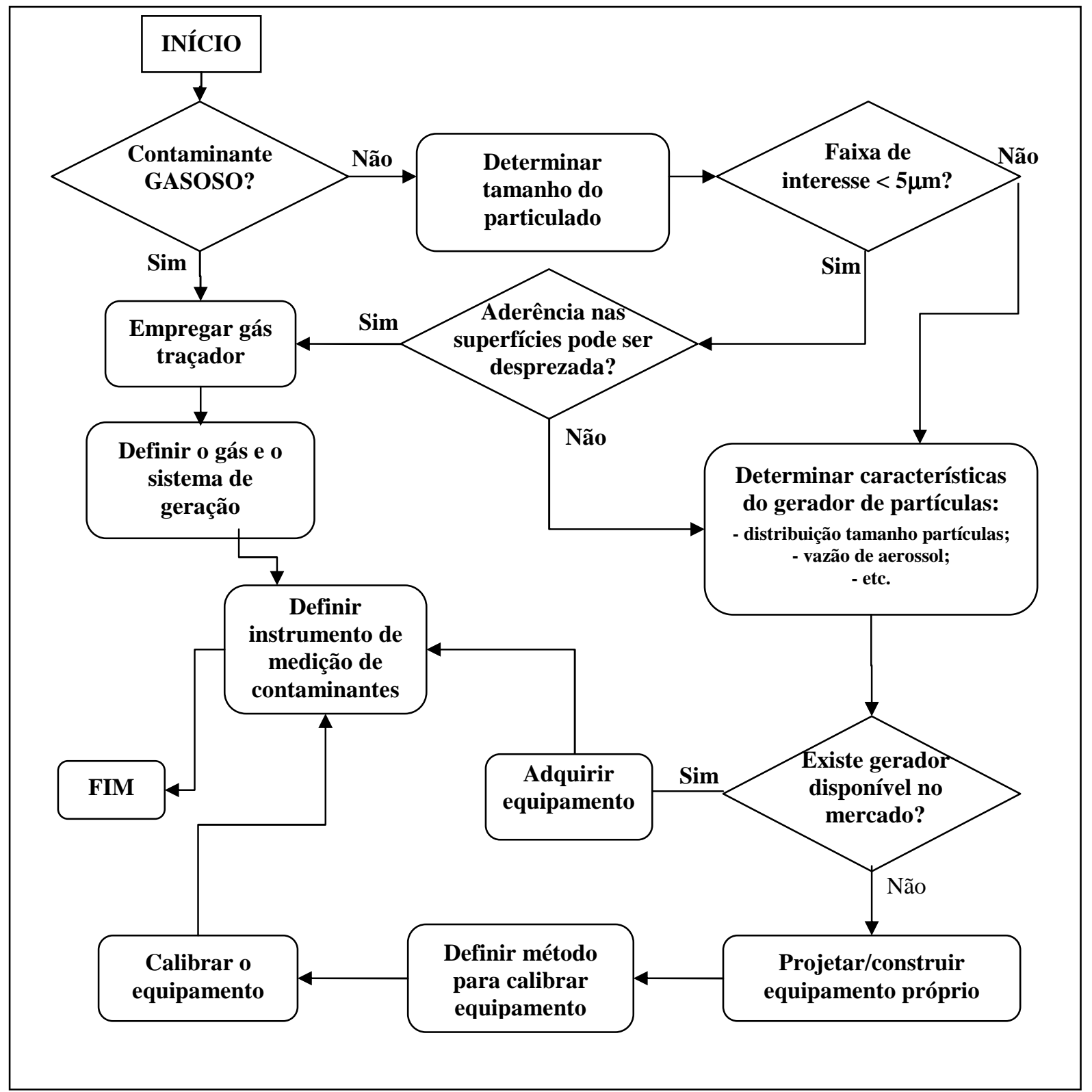

Figura 3-2. Fluxograma II: processo para definição do gerador de partículas (Conceição, 2012) 


\section{Passo 4: Método de detecção}

Tendo definido o método de geração, é preciso definir a metodologia de medição desses contaminantes (passo 4, Fig. 3-1). Para contaminantes gasosos, basta definir o tipo de gás e a faixa de concentrações que se deseja trabalhar, para então definir o medidor de gases mais adequado. Já para a identificação de partículas, têm-se utilizado contadores ópticos portáteis, capazes de fazer a contagem de partículas por unidade de volume de ar em diferentes faixas de tamanho, ou os espectrômetros, que fazem a contagem de partículas e a medição da sua concentração em massa, normalmente até partículas com diâmetro médio de $20 \mu \mathrm{m}$.

Os contadores ópticos de partículas utilizados no presente trabalho são descritos no Capítulo 4 - Procedimento experimental, item 4.6.

\section{Passo 5: Identificar variáveis críticas}

Uma vez definido o tipo de partículas, o regime de operação, o processo de geração e a definição do método de geração do contaminante, a próxima etapa é a identificação das variáveis que podem influenciar significativamente nos resultados do experimento, denominadas de variáveis críticas por Conceição, 2012.

Essas variáveis foram monitoradas e/ou controladas, de maneira a garantir a adequada repetibilidade e reprodutibilidade do experimento. Isto é de fundamental importância, tendo em vista a limitação da quantidade de equipamentos usualmente utilizados para medir partículas, decorrente do alto custo envolvido.

Além disso, existem vários parâmetros que influenciam diretamente os resultados deste tipo de experimento. Para que a influência de cada parâmetro seja avaliada individualmente, os outros parâmetros devem ser mantidos constantes. Por consequência, o número de experimentos cresce, bem como a necessidade de garantir adequada repetibilidade das condições de contorno dos experimentos.

As variáveis críticas e os procedimentos adotados para tratar cada uma delas ao longo dos experimentos - os procedimentos de ensaio - do presente trabalho são apresentados no Capítulo 4 - Procedimento experimental, item 4.7. 


\section{Passo 6: Integração de equipamentos no mock-up}

Segundo Conceição, 2012, na etapa 6, Figura 3-1, é feita a definição do(s) ponto(s) de inserção das partículas, bem como o(s) ponto(s) de medição dessas partículas. Mesmo quando forem requeridos diversos pontos de geração de partículas, esses devem ser avaliados separadamente, possibilitando assim uma melhor interpretação dos resultados. Como os equipamentos de medição de partículas são, em geral, de alto custo, deve-se repetir o experimento diversas vezes, reposicionando o instrumento de medição para cada repetição.

Quando o tamanho dos equipamentos é considerável e pode afetar a dinâmica do escoamento/contaminantes, pode-se posicioná-los fora da câmara experimental. No presente caso, isto ocorre com o gerador de partículas que foi posicionado fora do mock-up.

No Capítulo 4 - Procedimento experimental, item 4.9, são definidos os pontos de inserção dos contaminantes, bem como os pontos de medição desses contaminantes no interior do mock-up, baseado no trabalho de Wan et al., 2005. 


\section{Capitulo 4.}

\section{Procedimento experimental}

Neste capítulo é apresentado o método para a análise experimental de dispersão de partículas, considerando diferentes arquiteturas de distribuição de ar, em mock-up de 12 lugares, utilizando gerador e contadores de partículas.

\subsection{Introdução}

Conforme ressaltado no Capítulo 1, o sistema de distribuição de ar em cabines de aeronaves tem um papel fundamental para criar um ambiente seguro, saudável e confortável no interior dessas cabines. Normalmente, o sistema de distribuição de ar utilizado é por mistura (MV), ou seja, insuflamento de ar pela parte superior e lateral inferior dos bagageiros (bins) e retorno pela parte inferior lateral da cabine. A distribuição de temperaturas nesse sistema é mais uniforme, entretanto ocorre grande circulação de ar com velocidade muito alta próximo aos difusores, não provendo boas condições de conforto térmico e possibilitando uma maior dispersão de partículas, aumentando assim o risco de propagação de doenças infecciosas.

No presente trabalho foi realizada análise experimental da dispersão de partículas expiratórias considerando diferentes arquiteturas de distribuição de ar em um mock-up que reproduz o interior de cabine de aeronave comercial.

\subsection{O laboratório}

Para a realização dos ensaios foi realizada a montagem de um laboratório que permite a análise de diferentes sistemas de distribuição de ar (sistema da cabine), bem como de diferentes sistemas de ventilação personalizada (sistema personalizado) em um mock-up de cabine de aeronave instrumentado (Fig. 4-1). 


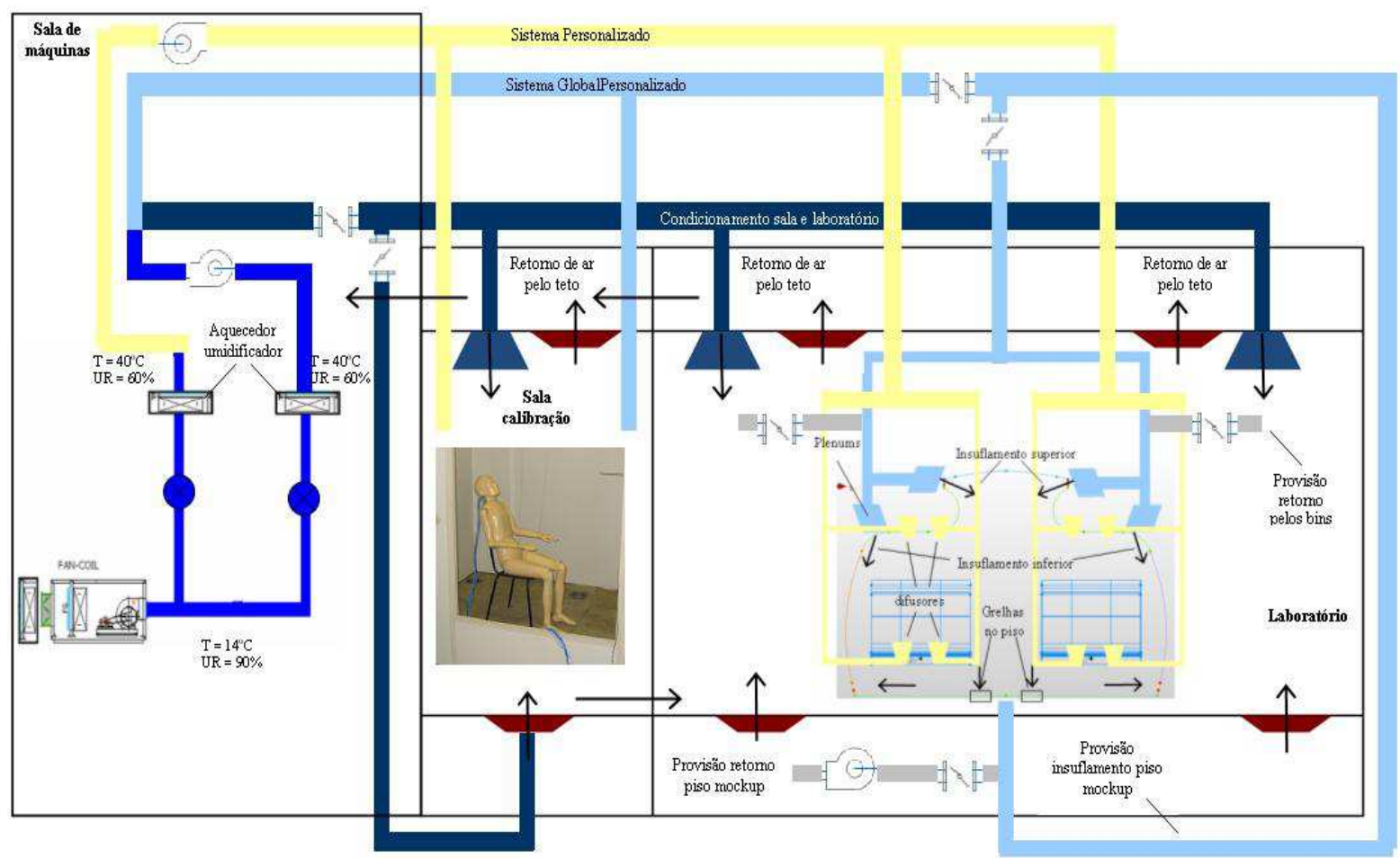

Figura 4-1. Representação esquemática do sistema de cabine (em azul claro) e personalizado (em amarelo) do mock-up

O laboratório é dotado de um sistema de climatização do tipo expansão indireta, composto por chiller e fan-coil, e possibilidade de aquecimento e umidificação do ar, com controlador lógico programável, CLP, que fornece ar tratado ao mock-up instrumentado.

A captação do ar do fan-coil é efetuada na casa de máquinas através de um duto com damper, ligado ao ambiente externo. Um exaustor, instalado na linha de retorno do ar, permite a exaustão e renovação de $100 \%$ do ar, importante para a realização do presente trabalho.

O controle e o ajuste da temperatura e da umidade do ar são obtidos por meio de transmissores de temperatura e umidade relativa do ar da Vaisala, modelo HMT-333, com faixas de operação de 0 a $100 \%$ UR $\pm(1,0+0,008 x$ leitura) \% UR e -40 a $80^{\circ} \mathrm{C}\left( \pm 0,2{ }^{\circ} \mathrm{C} @+20^{\circ} \mathrm{C}\right)$, que foram instalados nos dutos de insuflamento de ar do mock-up. 


\subsection{0 mock-up}

O interior do mock-up foi construído de modo a representar adequadamente o interior de uma cabine de aeronave comercial. Para isso, as curvas internas dos bagageiros (bins) e as paredes foram construídas em tubo estrutural e chapa metálica, com acabamento interno em revestimento melamínico e tecido automotivo. O piso foi confeccionado em madeira e revestido com carpete. A Figura 4-2 mostra o esquema interno do mock-up e um esquema de sua vista externa. Note que os detalhes em azul representam onde estão posicionadas as entradas e saídas de ar do mock-up.

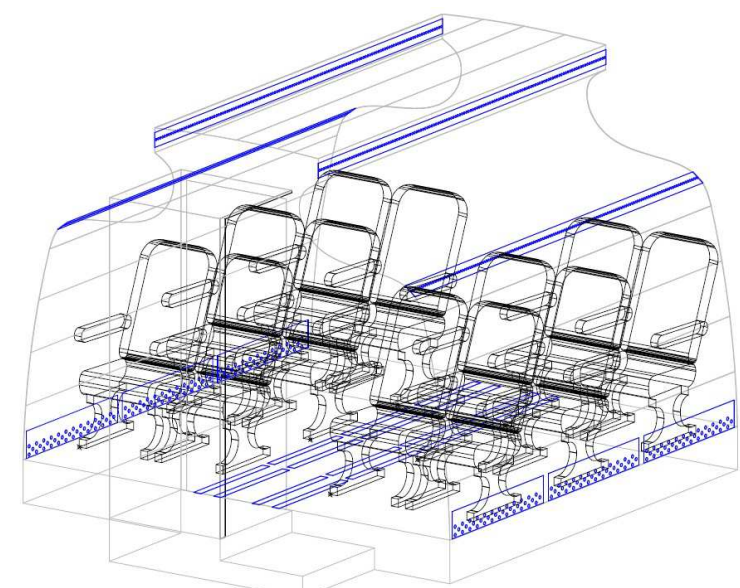

a)

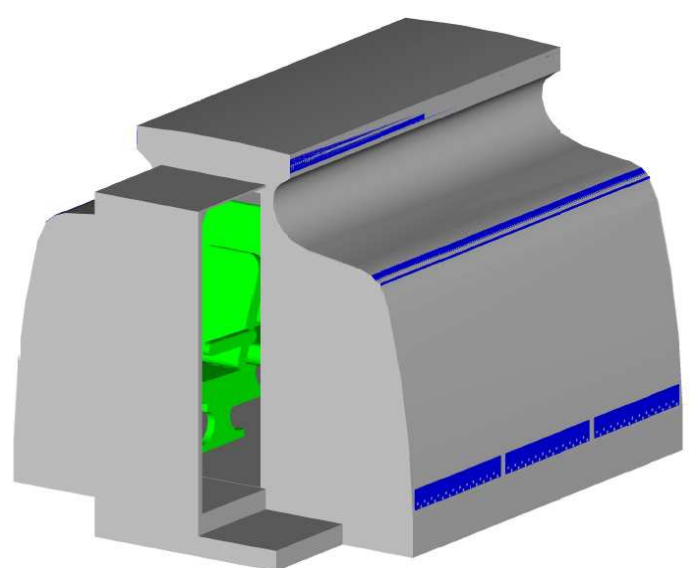

b)

Figura 4-2. a) Esquema interno do mock-up, b) Acesso e vista externa do mock-up

Os assentos utilizados são assentos de aeronave comercial e suas dimensões e espaçamentos entre assentos representam o interior deste tipo de cabine de aeronave. A Figura 4-3 mostra o interior do mock-up, juntamente com os manequins aquecidos, simulando a presença de passageiros, detalhados no Anexo A.

\subsection{Arquiteturas de distribuição de ar analisadas}

As Figuras 4-4 a 4-6 ilustram as arquiteturas de distribuição de ar que foram analisadas no presente trabalho, respectivamente: sistema por mistura (MV), sistema de distribuição de ar pelo piso (UFAD) e uma modificação no sistema 
UFAD, insuflando parte do ar pela parte inferior dos bagageiros (bins), conforme detalhado a seguir:

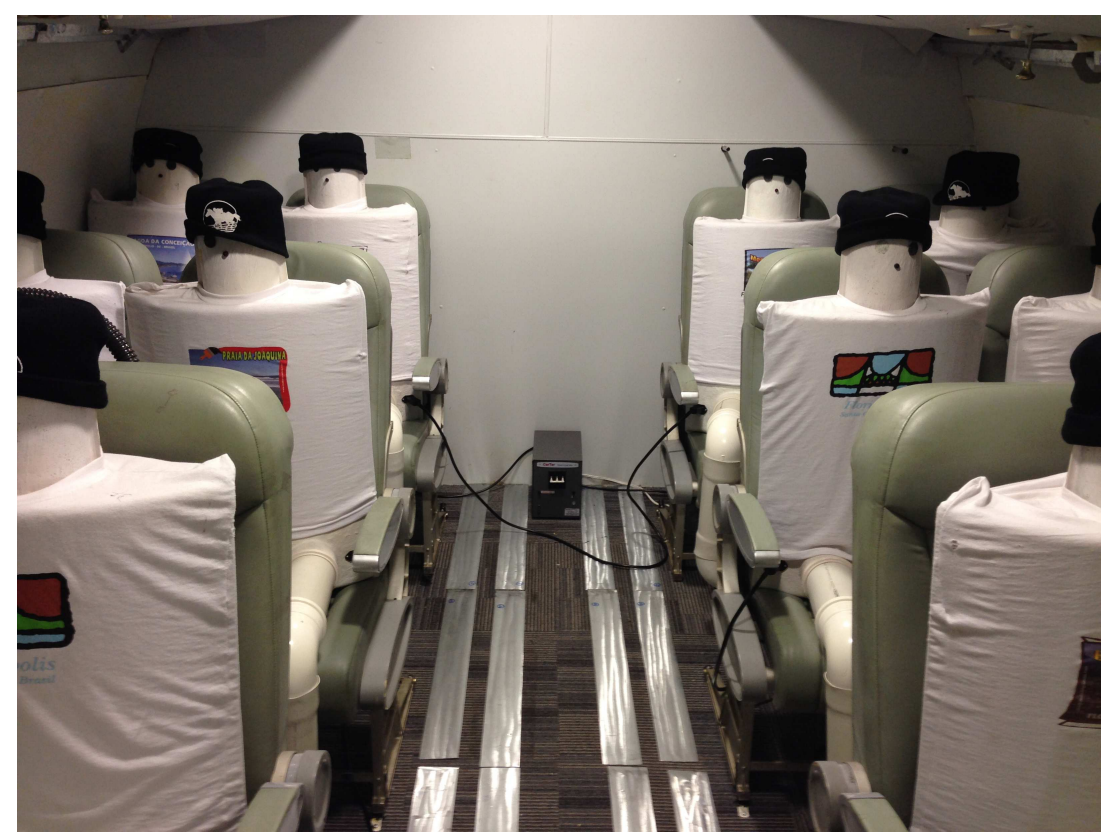

Figura 4-3. Vista interna do mock-up com os manequins aquecidos

- $\quad$ Arquitetura 1 - Sistema de ventilação por mistura (MV), com $40 \%$ de vazão de ar insuflada por difusores instalados na parte superior dos bins e $60 \%$ da vazão de ar $^{1}$ insuflada pelos difusores na parte lateral inferior dos bins e com exaustão de $100 \%$ da vazão de ar por grelhas instaladas na parte inferior lateral da cabine, sistema convencional de distribuição de ar, Figura 4-4.

- $\quad$ Arquitetura 2 - Sistema de distribuição de ar pelo piso (UFAD), com $100 \%$ de vazão de ar insuflada por difusores instalados na região central da cabine, e com exaustão de $40 \%$ da vazão de ar por grelhas localizadas na parte superior dos bins e com exaustão de $60 \%$ da vazão de ar pelas grelhas localizadas na parte lateral inferior dos bins, Figura 4-5.

- $\quad$ Arquitetura 3 - Sistema UFAD modificado, com 40\% da vazão de ar insuflada por difusores instalados na região central da cabine e $60 \%$ da vazão de ar insuflada por difusores instalados na parte lateral inferior dos bins e com exaustão de $100 \%$ da vazão do ar pelas grelhas instaladas na parte superior dos bins, Figura 4-6.

${ }^{1}$ A utilização da proporção da vazão de ar de $40 \%$ na parte superior dos bins e de $60 \%$ na parte lateral inferior dos bins é usual no setor aeronáutico (fonte: comunicação pessoal). 


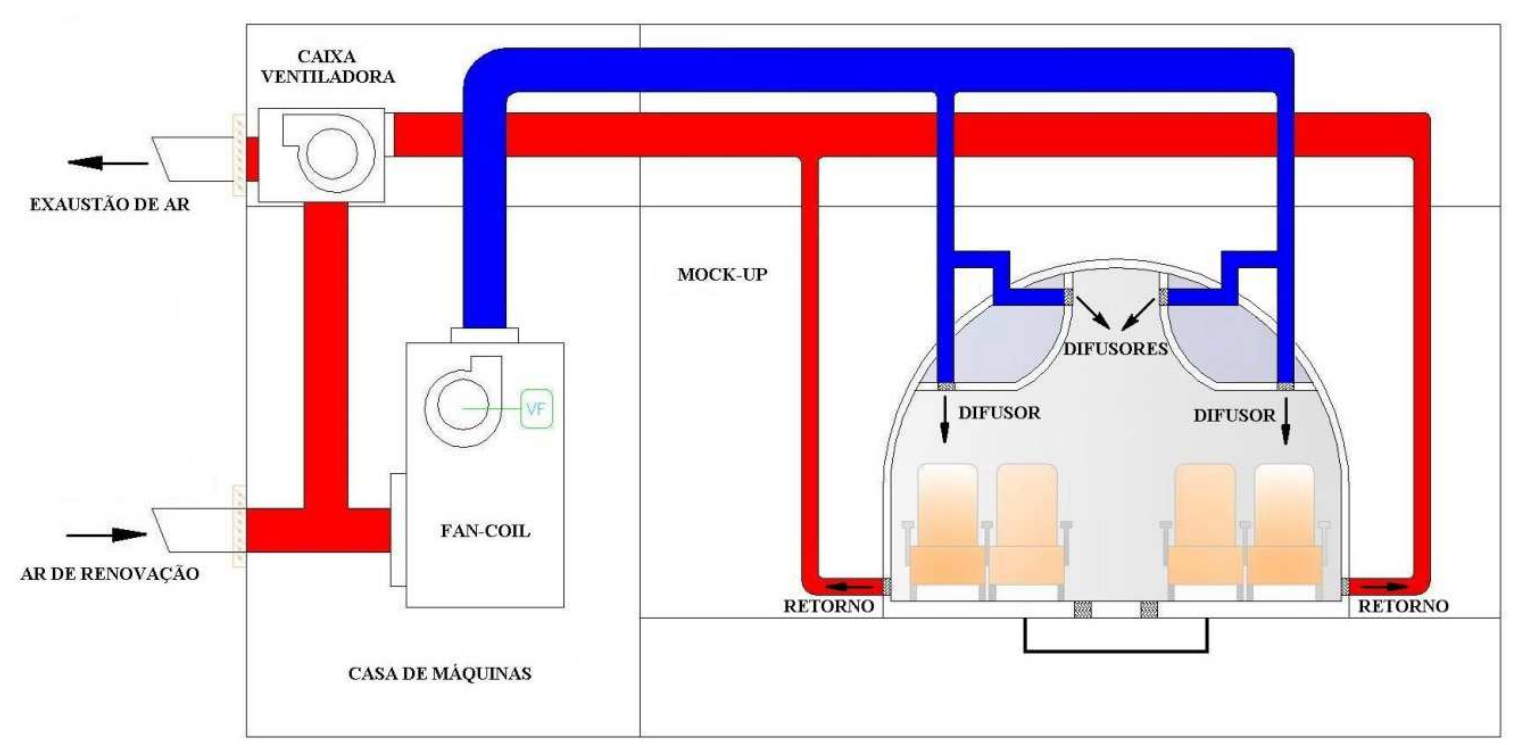

Figura 4-4. Arquitetura 1: Sistema de ventilação por mistura (MV)

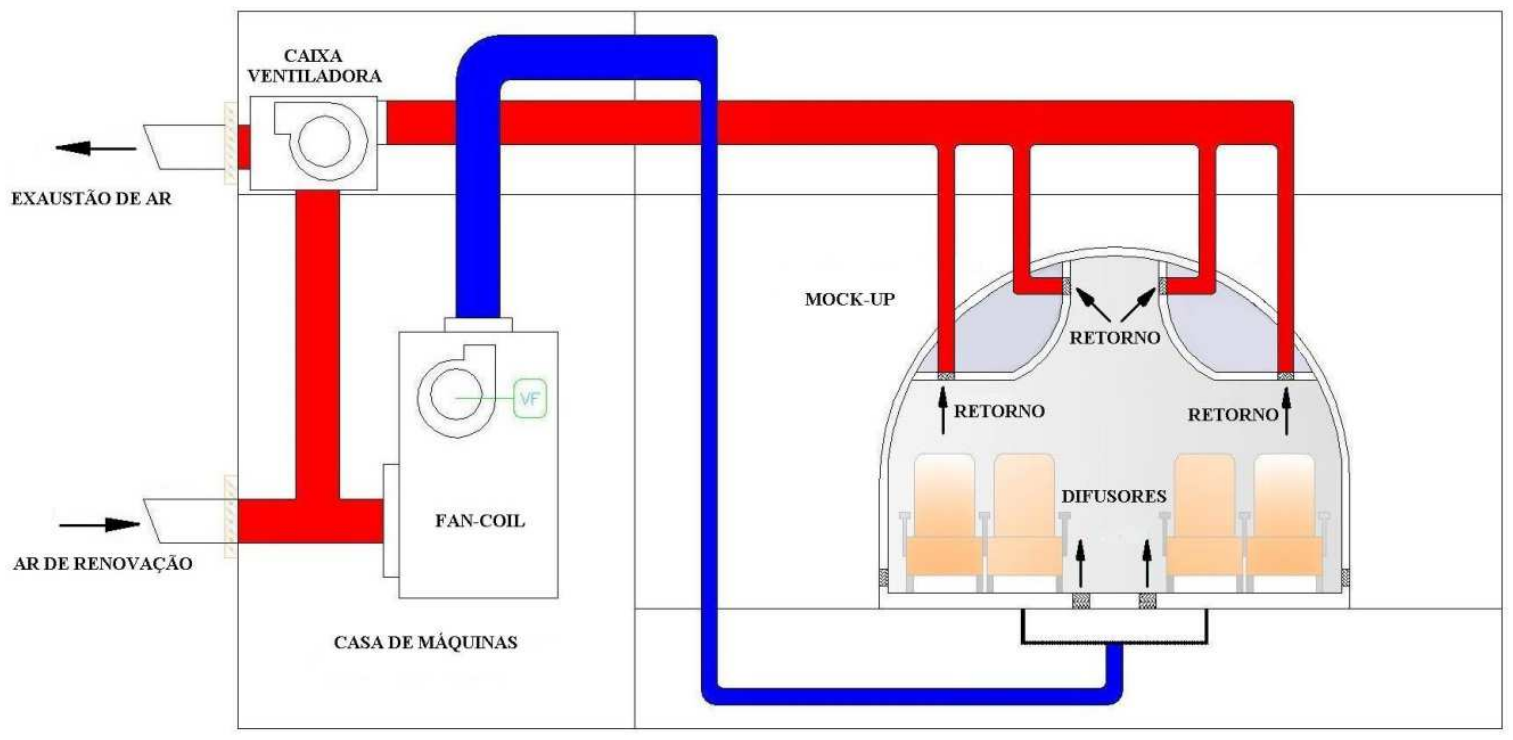

Figura 4-5. Arquitetura 2: Sistema de distribuição de ar pelo piso (UFAD) 


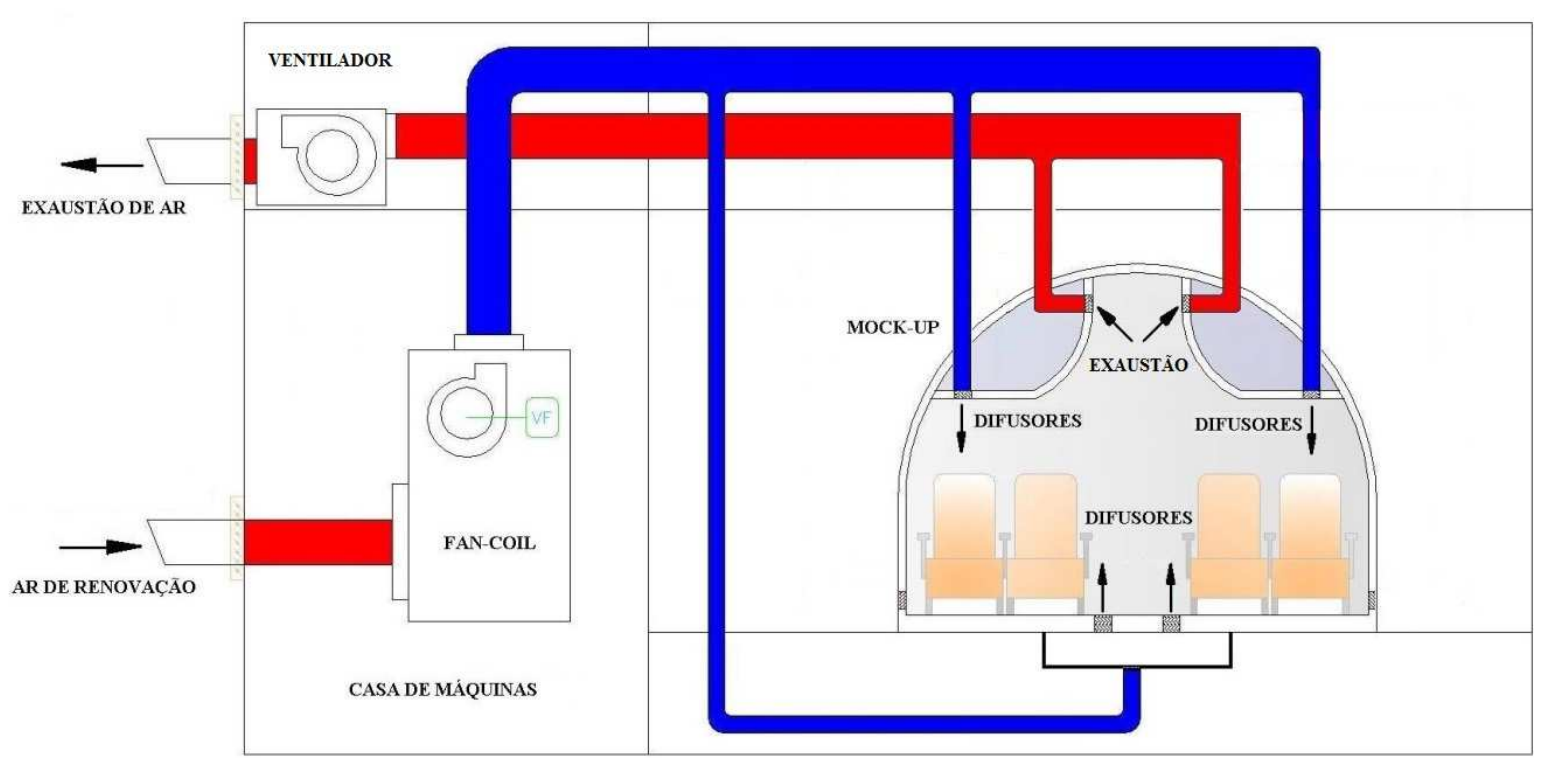

Figura 4-6. Arquitetura 3: Sistema UFAD modificado

\subsection{Gerador de partículas}

Com base nos requisitos estabelecidos por Conceição, 2012, apresentados no Capítulo 3, foi escolhido o gerador de aerossol da TSI Modelo 3475 (Fig. 4-7), que permite variar o tamanho médio e a concentração das partículas geradas. Este equipamento necessita de uma fonte de nitrogênio para seu funcionamento, pressurizando a linha durante a operação em aproximadamente 6 bar.

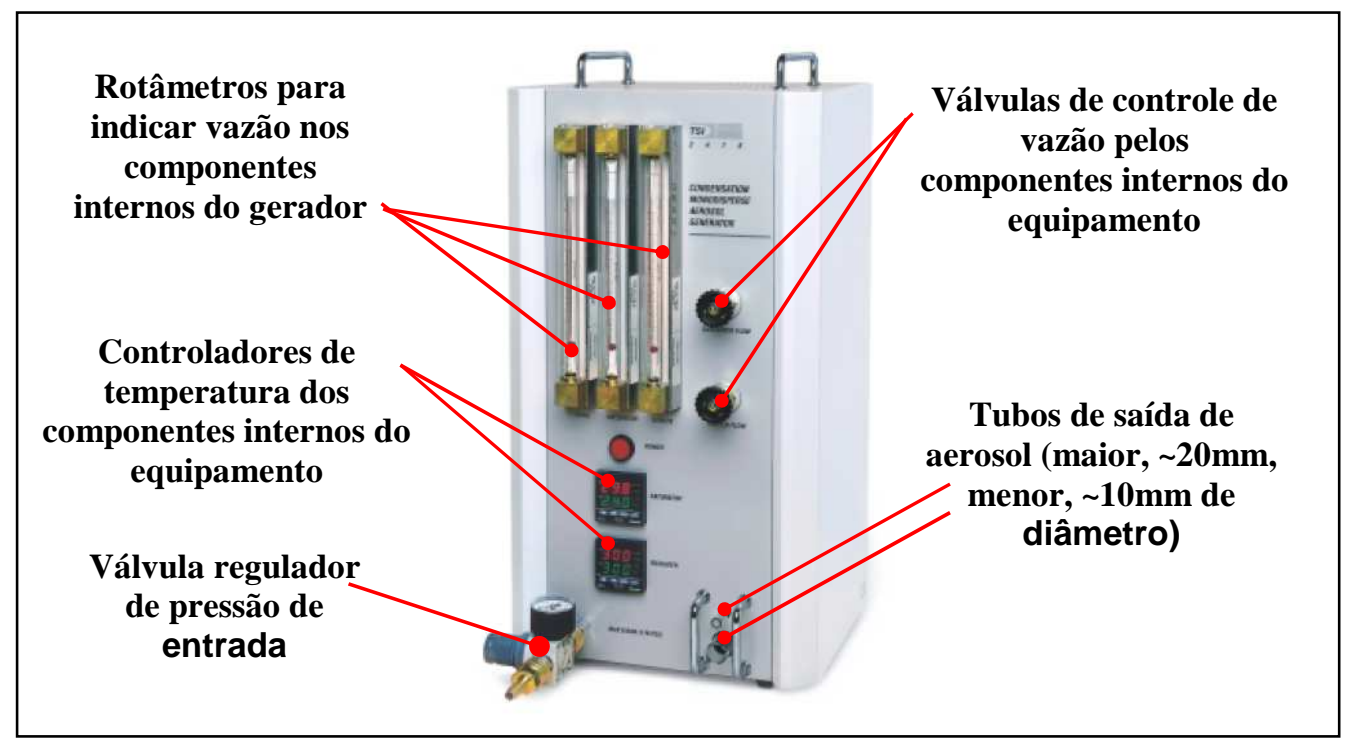

Figura 4-7. Gerador de aerossol TSI modelo 3475 (TSI, 2010) - imagem de catálogo.

O gerador TSI 3475 produz partículas com diâmetro médio entre 0,1 a $8 \mu \mathrm{m}$, faixa esta que engloba a maior quantidade de partículas geradas em atividades 
expiratórias (ver Figura 4-7) e pode produzir aerossol com concentração de $10^{11} / \mathrm{m}^{3}$ (TSI, 2004), que é da mesma ordem de grandeza da concentração de gotículas geradas em um espirro, conforme discutido no item 2-2. O aerossol é gerado com DEHS (Di-etil-hexil-sebacato), que é um líquido com baixa taxa de evaporação e massa específica próxima à da água $\left(915 \mathrm{~kg} / \mathrm{m}^{3}\right)$ (Hinds, 1999). Acompanha o equipamento um monitor de partículas PAM 3475, instalado em série, que monitora o diâmetro médio das partículas geradas, bem como a sua concentração (TSI, 2004).

Nos ensaios do presente trabalho o gerador operou com vazão de aerossol da ordem de $4 \mathrm{~L} / \mathrm{min}$, semelhante à vazão média de ar de inalação/exalação das pessoas (Yan et al., 2009). Considerando que o diâmetro do tubo de saída de aerossol é da ordem de $10 \mathrm{~mm}$, a velocidade em sua saída foi de aproximadamente $1 \mathrm{~m} / \mathrm{s}$. É importante destacar que o gerador selecionado foi utilizado por outros pesquisadores em estudos correlatos, dentre eles Zhang et al., 2008, Jones e Nicas, 2009 e Conceição, 2012.

O gerador de aerossol foi configurado para gerar partículas com tamanho médio de $4 \mu \mathrm{m} \pm 1 \mu \mathrm{m}$ e concentração em torno de $1,2.10^{6} / \mathrm{cm}^{3}$ (Fig. 4-8). Esse tamanho médio de $4 \mu \mathrm{m}$ foi escolhido devido aos resultados do gráfico da Figura 2-1, que mostram que para a atividade expiratória de um espirro tem-se uma quantidade maior de partículas nesse diâmetro escolhido. Esta concentração de partículas é da mesma ordem de grandeza da concentração de gotículas geradas em um espirro (ver item 2.2).

Embora este gerador produza, em sua grande maioria, partículas com o tamanho e a concentração desejados, ele também produz partículas, em menor quantidade, nas outras faixas de tamanho de 0,1 até $8 \mu \mathrm{m}$. $O$ fato da geração não ser totalmente monodispersa, mostrou-se interessante, pois permitiu a análise da dispersão de partículas também em faixas de tamanhos maiores de partículas, além daquela de 3,0 a 5,0 $\mu \mathrm{m}(4 \mu \mathrm{m} \pm 1 \mu \mathrm{m})$, em cada arquitetura de distribuição de ar analisada. 


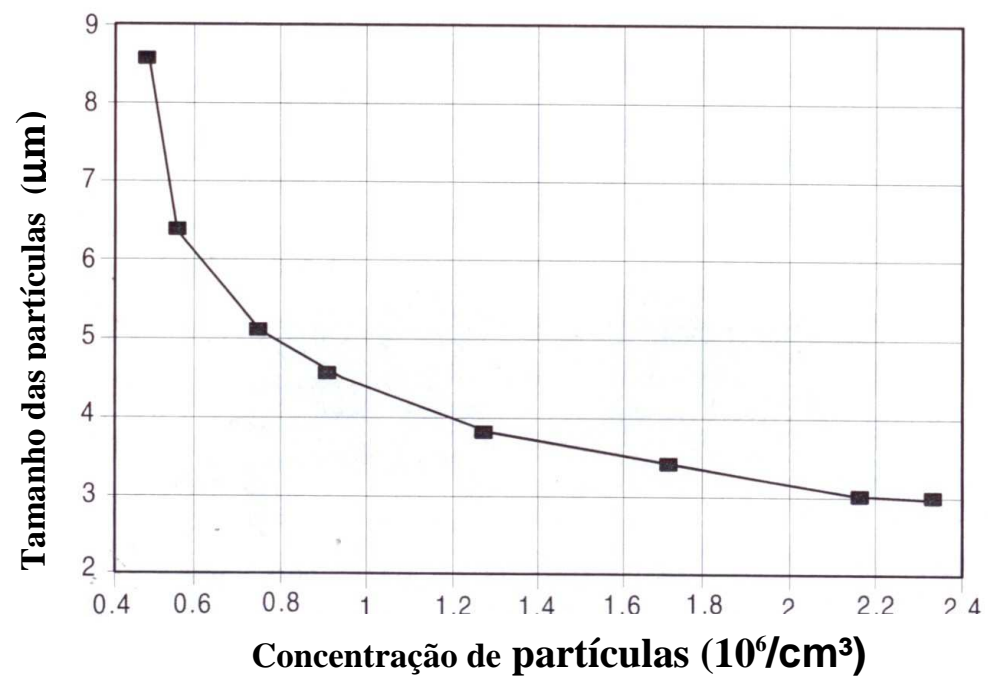

Figura 4-8. Concentração de partículas em função do tamanho da gotícula gerada (gráfico do catálogo do gerador TSI modelo 3475)

\subsection{Contadores de partículas}

A medição das partículas foi realizada com contador óptico da marca Met One (Fig. 4-9). O emprego dos contadores portáteis utilizados neste trabalho mostrou-se bastante adequado para os objetivos propostos, pois embora não apresentem precisão tão boa quanto os espectrômetros, possuem características que motivam seu emprego, dentre elas: a sua portabilidade e volume reduzido, o que facilitou o manuseio ao longo dos experimentos. A robustez deste equipamento permite várias horas de medição contínua, e pode ser operado de maneira remota, via cabos de comunicação RS232, tanto para comandar as medições como para transferir os dados medidos.

O contador possui 6 canais para contagem de partículas na faixa de 1,0 a $10,0 \mu \mathrm{m}(1,0$ a 2,0 $\mu \mathrm{m}$, de 2,0 a 3,0 $\mu \mathrm{m}$, de 3 a $5 \mu \mathrm{m}$, de 5 a $7 \mu \mathrm{m}$, de 7 a $10 \mu \mathrm{m}, \mathrm{e}$ maior do que $10 \mu \mathrm{m}$ ). Adequados, portanto, para a realização do presente trabalho, tendo em vista a faixa de partículas geradas pelo gerador TSI modelo 3475 , conforme descrito no item 4.5. 


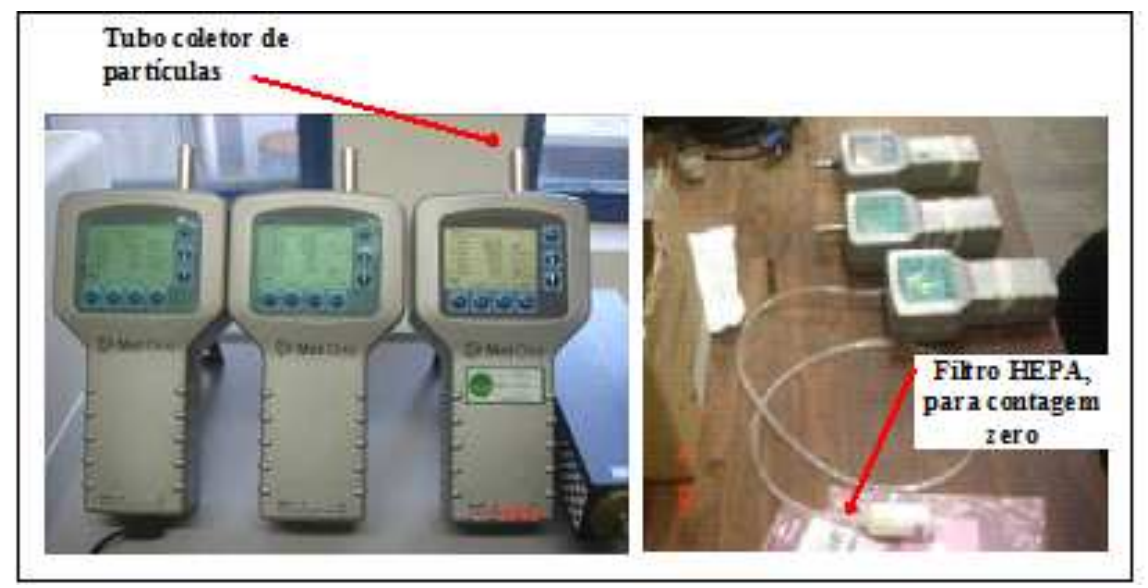

Figura 4-9. Contadores de partículas da MetOne, modelo HHPC6 (MetOne HHPC-6, 2010), utilizados nos experimentos (Conceição, 2012)

Este equipamento captura o ar do seu entorno por sucção promovida por uma bomba interna com vazão volumétrica de $0,1 \mathrm{cfm}(2,83 \mathrm{~L} / \mathrm{min}$.). A duração de cada amostragem pode ser definida entre $6 \mathrm{~s}$ e $10 \mathrm{~min}$, o que determina o volume total de ar amostrado em cada medição. Já o intervalo entre as amostragens pode ser definido entre $1 \mathrm{~s}$ e $1 \mathrm{~h}$. O tempo de duração mais adequado pode variar em função da aplicação específica e deve ser definido empiricamente. No presente estudo foi adotado tempo de 10 minutos de amostragem por assento, com um tempo de 10 minutos antes da medição de partículas.

O contador opera pelo principio de dispersão de um feixe luminoso (laser de diodo) ocasionada pela passagem das partículas aspiradas pela bomba. Um tubo coletor de partículas com diâmetro interno de $10 \mathrm{~mm}$ acompanha o contador de partículas, como mostrado na Figura 4-10.

A Figura 4-9 mostra também os contadores de partículas quando da limpeza com contagem zero, realizada com o auxílio de um filtro absoluto (HEPA), conectado ao tubo coletor de partículas por intermédio de uma mangueira flexível de silicone. Essa tarefa deve ser realizada idealmente sempre antes de começar as medições, para garantir que o aparelho não tenha impurezas aprisionadas nas proximidades do seu sensor ótico.

Segundo o manual deste equipamento, o erro de coincidência é da ordem $5 \%$ para concentrações de $2.10^{6} /$ pés $^{3}\left(7,0.10^{7} / \mathrm{m}^{3}\right)$ e a eficiência de contagem é de $50 \%$ para partículas de $0,3 \mu \mathrm{m}$ e de $100 \%$ para partículas maiores do que $0,45 \mu \mathrm{m}$. 
Conforme artigo técnico publicado pelo fabricante do equipamento (Latimer e Tang, 2007), a incerteza de medição na classificação de tamanhos das partículas coletadas é da ordem $7 \%$. Porém, como não se sabe o tamanho exato das partículas contadas em cada faixa de medição, esta informação parece não ajudar na definição das incertezas de medição.

Segundo Hinds, 1999, o erro sistemático de um contador de partículas óptico é função, principalmente, do diâmetro da partícula e de seu índice de refração. Como, de fato, os contadores utilizados são calibrados com partículas de PSL (polystirene latex spheres) que possuem índice de refração de 1,59 (MetOne HHPC-6, 2010), e o aerossol de DEHS contado nos experimentos possui índice de refração de 1,45 (Topas, 2012), este desvio precisaria ser investigado. Porém, com base nos estudos desenvolvidos por Yoo et al., 1996, com contadores ópticos semelhantes ao empregado no presente trabalho, tem-se que uma diferença de aproximadamente 0,15 no índice de refração não deve impactar significativamente nos resultados das medições.

Não obstante, considerando-se que a incerteza na contagem de partículas segue a estatística de Poisson (Kulkarni et al., 2011), a incerteza poderia ser estimada pela raiz quadrada do número de partículas contadas em cada medição. Função do acima exposto utiliza-se como valor de incerteza na contagem das partículas $\left(\Delta N^{2}\right)$,o maior valor numérico obtido por qualquer um dos dois critérios listados a seguir:

- $\Delta N= \pm \sqrt{N}$, (estatística de Poisson)

- $\Delta N=+5 \% N$ (perdas por coincidência)

\subsection{Variáveis críticas e condições de ensaio}

As condições do experimento no interior do mock-up foram baseadas nas normas ASHRAE 161 (2007), ASHRAE 55 (2010) e ISO 7726 (1998).

As variáveis críticas identificadas e os procedimentos adotados para tratar cada uma delas ao longo dos experimentos são apresentados a seguir.

\footnotetext{
${ }^{2} \mathrm{O}$ valor de $\mathrm{N}$ corresponde à média da quantidade de partículas contadas em cada ensaio em cada faixa de medição $(3,0$ a 5,0 $\mu \mathrm{m}, 5$ a 7,0 $\mu \mathrm{m}, 7,0$ a 10,0 $\mu \mathrm{m}$ e acima de $10 \mu \mathrm{m})$
} 


\subsubsection{Vazão de ar}

Para as três arquiteturas de distribuição de ar propostas, Figuras 4-4 a 4-6, a vazão de referência considerada foi de $9,5 \mathrm{l} / \mathrm{s}$ por pessoa, que corresponde a 34 $\mathrm{m}^{3} / \mathrm{h}$ (20 cfm) por pessoa, valor recomendado pela norma ASHRAE 161 (2007). Considerando que a cabine comporta 12 pessoas, a vazão de ar de insuflamento do mock-up foi controlada em aprox. $408 \mathrm{~m}^{3} / \mathrm{h}$ (240 cfm).

\subsubsection{Vazão de ar de renovação e filtragem do ar}

Conforme ressaltado no item 1.1, na maioria das aeronaves comerciais $50 \%$ do ar fornecido ao passageiro é recirculado como forma de melhorar o controle da circulação do ar na cabine, a umidade e a eficiência no consumo de combustível. Filtros HEPA são instalados nos dutos de recirculação para reter os contaminantes gerados na cabine. Estes $50 \%$ do ar recirculado, acrescidos dos $50 \%$ de ar de renovação, constituem a vazão de ar que é insuflado na cabine da aeronave.

No presente trabalho, conforme descrito no item 4.2, o sistema de climatização do mock-up conta com um exaustor, instalado na linha de retorno do ar, que permite a exaustão e renovação de $100 \%$ do ar do mock-up, não tendo sido necessário a instalação de filtro HEPA para retenção das partículas geradas na cabine, que são eliminadas na exaustão.

Também não houve necessidade de instalação de filtro adicional no sistema de climatização, uma vez que medições de partículas no ar de renovação insuflado no mock-up, mostraram valores bastante baixos para partículas maiores que $4,0 \mu \mathrm{m}$ - objeto de interesse do presente trabalho (ver item 4.9.2).

\subsubsection{Temperatura do ar de insuflamento}

As temperaturas do ar de insuflamento foram estabelecidas com base em requerimentos de operação de aeronaves da ASHRAE 161 (2007), que estabelece temperaturas do ar de cabine de $18,3^{\circ} \mathrm{C}$ a $23,9^{\circ} \mathrm{C}$, com tolerância do set point de $\pm 1,1^{\circ} \mathrm{C}$, tendo sido adotadas:

- Temperatura de insuflamento igual a $18^{\circ} \mathrm{C} \pm 0,5^{\circ} \mathrm{C}$

- Temperatura de insuflamento igual a $22^{\circ} \mathrm{C} \pm 0,5^{\circ} \mathrm{C}$. 


\subsubsection{Temperaturas das paredes internas do mock-up}

Para que não houvesse a interferência de correntes de ar resultantes da diferença de temperatura entre as superfícies internas da fuselagem e o ar no mock-up, a temperatura das paredes internas da fuselagem foi mantida em valores próximos à temperatura média do ar na cabine, em cada ensaio.

O estabelecimento desta condição foi conseguido com a colocação de material isolante térmico na parte externa do mock-up, bem como com o controle da temperatura do ar no ambiente externo ao mock-up.

\subsubsection{Umidade relativa do ar}

Embora seja uma variável crítica em ensaios de cabine de aeronave, devido à baixa umidade do ar verificada em voos longos, no presente trabalho a umidade relativa do ar foi apenas monitorada ao longo dos ensaios, conforme procedimento adotado por Zhang et al., 2008 e Conceição, 2012. Este procedimento é suficiente, uma vez que, no presente trabalho, a umidade relativa do ar da cabine também não influencia significativamente na concentração das partículas medidas ao longo do experimento. Esta afirmação está baseada no fato de que o gerador de partículas TSI Modelo 3475 utilizar um líquido com baixa taxa de evaporação, o DEHS, para geração do aerossol.

\subsection{Medição das variáveis, instrumentação e procedimentos de ensaio}

A seguir é detalhado o processo de medição das variáveis críticas, apresentada a instrumentação utilizada e discutidos os procedimentos de ensaio realizados em conformidade com a norma ISO 7726 (1998).

\subsubsection{Medição da velocidade e da temperatura do ar na cabine}

A velocidade e a temperatura do ar foram obtidos a partir de medições com o sistema ComfortSense da Dantec Dynamics (Fig. 4-10). Foram utilizados três transdutores, compostos de três sondas omnidirecionais para medição de velocidades do ar com frequência de resposta de $5 \mathrm{~Hz}$ e com sensores de temperatura de resposta rápida integrados, com intervalo de operação de 0,05 até $10 \mathrm{~m} / \mathrm{s}$ e $-20^{\circ} \mathrm{C}$ até $70^{\circ} \mathrm{C}$, e incertezas de medição, respectivamente, de $\pm(0,02$ 
$+0,02 \mathrm{~V}) \mathrm{m} / \mathrm{s}$ e $\pm 0,2{ }^{\circ} \mathrm{C}$, que atendem aos requisitos de precisão de equipamentos da norma ISO 7726 (1998).

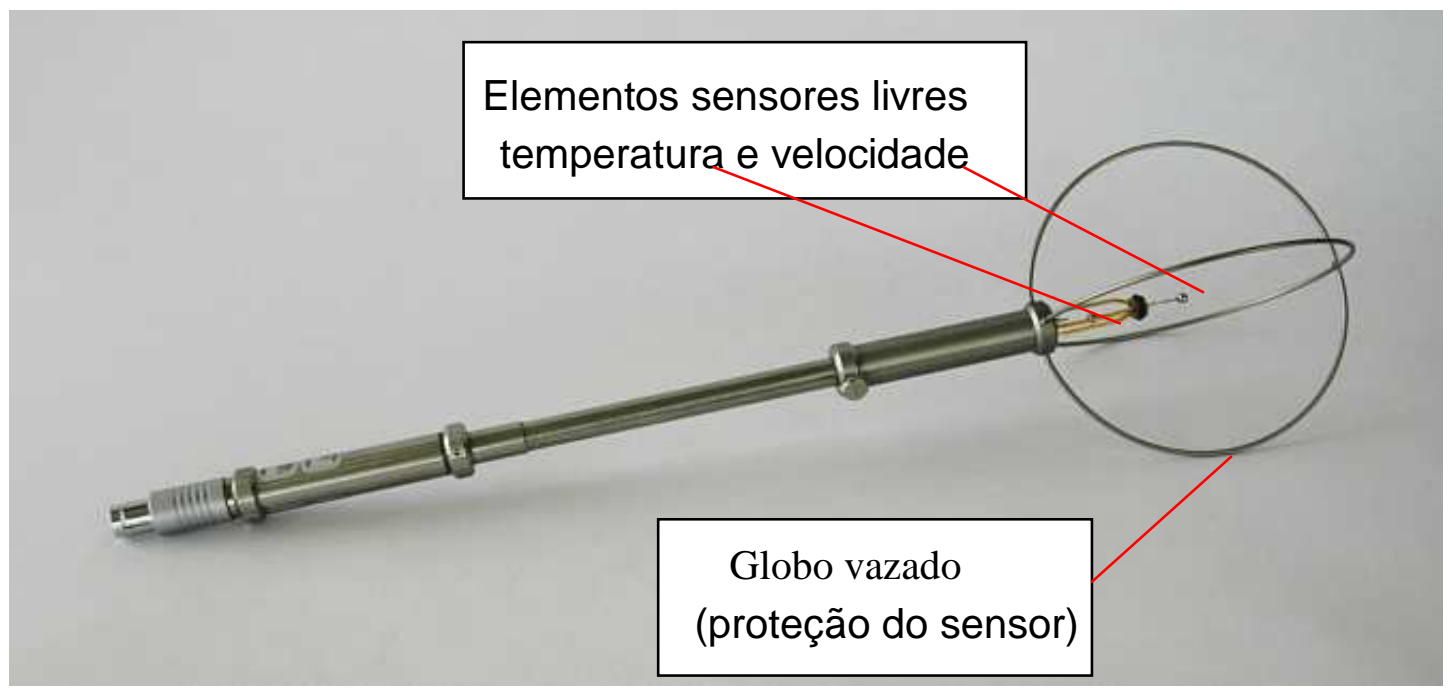

Figura 4-10. Sensor de anemômetro omnidirecional (elemento sensor livre)

As medidas foram realizadas em três pontos longitudinais, abordando as fileiras 1, 2 e 3, contidas nas cinco retas transversais, colunas A, B, C, D e E, e seguiram recomendação da ASHARE 55 (2010) com medição nas alturas 0,10, 0,60, e 1,10 m a partir do piso, correspondendo à região dos pés e tornozelos, das mãos e braços e do pescoço e cabeça, respectivamente, de uma pessoa sentada. Para a situação de pessoas em pé (corredor) foi adotada altura de 1,60m (Fig. 4-11). A título de ilustração, as Figuras 4-12 e 4-13 mostram a instalação das três sondas na cabine.
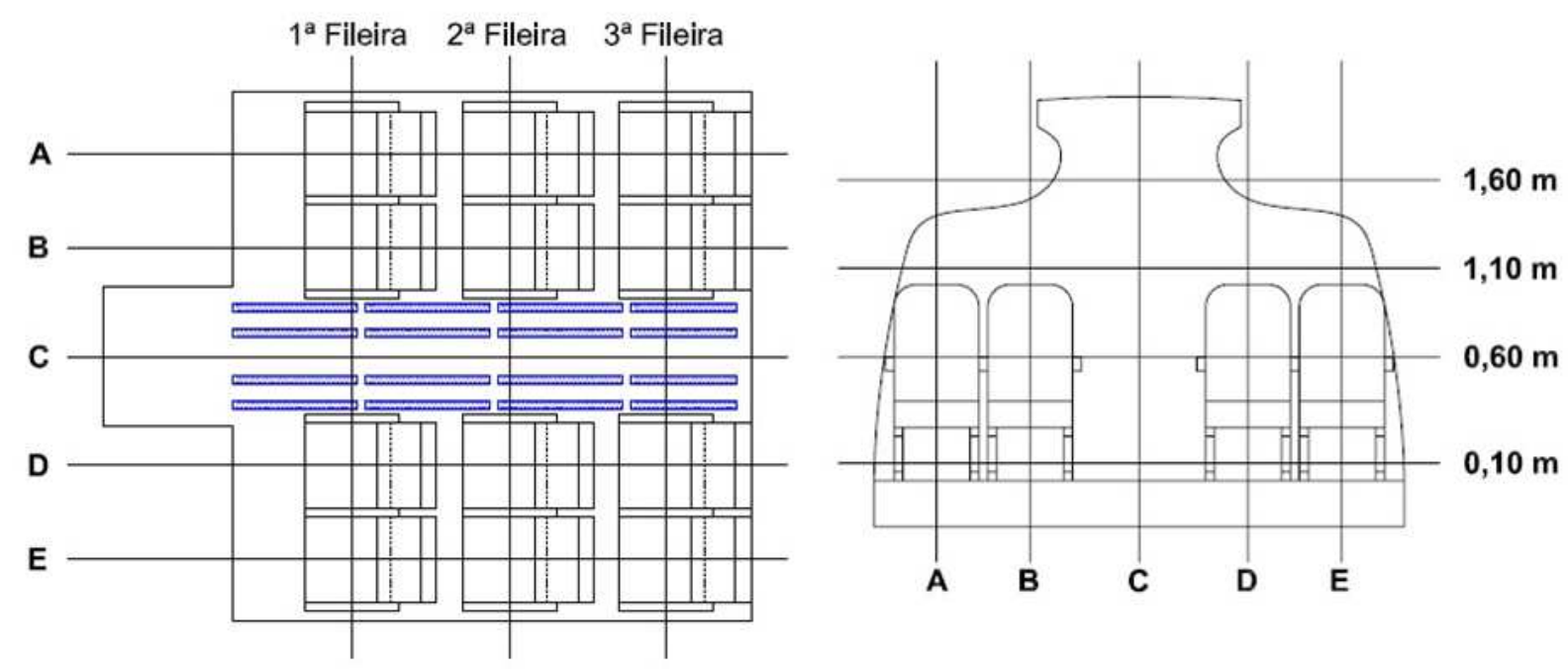

Figura 4-11. Pontos de medição de velocidade e temperatura 


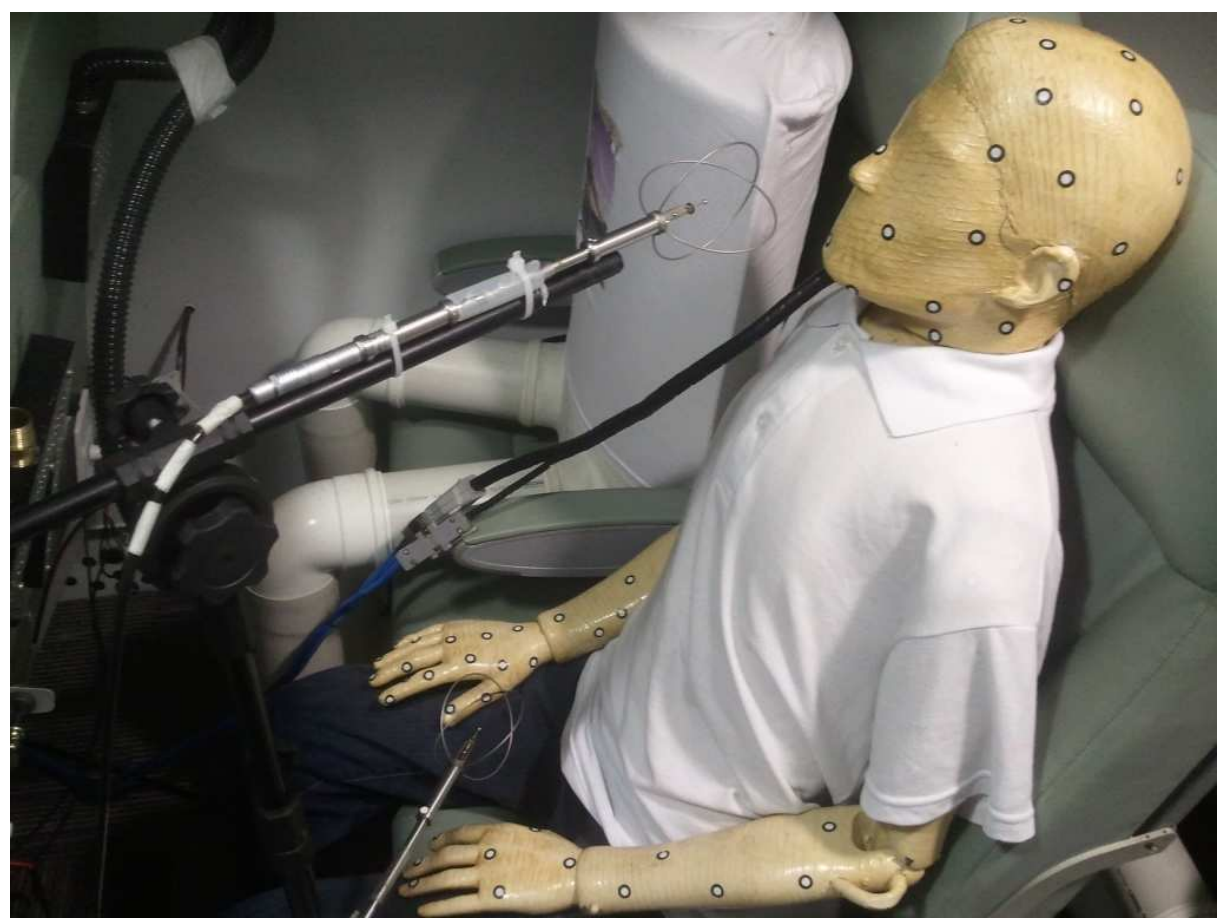

Figura 4-12. Posicionamento das sondas para medição de temperatura e velocidade do ar na altura de $0,60 \mathrm{~m}$ e de $1,10 \mathrm{~m}$ a partir do piso

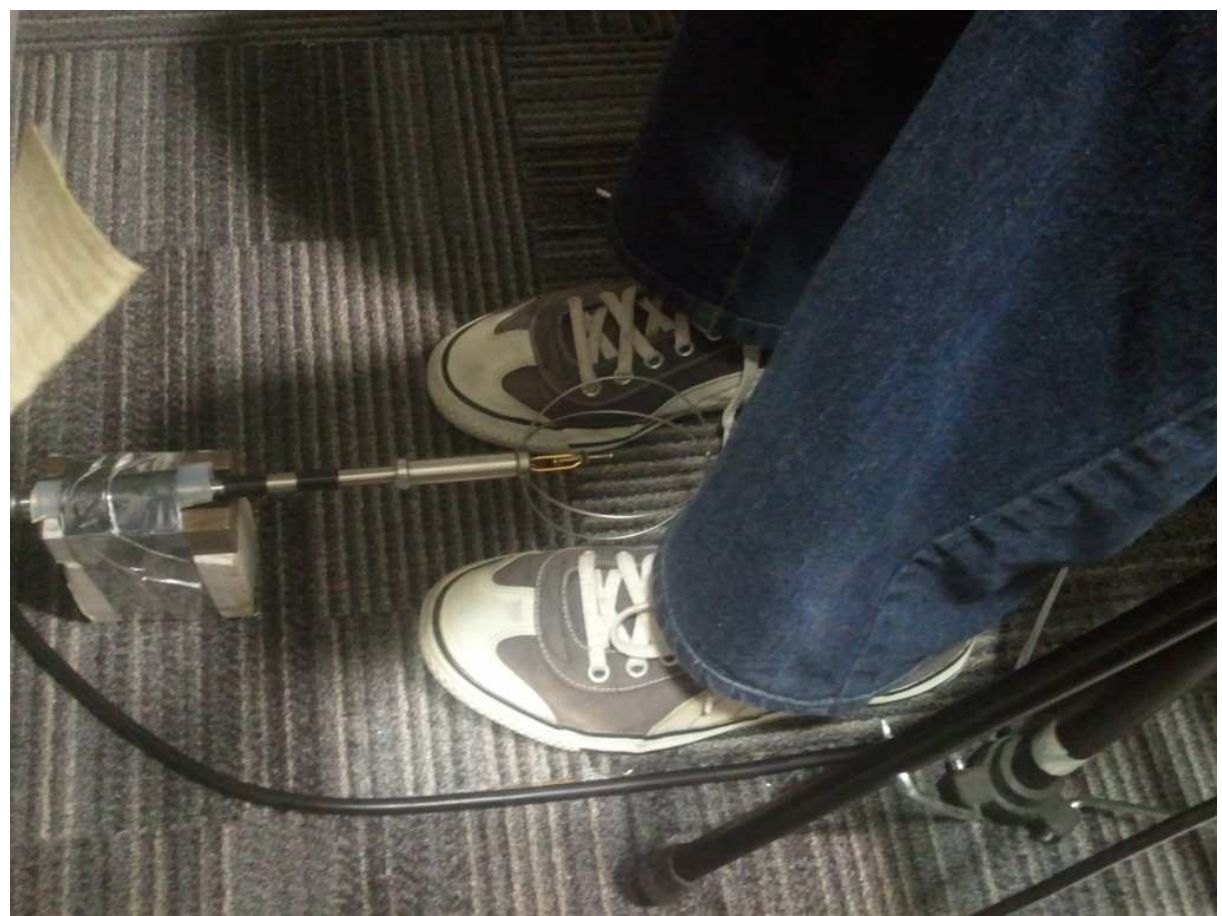

Figura 4-13. Posicionamento da sonda para medição de temperatura e velocidade do ar na altura de 0,10 $\mathrm{m}$ a partir do piso. 
As medições obedeceram à sequência alfanumérica dos planos de medições, com a exceção da coluna $C$ que foi efetuada por último, pois eram necessários ajustes nas alturas das sondas em relação ao tripé, suporte de fixação das sondas. A ordem sequencial ficou da seguinte forma: iniciou-se na posição $1 \mathrm{~A}$ e finalizou-se na posição $3 \mathrm{E}$, pulando as posições do corredor central. Após ajustar as alturas das sondas, foram efetuadas as medições nas posições $1 \mathrm{C}, 2 \mathrm{C}$ e $3 \mathrm{C}$.

Após a mudança do tripé para uma nova posição na cabine, as leituras de velocidade e de temperatura do ar somente eram feitas após a estabilização das condições na cabine. O critério de estabilização adotado foi o da temperatura do ar, conforme mostrado na Figura 4.14. Uma vez que a variação da temperatura do ar não foi significativa nos intervalos de tempo analisados na Figura 4.14, foi estabelecido que o tempo de aquisição dos dados seria de 5 minutos e o tempo entre uma medição e outra, após efetuar a troca de posição do tripé, seria de 10 minutos. Procedimento similar foi adotado por Zhang et al. (2007), que adotaram tempo de amostragem de 4 minutos.

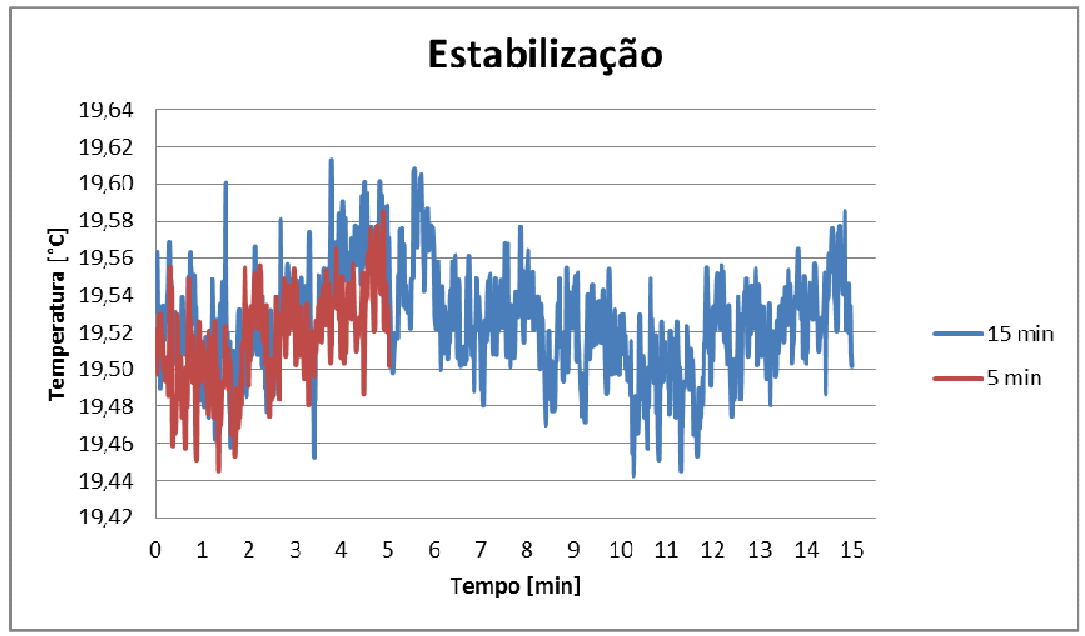

Figura 4-14. Tempo de estabilização da temperatura do ar após perturbação

\subsubsection{Medição da temperatura superficial das paredes e do ar de insuflamento}

As temperaturas superficiais das paredes do mock-up foram medidas e monitoradas por meio de termopares tipo T (cobre/constantan), bitola AWG 8 ( $\varnothing=$ $3,26 \mathrm{~mm}$ ) e haste de $200 \mathrm{~mm}$ de comprimento, com faixa de operação $-270{ }^{\circ} \mathrm{C}$ a $370{ }^{\circ} \mathrm{C}$ e f.e.m. (força eletromotriz) de $-6,258 \mathrm{mV}$ a $20,872 \mathrm{mV}$. Os termopares 
foram conectados a um data logger Agilent, modelo 34970A. Um dos termopares foi posicionado no duto de insuflamento para comparar os valores com o transmissor do sistema de automação e controle.

O data logger possui um programa de computador para a aquisição de dados denominado Agilent BenchLink Data Logger 3, que permitiu configurar os canais (termopares) que foram utilizados para monitorar a temperatura das superfícies. O programa também gera, em tempo real, o gráfico da temperatura da parede e do ar de insuflamento em função do tempo. Essa função é importante para estabelecer se as temperaturas das paredes encontram-se em regime permanente (condição de estabilidade).

\subsubsection{Medição da vazão de ar}

A vazão de ar foi determinada e monitorada a partir da medição de velocidade do ar nos dutos de exaustão do ar da cabine utilizando tubos de Pitot (Fig. 4-15). Foi projetado um sistema composto por um conjunto de manômetros diferenciais e tubos de Pitot instalados em tubos de PVC de $100 \mathrm{~mm}$ de diâmetro nas linhas de exaustão.
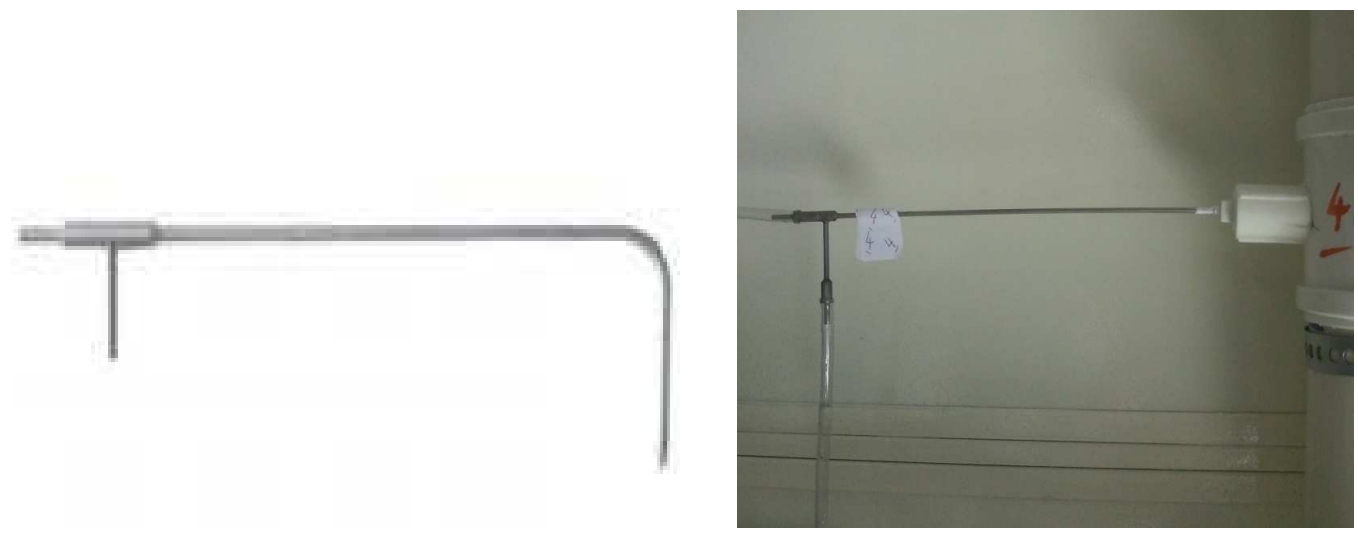

Figura 4-15. Vistas do tubo de Pitot antes e após a instalação

O tubo de Pitot utilizado foi da série 160 de aço inoxidável. Os manômetros diferenciais são do fabricante Dwyer (Fig. 4-16). A conexão dos tubos de Pitot com os manômetros foi realizada com mangueiras transparentes de silicone de $5 / 16$ ". Foi realizado um memorial de cálculo ${ }^{3}$ para converter o valor da diferença de pressão do manômetro em vazão.

\footnotetext{
${ }^{3} \mathrm{O}$ memorial de cálculo encontra-se no Anexo B.
} 


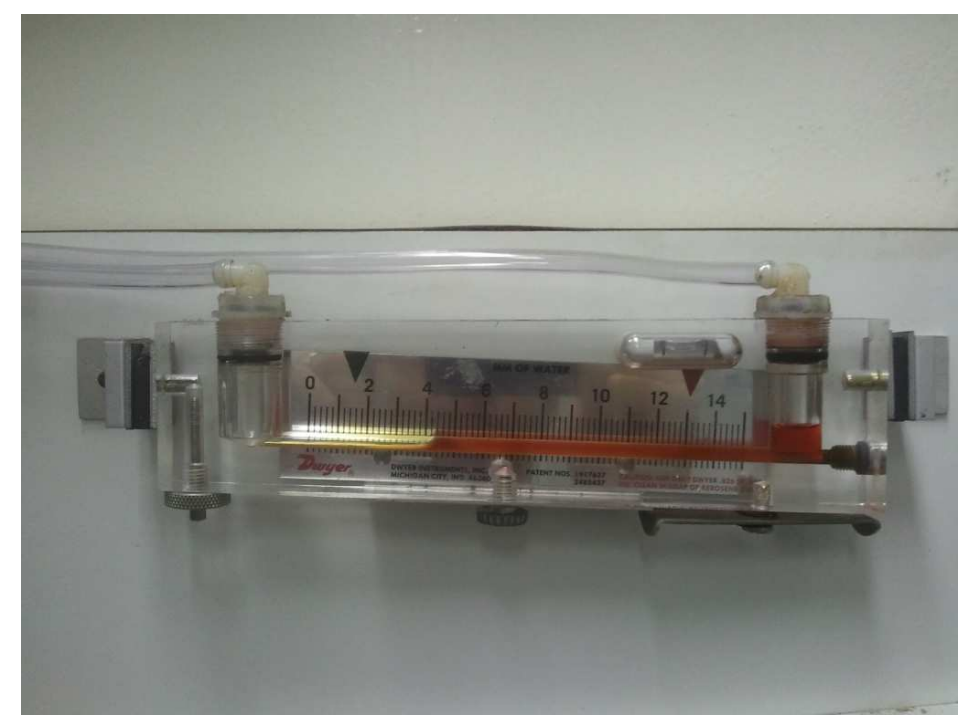

Figura 4-16. Manômetro diferencial para determinação e monitoramento da vazão de ar

$\mathrm{Na}$ entrada das linhas de exaustão (saídas do mock-up) foram instaladas telas metálicas retificadoras de fluxo e a $1000 \mathrm{~mm}$ (correspondente a 10 diâmetros dos dutos de PVC) das telas retificadoras foram instalados os tubos de Pitot, para garantir condições de perfil completamente desenvolvido no local de medição de velocidades máximas do ar no centro dos dutos (FOX, Mc DONALD e PRITCHARD, 2006).

Para o controle da vazão de ar nas diferentes arquiteturas propostas e analisadas, em cada linha de exaustão foram instalados dampers.

Uma vez que cada linha de exaustão do ar é independente uma da outra, a vazão total foi calculada como a soma das vazões em cada linha. Este fato é importante, pois permite ajustar, de forma independente, a vazão de ar conforme a necessidade de cada ensaio.

\subsection{Processo de geração e de medição da concentração de partículas}

Para minimizar influências no escoamento do ar no interior da cabine, o gerador de aerossol foi posicionado externamente ao mock-up, como mostra a Figura 4-17a) e o aerossol gerado injetado no ambiente interno da cabine mediante tubos metálicos e mangueiras de silicone de $10 \mathrm{~mm}$ de diâmetro interno, como ilustrado no detalhe na Figura 4-17b). 


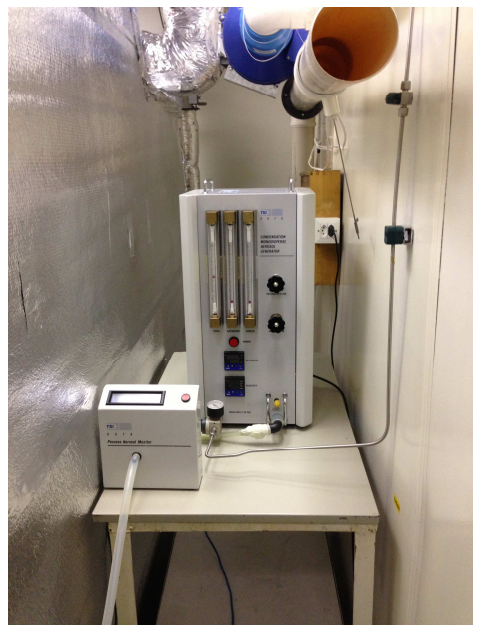

a)

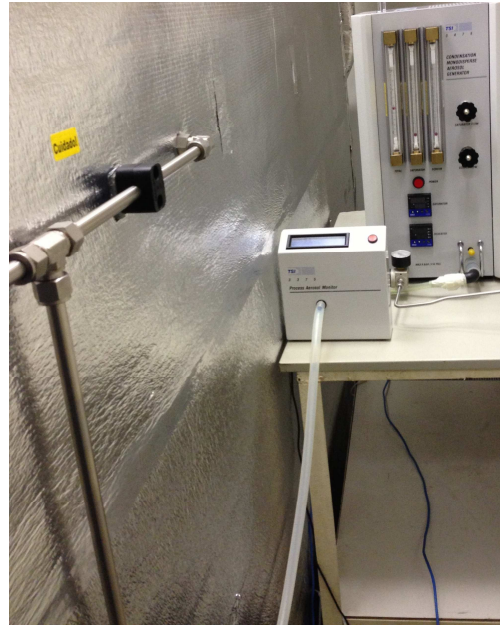

b)

Figura 4-17. a) Gerador de aerossol TSI modelo 3475 e monitor PAM 3475 posicionados externamente ao mock-up, b) Detalhe dos tubos e mangueiras de conexão

O tamanho e a concentração das partículas geradas foram constantemente monitorados com o uso do monitor PAM 3475. Este procedimento é de importância fundamental, porque assim pode-se garantir que todos os testes sejam realizados com a mesma quantidade e concentração de partículas geradas e injetadas no ambiente.

Adotando procedimento similar ao realizado por Wan et al., 2005,a injeção das partículas,simulando pessoa liberando partículas expiratórias ao tossir, foi feita, inicialmente, na poltrona junto à fuselagem e, posteriormente, na poltrona do passageiro sentado junto ao corredor. As partículas foram injetadas a $1,10 \mathrm{~m}$ a partir do piso, que corresponde à zona de respiração das pessoas, nas posições 3E e 3D, respectivamente (Fig. 4-18).

$\mathrm{Na}$ medição da concentração de partículas em cada poltrona do mock-up (Fig. 4-19) os contadores de partículas também foram posicionados na zona de respiração dos manequins, a 1,10 m do piso, como mostra a Figura 4-19. 


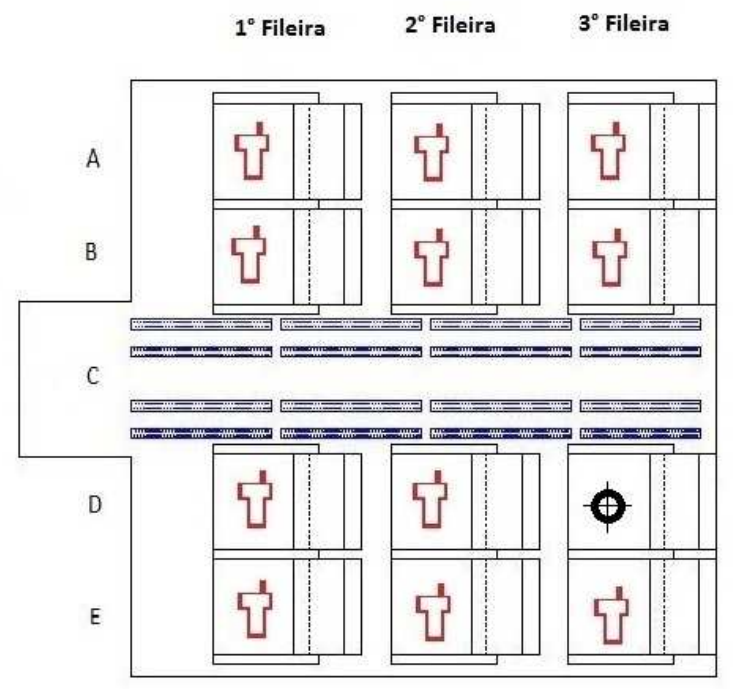

(a)

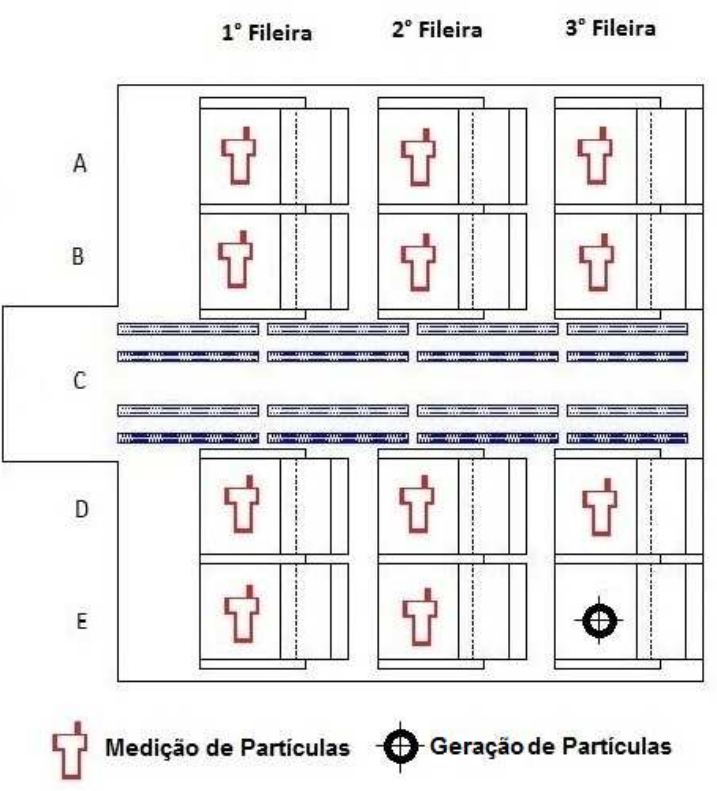

(b)

Figura 4-18. Pontos de injeção e medição de partículas no mock-up

(a) injeção de partículas na poltrona 3D (b) injeção de partículas na poltrona 3E

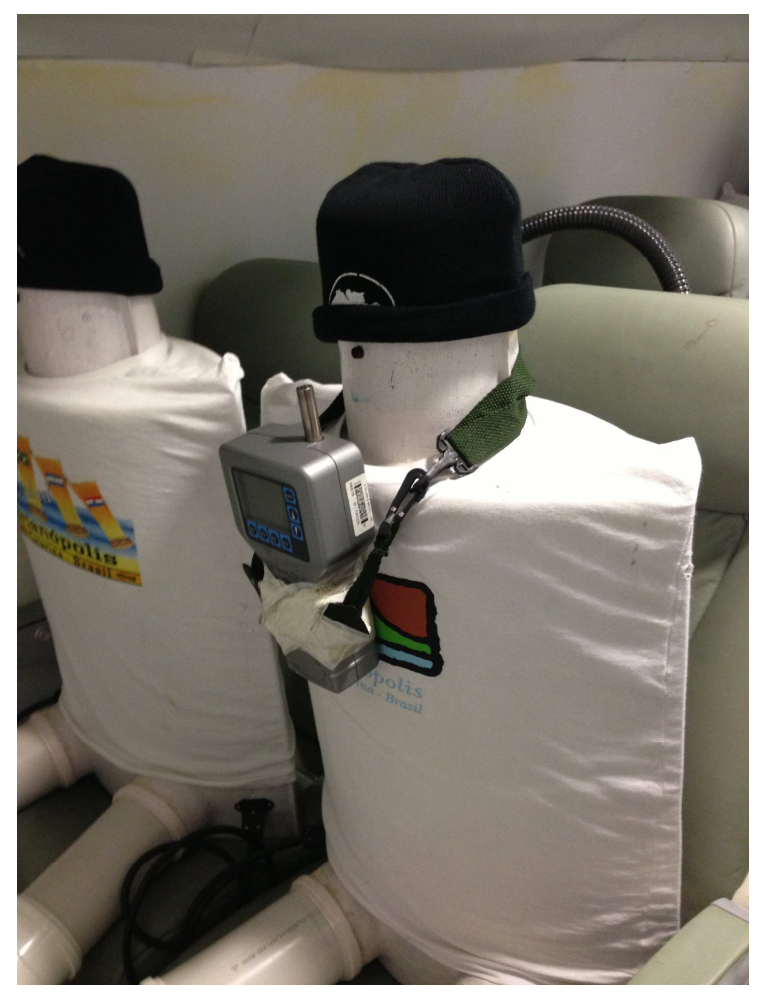

Figura 4-19. Posição dos contadores de partículas 


\subsubsection{Intervalo entre medições e tempo de medição das partículas}

O intervalo entre medições é função do tamanho das partículas analisadas. Quanto menor o tamanho das partículas, maior o tempo para a sua deposição após a ressuspensão causada pela movimentação no interior da cabine na troca da posição do contador de partículas.

No presente trabalho, cuja análise é focada em partículas maiores que $3 \mu \mathrm{m}$, verificou-se a necessidade de 10 minutos para que ocorra a estabilização. Assim, o tempo de medição também foi de 10 minutos, que é o mesmo tempo adotado na medição da velocidade e da temperatura do ar e de partículas por Zhang et al. 2007).

\subsubsection{Medição da concentração de fundo}

Entende-se por concentração de fundo a concentração de partículas medidas dentro do mock-up com o sistema de climatização em operação, insuflando ar na cabine, antes da injeção das partículas com a utilização do gerador.

Em medições preliminares, verificou-se que para partículas acima de $3 \mu \mathrm{m}$, a concentração de fundo pode ser desprezada. Medidas de partículas de fundo para partículas entre 3 e $5 \mu \mathrm{m}$ " $C_{3-5 \mu m}$ " no assento 2D, por exemplo, mostraram valor máximo de aprox. $6.67 \times 10^{3} \mathrm{P} / \mathrm{m}^{3}$. Considerando que o volume de ar aspirado pelos contadores " $v$ " é $0.0003 \mathrm{~m}^{3}$, pode-se calcular o número absoluto de partículas que efetivamente passaram pelo contador, com:

$$
N_{\text {absoluto_3-5 _ } \mu m}=C_{3-5 \mu m} \cdot v
$$

Aplicando-se a equação 4.1, chega-se à quantidade de partículas de fundo na faixa de 3 a $5 \mu \mathrm{m}$, medidas no assento 2D, de 2 partículas na média das medições. Nesta mesma situação, ao fazer a medição para a faixa de 5 a $7 \mu \mathrm{m}$ chegou-se ao valor de 0 partículas.

Nas mesmas faixas e na mesma posição (2D), o número médio de partículas depois da injeção de aerossol foi de 14.419 partículas para a faixa de 3 a $5 \mu \mathrm{m}$ e de 2.946 partículas para a faixa de 5 a $7 \mu \mathrm{m}$.

Para partículas menores que $3 \mu \mathrm{m}$ a quantidade de partículas de fundo não é 
desprezível. Para a análise da dispersão destas partículas haveria a necessidade de cuidados adicionais, incluindo uma melhor filtragem do ar no sistema de climatização e um intervalo maior entre medições.

\subsection{Repetitividade dos ensaios}

Para aumentar a confiabilidade das medições e dos resultados, para cada uma das arquiteturas propostas e para cada temperatura de insuflamento do ar na cabine, os ensaios foram repetidos em três dias diferentes.

\subsection{Sequência experimental}

A seguir é apresentada a sequência experimental para efetuar as medições, apresentada na forma de rotina:

- Inicialmente, são ajustadas as válvulas dos dutos de insuflamento e exaustão do ar para a arquitetura em estudo;

- Em seguida, é ligado o sistema de automação e controle e demais equipamentos e configurados todos os parâmetros para o ensaio;

- Depois, são ligados os manequins aquecidos para iniciar o processo de estabilização;

- Feito isso, são ligados os ventiladores instalados nos dutos de exaustão do mock-up;

- Em seguida, são realizadas medições da diferença de pressão nos manômetros diferenciais e realizados cálculos de vazão de ar, para o ajuste das vazões utilizando os dampers instalados em cada linha de exaustão;

- Depois, é iniciado o registro de dados do sistema de automação e controle e no data logger para determinar o período de estabilização das condições ambientais na cabine;

- Nesse momento, o gerador de partículas é ligado para que sua resistência seja aquecida, configurando-o para a geração do diâmetro e da concentração de partículas desejados; 
- Feito isso, as sondas omnidirecionais são posicionadas na posição a ser medida, simultaneamente com o contador de partículas, colocados próximos à zona de respiração (a 1,10 m do piso);

- Após a estabilização das condições ambientais na cabine, são efetuadas as medições para cada uma das posições do plano de medição do mock-up;

- Finalizadas as medições, são efetuados os registros e armazenamento dos dados;

- Finalmente, verifica-se novamente a diferença de pressão nos manômetros para assegurar que não houve variação durante os ensaios e;

- Após as etapas anteriores, os equipamentos são desligados e o processo de medição é concluído. 


\section{Capitulo 5.}

\section{Resultados Experimentais}

Neste capitulo são apresentados os resultados obtidos nas medições de velocidades, temperaturas do ar e de contagem de partículas no mock-up nas três arquiteturas de distribuição de ar testadas.

Objetivando a realização de análise comparativa dos resultados para cada arquitetura de distribuição de ar testada, os resultados de temperatura e de velocidade do ar são apresentados na forma de perfis e os de contagem de partículas, na forma de barras no presente trabalho.

Os valores numéricos, juntamente com as incertezas de medição, em cada situação analisada, são apresentados em tabelas nos Anexos C e D. No Anexo C são apresentados os resultados para a velocidade e a temperatura do ar e no Anexo $D$ os resultados de contagem de partículas.

Resultados preliminares do presente trabalho foram apresentados no ENCAC 2013 (Fabichak Jr et al., 2013a) e no SIMEA 2013 (Fabichak Jr et al., 2013b) ${ }^{4}$.

\subsection{Perfis de velocidades do ar}

Nas Figuras 5-1 e 5-2 são apresentados os perfis de velocidade do ar para as três arquiteturas de distribuição de ar (MV, UFAD e UFAD modificado) nas temperaturas de insuflamento do ar na cabine de 18 e $22^{\circ} \mathrm{C}$, respectivamente. É importante lembrar que as posições $1 \mathrm{C}, 2 \mathrm{C}$ e $3 \mathrm{C}$, correspondem à região do corredor, enquanto a alocação das asas e da cauda indicam a direção de voo e a localização dos assentos.

${ }^{4}$ O trabalho apresentado no SIMEA 2013 recebeu Menção Honrosa no tema Ensaios e Simulações do Congresso. 


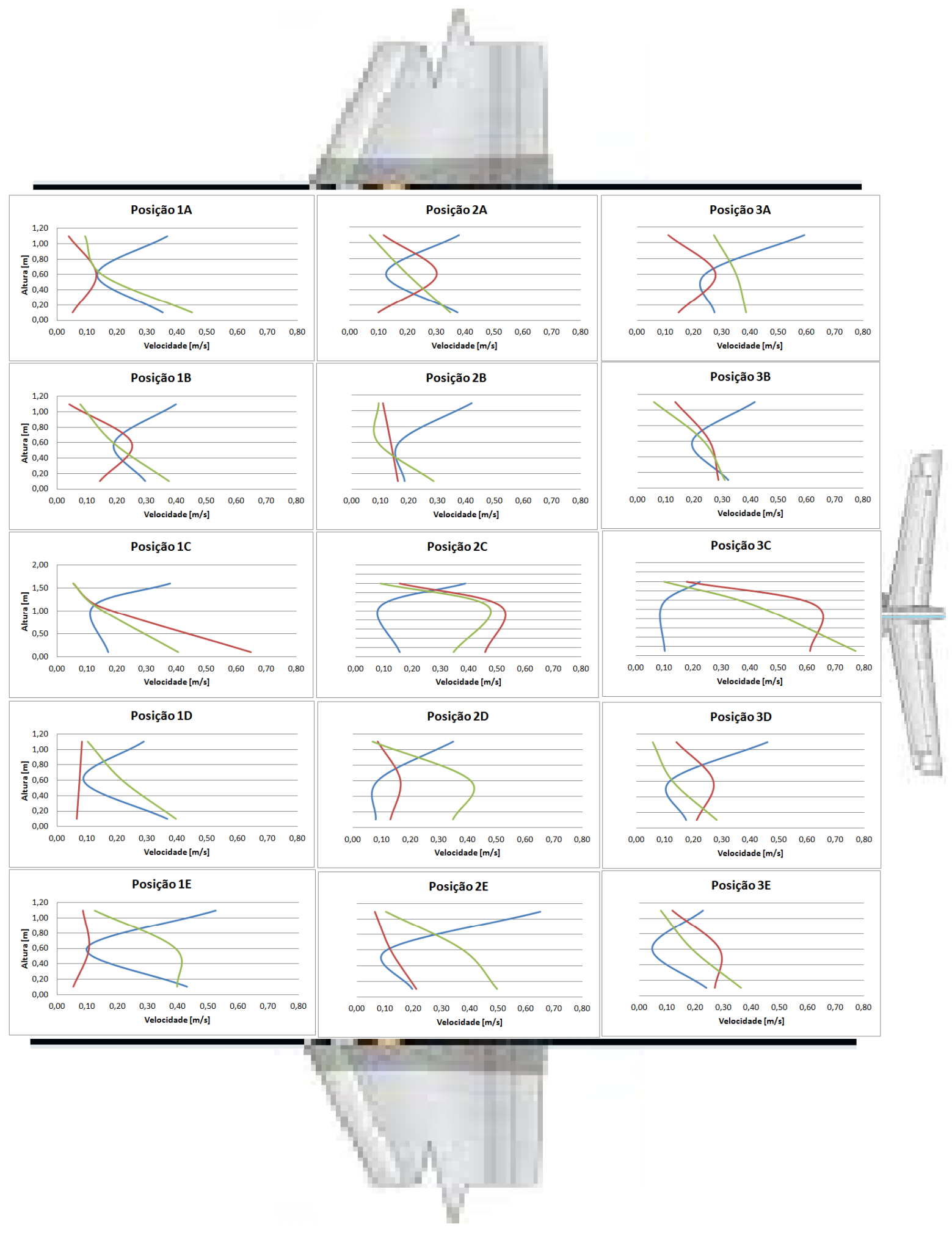

Figura 5-1. Perfis de velocidade do ar para insuflamento na cabine a $18^{\circ} \mathrm{C}$. 


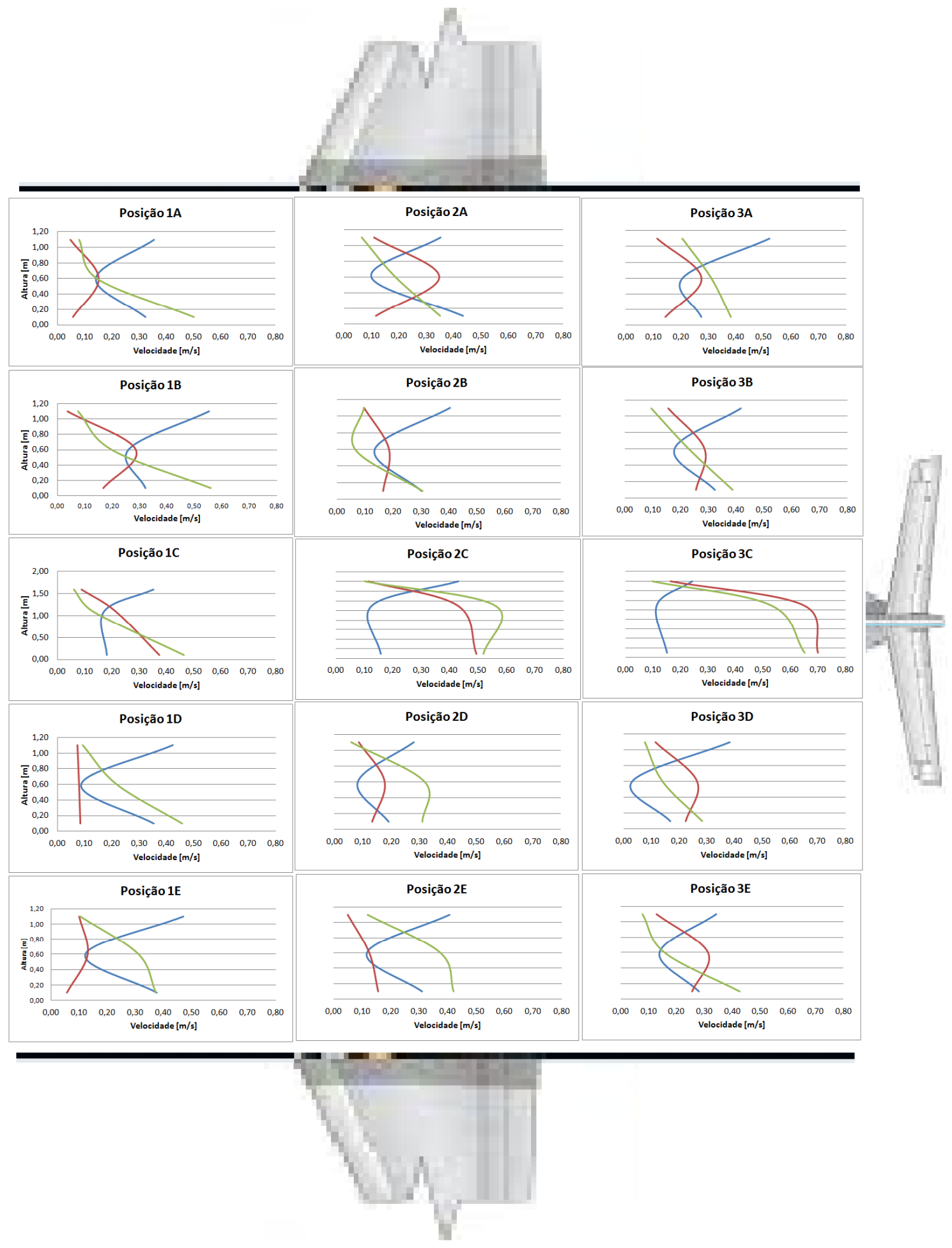

Figura 5-2. Perfis de velocidade do ar para insuflamento na cabine a $22^{\circ} \mathrm{C}$. 
$\mathrm{Na}$ análise das Figuras 5-1 e 5-2 verifica-se, na região das poltronas de pessoas sentadas, que:

a) os perfis de velocidade do ar para a arquitetura MV apresentam velocidades maiores na região da cabeça, próxima à área de insuflamento, com redução na região das coxas, mãos e antebraços, aumentando novamente na região dos pés.

b) a arquitetura UFAD, apresenta perfis bem definidos de baixa velocidade do ar na região dos pés, aumento da velocidade na região das coxas, mãos e antebraços, devido à maior influência da pluma térmica, com redução na região da cabeça.

c) a arquitetura UFAD modificado não apresentou perfis definidos, apresentando características da arquitetura MV, quanto a velocidades maiores junto ao piso e da arquitetura UFAD, com velocidades menores na região de respiração.

É importante destacar que comportamento similar da velocidade do ar (Figs. 5.1 e 5.2), para o sistema MV e UFAD, também foi verificado no trabalho de simulação numérica de Zhang e Chen (2007), discutido no item 1.2, Figura 1-7.

Adicionalmente, verifica-se da análise das Figuras 5-1 e 5-2, que a temperatura do ar insuflado na cabine tem uma pequena influência nos perfis de velocidade do ar. Isto ocorre devido ao maior efeito da pluma térmica em temperaturas mais baixas do ar na cabine (maior diferença entre a temperatura superficial dos passageiros e a temperatura do ar na cabine). Este fato tem consequência na quantidade de partículas na cabine, conforme será ressaltado no item 5.3.1.

\subsection{Perfis de temperatura do ar}

Nas Figuras 5-3 e 5-4 são apresentados os perfis de temperatura do ar para as três arquiteturas de distribuição de ar (MV, UFAD e UFAD modificado) nas temperaturas de insuflamento do ar na cabine de 18 e $22{ }^{\circ} \mathrm{C}$, respectivamente.

$\mathrm{Na}$ análise das Figuras 5-3 e 5-4 verifica-se a ocorrência de diferenças pequenas de temperatura do ar com a altura na cabine (estratificação de 
temperatura) para as três arquiteturas testadas nas duas condições de temperatura do ar insuflado.

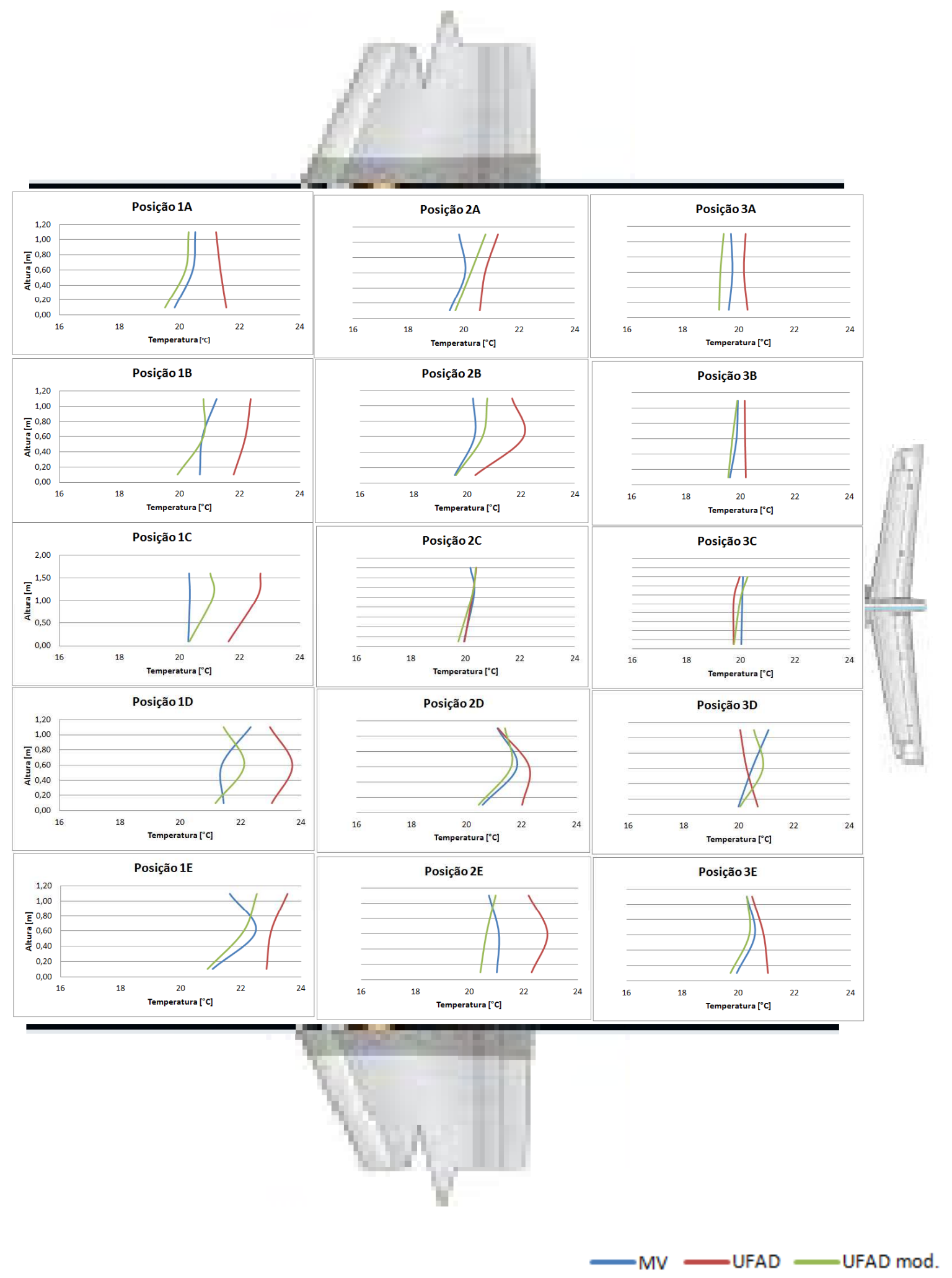

Figura 5-3. Perfis de temperatura do ar para insuflamento na cabine a $18^{\circ} \mathrm{C}$ 


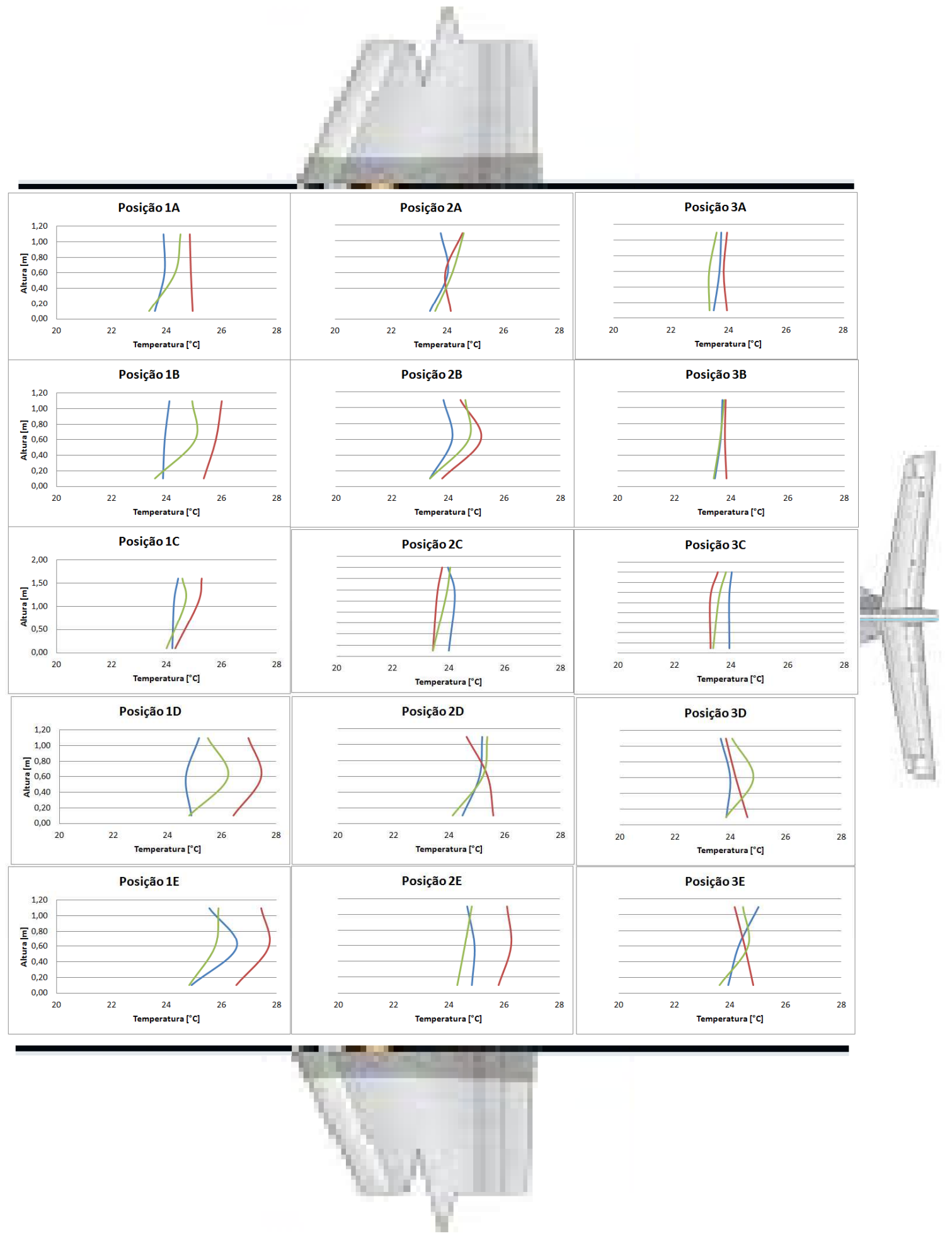

$\longrightarrow$ MV U UFD UFAD mod.

Figura 5-4. Perfis de temperatura do ar para insuflamento na cabine a $22^{\circ} \mathrm{C}$. 
Para a temperatura de insuflamento de $18^{\circ} \mathrm{C}$ foram encontrados valores máximos de diferença de temperatura entre os pés e a cabeça de $1,4^{\circ} \mathrm{C}$ para a arquitetura MV, de $1,8^{\circ} \mathrm{C}$ para a arquitetura UFAD e de $1,6^{\circ} \mathrm{C}$ para a arquitetura UFAD modificado. Para a temperatura de insuflamento de $22^{\circ} \mathrm{C}$ foram encontrados valores máximos de $1,7^{\circ} \mathrm{C}$ para a arquitetura $\mathrm{MV}$, de $1,4^{\circ} \mathrm{C}$ para a arquitetura UFAD e de $1,5^{\circ} \mathrm{C}$ para a arquitetura UFAD modificado.

Embora a estratificação da temperatura seja um fenômeno associado ao insuflamento pelo piso (sistema UFAD), pode-se verificar que a diferença de temperatura entre os pés e a cabeça foi inferior a $2,0^{\circ} \mathrm{C}$ em todas as situações analisadas. Este valor está abaixo do limite preconizado pela norma ASHRAE 55 (2010), que é de $3,0^{\circ} \mathrm{C}$.

\subsection{Resultados de medição de concentração de partículas}

Nas Figuras 5-5 a 5.8 são apresentados os resultados de concentração de partículas para as três arquiteturas de distribuição de ar (MV, UFAD e UFAD modificado) testadas. Nas Figuras 5.5 e 5.6 são apresentados resultados para temperatura de insuflamento do ar de $18{ }^{\circ} \mathrm{C}$, considerando injeção/geração de partículas na poltrona 3D e 3E, respectivamente. Nas Figuras 5.7 e 5.8 são apresentados os resultados para temperatura de insuflamento do ar de $22{ }^{\circ} \mathrm{C}$, considerando injeção/geração de partículas na poltrona 3D e 3E, respectivamente.

\subsubsection{Análise da concentração de partículas com relação à temperatura do ar insuflado}

Da análise das Figuras 5-5 a 5-8 verifica-se que, de uma maneira geral, há uma diminuição na concentração de partículas na zona da respiração em condições de insuflamento do ar a $18{ }^{\circ} \mathrm{C}$ em relação ao insuflamento a $22{ }^{\circ} \mathrm{C}$, principalmente no sistema UFAD. Este fato deve estar relacionado com a formação de uma pluma térmica maior em condições de temperatura do ar de insuflamento a $18{ }^{\circ} \mathrm{C}$, causado pelos manequins aquecidos na cabine, aumentando a velocidade do ar localmente e arrastando uma quantidade maior de partículas para a exaustão. 


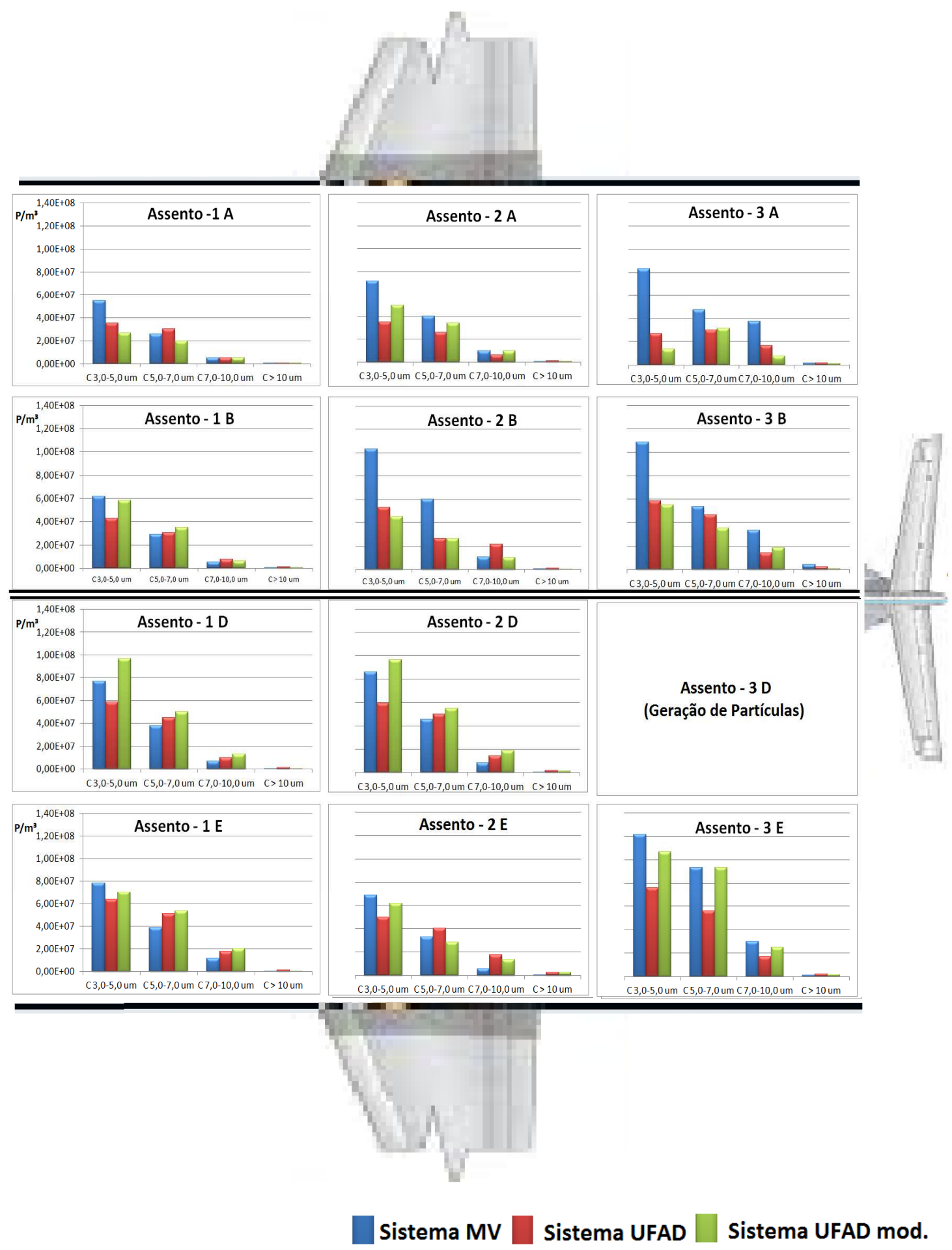

Figura 5-5. Concentração de partículas para temperatura de insuflamento de $18^{\circ} \mathrm{C}$, injeção de partículas no assento 3D 


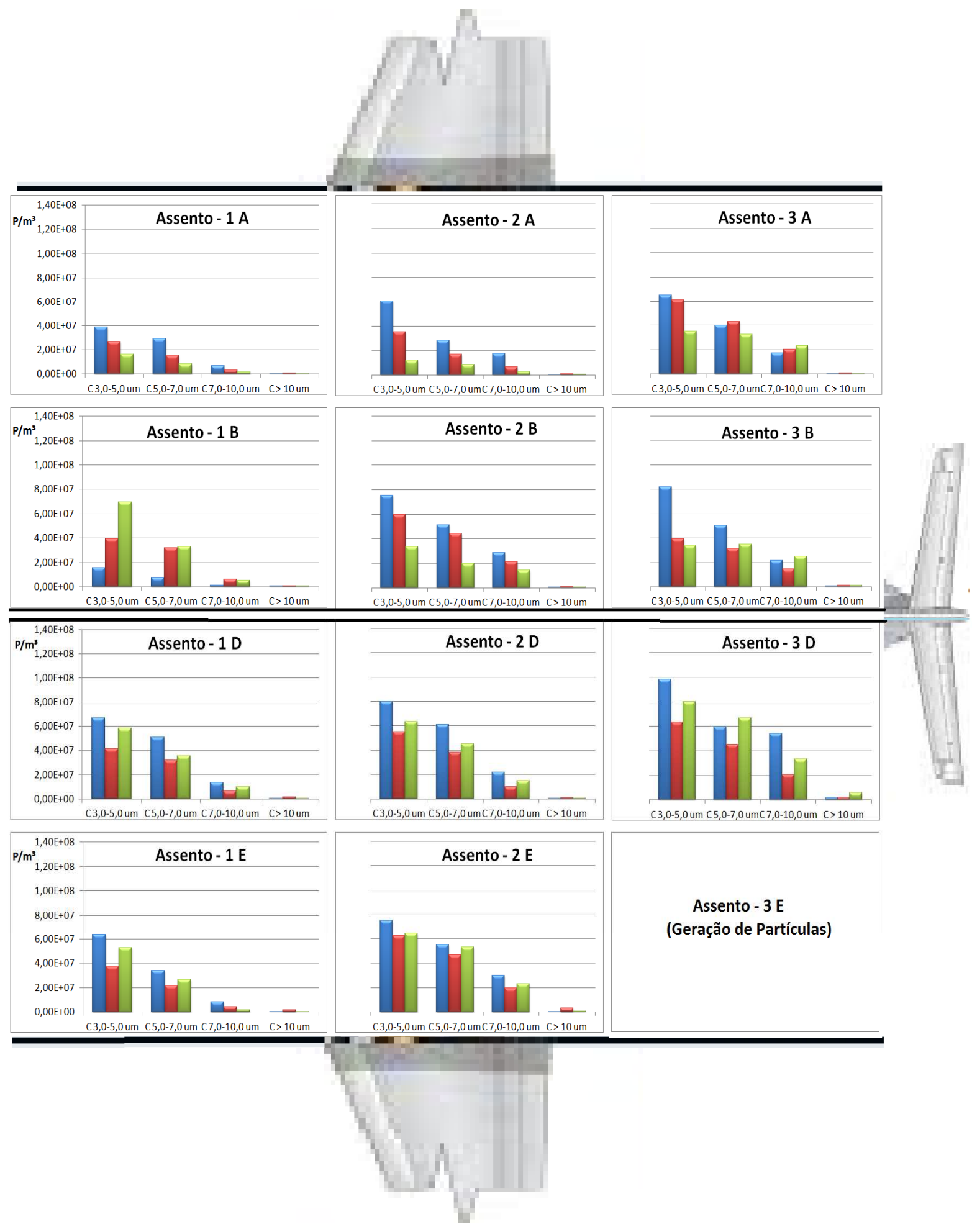

Sistema MV — Sistema UFAD $\square$ Sistema UFAD mod.

Figura 5-6. Concentração de partículas para temperatura de insuflamento de $18^{\circ} \mathrm{C}$, injeção de partículas no assento $3 E$ 


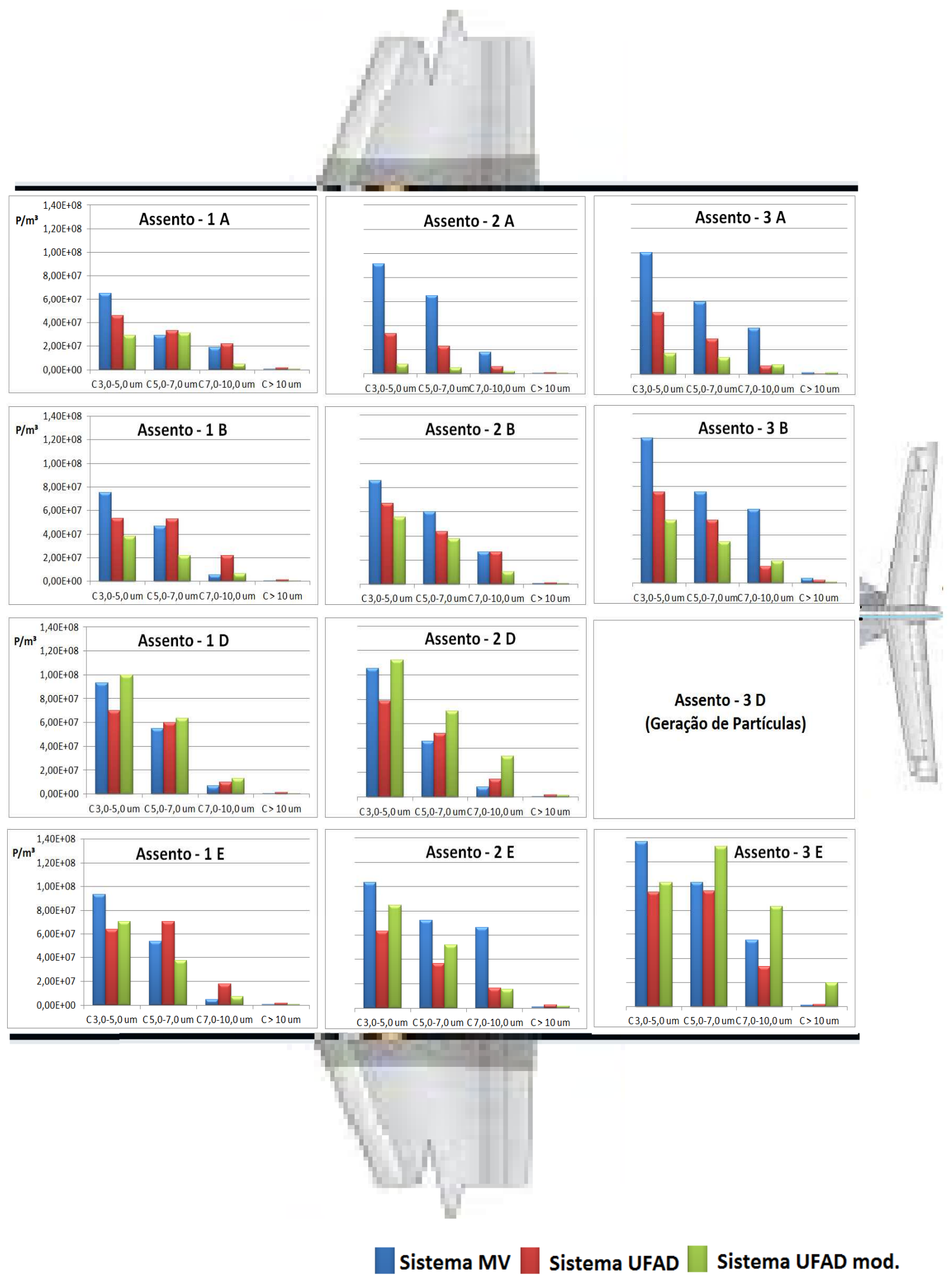

Figura 5-7. Concentração de partículas para temperatura de insuflamento de $22^{\circ} \mathrm{C}$, injeção de partículas no assento 3D 


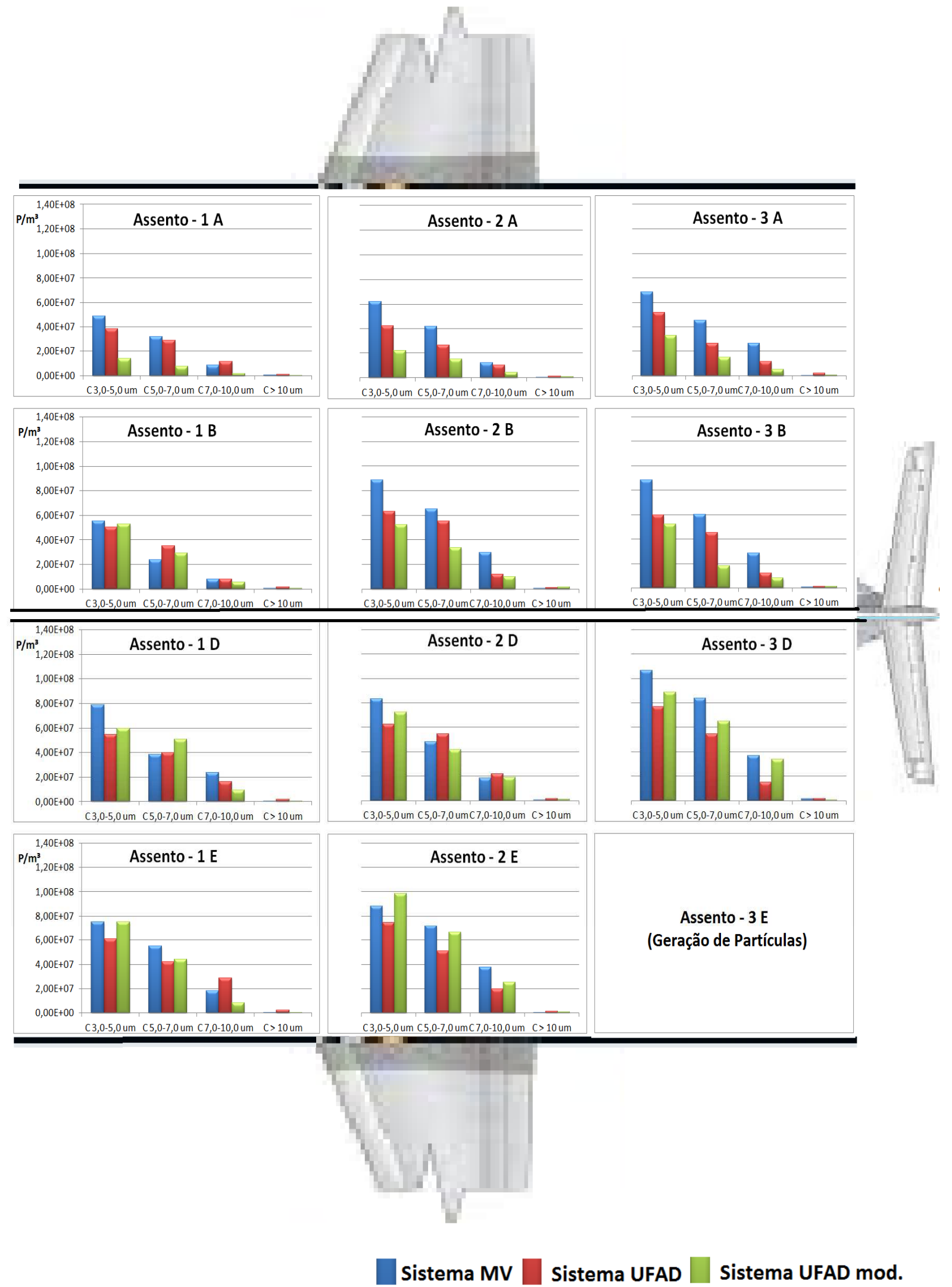

Figura 5-8. Concentração de partículas para temperatura de insuflamento de $22^{\circ} \mathrm{C}$, injeção de partículas no assento $3 \mathrm{E}$ 
À título de ilustração, a Figura 5-9 mostra o aumento na concentração de partículas com a temperatura do ar insuflado, para as três configurações analisadas, no assento 1D.

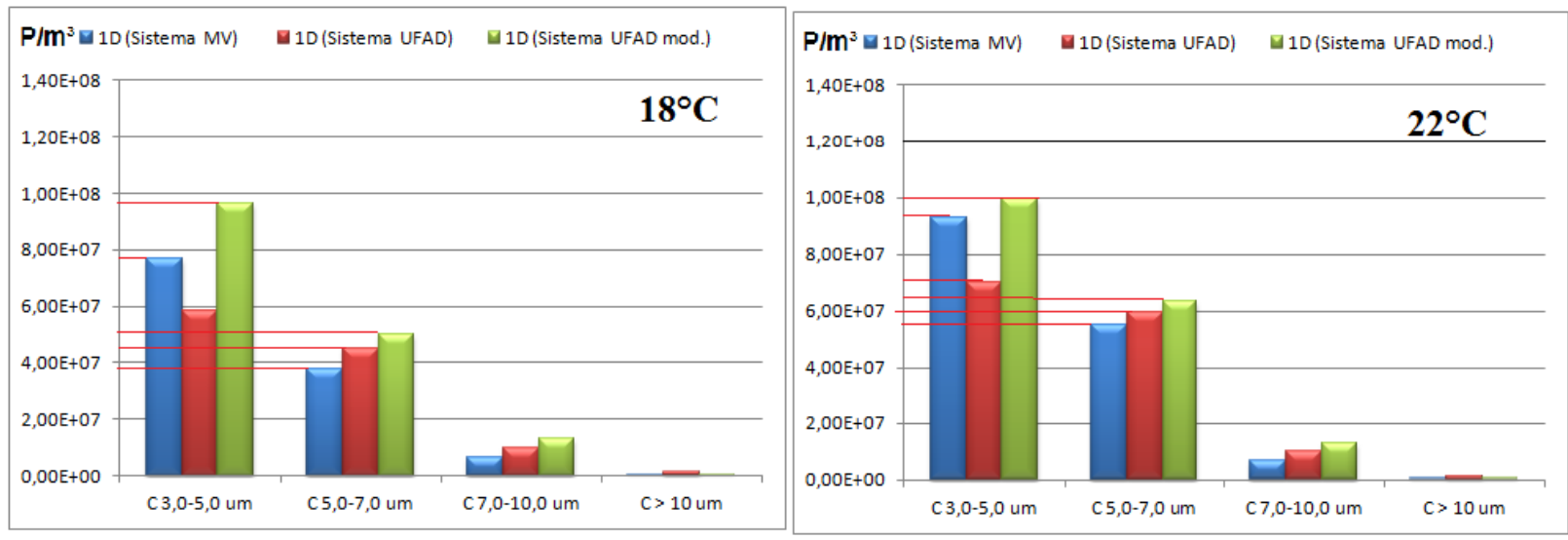

Figura 5-9. Concentração de partículas com relação à temperatura do ar insuflado no assento $1 \mathrm{D}$.

\subsubsection{Análise da concentração de partículas com relação ao local de injeção/geração}

Os resultados apresentados nas Figuras 5.5 e 5.7 referentes à injeção de partículas no assento 3D (junto ao corredor) e nas Figuras 5.6 e 5.8, referentes à injeção de partículas no assento $3 \mathrm{E}$ (junto à janela), mostram dispersão maior de partículas, com aumento na concentração de partículas na cabine como um todo nos pontos de medição (a 1,10 m do piso - zona de respiração), quando a injeção de partículas é realizada no assento 3D, em comparação a injeção no assento $3 \mathrm{E}$.

Conforme apresentado no item 1.2, este fato também foi observado por Wan et al., 2005, em ensaios com sistema MV em mock-up de 21 assentos (três fileiras de sete assentos). Segundo esses autores, o resultado teria sido função do fluxo de ar descendente junto à fuselagem ter suprimido a dispersão de partículas, enquanto o fluxo ascendente no centro do mock-up ter aumentado a dispersão. No presente trabalho, o resultado é similar, embora aos fenômenos envolvidos sejam diferentes. No caso dos sistemas MV e UFAD modificado também ocorre uma maior supressão na dispersão das partículas junto à parede em função da parcela de ar insuflado ser maior nesta parte da mock-up (60\%), com exaustão na parte inferior. Por outro lado, no sistema UFAD, ocorre um maior fluxo ascendente 
com maior remoção de partículas junto à parede em função da maior exaustão de ar nesta região do mock-up (60\%).

Na Figura 5-10 são reapresentados os níveis de concentração de partículas entre 3,0 e 5,0 $\mu \mathrm{m}$ - correspondentes às partículas expiratórias $(4,0 \mu \mathrm{m})$ - no assento $1 \mathrm{~A}$ (diametralmente oposto aos pontos de injeção/geração de partículas), que mostram que, mesmo nesta posição mais distante, ainda ocorre influência do ponto de injeção/geração de partículas na cabine.

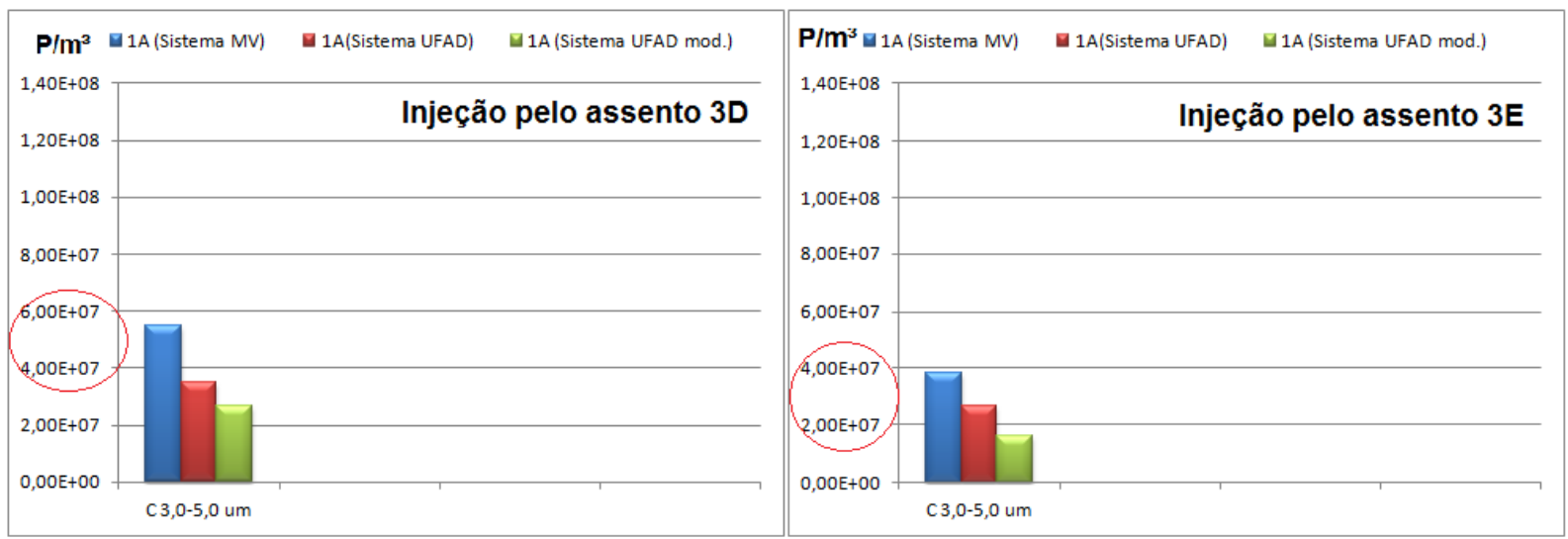

Figura 5-10. Concentração de partículas entre 3,0 e 5,0 $\mu \mathrm{m}$ no assento 1A, função do ponto de injeção/geração de partículas.

\subsubsection{Análise da concentração de partículas com relação às arquiteturas de distribuição de ar testadas}

Da análise das Figuras 5.5 a 5.8, verifica-se que, na maioria dos assentos, a concentração de partículas na faixa de 3,0 a 5,0 $\mu \mathrm{m}$, é maior no sistema MV comparado aos sistemas UFAD e UFAD modificado.

Verifica-se que o sistema de ventilação pelo teto, MV, promove uma maior dispersão de partículas ao longo da cabine, função da característica de mistura desse tipo de sistema de ventilação. Além disso, verifica-se uma maior concentração de partículas na cabine no sistema de ventilação MV, indicando uma menor eficiência na remoção das partículas da cabine nesse sistema de ventilação.

Por outro lado, o sistema pelo piso, UFAD, apresentou uma maior eficiência na remoção de partículas de 3,0 a $5,0 \mu \mathrm{m}$, inclusive, na região próxima à injeção/geração de partículas, com pequeno aumento na concentração de 
partículas maiores, nas faixas de 5,0 a $7,0 \mu \mathrm{m}$ e de 7,0 a $10,0 \mu \mathrm{m}$. Ou seja, 0 sistema UFAD, apesar de seu fluxo de ar ascendente possibilitar que partículas maiores flutuem por mais tempo no ambiente, ainda assim permite um maior controle na remoção e dispersão de partículas e, com isto, um maior controle na dispersão de contaminantes na cabine.

Devido a esses bons resultados de níveis de concentração de partículas no sistema UFAD, possibilitando melhor qualidade do ar na região da zona de respiração, foi proposto neste trabalho um novo sistema de ventilação relacionado com o insuflamento pelo piso, chamado no presente trabalho de UFAD modificado.

Os resultados deste sistema UFAD modificado, mostram que o lado da cabine onde houve a injeção das partículas nas fileiras $D$ e $E$ apresentam uma concentração de partículas maior do que os sistemas MV e UFAD, como mostra a Figura 5-11.

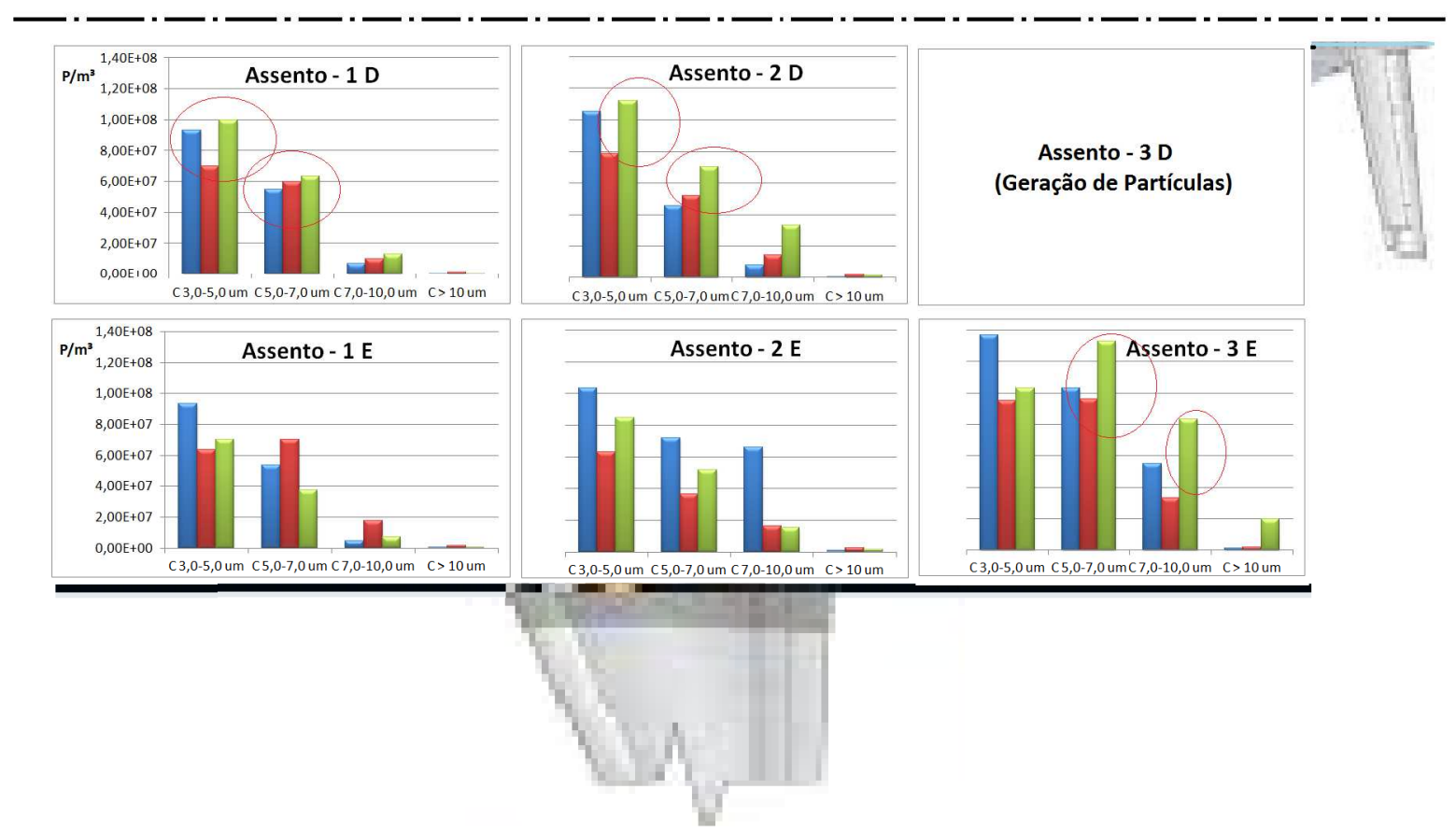

Sistema MV $\square$ Sistema UFAD $\square$ Sistema UFAD mod.

Figura 5-11. Concentração de partículas no sistema UFAD modificado (reprodução da parte de baixo da Figura 5.5)

Já o lado onde não houve injeção direta de partículas, essa concentração diminuiu muito. Provavelmente isso ocorre devido ao escoamento resultante do 
insuflamento pelo piso (de baixo para cima) e pelo bagageiro inferior (de cima para baixo). Esse insuflamento simultâneo faz com que as partículas geradas fiquem "aprisionadas" com baixa velocidade do ar na zona de respiração, como mostra a Figura 5-12, aumentando assim a concentração de partículas nesta região.

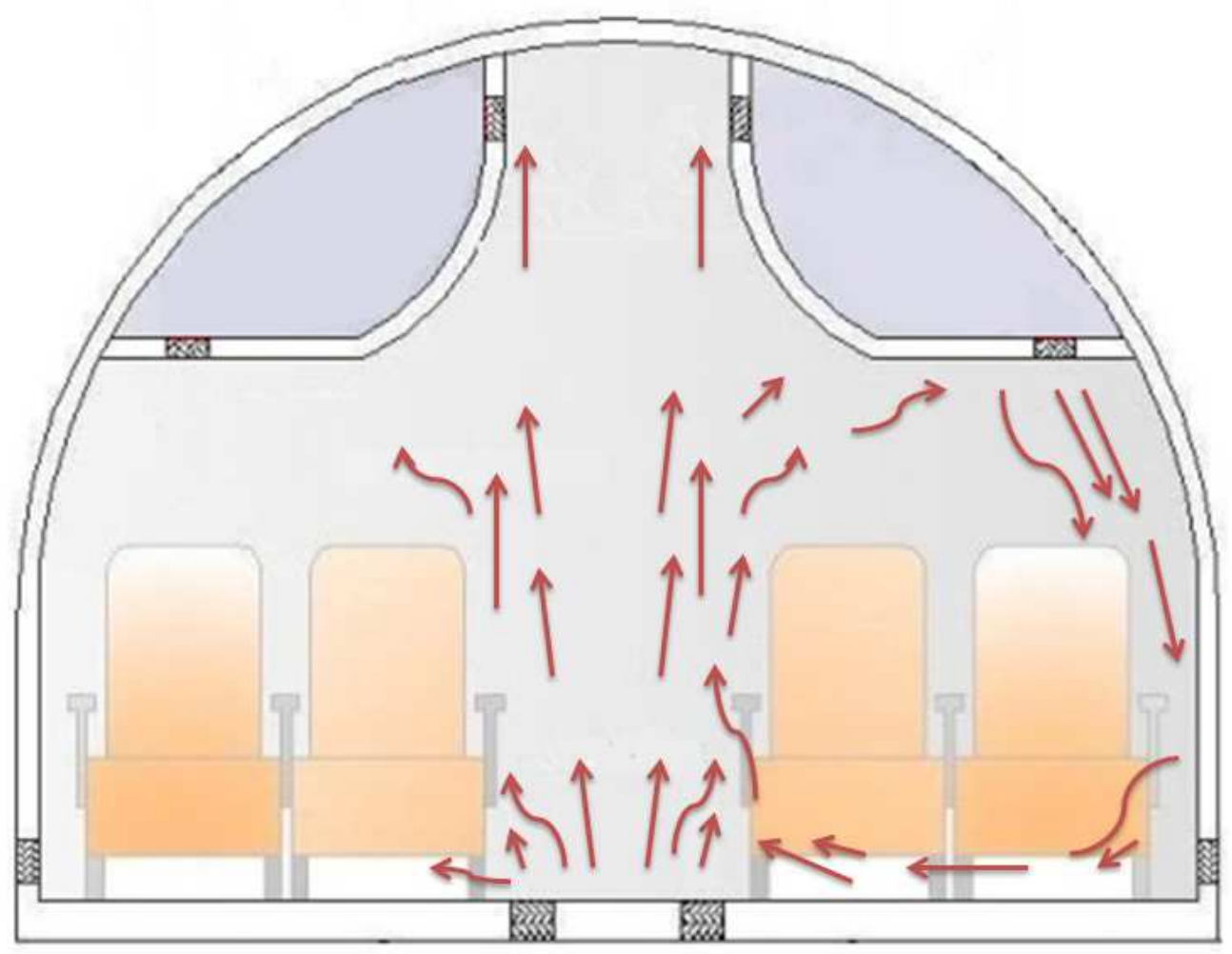

Figura 5-12. Movimento do ar no sistema UFAD modificado. 


\section{Capitulo 6.}

\section{Conclusão}

Os resultados do presente trabalho mostraram que o ponto de geração de partículas, bem como a temperatura do ar insuflado na cabine, tem grande influência na dispersão e na concentração de partículas ao longo da cabine nas três arquiteturas de distribuição de ar testadas.

A injeção de partículas na zona de respiração do assento simulando passageiro junto à fuselagem, em comparação com passageiro sentado em assento próximo ao corredor do mock-up, resultou em uma menor dispersão de partículas na zona de respiração ao longo da cabine. Ou seja, as partículas expiratórias geradas por um passageiro sentado junto ao corredor tem um potencial maior de serem inaladas por outros passageiros da cabine do que aquelas geradas por um passageiro sentado junto à fuselagem nas arquiteturas de distribuição analisadas.

Uma menor temperatura do ar insuflado na cabine favorece a formação de plumas térmicas junto aos passageiros, aumentando a eficiência na remoção de partículas da cabine na zona de respiração. Em função do escoamento do ar ser essencialmente de baixo para cima no sistema UFAD, esta arquitetura de distribuição de ar apresentou a maior influência das plumas térmicas, com a maior eficiência na remoção de partículas na temperatura de insuflamento do ar de $18{ }^{\circ} \mathrm{C}$.

Nenhuma das arquiteturas de distribuição de ar testadas apresentou estratificação significativa na temperatura do ar, com valores máximos da temperatura do ar entre os pés e a cabeça inferior a $2{ }^{\circ} \mathrm{C}$.

Os resultados mais promissores quanto à dispersão e à eficiência na remoção de partículas expiratórias da cabine, foram obtidos com o sistema UFAD. O aumento na remoção de partículas expiratórias de 3 a $5 \mu \mathrm{m}$, do sistema UFAD com relação ao sistema convencional $\mathrm{MV}$, foi de até $63,4 \%$. 


\subsection{Sugestões para a continuidade do trabalho}

Como desenvolvimento de trabalhos futuros, propõem-se os seguintes estudos:

a) Avaliar a influência de sistemas de ventilação personalizada, juntamente com diferentes sistemas de ventilação, na dispersão de partículas na cabine;

b) Avaliar a influência de difusores e defletores no insuflamento do ar de forma a melhorar o conforto térmico e qualidade do ar na cabine;

c) Realizar análise simultânea de condições de conforto térmico e de qualidade do ar para diferentes arquiteturas de distribuição de ar e de sistemas de ventilação.

d) Considerar estudo de dispersão de partículas finas, com diâmetros médios iguais a 2,5 $\mu \mathrm{m}(\mathrm{PM} 2,5)$ ou menores, que tendem a penetrar nas regiões de troca gasosa do pulmão. 


\section{Capitulo 7.}

\section{Referências Bibliográficas}

ASHRAE 55. Thermal environmental conditions for human occupancy, American Society of Heating, Refrigerating and Air Conditioning Engineers Inc., Atlanta, 2010.

ANSI/ASHRAE Standard 161, 2007, Air Quality Within Commercial Aircraft. American Society of Heating, Refrigerating and Air-Conditioning Engineers, Inc., Atlanta.

BAUMAN F., DAILY A., 2003, Underfloor air distribution (UFAD) design guide. American Society of Heating, Refrigerating and Air-Conditioning Engineers, Inc., Atlanta.

BÉMER, D., CALLÉ, S., GODINOT, S., RÉGNIER, R., DESSAGNE, J.M., 2000, Measurement of the Emission Rate of an Aerosol Source-Comparison of Aerosol and Gas Transport Coefficients, Journal of Appl. Occup. Environ. Hyg. 15:904910.

BOSBACH, J., HEIDER, A., DEHNE, T., MARKWART, m., GORES, I., BENDFELDT, P., Evaluation of cabin displacement ventilation under fight conditions. ICAS 2012, Brisbane (2012)

BOOKER, C., Pilots disabled by poisoned air, Telegraph, UK, Disponível em: http://www.telegraph.co.uk/news/main.jhtml?xml=/news/2007/06/24/nbook124a.x $\mathrm{ml}$. Acessado em outubro de (2013)

CHAO, C.Y.H, WAN, M.P., 2006, A study of the dispersion of expiratory aerosols in unidirectional downward and ceiling-return type airflows using a multiphase approach, Journal of Indoor Air 16:296-312.

CHAO, C.Y.H., WAN, M.P., MORAWSKA, L., JOHNSON, G.R., RISTOVSKI, Z.D., HARGREAVES, M., MENGERSEN, K., CORBETTE, S., LI, Y., XIE, X., KATOSHEVSKI, D., 2009, Characterization of expiration air jets and droplet size distributions immediately at the mouth opening, Journal of Aerosol Science 40:122-133.

CHEN Q, GLICKSMAN L. System performance evaluation and design guidelines for displacement ventilation. Altanta, GA: ASHRAE; 2003.

CHEN Q, MCDEVITT JJ, GUPTA JK, JONES BW, MAZUMDAR S, POUSSOU $\mathrm{SB}$, et al. Infectious disease transmission in airliner cabins. Report No. RITEACER-CoE-2012-1. Auburn, USA: National Air Transportation Center of Excellence RITE/ACER, 2012..

COLEMAN, H. W.; Steele, W. G. Experimentation and uncertainty analysis for engineers. John Wiley \& Son. New York, 1989. 
CONCEIÇÃO, S.T., PEREIRA, M.L., TRIBESS, A., 2011, A review of methods applied to study airborne biocontaminants inside aircraft cabins, Hindawi Publishing Corporation, International Journal of Aerospace Engineering, artigo 824591, $15 \mathrm{p}$.

CONCEIÇÃO, S. T., 2012. Contaminação aérea em cabines climatizadas: Processo de avaliação e análise da influência de sistema de ventilação personalziado. Tese de Doutorado. Departamento de Engenharia Mecânica, Escola Politécnica da USP, São Paulo, 218p.

CONNOR, M., 2009, Transmission of diseases and long-haul flights, ICE International Aviation Conference, NHS Dumfires \& Galloway, UK Scotland.

COT, 2006, Committee on Toxicity of Chemicals in Food Consumer Product and the Environment, disponível em http://cot.food.gov.uk/, acessado em junho, 2012.

CUPA, M., 2009, Air transport, aeronautic medecine, health, Bulletin de l'Academie Nationale de Medecine, 193(7)1619-1631.

DECHOW, M., SOHN, J. and STEINHANSES, J.(1997) Concentrations of cabin air of airbus arcraft, chemosphere, 35, 21-31

DLR, 2011. DLR and Airbus flight-test new aircraft ventilation system. http://www.dlr.de/dlr/en/desktopdefault.aspx/tabid-10256/366_read-1664. acessado em 12.09.2012.

DUGUID, J. P., 1946, The Size and the Duration of Air-Carriage of Respiratory Droplets and Droplet-Nuclei, J. Hyg. 44:471-479.

FABIAN, P., MCDEVITT, J.J., DEHAAN, W.H., FUNG, R.O.P., COWLING, B.J., CHAN, K.H., LEUNG, G.M., MILTON, D.K., 2008, Influenza virus in human exhaled breath: an observational study, PLoS ONE, 3(7),e2691.

FABICHAK Jr, D; SOUZA, E.S; MOREL, J.C.O.; TRIBESS, A. Análise experimental da distribuição de partículas aéreas em cabine de aeronave com insuflamento de ar pelo piso. XII Encontro Nacional de Conforto no Ambiente Construído, Brasília. XII Encontro Nacional de Conforto no Ambiente Construído ENCAC 2013a,10p.

FABICHAK Jr, D; SOUZA, E.S; MOREL, J.C.O; TRIBESS, A. Dispersão de partículas em cabine de aeronave com insuflamento convencional pelo teto e pelo piso. XXI Simpósio Internacional de Engenharia Automotiva, São Paulo. SIMEA 2013b, 16p.

FAIRCHILD, C.I., STAMPFER, J.K., 1987, Particle concentration in exhaled breath, Journal of Am. Ind. Hyg. Assoc. 48 (11), 948-949.

FANGER, P. O., MELIKOV, A. K., HAMNZAWA, H., RING, J., 1988. Air turbulence and sensation of draught. Energy and Buildings, 12: 21-39.

FISER, J., MIROSLAV, J., Impact of air distribution system on quality of ventilation in small aircraft cabin. Building and Environment Technická 2896/2, 61669 Brno, Czech Republic (2013)

FOX, R. W., Mcdonald, A. T., Pritchard, P. J. Introdução à Mecânica dos Fluidos. LTC, 6a. Ed., Rio de Janeiro, 2006. 
GAO, N.P. NIU, J.L., PERINO, M. HEISELBERG,P. 2007, The airborne transmission of infection between flats in high-rise residential buildings: Tracer gas simulation, Building and Environment 43: 1805-1817.

GUPTA, J.K., Lin, C.H., Chen, Q., 2011, Transport of expiratory droplets in an aircraft cabin, Indoor Air 2011; 21: 3-11

HEACE - Health Effects in Aircraft Cabin Environment. Web site: http://www.heace.org/index.html. Acessado em 27 de setembro de 2012.

HINDS, W. C., 1999. Aerosol Technology. New York, John Wiley Sons, Inc.

HOUSE OF LORDS UK, 2000., Select Committee on Science and Technology. Air Travel and Health: fifth report. http:// www.publications.parliament.uk/pa/ld199900/ Idselect/ldsctech/121/12101.htm (accessed Nov 20, 2013).

HUNT, E.H., SPACE, D.R.,[1994] "The Airplane Cabin Environment - Issues Pertaining to Flight Attendant Comfort", The Boeing Company, International Inflight Service Management Organization Conference, Montreal, Canada.

ICE, 2010, Ideal Cabin Environemnt, Disponível em http://www.asdstan.org/ICE.html. Acessado em setembro de 2012.

INMETRO, 1998. Guia para expressão da incerteza de medição, segunda edição brasileira publicada pelo INMETRO e pela ABNT, Agosto, 1998.

ISO 7726. Thermal Environments - Instruments and Methods for Measuring Physical Quantities. International Organization for Standardization, Geneva, 1998.

JONES, R., NICAS, M., 2009, Experimental Determination of Supermicrometer Particle Fate Subsequent to a Point Release within a Room under Natural and Forced Mixing, Aerosol Science and Technology, 43:9, 921-938.

KULKARNI, P., BARON, P.A., WILLEKE, K., 2011, Aerosol Measurement: Principles, Techniques, and Applications, John Wiley \& Sons.

LEITE, B. C. C. , TRIBESS, A., 2006, Analysis of thermal comfort in an office environment with underfloor air supply in a tropical climate. HVAC\&R Research. 12(2): 215-229.

LI, Y., LEUNG, G.M., Tang, J.W., YANG, X., CHAO, C.Y.H., LI, J.Z., LU, J.W., NIELSEN, P.V., NIU, J., QIAN, H., SLEIGH, A.C., SU, J., SUNDELL, J., WONG, T.W., YUEN, P.L., 2007, Role of ventilation in airborne transmission of infectious agents in the built environment - a multidisciplinary systematic review. Indoor Air, 17, pp. 2-18.

MANGILI A., GENDREAU, M.A., Transmission of infectious diseases during commercial air travel. Lancet 2005; 365: 989-96

MORAWSKA, L., 2005, "Droplet fate in indoor environments, or can we prevent the spread of infection?", Proceedings of Indoor Air 2005, Beijing, China.

MOURA, D., 2009, Condições do escoamento e de conforto térmico em cabine de aeronave. Dissertação de Mestrado. Departamento de Engenharia Mecânica da Escola Politécnica da USP, São Paulo, 74 p.

MÜLLER, D., SCHMIDT, M., MÜLLER, B.: Application of a displacement ventilation system for air distribution in aircraft cabins, AST 2011, Hamburg, Germany, March 31-April 1. (2011) 
NICAS, M., NAZAROFF, W.W., HUBBARD, A., 2005, Toward Understanding the Risk of Secondary Airborne Infection: Emission of Respirable Pathogens, $J$. Occup. Environ. Hyg. 2:143-154.

NIELSEN, P.V, BARTHOLOMAEUSSEN, N.M., JAKUBOWSKA, E., JIANG, H., JONSSON, O.T., KRAWIECKA, K., MIERZEJEWSKI, A., THOMAS, S.J., TRAMPCZYNSKA, K., POLAK, M., SOENNICHSEN, M., 2007, Chair with integrated personalized ventilation for minimizing cross infection. Procedings of Roomvent 2007.

NIELSEN, P.V., BARSZCZ, E., CZARNOTA, T., DYMALSKI, D.P., JASIENSKI, M.A., NOWOTKA, A., MOZER, A., WIANKOWSKA, S.M., JENSEN, R.L., 2008, The influence of draught on a seat with integrated personalized ventilation. Proceedings of Indoor Air 2008, Copenhagen, Denmark - Paper ID: 247.

NRC (National Research Council), 1986b. The Airliner Cabin Environment: Air Quality and Safety. Washington, DC: National Academy Press.

NRC. The airliner cabin environment and the health of passengers and crew. National Research Council ,Washington, DC: National Academy Press; 2002.

OLSEN S.J., CHANG H.L., CHEUNG T.Y., 2003. Transmission of the severe acute respiratory syndrome on aircraft. New England Journal of Medicine, 349, pp. 2416-2422.

PANG L, XU J, FANG L, GONG M, ZHANG H, ZHANG Y. Evaluation of an improved air distribution system for aircraft cabin. Building and Environment;59:145e52. (2013)

PAPINENI, R. S., AND ROSENTHAL, F. S. (1997). The Size Distribution of Droplets in the Exhaled Breath of Healthy Human Subjects, J. Aerosol Med. 10:105-161.

PEREIRA, M. L., GRAUDENZ, G., TRIBESS, A., MORAWSKA, L., 2009, Determination of particle concentration in the breathing zone for four different types of office ventilation systems. Building and Environment. 44: 904-911.

POUSSOU, S.B., MAZUMDAR, S., PLESNIAK, M.W., SOJKA, P.W., CHEN, Q., 2010, Flow and contaminant transport in an airliner cabin induced by a moving body: Model experiments and CFD predictions, Journal of Atmospheric Environment 44:2830-2839.

SHIMADA, M., OKUYAMA, K., OKAZAKI, S., ASAI, T., MATSUKURA, M., ISHIZU, Y., 1996, Numerical Simulation and Experiment on the Transport of Fine Particles in a Ventilated Room, Aerosol Science and Technology, 25: 3, 242-255.

SZE TO, G.N., WAN, M. P., Chao, C. Y. H., Fang, L. Melikov, A.(2009) 'Experimental Study of Dispersion and Deposition of Expiratory Aerosols in Aircraft Cabins and Impact on Infectious Disease Transmission', Aerosol Science and Technology, 43: 5, $466-485$.

TANG, J.W., LI, Y., EAMES, I., CHAN, P.K.S., RIDGWAY, G.L., 2006, Factors involved in the aerosol transmission of infection and control of ventilation in healthcare premises, Journal of Hospital Infection 64, 100-114.

TSI, Particle Generator Model 3079. Manufacturer manual available in: www.atitest.com. Accessed on July, 2010.TSI, 2004, Model 3475 Condensation 
Monodisperse Aerosol Generator Instruction Manual, Revision E, outubro 2004, TSI.

VOLAVÝ, J.,FISER, J., NÖSKE, I., Prediction of air temperature in the aircraft cabin under different operational conditions. EPJ Web of Conferences 4501096 (2013)

VUOLO, J. H. Fundamentos da teoria de erros, 20 ed., Edgard Blücher Ltda, 1996.

WAGNER, B.G., COBURN., BLOWER., 2009, Calculating the potential for withinflight transmission of influenza A (H1N1), BMC Medicine, 7:81 doi:10.1186/17417015-7-81

WALKINSHAW, D.S., 2010, Germs flying and the Truth, ASHRAE Journal, Vol. 52.

WAN, M.P., CHAO, C.Y.H., FANG, L., 2005, Transmission characteristics of passenger-exhaled droplets in a simulated air-cabin environment. Proceedings of Indoor Air 2005.

WAN, M. P., SZE TO, G.N., CHAO, C. Y. H., FANG, L. MELIKOV, A., 2009. Modeling the Fate of Expiratory Aerosols and the Associated Infection Risk in an Aircraft Cabin Environment', Aerosol Science and Technology, 43: 4, 322-343.

YAN, W., ZHANG, Y., SUN, Y., LI, D., 2009, Experimental and CFD study of unsteady airborne pollutant transport within an aircraft cabin mock-up. Building and Environment 44 (2009) 34-43.

YANG, C., YANG, X., XU, Y., SREBRIC, J., 2007, Contaminant dispersion in personal displacement ventilation, Proceedings of Building Simulation.

ZHANG T, CHEN X, MAZUNDAR S, ZHANG, T. CHEN, Q., 2007, Experimental and numerical investigation of airflow and contaminant transport in an airliner cabin mock-up. Proceedings of the $10^{\text {th }}$ International Conference on Air Distribution in Rooms - Roomvent 2007. Helsinki.

ZHANG T., CHEN Q., 2007, Novel air distribution systems for commercial aircraft cabins. Building and Environment (42):1675-1684.

ZHANG Z., CHEN X., MAZUNDAR S., ZHANG, T. CHEN, Q.,2009, Experimental and numerical investigation of airflow and contaminant transport in an airliner cabin mock-up. Building and Environment, 44(1) 85-94.

ZHANG, Z., CHEN, Q., 2006, Experimental measurements and numerical simulations of particle transport and distribution in ventilated rooms. Atmospheric Environment, 40(18), 3396-3408.

ZHANG, Z., CHEN, Q., 2007, Comparison of the eulerian and lagrangian methods for predicting particle transport in enclosed spaces. Atmospheric Environment 41 (2007) 5236-5248. 


\section{ANEXO A}

Os manequins aquecidos foram construídos em fibra de vidro e tubos e conexões de PVC (Moura, 2009), com forma semelhante a um corpo humano sentado, conforme mostrado na Figura A-1.

$\mathrm{Na}$ parte interna existe uma resistência elétrica, que dissipa calor, e um ventilador que propicia uma distribuição uniforme da temperatura do ar ao longo de toda a superfície do manequim. Os manequins são acoplados a uma unidade de potência por meio de cabos tripolares. A potência de dissipação de calor é ajustável por meio de software. A faixa de operação dos manequins aquecidos é de 30 a $120 \mathrm{~W} / \mathrm{m}^{2}$.
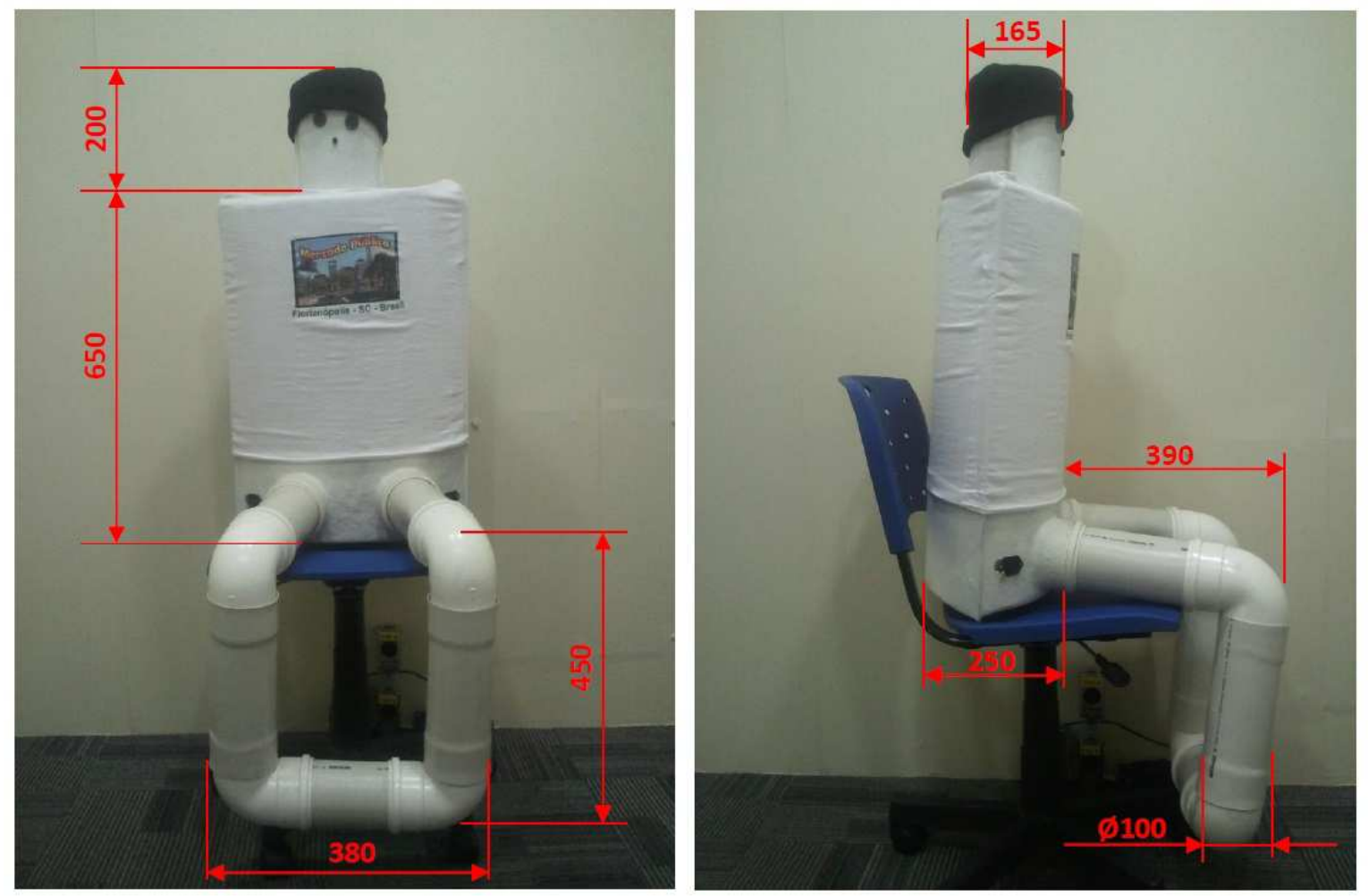

Figura A-1 - Os manequins aquecidos e suas respectivas dimensões. 
ANEXO B

\section{Memorial de cálculo do manômetro diferencial}

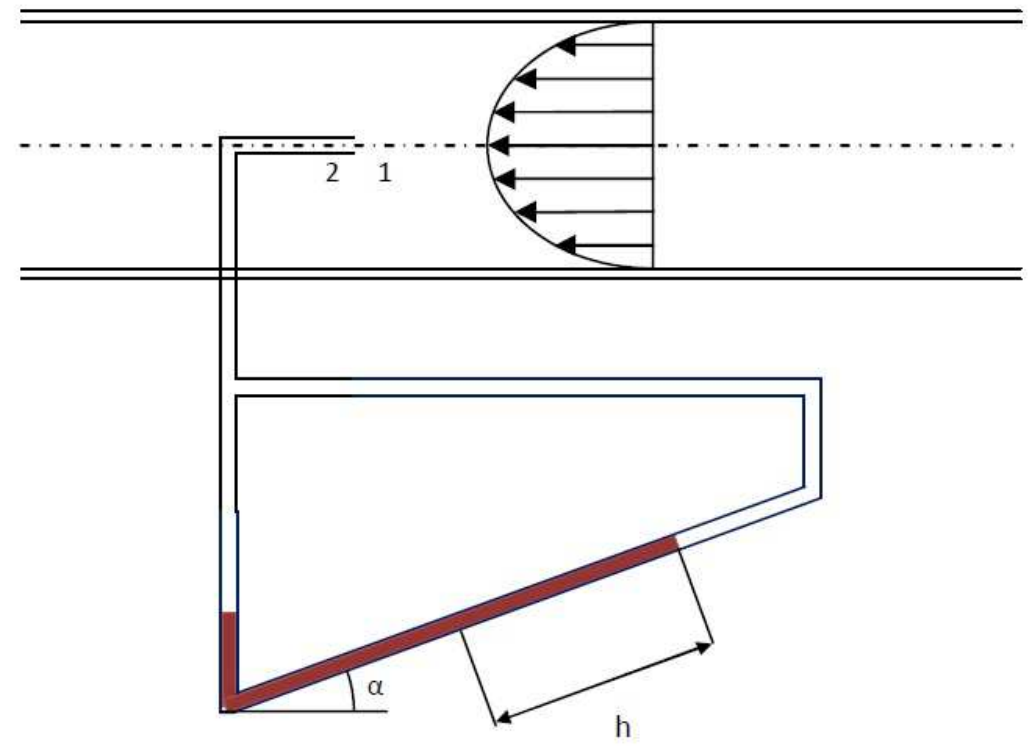

Cálculo:

Utilizando a equação de conservação de energia

$H_{1}=H_{2}$
$\frac{v_{1}^{2}}{2 g}+\frac{P_{1}}{\gamma}+z_{1}=\frac{v_{2}^{2}}{2 g}+\frac{P_{2}}{\gamma}+z_{2}$

Adotando-se o ponto 1 muito próximo do ponto 2 tem-se:

$v_{1}=\sqrt[2]{2 g\left(\frac{P_{2}-P_{1}}{\gamma_{a r}}\right)}$

Pois,

$z_{1}=z_{2}=0$

$v_{2}=0$ (ponto de estagnação)

Aplicando-se a equação manométrica entre os pontos 1 e 2 tem-se:

$P_{2}+\gamma_{a r} \cdot h-\gamma_{f} \cdot h=P_{1}$

Portanto, tem-se:

$\frac{P_{2}-P_{1}}{\gamma_{a r}}=h\left(\frac{\gamma_{f}}{\gamma_{a r}}-1\right)$

Substituindo (2) em (1) tem-se: 
$v_{1}=\sqrt[2]{2 g\left[h\left(\frac{\gamma_{f}}{\gamma_{a r}}-1\right)\right]}$

Em que:

$v_{1}=v_{\text {max }}$

Se o escoamento for turbulento, $\operatorname{Re}>2400$

$v_{\text {mid }}=\frac{49}{60} v_{m i x}$

Se o escoamento for laminar, $\operatorname{Re}<2400$

$v_{\operatorname{mid}}=0,5 \cdot v_{\max }$

A vazão média é dada por:

$Q_{\text {méd }}=A \cdot v_{\text {méd }}$

Em que:

$A=\frac{\pi \cdot d^{2}}{4}$

Dados para o cálculo do manômetro

$g_{\text {local }}=9.7856 \frac{\mathrm{m}}{\mathrm{s}}$

Par $020: 1,204 \frac{\mathrm{kg}}{\mathrm{m}^{2}}$

Pritio $=0,8260 @ 20^{\circ} \mathrm{C}$

$\rho_{\mathrm{H}_{2} 0020}{ }^{\mathrm{F}}=998,2071 \frac{\mathrm{kg}}{\mathrm{m}^{3}}$

$\mu_{a r}=1,74 \times 10^{-5} \mathrm{~Pa} \cdot \mathrm{s}$

$d_{\text {duto }}=100 \mathrm{~mm}$

Substituindo os valores, tem-se:

$v_{1}=115,685 \sqrt[7]{h}$

( $h$ é dado em metros)

ou

$v_{1}=3,658 \sqrt[3]{h}$

( $h$ é dado em milímetros) 


\section{ANEXO C}

\section{Resultados das medições e respectivas incertezas das velocidades e das temperaturas do ar}

Os resultados das velocidades e das temperaturas do ar, juntamente com as incertezas de medição, são apresentados nas Tabelas C.1 a C.6.

Os valores das velocidades e das temperaturas do ar são a média dos valores dos resultados dos três ensaios (ensaios em triplicata) em cada posição e em cada condição estudada.

As incertezas são o resultado da combinação das incertezas dos equipamentos de medição e dos desvios padrão em cada posição e em cada condição de ensaio (COLEMAN e STEELE, 1989; VUOLO, 1996; INMETRO, 1998).

A média das variáveis foi calculada utilizando a seguinte equação: $\bar{x}=\frac{1}{n} \sum_{i=1}^{n} x_{i}$

onde: $x$ representa o valor da variável e $n$ o número de amostras.

O desvio padrão das variáveis foi calculado utilizando a seguinte equação: $\sigma_{x}=\sqrt[2]{\frac{\sum(x-\bar{x})^{2}}{n-1}}$ $\sigma_{m}=\frac{\sigma_{x}}{\sqrt{n}}$

O desvio padrão para o valor médio foi calculado utilizando a equação:

E por fim, a incerteza padrão $\varepsilon$ que é a combinação da incerteza sistemática residual (incerteza do instrumento) e o desvio padrão para o valor médio, foi calculada utilizando a equação:

$\varepsilon=\sqrt[2]{\sigma_{m}^{2}+\sigma_{r}^{2}}$

onde: $\sigma_{r}$ é a incerteza sistemática residual (incerteza do instrumento). 
Tabela C-1. Resultados das velocidades e temperaturas do ar para temperatura de insuflamento de $18{ }^{\circ} \mathrm{C}$, região inferior. $(0,10 \mathrm{~m})$

\begin{tabular}{|c|c|c|c|c|c|c|c|c|c|c|c|c|c|c|c|c|c|c|}
\hline \multicolumn{19}{|c|}{ MV } \\
\hline \multirow[b]{2}{*}{ Posi } & \multicolumn{2}{|c|}{ Dia 1} & \multicolumn{2}{|c|}{ Dia 2} & \multicolumn{2}{|c|}{ Dia 3} & & & \multicolumn{2}{|c|}{ Dia 1} & \multicolumn{2}{|c|}{ Dia 2} & \multicolumn{2}{|c|}{ Dia 3} & \multirow[b]{2}{*}{$\overline{T_{a r}}$} & \multirow[b]{2}{*}{$\varepsilon_{\operatorname{Tor}}$} & \multirow[b]{2}{*}{$T_{u}$} & \multirow[b]{2}{*}{$D R$} \\
\hline & $\overline{v_{a x}}$ & $\sigma_{v_{\text {or }}}$ & $\overline{v_{a x}}$ & $\sigma_{v_{g r}}$ & $\overline{v_{a r}}$ & $\sigma_{v_{y r}}$ & $\overline{v_{a r}}$ & $\varepsilon_{v_{\text {or }}}$ & $\overline{T_{a r}}$ & $\sigma_{T_{y r}}$ & $\overline{T_{a r}}$ & $\sigma_{T_{y y}}$ & $\overline{T_{a r}}$ & $\sigma_{7 g x}$ & & & & \\
\hline $1 \mathrm{~A}$ & 0,3 & 0,07 & 0,3 & 0,08 & 0,3 & 0,08 & 0,3 & 0,04 & 19, & 0,2 & 19, & 0,2 & 19, & 0,2 & 19 & 0,1 & 21 & 39 \\
\hline $1 \mathrm{~B}$ & 0,3 & 0,08 & 0,2 & 0,16 & 0,2 & 0,08 & 0,3 & 0,05 & 20 & 0,2 & 20, & 0,2 & 20 & 0,2 & 20, & 0,1 & 36 & 40 \\
\hline $1 C$ & 0,1 & 0,09 & 0,1 & 0,09 & 0,1 & 0,09 & 0,1 & 0,05 & 20 , & 0,2 & 20 , & 0,2 & 20 & 0,2 & 20 , & 0,1 & 52 & 24 \\
\hline $1 D$ & 0,3 & 0,08 & 0,3 & 0,07 & 0,3 & 0,08 & 0,3 & 0,04 & 21, & 0,2 & 21, & 0,2 & 21 & 0,2 & 21, & 0,1 & 21 & 36 \\
\hline $1 \mathrm{E}$ & 0,4 & 0,06 & 0,4 & 0,06 & 0,4 & 0,06 & 0,4 & 0,03 & 21 & 0,2 & 21, & 0,2 & 21 & 0,2 & 21, & 0,1 & 14 & 38 \\
\hline $2 \mathrm{~A}$ & 0,3 & 0,11 & 0,3 & 0,10 & 0,4 & 0,10 & 0,3 & 0,06 & 19, & 0,2 & 19, & 0,2 & 19, & 0,2 & 19, & 0,1 & 28 & 50 \\
\hline $2 B$ & 0,1 & 0,06 & 0,1 & 0,06 & 0,1 & 0,06 & 0,1 & 0,03 & 19 , & 0,2 & 19, & 0,2 & 19 & 0,2 & 19, & 0,1 & 33 & 22 \\
\hline $2 \mathrm{C}$ & 0,1 & 0,06 & 0,1 & 0,06 & 0,1 & 0,06 & 0,1 & 0,03 & 20 , & 0,2 & 19 , & 0,2 & 19, & 0,2 & 19, & 0,1 & 38 & 19 \\
\hline $2 D$ & 0,0 & 0,04 & 0,0 & 0,04 & 0,0 & 0,04 & 0,0 & 0,02 & 20 , & 0,2 & 20 , & 0,2 & 20 & 0,2 & 20 , & 0,1 & 54 & 7 \\
\hline $2 \mathrm{E}$ & 0,2 & 0,06 & 0,2 & 0,07 & 0,1 & 0,06 & 0,2 & 0,04 & 21, & 0,2 & 21, & 0,2 & 21, & 0,2 & 21 , & 0,1 & 34 & 22 \\
\hline $3 A$ & 0,2 & 0,08 & 0,2 & 0,08 & 0,2 & 0,08 & 0,2 & 0,04 & 19, & 0,2 & 19, & 0,2 & 19, & 0,2 & 19, & 0,1 & 28 & 34 \\
\hline $3 B$ & 0,3 & 0,08 & 0,3 & 0,08 & 0,3 & 0,07 & 0,3 & 0,04 & 19, & 0,2 & 19 & 0,2 & 19 & 0,2 & 19 & 0,1 & 24 & 38 \\
\hline $3 C$ & 0,1 & 0,05 & 0,1 & 0,05 & 0,1 & 0,05 & 0,1 & 0,03 & 20 , & 0,2 & 20, & 0,2 & 20 & 0,2 & 20, & 0,1 & 52 & 11 \\
\hline $3 D$ & 0,1 & 0,07 & 0,1 & 0,07 & 0,1 & 0,07 & 0,1 & 0,04 & 20, & 0,2 & 20 , & 0,2 & 20 & 0,2 & 20 , & 0,1 & 40 & 22 \\
\hline $3 \mathrm{E}$ & 0,2 & 0,08 & 0,2 & 0,08 & 0,2 & 0,08 & 0,2 & 0,05 & 20, & 0,2 & 19, & 0,2 & 19, & 0,2 & 19, & 0,1 & 33 & 30 \\
\hline & & & & & & & & UFA & 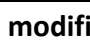 & 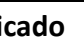 & & & & & & & & \\
\hline & & ia 1 & & ia 2 & & ia 3 & & & $\mathrm{Di}$ & a 1 & & ia & Di & a 3 & & & & \\
\hline Posi & $\overline{v_{a r}}$ & $\sigma_{v_{\text {var }}} \sigma$ & $\bar{v}$ & $\sigma_{v_{x y}} \sigma$ & 4 & $\sigma_{v_{\text {or }}} \sigma$ & $\overline{v_{a r} v}$ & $\varepsilon_{v_{a x}} \varepsilon$ & $\overline{T_{a r} T}$ & $\sigma_{T y y} \sigma$ & $\overline{T_{a r} T}$ & $\sigma_{\operatorname{Tox}} \sigma$ & $\overline{T_{a r} T}$ & $\sigma_{T_{a r}} \sigma$ & $\overline{T_{a r} T}$ & $\varepsilon_{T_{g y}} \varepsilon$ & $T_{u} T$ & $D R D$ \\
\hline $1 \mathrm{~A}$ & 0,4 & 0,06 & 0,4 & 0,05 & 0,4 & 0,05 & 0,4 & 0,03 & 17 & 0,2 & 17 & 0,2 & 17 & 0,2 & 17 & 0,1 & 12 & 47 \\
\hline $1 B$ & 0,3 & 0,08 & 0,3 & 0,08 & 0,3 & 0,08 & 0,3 & 0,05 & 18, & 0,2 & 17, & 0,2 & 17 & 0,2 & 17, & 0,1 & 22 & 50 \\
\hline $1 C$ & 0,4 & 0,12 & 0,4 & 0,13 & 0,4 & 0,14 & 0,4 & 0,07 & 18, & 0,2 & 18, & 0,2 & 18, & 0,2 & 18, & 0,1 & 31 & 65 \\
\hline $1 D$ & 0,3 & 0,05 & 0,4 & 0,06 & 0,3 & 0,06 & 0,4 & 0,03 & 19, & 0,2 & 19, & 0,2 & 19, & 0,2 & 19, & 0,1 & 15 & 40 \\
\hline $1 \mathrm{E}$ & 0,4 & 0,05 & 0,3 & 0,06 & 0,4 & 0,06 & 0,4 & 0,03 & 18, & 0,2 & 18, & 0,2 & 18 & 0,2 & 18, & 0,1 & 4 & 41 \\
\hline $2 \mathrm{~A}$ & 0,3 & 0,08 & 0,3 & 0,07 & 0,3 & 0,08 & 0,3 & 0,05 & 17 & 0 & 17 & 0 & 17, & 0,2 & 17, & 0,1 & 22 & 47 \\
\hline $2 B$ & 0,2 & 0,05 & 0,2 & 0,05 & 0,2 & 0,06 & 0,2 & 0,03 & 17 & 0,2 & 17 & 0,2 & 17 & 0,2 & 17 & 0,1 & 19 & 35 \\
\hline $2 \mathrm{C}$ & 0,3 & 0,08 & 0,3 & 0,08 & 0,3 & 0,09 & 0,3 & 0,05 & 17, & 0,2 & 17, & 0,2 & 17, & 0,2 & 17, & 0,1 & 25 & 48 \\
\hline $2 \mathrm{D}$ & 0,3 & 0,11 & 0,3 & 0,10 & 0,3 & 0,12 & 0,3 & 0,06 & 18, & 0,2 & 18, & 2 & 18, & 0,2 & 18, & 0,1 & 32 & 54 \\
\hline $2 \mathrm{E}$ & 0,4 & 0,11 & 0,4 & 0,11 & 0,5 & 0,10 & 0,5 & 0,06 & 18, & 0,2 & 18, & 0,2 & 18 , & 0,2 & 18, & 0,1 & 21 & 66 \\
\hline $3 A$ & 0,3 & 0,08 & 0,3 & 0,08 & 0,3 & 0,08 & 0,3 & 0,04 & 17, & 0,2 & 17 , & 0,2 & 17 & 0,2 & 17 , & 0,1 & 20 & 51 \\
\hline $3 B$ & 0,3 & 0,08 & 0,3 & 0,08 & 0,3 & 0,09 & 0,3 & 0,05 & 17 & 0.2 & 17 & 0,2 & 17 & 0,2 & 17, & 0,1 & 27 & 44 \\
\hline $3 C$ & 0,7 & 0,09 & 0,7 & 0,09 & 0,7 & 0,09 & 0,7 & 0,05 & 17, & 0,2 & 17 , & 0,2 & 17 & 0,2 & 17, & 0,1 & 12 & 85 \\
\hline $3 \mathrm{D}$ & 0,2 & 0,09 & 0,2 & 0,10 & 0,2 & 0,10 & 0,2 & 0,06 & 18, & 0 & 18, & 0,2 & 18 & 0,2 & 18, & 0,1 & 34 & 43 \\
\hline $3 \mathrm{E}$ & 0,3 & 0,12 & 0,3 & 0,12 & 0,3 & 0,11 & 0,3 & 0,07 & 17 , & 0,2 & 17 , & 0,2 & 17, & 0,2 & 17 , & 0,1 & 32 & 59 \\
\hline & & & & & & & & & AD & & & & & & & & & \\
\hline & & ia 1 & & ia 2 & $\mathrm{Di}$ & ia 3 & & & $\mathrm{Di}$ & a 1 & & ia 2 & & a 3 & & & & \\
\hline Posi & $\overline{v_{a r} v_{0}}$ & $\sigma_{v a r} \sigma$ & $\overline{v_{a r} v}$ & $\sigma_{v_{g r}} \sigma$ & $\overline{v_{a r}}$ & $\sigma_{v_{\text {grr }}} \sigma$ & $\overline{v_{a r} v}$ & $\varepsilon_{v_{\text {ar }}} \varepsilon$ & $\overline{T_{a r} T}$ & $\sigma_{T_{G r}} \sigma$ & $\overline{T_{a r} T}$ & $\sigma_{T_{g r}} \sigma$ & $\overline{T_{a r} T}$ & $\sigma_{T_{a r}} \sigma$ & $\overline{T_{a r} T}$ & $\varepsilon_{T_{g r}} \varepsilon$ & $T_{u} T$ & $D R D$ \\
\hline $1 \mathrm{~A}$ & 0,0 & 0,04 & 0,0 & 0,04 & 0,0 & 0,04 & 0,0 & 0,02 & 21 & 0,2 & 21 & 0,2 & 21 & 0,2 & 21 & 0,1 & 75 & 1 \\
\hline $1 \mathrm{~B}$ & 0,1 & 0,06 & 0,1 & 0,05 & 0,1 & 0,06 & 0,1 & 0,03 & 21, & 0,2 & 21, & 0,2 & 21 & 0,2 & 21, & 0,1 & 39 & 15 \\
\hline $1 \mathrm{C}$ & 0,6 & 0,13 & 0,6 & 0,14 & 0,6 & 0,13 & 0,6 & 0,08 & 21, & 0,2 & 21, & 0,2 & 21, & 0,2 & 21, & 0,1 & 21 & 73 \\
\hline $1 D$ & 0,0 & 0,04 & 0,0 & 0,05 & 0,0 & 0,04 & 0,0 & 0,03 & 23, & 0,2 & 23, & 0,2 & 23 & 0,2 & 23, & 0,1 & 69 & 4 \\
\hline $1 \mathrm{E}$ & 0,0 & 0,03 & 0,0 & 0,03 & 0,0 & 0,03 & 0,0 & 0,02 & 22 , & 0,2 & 22 , & 0,2 & 22 & 0,2 & 22 , & 0,1 & 57 & 1 \\
\hline $2 \mathrm{~A}$ & 0,1 & 0,05 & 0,0 & 0,05 & 0,1 & 0,05 & 0,1 & 0,03 & 20 , & 0,2 & 20 , & 0,2 & 20 & 0,2 & 20 , & 0,1 & 50 & 10 \\
\hline $2 \mathrm{~B}$ & 0,1 & 0,04 & 0,1 & 0,04 & 0,1 & 0,04 & 0,1 & 0,02 & 20 , & 0,2 & 20 , & 0,2 & 20 & 0,2 & 20 , & 0,1 & 26 & 16 \\
\hline $2 \mathrm{C}$ & 0,4 & 0,11 & 0,4 & 0,13 & 0,4 & 0,12 & 0,4 & 0,07 & 20 , & 0,2 & 20 , & 0,2 & 19, & 0,2 & 20 , & 0,1 & 26 & 61 \\
\hline $2 D$ & 0,1 & 0,06 & 0,1 & 0,06 & 0,1 & 0,06 & 0,1 & 0,03 & 22, & 0,2 & 22, & 0,2 & 22 & 0,2 & 22 , & 0,1 & 44 & 13 \\
\hline $2 \mathrm{E}$ & 0,2 & 0,09 & 0,2 & 0,09 & 0,2 & 0,09 & 0,2 & 0,05 & 22, & 0,2 & 22, & 0,2 & 22 & 0,2 & 22, & 0,1 & 42 & 24 \\
\hline $3 A$ & 0,1 & 0,05 & 0,1 & 0,06 & 0,1 & 0,06 & 0,1 & 0,03 & 20 , & 0,2 & 20 , & 0,2 & 20 & 0,2 & 20 , & 0,1 & 38 & 17 \\
\hline $3 B$ & 0,2 & 0,05 & 0,2 & 0,05 & 0,3 & 0,05 & 0,2 & 0,03 & 20 , & 0,2 & 20 , & 0,2 & 20 & 0,2 & 20 , & 0,1 & 18 & 29 \\
\hline $3 C$ & 0,6 & 0,13 & 0,6 & 0,11 & 0,6 & 0,11 & 0,6 & 0,07 & 19, & 0,2 & 19, & 0,2 & 19, & 0,2 & 19, & 0,1 & 19 & 75 \\
\hline $3 D$ & 0,2 & 0,06 & 0,2 & 0,06 & 0,2 & 0,06 & 0,2 & \begin{tabular}{|l|}
0,03 \\
\end{tabular} & 20 , & 0,2 & 20 , & 0,2 & 20 & 0,2 & 20 , & 0,1 & 27 & 23 \\
\hline $3 \mathrm{E}$ & 0,2 & 0,07 & 0,2 & 0,06 & 0,2 & 0,07 & 0,2 & 0,04 & 21, & 0,3 & 21, & 0,3 & 21, & 0,3 & 21, & 0,1 & 25 & 29 \\
\hline
\end{tabular}


Tabela C-2. Resultados das velocidades e temperaturas do ar para temperatura de insuflamento de $18{ }^{\circ} \mathrm{C}$, região inferior. $(0,60 \mathrm{~m})$

\begin{tabular}{|c|c|c|c|c|c|c|c|c|c|c|c|c|c|c|c|c|c|c|}
\hline \multicolumn{19}{|c|}{ MV } \\
\hline & \multicolumn{2}{|c|}{ Dia 1} & \multicolumn{2}{|c|}{ Dia 2} & \multicolumn{2}{|c|}{ Dia 3} & & & \multicolumn{2}{|c|}{ Dia 1} & \multicolumn{2}{|c|}{ Dia 2} & \multicolumn{2}{|c|}{ Dia 3} & \multirow[b]{2}{*}{$\overline{T_{a r} T}$} & \multirow[b]{2}{*}{$\varepsilon_{T_{a x}} \varepsilon$} & \multirow[b]{2}{*}{$T_{u} T$} & \multirow[b]{2}{*}{$D R D$} \\
\hline Posi & $\overline{v_{\alpha r} v_{0}}$ & $\sigma_{v, v} \sigma$ & $\overline{v_{a r} v}$ & $\sigma_{v_{\mathrm{gx}}} \sigma$ & $\overline{v_{a r} v}$ & $\sigma_{v_{a v}} \sigma$ & $\overline{v_{a r} v}$ & $\varepsilon_{v a r} \varepsilon$ & $\overline{T_{a r} T}$ & $\sigma_{T, x} \sigma$ & $\overline{T_{a r} T}$ & $\sigma_{T_{p r} \sigma}$ & $\overline{T_{a x} T}$ & $\sigma_{T, p} \sigma$ & & & & \\
\hline $1 \mathrm{~A}$ & 0,1 & 0,06 & 0,1 & 0,07 & 0,1 & 0,06 & 0,1 & 0,04 & 20 & 0,2 & 20 & 0,2 & 20 , & 0,2 & 20 , & 0,1 & 47 & 16 \\
\hline $1 \mathrm{~B}$ & 0,1 & 0,10 & 0,2 & 0,14 & 0,1 & 0,09 & 0,1 & 0,06 & 20, & 0,2 & 20 & 0,3 & 20, & 0,2 & 20 , & 0,1 & 57 & 27 \\
\hline $1 \mathrm{C}$ & 0,1 & 0,05 & 0,1 & 0,05 & 0,1 & 0,05 & 0,1 & 0,03 & 20 & 0,2 & 20 & 0,2 & 20, & 0,2 & 20 , & 0,1 & 42 & 13 \\
\hline $1 D$ & 0,0 & 0,05 & 0,0 & 0,05 & 0,1 & 0,05 & 0,0 & 0,03 & 21, & 0,2 & 21, & 0,2 & 21 & 0,2 & 21, & 0,1 & 53 & 8 \\
\hline $1 \mathrm{E}$ & 0,1 & 0,04 & 0,1 & 0,04 & 0,1 & 0,05 & 0,1 & 0,03 & 22 & 0,3 & 22 & 0,3 & 22 & 0,3 & 22 , & 0,2 & 45 & 8 \\
\hline $2 \mathrm{~A}$ & 0,1 & 0,08 & 0,1 & 0,08 & 0,1 & 0,08 & 0,1 & 0,05 & 20 & 0,2 & 20 & 0,2 & 20, & 0,2 & 20 , & 0,1 & 63 & 17 \\
\hline $2 B$ & 0,1 & 0,10 & 0,1 & 0,09 & 0,1 & 0,10 & 0,1 & 0,05 & 20 & 0,2 & 20 & 0,2 & 20, & 0,2 & 20 , & 0,1 & 57 & 24 \\
\hline $2 \mathrm{C}$ & 0,0 & 0,05 & 0,0 & 0,05 & 0,0 & 0,05 & 0,0 & 0,03 & 20 & 0,2 & 20 & 0,2 & 20, & 0,2 & 20 , & 0,1 & 54 & 8 \\
\hline $2 D$ & 0,0 & 0,05 & 0,0 & 0,05 & 0,0 & 0,05 & 0,0 & 0,03 & 21, & 0,3 & 21 & 0,3 & 21, & 0,3 & 21, & 0,2 & 60 & 8 \\
\hline $2 \mathrm{E}$ & 0,1 & 0,04 & 0,1 & 0,05 & 0,1 & 0,05 & 0,1 & 0,03 & 21, & 0,2 & 21, & 0,2 & 21, & 0,2 & 21, &, 1 & 43 & 10 \\
\hline $3 A$ & 0,2 & 0,06 & 0,2 & 0,06 & 0,2 & 0,06 & 0,2 & 0,04 & 19, & 0,2 & 19, & 0,2 & 19, & 0,2 & 19, & 0,1 & 25 & 28 \\
\hline $3 B$ & 0,1 & 0,07 & 0,1 & 0,08 & 0,1 & 0,08 & 0,1 & 0,04 & 19, & 0,2 & 19, & 0,2 & 19, & 0,2 & 19, & 0,1 & 40 & 25 \\
\hline $3 C$ & 0,0 & 0,06 & 0,0 & 0,06 & 0,1 & 0,06 & 0,0 & 0,04 & 20, & 0,2 & 20, & 0,2 & 20, & 0,2 & 20 , & 1 & 9 & 11 \\
\hline $3 D$ & 0,1 & 0,03 & 0,1 & 0,03 & 0,1 & 0,04 & 0,1 & 0,02 & 20, & 0,2 & 20, & 0,2 & 20, & 0,2 & 20 , & 0,1 & 29 & 11 \\
\hline $3 \mathrm{E}$ & 0,0 & 0,03 & 0,0 & 0,03 & 0,0 & 0,03 & 0,0 & 0,02 & 20, & 0,2 & 20 & 0,2 & 20, & 0,2 & 20 , & 0,1 & 71 & 0 \\
\hline \multicolumn{19}{|c|}{ UFAD modificado } \\
\hline & \multicolumn{2}{|c|}{ Dia 1} & & ia 2 & & ia 3 & & & & ia 1 & & ia 2 & & ia 3 & & & & \\
\hline Posi & $\overline{v_{\alpha r} v_{0}}$ & $\sigma_{v_{\text {arr }}} \sigma$ & $\overline{v_{a r} v}$ & $\sigma_{v_{a r}} \sigma$ & $\bar{v}$ & $\sigma_{v_{a r}} \sigma$ & $\overline{v_{a r} v}$ & $\varepsilon_{v_{a r}} \varepsilon_{i}$ & $\overline{T_{a r} T}$ & $\sigma_{T_{\text {ar }}} \sigma$ & $\overline{T_{a r} T}$ & $\sigma_{T_{a r}} \sigma$ & $\overline{T_{a r} T}$ & $\sigma_{\operatorname{Tar}} \sigma$ & $\overline{T_{a r} T}$ & $\varepsilon_{T_{\text {ar }}} \varepsilon$ & $T_{u} T$ & $D R D$ \\
\hline $1 \mathrm{~A}$ & 0,1 & 0,07 & 0,1 & 0,07 & 0,1 & 0,06 & 0,1 & 0,04 & 18, & 0,2 & 17 & 0,2 & 18 & 0,2 & 18 & 0,1 & 46 & 22 \\
\hline $1 \mathrm{~B}$ & 0,1 & 0,07 & 0,2 & 0,07 & 0,1 & 0,07 & 0,1 & 0,04 & 19, & 0,2 & 17 & 0 & 19, & 0,2 & 18 &, 1 & 36 & 25 \\
\hline $1 C$ & 0,1 & 0,06 & 0,1 & 0,06 & 0,1 & 0,06 & 0,1 & 0,03 & 19, & 0,2 & 19 & 0,2 & 19, & 0,2 & 19, & 0,1 & 46 & 16 \\
\hline $1 D$ & 0,2 & 0,06 & 0,2 & 0,06 & 0,1 & 0,06 & 0,2 & 0,03 & 20 & 0,2 & 20 & 0 & 20 , & 0,2 & 20 , & 1 & 28 & 25 \\
\hline $1 \mathrm{E}$ & 0,3 & 0,07 & 0,3 & 0,08 & 0,3 & 0,07 & 0,3 & 0,04 & 20, & 2 & 20 & 0,2 & 20 , & 0,2 & 20 , & 0,1 & 19 & 42 \\
\hline $2 A$ & 0,2 & 0,08 & 0,2 & 0,08 & 0,1 & 0,08 & 0,2 & 0,05 & 18, & 0,2 & 18, & 0,2 & 18 & 0,2 & 18 , & 0,1 & 40 & 30 \\
\hline $2 B$ & 0,0 & 0,05 & 0,0 & 0,05 & 0,0 & 0,05 & 0,0 & 0,03 & 18 & 0,2 & 18 & 0,2 & 18, & 0,2 & 18, & 0,1 & 54 & 10 \\
\hline $2 \mathrm{C}$ & 0,4 & 0,11 & 0,4 & 0,11 & 0,4 & 0,12 & 0,4 & 0,06 & 18, & 0,2 & 18, & 0.2 & 18, & 0,2 & 18 , & 0,1 & 24 & 67 \\
\hline $2 \mathrm{D}$ & 0,4 & \begin{tabular}{|l|}
0,08 \\
\end{tabular} & 0,4 & \begin{tabular}{|l|}
0,08 \\
\end{tabular} & 0,4 & 0,07 & 0,4 & 0,04 & 19, & 0,3 & 19 & 0,3 & 19, & 0,2 & 19, & 0,1 & 18 & 45 \\
\hline $2 \mathrm{E}$ & 0,3 & 0,10 & 0,3 & 0,10 & 0,3 & 0,10 & 0,3 & 0,06 & 18 & 0 & 18 & 0 & 18, & 0 & 18, & 0,1 & 27 & 53 \\
\hline $3 A$ & 0,6 & 0,12 & 0,5 & 0,12 & 0,6 & 0,12 & 0,6 & 0,07 & 17 & 0,2 & 17 & 0,2 & 17 & 0,2 & 17 , & 0,1 & 20 & 85 \\
\hline $3 B$ & 0,2 & 0,06 & 0,2 & 0,07 & 0,2 & 0,06 & 0,2 & 0,04 & 17, & 0 , & 17 & 0 , & 17 & ר & 17 , & 0,1 & 27 & 31 \\
\hline $3 C$ & 0,4 & 0,12 & 0,4 & 0,12 & 0,4 & 0,12 & 0,4 & 0,07 & 18, & 0 & 18 & 0 & 17 & 0 & 18 , & 1 & 29 & 65 \\
\hline $3 \mathrm{D}$ & 0,1 & 0,06 & 0,1 & 0,06 & 0,1 & 0,06 & 0,1 & 0,03 & 18, & 0,3 & 18, & 0,2 & 18, & 0,2 & 18, & 0,1 & 47 & 16 \\
\hline $3 \mathrm{E}$ & 0,1 & 0,06 & 0,1 & 0,06 & 0,1 & 0,06 & 0,1 & 0,03 & 18, & 0,2 & 18 & 0,2 & 18 & 0,2 & 18 & 0,1 & 32 & 24 \\
\hline & & & & & & & & & UFAD & & & & & & & & & \\
\hline & & ia 1 & & ia 2 & & ia 3 & & & & ia 1 & & ia 2 & & ia 3 & & & & \\
\hline Posi & $\overline{v_{a r}}$ & $\sigma_{v_{a r}} \sigma$ & $\overline{v_{a r} v}$ & $\sigma_{v_{\mathrm{grr}}} \sigma$ & $\overline{v_{a r} v}$ & $\sigma_{v_{g r}} \sigma$ & $\overline{v_{a r} v}$ & $\varepsilon_{v_{G r}} \varepsilon_{\text {, }}$ & $\overline{T_{a r} T}$ & $\sigma_{T_{\sigma \gamma}} \sigma$ & $\overline{T_{a r} T}$ & $\sigma_{T_{a r}} \sigma$ & $\overline{T_{a r} T}$ & $\sigma_{T_{a r}} \sigma$ & $\overline{T_{a r} T}$ & $\varepsilon_{T_{\sigma \gamma}} \varepsilon$ & $T_{u} T$ & $D R D$ \\
\hline $1 \mathrm{~A}$ & 0,1 & 0,05 & 0,1 & 0,05 & 0,1 & 0,05 & 0,1 & 0,03 & 21, & 0,2 & 21 & 0,2 & 21 & 0,2 & 21, & 0,1 & 35 & 13 \\
\hline $1 \mathrm{~B}$ & 0,2 & 0,05 & 0,2 & 0,05 & 0,2 & 0,05 & 0,2 & 0,03 & 22 & 0,3 & 22 & 0,3 & 22 & 0,3 & 22 & 0,2 & 19 & 21 \\
\hline $1 C$ & 0,1 & 0,06 & 0,1 & 0,06 & 0,1 & 0,05 & 0,1 & 0,03 & 22 & 0,2 & 22 & 0,2 & 22, & 0,2 & 22 , & 0,1 & 41 & 14 \\
\hline $1 D$ & 0,0 & 0,04 & 0,0 & 0,04 & 0,0 & 0,04 & 0,0 & 0,02 & 23, & 0,2 & 23 & 0,2 & 23 & 0,2 & 23, & 0,1 & 49 & 5 \\
\hline $1 \mathrm{E}$ & 0,1 & 0,04 & 0,1 & 0,04 & 0,1 & 0,04 & 0,1 & 0,02 & 22 & 0,2 & 23 & 0,2 & 23 & 0,2 & 23, & 0,1 & 40 & 9 \\
\hline $2 \mathrm{~A}$ & 0,3 & 0,07 & 0,3 & 0,08 & 0,3 & 0,07 & 0,3 & 0,04 & 20 & 0,2 & 20 & 0,2 & 20, & 0,2 & 20 , & 0,1 & 24 & 33 \\
\hline $2 \mathrm{~B}$ & 0,1 & 0,06 & 0,1 & 0,05 & 0,1 & 0,05 & 0,1 & 0,03 & 22 & 0,3 & 22 & 0,3 & 22 & 0,3 & 22 , & 0,2 & 40 & 13 \\
\hline $2 C$ & 0,5 & 0,11 & 0,5 & 0,11 & 0,5 & 0,11 & 0,5 & 0,06 & 20 & 0,2 & 20 & 0,2 & 20 & 0,2 & 20 , & 0,1 & 22 & 62 \\
\hline $2 \mathrm{D}$ & 0,1 & 0,07 & 0,1 & 0,06 & 0,1 & 0,06 & 0,1 & 0,04 & 22 & 0,4 & 22 & 0,4 & 22, & 0,5 & 22 , & 0,2 & 37 & 17 \\
\hline $2 \mathrm{E}$ & 0,1 & 0,05 & 0,1 & 0,05 & 0,1 & 0,05 & 0,1 & 0,03 & 22 & 0,2 & 22 & 0,2 & 22 & 0,2 & 22 & 0,1 & 44 & 11 \\
\hline $3 \mathrm{~A}$ & 0,2 & 0,05 & 0,2 & 0,06 & 0,2 & 0,05 & 0,2 & 0,03 & 20, & 0,2 & 20 & 0,2 & 20 & 0,2 & 20 , & 0,1 & 20 & 29 \\
\hline $3 B$ & 0,2 & 0,06 & 0,2 & 0,07 & 0,2 & 0,06 & 0,2 & 0,04 & 20 & 0,2 & 20 & 0,2 & 20, & 0,2 & 20 , & 0,1 & 25 & 28 \\
\hline $3 C$ & 0,6 & 0,13 & 0,6 & 0,15 & 0,6 & 0,13 & 0,6 & 0,08 & 19, & 0,2 & 19 & 0,2 & 19, & 0,2 & 19, & 0,1 & 22 & 83 \\
\hline $3 D$ & 0,2 & 0,07 & 0,2 & 0,07 & 0,2 & 0,07 & 0,2 & 0,04 & 20, & 0,2 & 20, & 0,2 & 20 & 0,2 & 20 , & 0,1 & 27 & 31 \\
\hline $3 \mathrm{E}$ & 0,2 & 0,05 & 0,2 & 0,05 & 0,2 & 0,06 & 0,2 & 0,03 & 20 & 0,2 & 20 & 0,2 & 20, & 0,2 & 20 , & 0,1 & 19 & 28 \\
\hline
\end{tabular}


Tabela C-3. Resultados das velocidades e temperaturas do ar para temperatura de insuflamento de $18{ }^{\circ} \mathrm{C}$, região inferior. $(1,10 \mathrm{~m})$

\begin{tabular}{|c|c|c|c|c|c|c|c|c|c|c|c|c|c|c|c|c|c|c|}
\hline \multicolumn{19}{|c|}{ MV } \\
\hline & \multicolumn{2}{|c|}{ Dia 1} & \multicolumn{2}{|c|}{ Dia 2} & \multicolumn{2}{|c|}{ Dia 3} & & & \multicolumn{2}{|c|}{ Dia 1} & \multicolumn{2}{|c|}{ Dia 2} & \multicolumn{2}{|c|}{ Dia 3} & \multirow[b]{2}{*}{$\overline{T_{a r} T}$} & \multirow[b]{2}{*}{$\varepsilon_{T_{u y}} \varepsilon$} & \multirow[b]{2}{*}{$T_{a} T$} & \multirow[b]{2}{*}{$D R D$} \\
\hline Posi & $\overline{v_{\alpha r}}$ & $\sigma_{v, v} \sigma$ & $\overline{v_{a r} v}$ & $\sigma_{v_{\text {ng }}} \sigma$ & $\overline{v_{a r} V}$ & $\sigma_{v_{a v}} \sigma$ & $\overline{v_{a r} v}$ & $\varepsilon_{v, v} \varepsilon_{p}$ & $\overline{T_{a r} T}$ & $\sigma_{T, y} \sigma$ & $\overline{T_{a r} \bar{T}}$ & $\sigma_{\operatorname{Tg}} \sigma$ & $\overline{T_{a v} T}$ & $\sigma_{T, p} \sigma$ & & & & \\
\hline $1 \mathrm{~A}$ & 0,3 & 0,13 & 0,3 & 0,14 & 0,3 & 0,14 & 0,3 & 0,08 & 20 & 0,2 & 20 , & 0,2 & 20 & 0,2 & 20 , & 0,1 & 37 & 54 \\
\hline $1 \mathrm{~B}$ & 0,5 & 0,14 & 0,2 & 0,17 & 0,4 & 0,14 & 0,4 & 0,08 & 21 , & 0,3 & 21, & 0,3 & 21, & 0,3 & 21, & 0,1 & 46 & 71 \\
\hline $1 \mathrm{C}$ & 0,3 & 0,15 & 0,3 & 0,16 & 0,3 & 0,17 & 0,3 & 0,09 & 20 , & 0,2 & 20 & 0,2 & 20, & 0,2 & 20 , & 0,1 & 42 & 62 \\
\hline $1 \mathrm{D}$ & 0,2 & 0,07 & 0,2 & 0,07 & 0,3 & 0,08 & 0,2 & 0,04 & 22 & 0,2 & 22 & 0,2 & 22 & 0,2 & 22, & 0,1 & 26 & 28 \\
\hline $1 \mathrm{E}$ & 0,5 & 0,15 & 0,5 & 0,13 & 0,5 & 0,14 & 0,5 & 0,08 & 21, & 0,2 & 21, & 0,2 & 21, & 0,2 & 21, & 0,1 & 26 & 64 \\
\hline $2 \mathrm{~A}$ & 0,3 & 0,13 & 0,3 & 0,13 & 0,3 & 0,14 & 0,3 & 0,08 & 19, & 0,2 & 19, & 0,2 & 19, & 0,2 & 19, & 0,1 & 35 & 58 \\
\hline $2 \mathrm{~B}$ & 0,4 & 0,12 & 0,4 & 0,12 & 0,4 & 0,11 & 0,4 & 0,07 & 20, & 0,3 & 20, & 0,3 & 20, & 0,3 & 20, & 0,2 & 28 & 56 \\
\hline $2 \mathrm{C}$ & 0,3 & 0,11 & 0,3 & 0,09 & 0,3 & 0,10 & 0,3 & 0,06 & 20 , & 0,2 & 20 & 0,2 & 20, & 0,2 & 20, & 0,1 & 25 & 48 \\
\hline $2 \mathrm{D}$ & 0,3 & 0,07 & 0,3 & 0,07 & 0,3 & 0,07 & 0,3 & 0,04 & 21, & 0,2 & 21, & 0,2 & 21, & 0,2 & 21, & 0,1 & 21 & 35 \\
\hline $2 \mathrm{E}$ & 0,6 & 0,15 & 0,6 & 0,14 & 0,6 & 0,14 & 0,6 & 0,08 & 20 , & 0,2 & 20 & 0,2 & 20 , & 0,2 & 20, & 0,1 & 22 & 82 \\
\hline $3 A$ & 0,5 & 0,10 & 0,6 & 0,10 & 0,5 & 0,11 & 0,5 & 0,06 & 19, & 0,2 & 19, & 0,2 & 19, & 0,2 & 19, & 0,1 & 17 & 68 \\
\hline $3 B$ & 0,4 & 0,12 & 0,4 & 0,12 & 0,4 & 0,11 & 0,4 & 0,07 & 19 & 0,2 & 19 , & 0,2 & 19, & 0,2 & 19, & 0,1 & 28 & 56 \\
\hline $3 C$ & 0,2 & 0,08 & 0,2 & 0,08 & 0,2 & 0,09 & 0,2 & 0,05 & 20 , & 0,2 & 20, & 0,2 & 20, & 0,2 & 20, & 1 & 36 & 29 \\
\hline $3 D$ & 0,4 & 0,08 & 0,4 & 0,08 & 0,4 & 0,08 & 0,4 & 0,05 & 21, & 0,2 & 21, & 0,2 & 21, & 0,2 & 21, & 0,1 & 17 & 45 \\
\hline $3 \mathrm{E}$ & 0,2 & 0,08 & 0,2 & 0,08 & 0,2 & 0,08 & 0,2 & 0,05 & 20, & 0,2 & 20, & 0,2 & 20, & 0,2 & 20, & 0.1 & 37 & 29 \\
\hline \multicolumn{19}{|c|}{ UFAD modificado } \\
\hline & \multicolumn{2}{|c|}{ Dia 1} & & ia 2 & & ia 3 & & & & a 1 & & ia 2 & & ia 3 & & & & \\
\hline Posi & $\overline{v_{\alpha r} v_{n}}$ & & $\overline{v_{c}}$ & & & $\sigma_{v_{a r}} \sigma$ & $\overline{v_{a r} v}$ & $\varepsilon_{v_{a r}} \varepsilon_{i}$ & $\overline{T_{a r} T}$ & $\sigma_{T_{a r}} \sigma$ & $\overline{T_{a r} T}$ & $\sigma_{\operatorname{Tar}} \sigma$ & $=\overline{T_{a r} T}$ & $\sigma_{\operatorname{Tar}} \sigma$ & $\overline{T_{a r} T}$ & $\varepsilon_{T r y} \varepsilon$ & $T_{u} T$ & $D R D$ \\
\hline $1 \mathrm{~A}$ & 0,1 & 0,03 & 0,0 & 0,03 & 0,0 & 0,03 & 0,0 & 0,02 & 18, & 0,2 & 17 & 0,2 & 18 & 0,2 & 18 & 0,1 & 35 & 10 \\
\hline $1 \mathrm{~B}$ & 0,0 & 0,05 & 0,0 & 0,05 & 0,0 & 0,04 & 0,0 & 0,03 & 19, & 0 & 17, & 0 & 19, & 0,2 & 18, & 1 & 58 & 8 \\
\hline $1 \mathrm{C}$ & 0,0 & 0,04 & 0,0 & 0,04 & 0,0 & 0,04 & 0,0 & 0,02 & 18, & 0 , & 19, & 0,2 & 19, & 0,2 & 19, & 0,1 & 74 & 2 \\
\hline $1 \mathrm{D}$ & 0,1 & 0,04 & 0,0 & 0,04 & 0,1 & 0,04 & 0,1 & 0,02 & 19, & 0 & 19, & 0 & 19, & - & 19, & 1 & 2 & 11 \\
\hline $1 \mathrm{E}$ & 0,1 & 0,04 & 0,1 & 0,04 & 0,1 & 0,04 & 0,1 & 0,02 & 20, & 0 & 20 , & 0 & 20, & 0,3 & 20, & 2 & 3 & 12 \\
\hline $2 \mathrm{~A}$ & 0,0 & 0,04 & 0,0 & 0,04 & 0,0 & 0,04 & 0,0 & 0,03 & 18, & 0 & 18, & 0,2 & 18 & 0,2 & 18, & 0,1 & 63 & 6 \\
\hline $2 \mathrm{~B}$ & 0,0 & 0,04 & 0,1 & 0,04 & 0,0 & 0,04 & 0,0 & 0,02 & 18, & 0,2 & 18, & 0,2 & 18 & 0,2 & 18, & 0,1 & 42 & 10 \\
\hline $2 \mathrm{C}$ & 0,0 & 0,05 & 0,0 & 0,05 & 0,0 & 0,05 & 0,0 & 0,03 & 18, & 0 & 18 , & 0,2 & 18 & 0,2 & 18, & 0,1 & 59 & 10 \\
\hline $2 \mathrm{D}$ & 0,0 & 0,05 & 0,0 & 0,05 & 0,0 & 0,05 & 0,0 & 0,03 & 19, & 0 & 19, & 0 & 19, & 0,3 & 19, & 0,2 & 73 & 6 \\
\hline $2 \mathrm{E}$ & 0 & 0,04 & 0 , & 0,04 & 0,0 & 0,04 & 0,1 & 0,02 & 19, & 0 & 18, & 0 & 19, & 0 , & 19, & 1 & 2 & 11 \\
\hline $3 A$ & 0,2 & 0,11 & 0,2 & 0,11 & 0,2 & 0,11 & 0,2 & 0,06 & 17, & 0, & 17, & 0,2 & 17 & 0,2 & 17, & 0,1 & 41 & 47 \\
\hline $3 B$ & 0,0 & 0,04 & 0,0 & 0,05 & 0,0 & 0,04 & 0,0 & 0,03 & 17 & & 17 & & 17 & & 17, & 0,1 & 7 & 4 \\
\hline $3 C$ & 0,0 & 0,05 & 0 & 0,05 & 0,1 & 0,05 & 0,1 & 0,03 & 18, & 0 & 18, & 0 & 18, & $E$ & 18, & 1 & 2 & 12 \\
\hline $3 D$ & 0,0 & 0,04 & 0,0 & \begin{tabular}{|l|}
0,04 \\
\end{tabular} & 0,0 & 0,04 & 0,0 & 0,03 & 18, & 0,2 & 18, & 0,2 & 18, & 0,2 & 18, & 0,1 & 77 & 3 \\
\hline $3 \mathrm{E}$ & 0,0 & 0,05 & 0,0 & 0,05 & 0,0 & 0,05 & 0,0 & 0,03 & 18, & 0,2 & 18 & 0,2 & 18 & 0,2 & 18, & 0,1 & 62 & 8 \\
\hline & & & & & & & & & UFAD & & & & & & & & & \\
\hline & & ia 1 & & ia 2 & & ia 3 & & & & a 1 & & ia 2 & & ia 3 & & & & \\
\hline Posi & $\overline{v_{a r}}$ & $\sigma_{v_{a r}} \sigma$ & $\overline{v_{a r} v}$ & $\sigma_{v_{u r}} \sigma$ & $\overline{v_{a r} v}$ & $\sigma_{v_{g r}} \sigma$ & $\overline{v_{a r}}$ & $\varepsilon_{v_{a r}} \varepsilon$ & $\overline{T_{a r} T}$ & $\sigma_{T_{g r}} \sigma$ & $\overline{T_{a r} T}$ & $\sigma_{T_{\text {ar }}} \sigma$ & $\overline{T_{a r} T}$ & $\sigma_{T_{a r}} \sigma$ & $\overline{T_{a r} T}$ & $\varepsilon_{T_{S Y}} \varepsilon$ & $T_{u} T$ & $D R D$ \\
\hline $1 \mathrm{~A}$ & 0,0 & 0,04 & 0,0 & 0,04 & 0,0 & 0,04 & 0,0 & 0,02 & 21, & 0,2 & 21, & 0,2 & 21, & 0,3 & 21 & 0,1 & 93 & 0 \\
\hline $1 \mathrm{~B}$ & 0,0 & 0,04 & 0,0 & 0,03 & 0,0 & 0,03 & 0,0 & 0,02 & 22 & 0,2 & 22 & 0,2 & 22 & 0,2 & 22, & 0,1 & 85 & 0 \\
\hline $1 \mathrm{C}$ & 0,0 & 0,04 & 0,0 & \begin{tabular}{|l|}
0,04 \\
\end{tabular} & 0,0 & 0,04 & 0,0 & 0,02 & 22, & 0,3 & 22, & 0,3 & 22, & 0,3 & 22, & 0,2 & 69 & 2 \\
\hline $1 \mathrm{D}$ & 0,0 & 0,05 & 0,0 & 0,05 & 0,0 & 0,05 & 0,0 & 0,03 & 22 & 0,2 & 23, & 0,2 & 23 & 0,2 & 23, & 0,1 & 59 & 6 \\
\hline $1 \mathrm{E}$ & 0,0 & 0,04 & 0,0 & 0,04 & 0,0 & 0,04 & 0,0 & 0,02 & 23 & 0,2 & 23 & 0,3 & 23 & 0,3 & 23, & 0,1 & 44 & 6 \\
\hline $2 \mathrm{~A}$ & 0,1 & 0,04 & 0,1 & 0,04 & 0,1 & 0,05 & 0,1 & 0,03 & 21, & 0,3 & 21, & 0,3 & 21, & 0,2 & 21, & 0,1 & 39 & 12 \\
\hline $2 \mathrm{~B}$ & 0,1 & 0,05 & 0,1 & 0,05 & 0,1 & 0,05 & 0,1 & 0,03 & 21, & 0, & 21, & 0,4 & 21, & 0,5 & 21, & 0,3 & 46 & 11 \\
\hline $2 C$ & 0,1 & 0,06 & 0,1 & 0,06 & 0,1 & 0,07 & 0,1 & 0,04 & 20 & 0,2 & 20 & 0,2 & 20 & 0,2 & 20 & 0,1 & 42 & 19 \\
\hline $2 \mathrm{D}$ & 0,0 & 0,05 & 0,0 & 0,05 & 0,0 & 0,06 & 0,0 & 0,03 & 21, & 0,3 & 21, & 0,3 & 21, & 0,2 & 21, & 0,1 & 59 & 8 \\
\hline $2 \mathrm{E}$ & 0,0 & 0,04 & 0,0 & 0,04 & 0,0 & 0,04 & 0,0 & 0,02 & 22 & 0,3 & 22 & 0,3 & 22 & 0,4 & 22, & 0,2 & 62 & 3 \\
\hline $3 A$ & 0,1 & 0,04 & 0,1 & 0,05 & 0,1 & 0,04 & 0,1 & 0,03 & 20 & 0,2 & 20 & 0,2 & 20 & 0,2 & 20 & 0,1 & 40 & 12 \\
\hline $3 \mathrm{~B}$ & 0,1 & 0,06 & 0,1 & 0,06 & 0,1 & 0,06 & 0,1 & 0,03 & 20, & 0,2 & 20, & 0,2 & 20, & 0,2 & 20, & 0,1 & 45 & 16 \\
\hline $3 C$ & 0,1 & 0,07 & 0,1 & 0,09 & 0,1 & 0,09 & 0,1 & 0,05 & 20 & 0,2 & 19, & 0,2 & 19, & 0,2 & 20, & 0,1 & 46 & 24 \\
\hline $3 \mathrm{D}$ & 0,1 & 0,07 & 0,1 & 0,07 & 0,1 & 0,08 & 0,1 & 0,04 & 20 , & 0,2 & 20 & 0,2 & 20, & 0,2 & 20, & 0,1 & 53 & 18 \\
\hline $3 \mathrm{E}$ & 0,1 & 0,04 & 0,1 & 0,04 & 0,1 & 0,04 & 0,1 & 0,02 & 20 & 0,2 & 20 , & 0,2 & 20, & 0,2 & 20, & 0,1 & 35 & 12 \\
\hline
\end{tabular}


Tabela C-4. Resultados das velocidades e temperaturas do ar para temperatura de insuflamento de $22{ }^{\circ} \mathrm{C}$, região inferior. $(0,10 \mathrm{~m})$

\begin{tabular}{|c|c|c|c|c|c|c|c|c|c|c|c|c|c|c|c|c|c|c|}
\hline \multicolumn{19}{|c|}{ MV } \\
\hline & \multicolumn{2}{|c|}{ Dia 1} & \multicolumn{2}{|c|}{ Dia 2} & \multicolumn{2}{|c|}{ Dia 3} & & & \multicolumn{2}{|c|}{ Dia 1} & \multicolumn{2}{|c|}{ Dia 2} & \multicolumn{2}{|c|}{ Dia 3} & \multirow[b]{2}{*}{$\overline{T_{a n} T}$} & \multirow[b]{2}{*}{$\varepsilon_{T y} \varepsilon$} & \multirow[b]{2}{*}{$T_{u} T$} & \multirow[b]{2}{*}{$D R D$} \\
\hline Posi & $\overline{v_{a r}} v_{\mathrm{C}}$ & $\sigma_{v_{a r}} \sigma$ & $\overline{v_{a r} v}$ & $\sigma_{v_{y y}} \sigma$ & $\overline{v_{a r} v}$ & $\sigma_{v_{a r}} \sigma$ & $\overline{v_{a r} v}$ & $\varepsilon_{v_{\text {or }}} \varepsilon_{0}$ & $\overline{T_{a r} T}$ & $\sigma_{T_{a r}} \sigma$ & $\overline{T_{a r} T}$ & $\sigma_{T_{b y}} \sigma$ & $\overline{T_{a r} T}$ & $\sigma_{T_{a r}} \sigma$ & & & & \\
\hline $1 \mathrm{~A}$ & 0,3 & 0,06 & 0,3 & 0,07 & 0,3 & 0,07 & 0,3 & 0,04 & 23, & 0,2 & 23, & 0,2 & 23 & 0,2 & 23, & 0,1 & 21 & 26 \\
\hline $1 \mathrm{~B}$ & 0,3 & \begin{tabular}{|l|}
0,07 \\
\end{tabular} & 0,3 & \begin{tabular}{|l|}
0,07 \\
\end{tabular} & 0,3 & 0,06 & 0,3 & 0,04 & 23, & 0,2 & 23 & 0,2 & 23, & 0,2 & 23, & 0,1 & 21 & 26 \\
\hline $1 C$ & 0,1 & \begin{tabular}{|l|}
0,09 \\
\end{tabular} & 0,1 & 0,09 & 0,1 & 0,09 & 0,1 & 0,05 & 24 & 0,2 & 24, & 0,2 & 24 & 0,2 & 24, & 0,1 & 49 & 18 \\
\hline 1D & 0,3 & 0,07 & 0,3 & 0,06 & 0,3 & 0,07 & 0,3 & 0,04 & 24, & 0,2 & 24, & 0,2 & 24, & 0,2 & 24, & 0,1 & 19 & 25 \\
\hline $1 \mathrm{E}$ & 0,3 & 0,05 & 0,3 & 0,05 & 0,3 & 0,05 & 0,3 & 0,03 & 24, & 0,2 & 24, & 0,2 & 24, & 0,2 & 24, & 0,1 & 14 & 23 \\
\hline $2 \mathrm{~A}$ & 0,4 & 0,11 & 0,4 & 0,11 & 0,4 & 0,11 & 0,4 & 0,06 & 23, & 0,2 & 23, & 0,2 & 23 & 0,2 & 23, & 0,1 & 26 & 43 \\
\hline $2 B$ & 0,3 & 0,10 & 0,2 & 0,10 & 0,3 & 0,10 & 0,3 & 0,06 & 23, & 0,2 & 23, & 0,2 & 23, & 0,2 & 23, & 0,1 & 33 & 31 \\
\hline $2 \mathrm{C}$ & 0,1 & 0,08 & 0,1 & 0,09 & 0,1 & 0,08 & 0,1 & 0,05 & 24, & 0,2 & 24, & 0,2 & 24, & 0,2 & 24, & 0,1 & 54 & 16 \\
\hline $2 \mathrm{D}$ & 0,3 & \begin{tabular}{|l|}
0,06 \\
\end{tabular} & 0,0 & \begin{tabular}{|l|}
0,06 \\
\end{tabular} & 0,0 & 0,05 & 0,1 & 0,03 & 25 & 0,2 & 24, & 0,2 & 24 & 0,2 & 24, & 0,1 & 44 & 15 \\
\hline $2 \mathrm{E}$ & 0,3 & 0,08 & 0,3 & 0,08 & 0,3 & 0,08 & 0,3 & 0,05 & 24, & 0,2 & 24, & 0,2 & 24, & 0,2 & 24, & 0,1 & 26 & 24 \\
\hline $3 \mathrm{~A}$ & 0,2 & 0,08 & 0,2 & 0,08 & 0,2 & 0,08 & 0,2 & 0,05 & 23, & 0,2 & 23 & 0,2 & 23 & 0,2 & 23 & 0,1 & 29 & 26 \\
\hline $3 \mathrm{~B}$ & 0,3 & \begin{tabular}{|l|}
0,09 \\
\end{tabular} & 0,3 & \begin{tabular}{|l|}
0,09 \\
\end{tabular} & 0,3 & 0,09 & 0,3 & 0,05 & 23, & 0,2 & 23 & 0,2 & 23 & 0,2 & 23, & 0,1 & 27 & 30 \\
\hline $3 C$ & 0,1 & 0,07 & 0,1 & 0,07 & 0,1 & 0,07 & 0,1 & 0,04 & 23, & 0,2 & 23, & 0,2 & 24, & 0,2 & 23, & 1 & 45 & 14 \\
\hline $3 \mathrm{D}$ & 0,1 & \begin{tabular}{|l|}
0,06 \\
\end{tabular} & 0,1 & \begin{tabular}{|l|}
0,06 \\
\end{tabular} & 0,1 & 0,06 & 0,1 & 0,03 & 23, & 0,2 & 23, & 0,2 & 23, & 0,2 & 23, & 1 & 35 & 14 \\
\hline $3 \mathrm{E}$ & 0,2 & 0,10 & 0,2 & 0,10 & 0,2 & 0,10 & 0,2 & 0,06 & 23, & 0,2 & 23, & 0,2 & 24, & 0,2 & 23, & 0,1 & 36 & 28 \\
\hline \multicolumn{19}{|c|}{ UFAD modificado } \\
\hline & \multicolumn{2}{|c|}{ Dia 1} & & a 2 & & ia 3 & & & & a 1 & & 2 & & 3 & & & & \\
\hline Posi & $\overline{v_{\alpha r}} v_{s}$ & $\sigma_{v_{a r}} \sigma$ & $\overline{v_{a r}}$ & $\sigma_{v_{a r}} \sigma$ & & $\sigma_{v_{a x}} \sigma$ & $\overline{v_{a r} v}$ & $\varepsilon_{v_{a r}} \varepsilon_{i}$ & $\overline{T_{a r} T}$ & $\sigma_{T_{O Y}} \sigma$ & $\overline{T_{a r} T}$ & $\sigma_{T_{\text {ar }}} \sigma$ & $\overline{T_{a r} T}$ & $\sigma_{T_{a r}} \sigma$ & $\overline{T_{a r} T}$ & $\varepsilon_{T_{u r}} \varepsilon$ & $T_{u} T$ & $D R D$ \\
\hline $1 \mathrm{~A}$ & 0,5 & 0,06 & 0,5 & 0,06 & 0,5 & 0,06 & 0,5 & 0,03 & 21, & 0,2 & 21 & 0,2 & 21, & 0,2 & 21, & 0,1 & 11 & 40 \\
\hline $1 B$ & 0,5 & 0,07 & 0,5 & \begin{tabular}{|l|}
0,07 \\
\end{tabular} & 0,5 & 0,07 & 0,5 & 0,04 & 21, & 0 & 21, & 0,2 & 21 & 0,2 & 21, & 1 & 12 & 47 \\
\hline $1 C$ & 0,4 & \begin{tabular}{|l|}
0,13 \\
\end{tabular} & 0,4 & \begin{tabular}{|l|}
0,13 \\
\end{tabular} & 0,4 & 0,13 & 0,4 & 0,07 & 22 & 0,2 & 22, & 0,2 & 21, & 0,2 & 22, & 0,1 & 28 & 55 \\
\hline $1 D$ & 0,4 & 0,06 & 0,4 & 0,06 & 0,4 & 0,06 & 0,4 & 0,04 & 22 & 02 & 22 , & 0,2 & 22 & ? & 22, & 0.1 & 14 & 35 \\
\hline $1 \mathrm{E}$ & 0,3 & \begin{tabular}{|l|}
0,05 \\
\end{tabular} & 0,3 & \begin{tabular}{|l|}
0,05 \\
\end{tabular} & 0,3 & 0,05 & 0,3 & 0,03 & 22, & 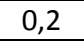 & 22 & 0 & 22 & 0,2 & 22, & 0,1 & 3 & 27 \\
\hline $2 \mathrm{~A}$ & 0,3 & \begin{tabular}{|l|}
0,07 \\
\end{tabular} & 0,3 & 0,08 & 0,3 & 0,08 & 0,3 & 0,04 & 21, & 0,2 & 21, & 0,2 & 21, & 0,2 & 21, & 0,1 & 21 & 35 \\
\hline $2 \mathrm{~B}$ & 0,3 & \begin{tabular}{|l|}
0,05 \\
\end{tabular} & 0,3 & \begin{tabular}{|l|}
0,05 \\
\end{tabular} & 0,3 & 0,05 & 0,3 & 0,03 & 21, & 0,2 & 21, & 0,2 & 21, & 0,2 & 21, & 0,1 & 17 & 27 \\
\hline $2 C$ & 0,5 & \begin{tabular}{|l|}
0,11 \\
\end{tabular} & 0,5 & \begin{tabular}{|l|}
0,12 \\
\end{tabular} & 0,5 & 0,11 & 0,5 & 0,07 & 21 & 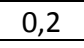 & 21, & 0 & 21, & 0,2 & 2 & 1 & 22 & 58 \\
\hline $2 \mathrm{D}$ & 0,3 & \begin{tabular}{|l|}
0,10 \\
\end{tabular} & 0,3 & \begin{tabular}{|l|}
0,11 \\
\end{tabular} & 0,3 & 0,10 & 0,3 & 0,06 & 22 & 0,2 & 22 & 0,2 & 22 & 0,2 & 22 , & 0,1 & 33 & 36 \\
\hline $2 \mathrm{E}$ & 0,4 & 0,09 & 0,4 & 0,10 & 0,4 & 0,10 & 0,4 & 0,06 & 22 & ? & 22 , & ? & 22, & & 22, & 0,1 & 3 & 42 \\
\hline $3 A$ & 0,3 & \begin{tabular}{|l|}
0,08 \\
\end{tabular} & 0,3 & \begin{tabular}{|l|}
0,08 \\
\end{tabular} & 0,3 & 0,08 & 0,3 & 0,05 & 21 & & 21 & 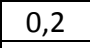 & & - 72 & & & - & 39 \\
\hline $3 B$ & 0,3 & 0,10 & 0,3 & 0,09 & 0,3 & 0,10 & 0,3 & 0,06 & 21, & 0 , & 21, & 0 , & 21, & 0,2 & 21, & 0,1 & 25 & 43 \\
\hline $3 C$ & 0,6 & 0,13 & 0,6 & 0,13 & 0,6 & 0,13 & 0,6 & 0,07 & 21, & & 21, & & 21, & & 21, & 0,1 & 20 & 73 \\
\hline $3 \mathrm{D}$ & 0,2 & \begin{tabular}{|l|}
0,09 \\
\end{tabular} & 0,2 & \begin{tabular}{|l|}
0,10 \\
\end{tabular} & 0,2 & 0,10 & 0,2 & 0,06 & 21, & & 21, & 0, & & 0,2 & & 0,1 & 34 & 33 \\
\hline $3 \mathrm{E}$ & 0,4 & 0,13 & 0,4 & 0,13 & 0,4 & 0,12 & 0,4 & 0,07 & 21, & 0,2 & 21, & 0,2 & 21, & 0,2 & 21, & 0,1 & 29 & 53 \\
\hline & & & & & & & & & $=A D$ & & & & & & & & & \\
\hline & & a 1 & & a 2 & & ia 3 & & & & a 1 & & a 2 & & a 3 & & & & \\
\hline Posi & $\overline{v_{a r}}$ & $\sigma_{v_{g r}} \sigma$ & $\overline{v_{a r} v}$ & $\sigma_{v_{g r}} \sigma$ & $\overline{v_{a r} v_{b}}$ & $\sigma_{v_{g r}} \sigma$ & $\overline{v_{a r} v}$ & $\varepsilon_{v_{a r}} \varepsilon_{n}$ & $\overline{T_{a r} T}$ & $\sigma_{T_{g r}} \sigma$ & $\overline{T_{a r} T}$ & $\sigma_{T_{a r}} \sigma$ & $\overline{T_{a r} T}$ & $\sigma_{T_{a r}} \sigma$ & $\overline{T_{a r} T}$ & $\varepsilon_{T_{B Y}} \varepsilon$ & $T_{u} T$ & $D R D$ \\
\hline $1 \mathrm{~A}$ & 0,0 & 0,04 & 0,0 & 0,04 & 0,0 & 0,04 & 0,0 & 0,02 & 24, & 0,2 & 24 & 0,2 & 25 & 0,2 & 25, & 0,1 & 69 & 2 \\
\hline $1 B$ & 0,1 & \begin{tabular}{|l|}
0,06 \\
\end{tabular} & 0,1 & \begin{tabular}{|l|}
0,06 \\
\end{tabular} & 0,1 & 0,05 & 0,1 & 0,03 & 25 & 0,2 & 25, & 0,2 & 25 & 02 & 25, & 0,1 & 33 & 12 \\
\hline $1 C$ & 0,3 & \begin{tabular}{|l|}
0,09 \\
\end{tabular} & 0,3 & \begin{tabular}{|l|}
0,10 \\
\end{tabular} & 0,3 & 0,10 & 0,3 & 0,05 & 24, & 0,2 & 24 & 0,2 & 24 & 0,2 & 24, & 0,1 & 25 & 32 \\
\hline $1 D$ & 0,0 & \begin{tabular}{|l|}
0,05 \\
\end{tabular} & 0,0 & 0,05 & 0,0 & 0,05 & 0,0 & 0,03 & 26 & 0,2 & 26 , & 0,2 & 26 , & 0,2 & 26, & 0,1 & 56 & 5 \\
\hline $1 \mathrm{E}$ & 0,0 & \begin{tabular}{|l|}
0,03 \\
\end{tabular} & 0,0 & 0,03 & 0,0 & 0,03 & 0,0 & 0,02 & 26 & 0,2 & 26, & 0,2 & 26 & 0,2 & 26, & 0,1 & 60 & 1 \\
\hline $2 A$ & 0,1 & 0,05 & 0,1 & 0,06 & 0,1 & 0,05 & 0,1 & 0,03 & 24 & 0,2 & 24 & 0,2 & 24 & 0,2 & 24, & 0,1 & 47 & 9 \\
\hline $2 \mathrm{~B}$ & 0,1 & 0,04 & 0,1 & 0,04 & 0,1 & 0,04 & 0,1 & 0,03 & 23 & 0,2 & 23, & 0,2 & 23, & 0,2 & 23, & 0,1 & 27 & 13 \\
\hline $2 C$ & 0,5 & 0,15 & 0,4 & 0,13 & 0,4 & 0,14 & 0,4 & 0,08 & 23, & 0,2 & 23 & 0,2 & 23 & 0,2 & 23, & 0,1 & 28 & 53 \\
\hline $2 \mathrm{D}$ & 0,1 & \begin{tabular}{|l|}
0,06 \\
\end{tabular} & 0,1 & \begin{tabular}{|l|}
0,06 \\
\end{tabular} & 0,1 & 0,05 & 0,1 & 0,03 & 25, & 0,2 & 25 & 0,2 & 25 & 0,2 & 25, & 0,1 & 42 & 9 \\
\hline $2 \mathrm{E}$ & 0,1 & 0,06 & 0,1 & 0,06 & 0,1 & 0,06 & 0,1 & 0,04 & 25, & 0,2 & 25 & 0,2 & 25 & 0,2 & 25, & 0,1 & 41 & 11 \\
\hline $3 \mathrm{~A}$ & 0,1 & \begin{tabular}{|l|}
0,05 \\
\end{tabular} & 0,1 & \begin{tabular}{|l|}
0,06 \\
\end{tabular} & 0,1 & 0,06 & 0,1 & 0,03 & 24 & 0,2 & 23 & 0,2 & 23, & 0,2 & 23, & 0,1 & 41 & 12 \\
\hline $3 B$ & 0,2 & \begin{tabular}{|l|}
0,04 \\
\end{tabular} & 0,2 & \begin{tabular}{|l|}
0,04 \\
\end{tabular} & 0,2 & 0,04 & 0,2 & 0,02 & 23, & 0,2 & 23 & 0,2 & 23 & 0,2 & 23, & 0,1 & 17 & 18 \\
\hline $3 C$ & 0,7 & 0,21 & 0,6 & 0,21 & 0,6 & 0,20 & 0,7 & 0,12 & 23, & 0,2 & 23, & 0,2 & 23 & 0,2 & 23, & 0,1 & 29 & 88 \\
\hline $3 \mathrm{D}$ & 0,2 & \begin{tabular}{|l|}
0,06 \\
\end{tabular} & 0,2 & \begin{tabular}{|l|}
0,07 \\
\end{tabular} & 0,2 & 0,06 & 0,2 & 0,04 & 24 & 0,2 & 24, & 0,2 & 24 & 0,2 & 24, & 0,1 & 28 & 17 \\
\hline $3 \mathrm{E}$ & 0,2 & 0,07 & 0,2 & 0,07 & 0,2 & 0,06 & 0,2 & 0,04 & 24, & 0,2 & 24 , & 0,2 & 24 & 0,2 & 24, & 0,1 & 26 & 19 \\
\hline
\end{tabular}


Tabela C-5. Resultados das velocidades e temperaturas do ar para temperatura de insuflamento de $22{ }^{\circ} \mathrm{C}$, região inferior. $(0,60 \mathrm{~m})$

\begin{tabular}{|c|c|c|c|c|c|c|c|c|c|c|c|c|c|c|c|c|c|c|}
\hline \multicolumn{19}{|c|}{ MV } \\
\hline & \multicolumn{2}{|c|}{ Dia 1} & \multicolumn{2}{|c|}{ Dia 2} & \multicolumn{2}{|c|}{ Dia 3} & & & \multicolumn{2}{|c|}{ Dia 1} & \multicolumn{2}{|c|}{ Dia 2} & \multicolumn{2}{|c|}{ Dia 3} & \multirow[b]{2}{*}{$\overline{T_{a r} T}$} & \multirow[b]{2}{*}{$\varepsilon_{T_{u y}} \varepsilon$} & \multirow[b]{2}{*}{$T_{u} T$} & \multirow[b]{2}{*}{$D R D$} \\
\hline Posi & $\overline{v_{\alpha r}}$ & $\sigma_{v, v} \sigma$ & $\overline{v_{a r} v}$ & $\sigma_{v_{\text {ng }}} \sigma$ & $\overline{v_{a r} V}$ & $\sigma_{v_{a v}} \sigma$ & $\overline{v_{a r} v}$ & $\varepsilon_{v, v} \varepsilon_{p}$ & $\overline{T_{a r} T}$ & $\sigma_{T, y} \sigma$ & $\overline{T_{a r} \bar{T}}$ & $\sigma_{\operatorname{Tg}} \sigma$ & $\overline{T_{a v} T}$ & $\sigma_{T, p} \sigma$ & & & & \\
\hline $1 \mathrm{~A}$ & 0,1 & 0,07 & 0,1 & 0,06 & 0,1 & 0,07 & 0,1 & 0,04 & 24, & 0,2 & 23 & 0,2 & 23 & 0,2 & 23, & 0,1 & 47 & 13 \\
\hline $1 \mathrm{~B}$ & 0,2 & 0,10 & 0,2 & 0,10 & 0,2 & 0,10 & 0,2 & 0,06 & 23 & 0,2 & 23 & 0,2 & 23 & 0,2 & 23 & 0,1 & 38 & 26 \\
\hline $1 \mathrm{C}$ & 0,1 & 0,07 & 0,1 & 0,07 & 0,1 & 0,07 & 0,1 & 0,04 & 24, & 0,2 & 24, & 0,2 & 24, & 0,2 & 24, & 0,1 & 41 & 15 \\
\hline $1 \mathrm{D}$ & 0,0 & 0,05 & 0,0 & 0,05 & 0,0 & 0,05 & 0,0 & 0,03 & 24 & 0,2 & 24, & 0,2 & 24 & 0,2 & 24, & 0,1 & 53 & 6 \\
\hline $1 \mathrm{E}$ & 0,1 & 0,04 & 0,1 & 0,04 & 0,1 & 0,04 & 0,1 & 0,03 & 26 , & 0,3 & 26 , & 0,3 & 26, & 0,3 & 26, & 0,2 & 36 & 7 \\
\hline $2 \mathrm{~A}$ & 0,0 & 0,07 & 0,1 & 0,07 & 0,1 & 0,08 & 0,1 & 0,04 & 24, & 0,2 & 24, & 0,2 & 24, & 0,2 & 24, & 0,1 & 76 & 9 \\
\hline $2 \mathrm{~B}$ & 0,1 & 0,07 & 0,1 & 0,09 & 0,1 & 0,08 & 0,1 & 0,05 & 24, & 0,2 & 24, & 0,2 & 24 & 0,2 & 24, & 0,1 & 60 & 13 \\
\hline $2 \mathrm{C}$ & 0,1 & 0,05 & 0,1 & 0,05 & 0,1 & 0,04 & 0,1 & 0,03 & 24, & 0,2 & 24, & 0,2 & 24, & 0,2 & 24, & 0,1 & 38 & 10 \\
\hline $2 \mathrm{D}$ & 0,0 & 0,05 & 0,0 & 0,05 & 0,0 & 0,05 & 0,0 & 0,03 & 24, & 0,2 & 25, & 0,3 & 25 & 0,3 & 24, & 0,1 & 61 & 6 \\
\hline $2 \mathrm{E}$ & 0,1 & 0,04 & 0,1 & 0,04 & 0,1 & 0,04 & 0,1 & 0,02 & 25 , & 0,2 & 24, & 0,2 & 24 & 0,2 & 24, & 1 & 33 & 8 \\
\hline $3 A$ & 0,2 & 0,07 & 0,2 & 0,06 & 0,2 & 0,06 & 0,2 & 0,04 & 23, & 0,2 & 23 & 0,2 & 23 & 0,2 & 23, & 0,1 & 31 & 18 \\
\hline $3 B$ & 0,1 & 0,08 & 0,1 & 0,08 & 0,1 & 0,08 & 0,1 & 0,05 & 23 & 0,2 & 23, & 0,2 & 23 & 0,2 & 23, & 0,1 & 44 & 17 \\
\hline $3 C$ & 0,1 & 0,07 & 0,1 & 0,07 & 0,1 & 0,07 & 0,1 & 0,04 & 24, & 0,2 & 23, & 0,2 & 23, & 0,2 & 23, & 1 & 63 & 11 \\
\hline $3 D$ & 0,0 & 0,03 & 0,0 & 0,03 & 0,0 & 0,03 & 0,0 & 0,02 & 24, & 0,2 & 24, & 0,2 & 24, & 0,2 & 24, & 0,1 & 10 & 0 \\
\hline $3 \mathrm{E}$ & 0,1 & 0,04 & 0,1 & 0,03 & 0,1 & 0,03 & 0,1 & 0,02 & 24, & 0,2 & 24, & 0,2 & 24, & 0,2 & 24, & 0.1 & 25 & 10 \\
\hline \multicolumn{19}{|c|}{ UFAD modificado } \\
\hline & \multicolumn{2}{|c|}{ Dia 1} & & ia 2 & & ia 3 & & & & a 1 & & ia 2 & & ia 3 & & & & \\
\hline Posi & $\overline{v_{\alpha r} v_{n}}$ & & $\overline{v_{a r}}$ & & & $\sigma_{v_{a r}} \sigma$ & $\overline{v_{a r} v}$ & $\varepsilon_{v_{a r}} \varepsilon_{i}$ & $\overline{T_{a r} T}$ & $\sigma_{T_{g r}} \sigma$ & $\overline{T_{a r} T}$ & $\sigma_{\operatorname{Tor}} \sigma$ & $\overline{T_{a r} T}$ & $\sigma_{\operatorname{Tar}} \sigma$ & $\overline{T_{a r} T}$ & $\varepsilon_{T r y} \varepsilon$ & $T_{u} T$ & $D R D$ \\
\hline $1 \mathrm{~A}$ & 0,1 & 0,05 & 0,1 & 0,06 & 0,1 & 0,05 & 0,1 & 0,03 & 22, & 0,2 & 22 & 0,2 & 22 & 0,2 & 22 & 0,1 & 37 & 14 \\
\hline $1 \mathrm{~B}$ & 0,2 & 0,06 & 0,1 & 0,06 & 0,2 & 0,06 & 0,2 & 0,04 & 23 & 0 & 23 & 0 & 23 & 0,3 & 23, & 2 & 32 & 8 \\
\hline $1 \mathrm{C}$ & 0,1 & 0,07 & 0,1 & 0,06 & 0,1 & 0,06 & 0,1 & 0,04 & 22 & 0,2 & 22 & 0,2 & 22 & 0,2 & 22, & 0,1 & 50 & 13 \\
\hline $1 \mathrm{D}$ & 0,2 & 0,06 & 0,2 & 0,05 & 0,2 & 0,06 & 0,2 & 0,03 & 24, & 0 & 24, & 0 & 24, & 0 & 24, & 1 & 6 & 17 \\
\hline $1 \mathrm{E}$ & 0,3 & 0,09 & 0,2 & \begin{tabular}{|l|}
0,09 \\
\end{tabular} & 0,3 & 0,09 & 0,3 & 0,05 & 23, & 0 & 23, & 0 & 23 & 0,2 & 23, & 1 & 9 & 29 \\
\hline $2 \mathrm{~A}$ & 0,1 & 0,07 & 0,1 & 0,07 & 0,1 & 0,08 & 0,1 & 0,04 & 22 & 0 & 22 & 0,2 & 22 & 0,2 & 22 & 0,1 & 40 & 20 \\
\hline $2 \mathrm{~B}$ & 0,0 & 0,04 & 0,0 & 0,03 & 0,0 & 0,04 & 0,0 & 0,02 & 22, & 0,2 & 22, & 0,2 & 22 & 0,2 & 22, & 0,1 & 55 & 4 \\
\hline $2 \mathrm{C}$ & 0,5 & 0,12 & 0,5 & 0,13 & 0,5 & 0,11 & 0,5 & 0,07 & 21, & 0 & 21, & 0,2 & 21, & 0,2 & 21, & 0,1 & 21 & 60 \\
\hline $2 \mathrm{D}$ & 0,4 & 0,07 & 0,5 & 0,07 & 0,4 & 0,07 & 0,4 & 0,04 & 23, & 0 & 23, & 0,2 & 23 & 0,2 & 23, & 0,1 & 14 & 38 \\
\hline $2 \mathrm{E}$ & 0 & 0,11 & 0 & 0,11 & 0,3 & 0,13 & 0,3 & 0,07 & 22, & 0 & 22, & 0 & 22, & 0,2 & 22, & 1 & 1 & 43 \\
\hline $3 A$ & 0,6 & 0,11 & 0,6 & 0,11 & 0,6 & 0,10 & 0,6 & 0,06 & 21, & 0,2 & 21, & 0,2 & 21, & 0,2 & 21, & 0,1 & 17 & 64 \\
\hline $3 B$ & 0,2 & 0,06 & 0,2 & 0,06 & 0,2 & 0,07 & 0,2 & 0,04 & 21, & & 21, & & 21, & & 21, & 0,1 & 77 & 23 \\
\hline $3 C$ & 0,5 & 0,12 & 0 & 0,12 & 0,5 & 0,12 & 0,5 & 0,07 & 21, & 0 & 21, & 0 & 21, & $E$ & 21, & 1 & 3 & 50 \\
\hline $3 D$ & 0,1 & 0,06 & 0,1 & \begin{tabular}{|l|}
0,06 \\
\end{tabular} & 0,1 & 0,07 & 0,1 & 0,04 & 22 & 0,3 & 22, & 0,3 & 22 & 0,3 & 22, & 0,2 & 47 & 14 \\
\hline $3 \mathrm{E}$ & 0,1 & 0,07 & 0,1 & 0,06 & 0,1 & 0,06 & 0,1 & 0,04 & 22 & 0,2 & 22 & 0,2 & 22 & 0,2 & 22, & 0,1 & 39 & 15 \\
\hline & & & & & & & & & UFAD & & & & & & & & & \\
\hline & & ia 1 & & ia 2 & & ia 3 & & & & a 1 & & ia 2 & & ia 3 & & & & \\
\hline Posi & $\overline{v_{a r}}$ & $\sigma_{v_{a r}} \sigma$ & $\overline{v_{a r} v}$ & $\sigma_{v_{u r}} \sigma$ & $\overline{v_{a r} v}$ & $\sigma_{v_{g r}} \sigma$ & $\overline{v_{a r}}$ & $\varepsilon_{v_{a r}} \varepsilon$ & $\overline{T_{a r} T}$ & $\sigma_{T_{g r}} \sigma$ & $\overline{T_{a r} T}$ & $\sigma_{T_{\text {ar }}} \sigma$ & $\overline{T_{a r} T}$ & $\sigma_{T_{a r}} \sigma$ & $\overline{T_{a r} T}$ & $\varepsilon_{T_{S Y}} \varepsilon$ & $T_{u} T$ & $D R D$ \\
\hline $1 \mathrm{~A}$ & 0,1 & 0,05 & 0,1 & 0,04 & 0,1 & 0,05 & 0,1 & 0,03 & 24 & 0,2 & 24 & 0,2 & 24 & 0,2 & 24 & 0,1 & 30 & 11 \\
\hline $1 \mathrm{~B}$ & 0,2 & 0,06 & 0,2 & 0,05 & 0,2 & 0,05 & 0,2 & 0,03 & 25, & 0,3 & 25, & 0,3 & 25, & 0,3 & 25, & 0,1 & 19 & 17 \\
\hline $1 \mathrm{C}$ & 0,2 & 0,08 & 0,2 & \begin{tabular}{|l|}
0,09 \\
\end{tabular} & 0,2 & 0,08 & 0,2 & 0,05 & 25, & 0,2 & 25, & 0,2 & 25, & 0,2 & 25, & 0,1 & 39 & 18 \\
\hline $1 \mathrm{D}$ & 0,0 & 0,04 & 0,0 & 0,03 & 0,0 & 0,04 & 0,0 & 0,02 & 27 & 0 & 27 & 0,2 & 27 & 0,2 & 27, & 0,1 & 45 & 3 \\
\hline $1 \mathrm{E}$ & 0,1 & 0,05 & 0,1 & 0,05 & 0,1 & 0,04 & 0,1 & 0,03 & 27 & 0,2 & 27 & 0,2 & 27 & 0,2 & 27, & 0,1 & 36 & 6 \\
\hline $2 \mathrm{~A}$ & 0,3 & 0,07 & 0,3 & 0,08 & 0,3 & 0,07 & 0,3 & 0,04 & 24 & 0,2 & 23 & 0,2 & 23 & 0,2 & 23 & 0,1 & 21 & 28 \\
\hline $2 \mathrm{~B}$ & 0,1 & 0,06 & 0,1 & 0,06 & 0,1 & 0,06 & 0,1 & 0,03 & 25, & 0, & 25, & 0,3 & 25 & 0,2 & 25, & 0,1 & 31 & 14 \\
\hline $2 C$ & 0,4 & 0,11 & 0,4 & 0,11 & 0,4 & 0,12 & 0,4 & 0,06 & 23 & 0,2 & 23 & 0,2 & 23 & 0,2 & 23, & 0,1 & 26 & 42 \\
\hline $2 \mathrm{D}$ & 0,1 & 0,06 & 0,1 & 0,07 & 0,1 & 0,07 & 0,1 & 0,04 & 25 & 0,3 & 25, & 0,3 & 25, & 0,3 & 25 & 0,2 & 37 & 13 \\
\hline $2 \mathrm{E}$ & 0,1 & 0,05 & 0,1 & 0,06 & 0,1 & 0,06 & 0,1 & 0,03 & 26, & 0,3 & 26 & 0,2 & 26, & 0,3 & 26, & 0,1 & 44 & 8 \\
\hline $3 A$ & 0,2 & 0,06 & 0,2 & 0,06 & 0,2 & 0,06 & 0,2 & 0,03 & 23 & 0,2 & 23 & 0,2 & 23 & 0,2 & 23 & 0,1 & 21 & 21 \\
\hline $3 \mathrm{~B}$ & 0,2 & 0,06 & 0,2 & 0,06 & 0,2 & 0,06 & 0,2 & 0,03 & 23, & 0,2 & 23, & 0,2 & 23, & 0,2 & 23, & 0,1 & 20 & 22 \\
\hline $3 C$ & 0,6 & 0,14 & 0,6 & 0,13 & 0,6 & 0,14 & 0,6 & 0,08 & 23 & 0,2 & 23 & 0,2 & 23 & 0,2 & 23, & 0,1 & 21 & 65 \\
\hline $3 \mathrm{D}$ & 0,2 & 0,06 & 0,2 & 0,06 & 0,2 & 0,07 & 0,2 & 0,04 & 24, & 0,2 & 24 & 0,2 & 24 & 0,2 & 24, & 0,1 & 25 & 21 \\
\hline $3 \mathrm{E}$ & 0,3 & 0,05 & 0,3 & 0,06 & 0,3 & 0,05 & 0,3 & 0,03 & 24, & 0,2 & 24, & 0,2 & 24, & 0,2 & 24, & 0,1 & 17 & 21 \\
\hline
\end{tabular}


Tabela C-6. Resultados das velocidades e temperaturas do ar para temperatura de insuflamento de $22{ }^{\circ} \mathrm{C}$, região inferior. $(1,10 \mathrm{~m})$

\begin{tabular}{|c|c|c|c|c|c|c|c|c|c|c|c|c|c|c|c|c|c|c|}
\hline \multicolumn{19}{|c|}{ MV } \\
\hline & \multicolumn{2}{|c|}{ Dia 1} & \multicolumn{2}{|c|}{ Dia 2} & \multicolumn{2}{|c|}{ Dia 3} & & & \multicolumn{2}{|c|}{ Dia 1} & \multicolumn{2}{|c|}{ Dia 2} & \multicolumn{2}{|c|}{ Dia 3} & \multirow[b]{2}{*}{$\overline{T_{a r} T}$} & \multirow[b]{2}{*}{$\varepsilon_{T_{u r}} \varepsilon$} & \multirow[b]{2}{*}{$T_{u} T$} & \multirow[b]{2}{*}{$D R D$} \\
\hline Posi & $\overline{v_{\alpha r} v_{4}}$ & $\sigma_{v, v} \sigma$ & $\overline{v_{a r} v}$ & $\sigma_{v_{x y}} \sigma$ & $\overline{v_{a r} v_{b}}$ & $\sigma_{v_{g x}} \sigma$ & $\overline{v_{\alpha x}{ }^{2}}$ & $\varepsilon_{v, v_{p}} \varepsilon_{0}$ & $\overline{T_{a r} T}$ & $\sigma_{T y x} \sigma$ & $\overline{T_{a x} T}$ & $\sigma_{T, \sigma} \sigma$ & $\overline{T_{a x} T}$ & $\sigma_{T, p} \sigma$ & & & & \\
\hline $1 \mathrm{~A}$ & 0,3 & 0,13 & 0,3 & 0,14 & 0,3 & 0,13 & 0,3 & 0,08 & 23, & 0,2 & 23 & 0,2 & 23 & 0,2 & 23 & 0,1 & 38 & 40 \\
\hline $1 \mathrm{~B}$ & 0,5 & 0,18 & 0,5 & 0,20 & 0,5 & 0,18 & 0,5 & 0,11 & 24, & 0,2 & 24 , & 0,2 & 24 & 0,2 & 24, & 0,1 & 34 & 65 \\
\hline $1 C$ & 0,3 & 0,14 & 0,3 & 0,14 & 0,3 & 0,13 & 0,3 & 0,08 & 24, & 0,2 & 24, & 0,2 & 24, & 0,2 & 24, & 0,1 & 38 & 37 \\
\hline 1D & 0,4 & 0,08 & 0,4 & 0,08 & 0,4 & 0,08 & 0,4 & 0,05 & 25, & 0,2 & 25 & 0,2 & 25 & 0,2 & 25, & 0,1 & 19 & 30 \\
\hline $1 \mathrm{E}$ & 0,4 & 0,14 & 0,4 & 0,14 & 0,4 & 0,13 & 0,4 & 0,08 & 25 & 0,2 & 25 & 0,2 & 25, & 0,2 & 25, & 0,1 & 29 & 40 \\
\hline $2 \mathrm{~A}$ & 0,3 & 0,12 & 0,3 & 0,12 & 0,3 & 0,12 & 0,3 & 0,07 & 23, & 0,2 & 23, & 0,2 & 23 & 0,2 & 23, & 0,1 & 34 & 37 \\
\hline $2 B$ & 0,4 & 0,10 & 0,4 & 0,11 & 0,4 & 0,10 & 0,4 & 0,06 & 23, & 0,2 & 23 & 0,2 & 23 & 0,2 & 23, & 0,1 & 25 & 37 \\
\hline $2 \mathrm{C}$ & 0,4 & 0,09 & 0,4 & 0,08 & 0,4 & 0,08 & 0,4 & 0,05 & 24, & 0,2 & 24, & 0,2 & 24, & 0,2 & 24, & 0,1 & 19 & 34 \\
\hline $2 D$ & 0,0 & 0,04 & 0,3 & 0,07 & 0,3 & 0,07 & 0,2 & 0,03 & 25 & 0,3 & 25 & 0,2 & 24, & 0,2 & 25, & 0,1 & 31 & 17 \\
\hline $2 \mathrm{E}$ & 0,4 & 0,13 & 0,4 & 0,13 & 0,4 & 0,13 & 0,4 & 0,08 & 24, & 0,2 & 24, & 0,2 & 24, & 0,2 & 24 & 1 & 32 & 39 \\
\hline $3 \mathrm{~A}$ & 0,5 & 0,10 & 0,5 & 0,11 & 0,5 & 0,10 & 0,5 & 0,06 & 24, & 0,2 & 23 & 0,2 & 23 & 0,2 & 23, & 0,1 & 20 & 45 \\
\hline $3 B$ & 0,4 & 0,12 & 0,4 & 0,12 & 0,4 & 0,12 & 0,4 & 0,07 & 23 & 0,2 & 23 & 0,2 & 23 & 0,2 & 23, & 0,1 & 29 & 42 \\
\hline $3 C$ & 0,2 & 0,10 & 0,2 & 0,09 & 0,2 & 0,11 & 0,2 & 0,06 & 24, & 0,2 & 24, & 0,2 & 24, & 0,2 & 24 & 1 & 41 & 24 \\
\hline $3 \mathrm{D}$ & 0,3 & 0,07 & 0,3 & 0,07 & 0,3 & 0,07 & 0,3 & 0,04 & 23, & 0,2 & 23, & 0,2 & 23, & 0,2 & 23, & 0,1 & 19 & 30 \\
\hline $3 \mathrm{E}$ & 0,3 & 0,08 & 0,3 & 0,08 & 0,3 & 0,08 & 0,3 & 0,05 & 25, & 0,2 & 25, & 0,2 & 25, & 0,2 & 25, & 0,1 & 24 & 26 \\
\hline \multicolumn{19}{|c|}{ UFAD modificado } \\
\hline & \multicolumn{2}{|c|}{ Dia 1} & $\mathrm{Di}$ & a 2 & & ia 3 & & & & a 1 & & ia 2 & & ia 3 & & & & \\
\hline Posi & $\overline{v_{a r} v_{p}}$ & $\sigma_{v_{a r}} \sigma$ & $\overline{v_{a r}}$ & & & $\sigma_{v_{a r}} \sigma$ & $\overline{v_{\alpha r^{2}}}$ & $\varepsilon_{v_{a r}} \varepsilon_{i}$ & $\overline{T_{a r} T}$ & $\sigma_{T_{u r}} \sigma$ & $\overline{T_{a r} T}$ & $\sigma_{T a r} \sigma$ & $\overline{T_{a r} T}$ & $\sigma_{\operatorname{Tar}} \sigma$ & $\overline{T a r} T$ & $\varepsilon_{T y} \varepsilon$ & $T_{u} T$ & $D R D$ \\
\hline $1 \mathrm{~A}$ & 0,0 & 0,04 & 0,0 & 0,04 & 0,0 & 0,03 & 0,0 & 0,02 & 22 & 0,2 & 22, & 0,2 & 22 & 0,2 & 22 & 0,1 & 44 & 6 \\
\hline 1B & 0,0 & 0,04 & 0,0 & 0,05 & 0,0 & 0,04 & 0,0 & 0,03 & 22 & 0 , & 22 & 0 & 22 & 0,2 & 22 & 1 & 0 & 5 \\
\hline $1 C$ & 0,0 & 0,04 & 0,0 & 0,04 & 0,0 & 0,04 & 0,0 & 0,02 & 22 & 0,2 & 22 & 0,2 & 22 & 0,2 & 22 & 0,1 & 68 & 3 \\
\hline $1 D$ & 0,0 & 0,03 & 0,0 & 0,04 & 0,0 & 0,03 & 0,0 & 0,02 & 23, & 0,2 & 23, & 0 & 23, & 0,2 & 23, & 1 & 7 & 7 \\
\hline $1 \mathrm{E}$ & \begin{tabular}{|l|}
0,1 \\
\end{tabular} & 0,04 & 0,1 & 0,03 & 0,1 & 0,03 & 0,1 & 0,02 & 24, & 0 & 23, & 0,3 & 23, & 0,3 & 23 & 2 & 4 & 7 \\
\hline $2 \mathrm{~A}$ & 0,0 & 0,04 & 0,0 & 0,04 & 0,0 & 0,05 & 0,0 & 0,03 & 22, & 0,2 & 22 & 0,2 & 22 & 0,2 & 22, & 0,1 & 68 & 4 \\
\hline $2 B$ & 0,0 & 0,04 & 0,0 & 0,04 & 0,1 & 0,04 & 0,1 & 0,02 & 22 & 0,2 & 22 & 0,2 & 22 & 0,2 & 22 & 0,1 & 39 & 8 \\
\hline $2 \mathrm{C}$ & 0,1 & 0,06 & 0,1 & 0,06 & 0,1 & 0,06 & 0,1 & 0,03 & 22 & 0,2 & 22, & 0,2 & 22 & 0,2 & 22 & 0,1 & 60 & 10 \\
\hline $2 \mathrm{D}$ & 0,0 & 0,04 & 0,0 & 0,04 & 0,0 & 0,05 & 0,0 & 0,02 & 23, & 0,3 & 23 & 0,3 & 23 & 0,3 & 23 & 0,2 & 72 & 2 \\
\hline $2 \mathrm{E}$ & 0,1 & 0,04 & 0,1 & 0,04 & 0,1 & 0,04 & 0,1 & 0,02 & 22 & 0 , & 22, & 0 & 22, & 0,2 & 22, & 1 & 35 & 10 \\
\hline $3 \mathrm{~A}$ & 0,2 & 0,09 & 0,2 & 0,08 & 0,2 & 0,08 & 0,2 & 0,05 & 21, & 0,2 & 21, & 0,2 & 21, & 0,2 & 21, & 0,1 & 41 & 24 \\
\hline $3 B$ & 0,0 & \begin{tabular}{|l|}
0,05 \\
\end{tabular} & 0,1 & 0,06 & 0,0 & 0,05 & 0,1 & 0,03 & 21, & 0 , & 21, & 0 , & 21, & 0,2 & 21, & 0,1 & 56 & 9 \\
\hline $3 C$ & 0,1 & 0,05 & 0,1 & 0,06 & 0,1 & 0,06 & 0,1 & 0,03 & 21, & 0 , & 21, & 0 & 21, & 0,2 & 21, & 1 & 56 & 10 \\
\hline $3 D$ & 0,0 & \begin{tabular}{|l|}
0,05 \\
\end{tabular} & 0,0 & 0,04 & 0,0 & 0,05 & 0,0 & 0,03 & 22 & 0,2 & 22 & 0,2 & 22 & 0,2 & 22 & 0,1 & 62 & 6 \\
\hline $3 \mathrm{E}$ & 0,0 & 0,04 & 0,0 & 0,04 & 0,0 & 0,04 & 0,0 & 0,02 & 22, & 0,3 & 22 & 0,3 & 22 & 0,3 & 22 & 0,2 & 54 & 6 \\
\hline & & & & & & & & & UFAD & & & & & & & & & \\
\hline & & ia 1 & $\mathrm{Di}$ & a 2 & & ia 3 & & & & a 1 & & ia 2 & & ia 3 & & & & \\
\hline Posi & $\overline{v_{a r}}$ & $\sigma_{v_{\text {gr }}} \sigma$ & $\overline{v_{a r}}$ & $\sigma_{v_{a r}} \sigma$ & $\overline{v_{a r} v}$ & $\sigma_{v_{g r}} \sigma$ & $\overline{v_{a r}{ }^{2}}$ & $\varepsilon_{v_{a r}} \varepsilon_{\text {, }}$ & $\overline{T_{a r} T}$ & $\sigma_{T_{G r}} \sigma$ & $\overline{T_{a r} T}$ & $\sigma_{T_{a r}} \sigma$ & $\overline{T_{a r} T}$ & $\sigma_{T_{a r}} \sigma$ & $\overline{T_{a r} T}$ & $\varepsilon_{T_{B Y}} \varepsilon$ & $T_{u} T$ & $D R D$ \\
\hline $1 \mathrm{~A}$ & 0,0 & 0,04 & 0,0 & 0,04 & 0,0 & 0,04 & 0,0 & 0,02 & 24 & 0,3 & 24 & 0,3 & 24 & 0,3 & 24 & 0,2 & 83 & 0 \\
\hline $1 \mathrm{~B}$ & 0,0 & 0,03 & 0,0 & 0,03 & 0,0 & 0,04 & 0,0 & 0,02 & 26 & 0,2 & 26 & 0,2 & 26, & 0,2 & 26, & 0,1 & 95 & 0 \\
\hline $1 C$ & 0,0 & 0,06 & 0,0 & 0,06 & 0,0 & 0,06 & 0,0 & 0,04 & 25 & 0,2 & 25, & 0,2 & 25, & 0,2 & 25, & 0,1 & 68 & 6 \\
\hline $1 D$ & 0,0 & 0,04 & 0,0 & 0,04 & 0,0 & 0,04 & 0,0 & 0,02 & 27, & 0,2 & 27 & 0,2 & 26 & 0,2 & 27, & 0,1 & 57 & 3 \\
\hline $1 \mathrm{E}$ & 0,1 & 0,04 & 0,1 & 0,04 & 0,1 & 0,04 & 0,1 & 0,02 & 27, & 0,2 & 27 & 0,3 & 27 & 0,3 & 27, & 0,1 & 37 & 5 \\
\hline $2 \mathrm{~A}$ & 0,1 & 0,04 & 0,1 & 0,04 & 0,1 & 0,04 & 0,1 & 0,02 & 24 & 0,2 & 24 & 0,2 & 24, & 0,2 & 24, & 0,1 & 38 & 8 \\
\hline $2 \mathrm{~B}$ & 0,0 & 0,06 & 0,1 & 0,05 & 0,1 & 0,06 & 0,1 & 0,03 & 24 & 0,2 & 24 & 0,2 & 24 & 0,2 & 24 & 0,1 & 57 & 7 \\
\hline $2 C$ & 0,1 & 0,06 & 0,1 & 0,06 & 0,1 & 0,06 & 0,1 & 0,03 & 23, & 0,2 & 23 & 0,2 & 23 & 0,2 & 23 & 0,1 & 52 & 10 \\
\hline $2 \mathrm{D}$ & 0,0 & 0,05 & 0,0 & 0,05 & 0,0 & 0,05 & 0,0 & 0,03 & 24 & 0,2 & 24, & 0,3 & 24, & 0,3 & 24, & 0,1 & 57 & 6 \\
\hline $2 \mathrm{E}$ & 0,0 & 0,04 & 0,0 & 0,04 & 0,0 & 0,04 & 0,0 & 0,02 & 26, & 0,3 & 26 & 0,3 & 26 & 0,3 & 26, & 0,2 & 80 & 0 \\
\hline $3 A$ & 0,1 & 0,05 & 0,1 & 0,05 & 0,1 & 0,05 & 0,1 & 0,03 & 24, & 0,2 & 23 & 0,2 & 23 & 0,2 & 23, & 0,1 & 42 & 9 \\
\hline $3 B$ & 0,1 & 0,06 & 0,1 & 0,06 & 0,1 & 0,06 & 0,1 & 0,03 & 23, & 0,2 & 23, & 0,2 & 23, & 0,2 & 23, & 0,1 & 36 & 13 \\
\hline $3 C$ & 0,1 & 0,08 & 0,1 & 0,07 & 0,1 & 0,07 & 0,1 & 0,04 & 23, & 0,2 & 23 & 0,2 & 23 & 0,2 & 23 & 0,1 & 46 & 16 \\
\hline $3 \mathrm{D}$ & 0,1 & 0,06 & 0,1 & 0,06 & 0,1 & 0,06 & 0,1 & 0,03 & 23, & 0,2 & 23, & 0,2 & 23 & 0,2 & 23, & 0,1 & 51 & 10 \\
\hline $3 \mathrm{E}$ & 0,1 & 0,04 & 0,1 & 0,04 & 0,1 & 0,04 & 0,1 & 0,03 & 24, & 0,2 & 24, & 0,2 & 24, & 0,2 & 24, & 0,1 & 34 & 10 \\
\hline
\end{tabular}




\section{ANEXO D}

Resultados das medições e respectivas incertezas da concentração de partículas

Os resultados da concentração de partículas, juntamente com as incertezas de medição, são apresentados nas Tabelas D.1 a D.12.

Os valores das concentrações de partículas são a média dos valores dos resultados dos três ensaios (ensaios em triplicata) em cada posição e em cada condição estudada.

A exemplo do Apêndice $C$, as incertezas das medições são o resultado da combinação das incertezas do equipamento de medição (contador de partículas) e dos desvios padrão em cada posição e em cada condição de ensaio dos ensaios em triplicata (COLEMAN e STEELE, 1989; VUOLO, 1996; INMETRO, 1998).

A incerteza do equipamento de medição (contador de partículas) na contagem de partículas segue a estatística de Poisson (Kulkarni et al., 2011), com esta incerteza sendo estimada pela raiz quadrada do número de partículas contadas em cada medição. 
Tabela D-1. Resultados das medições de partículas no assento (Sistema MV à $18^{\circ} \mathrm{C}$ - injeção pelo assento $3 \mathrm{D}$ )

\begin{tabular}{|c|c|c|c|c|c|c|c|c|}
\hline & & Unidade & $1,0-2,0 \mu \mathrm{m}$ & $2,0-3,0 \mu \mathrm{m}$ & $3,0-5,0 \mu \mathrm{m}$ & $5,0-7,0 \mu \mathrm{m}$ & $|7,0-10,0 \mu \mathrm{m}|$ & $>10,0 \mu \mathrm{m}$ \\
\hline \multirow{8}{*}{ Assento 3E } & $\begin{array}{c}\text { Concentração média de } \\
\text { fundo }\end{array}$ & $\mathrm{P} / \mathrm{m}^{3}$ & $8,00 E+04$ & $3,67 \mathrm{E}+04$ & $6,67 E+03$ & $0,00 \mathrm{E}+00$ & $0,00 E+00$ & $0,00 \mathrm{E}+00$ \\
\hline & $\begin{array}{c}\text { Número de particulas de } \\
\text { fundo }\end{array}$ & $\mathbf{p}$ & 24 & 11 & 2 & 0 & 0 & 0 \\
\hline & $\begin{array}{l}\text { Concentração média } \\
\text { liquida }\end{array}$ & $\mathrm{P} / \mathrm{m}^{3}$ & $2,65 \mathrm{E}+08$ & $1,86 \mathrm{E}+08$ & $1,22 \mathrm{E}+08$ & $9,33 \mathrm{E}+07$ & $2,98 \mathrm{E}+07$ & $1,20 \mathrm{E}+06$ \\
\hline & $\begin{array}{c}\text { Número de Particulas } \\
\text { média liquida }\end{array}$ & $\mathbf{p}$ & 79511 & 55685 & 36542 & 28000 & 8942 & 361 \\
\hline & Desvio - Poisson & $\#$ & 281,98 & 235,98 & 191,16 & 167,33 & 94,56 & 19,00 \\
\hline & $\begin{array}{l}\text { Desvio - Poisson - } \\
\text { Relativo }\end{array}$ & $\%$ & 0,4 & 0,4 & 0,5 & 0,6 & 1,1 & 5,3 \\
\hline & $\begin{array}{c}\text { Desvio padrão } \\
\text { Concentração } \\
\end{array}$ & $\mathrm{P} / \mathrm{m}^{3}$ & $2,51 E+04$ & $1,68 \mathrm{E}+04$ & $1,25 \mathrm{E}+04$ & $1,03 E+04$ & $3,89 \mathrm{E}+02$ & $1,53 E+02$ \\
\hline & DP/Concentração média & $\%$ & 0,0095 & 0,0091 & 0,0103 & 0,0111 & 0,0013 & 0,0127 \\
\hline \multirow{2}{*}{\multicolumn{2}{|c|}{ Erro total medições(E) }} & $\mathrm{P} / \mathrm{m}^{3}$ & $9,40 E+05$ & $7,87 E+05$ & $6,37 E+05$ & $5,58 \mathrm{E}+05$ & $3,15 E+05$ & $6,33 E+04$ \\
\hline & & Unidade & $1,0-2,0 \mu \mathrm{m}$ & $2,0-3,0 \mu \mathrm{m}$ & $3,0-5,0 \mu \mathrm{m}$ & $5,0-7,0 \mu \mathrm{m}$ & $7,0-10,0 \mu \mathrm{m}$ & $>10,0 \mu \mathrm{m}$ \\
\hline \multirow{8}{*}{ Assento 2D } & $\begin{array}{c}\text { Concentração média de } \\
\text { fundo }\end{array}$ & $\mathrm{P} / \mathrm{m}^{3}$ & $1,63 E+05$ & $4,33 E+04$ & $3,33 E+03$ & $1,67 \mathrm{E}+03$ & $0,00 E+00$ & $0,00 E+00$ \\
\hline & $\begin{array}{c}\begin{array}{c}\text { Número de particulas de } \\
\text { fundo }\end{array} \\
\end{array}$ & $\mathbf{P}$ & 49 & 13 & 1 & 0,5 & 0 & 0 \\
\hline & $\begin{array}{c}\text { Concentração média } \\
\text { liquida }\end{array}$ & $\mathrm{P} / \mathrm{m}^{3}$ & $1,23 E+08$ & $9,70 E+07$ & $8,61 E+07$ & $4,55 E+07$ & $8,17 E+06$ & $5,13 E+05$ \\
\hline & $\begin{array}{c}\text { Número de Particulas } \\
\text { média liquida }\end{array}$ & $\mathbf{p}$ & 36984 & 29100 & 25818 & 13650 & 2452 & 154 \\
\hline & Desvio - Poisson & $\#$ & 192,31 & 170,59 & 160,68 & 116,83 & 49,51 & 12,41 \\
\hline & $\begin{array}{l}\text { Desvio - Poisson - } \\
\text { Relativo }\end{array}$ & $\%$ & 0,5 & 0,6 & 0,6 & 0,9 & 2,0 & 8,1 \\
\hline & $\begin{array}{l}\text { Desvio padrão } \\
\text { Concentração }\end{array}$ & $\mathrm{P} / \mathrm{m}^{3}$ & $1,75 \mathrm{E}+03$ & $3,67 E+03$ & $4,73 E+03$ & $2,00 E+03$ & $4,90 E+02$ & $1,10 E+02$ \\
\hline & DP/Concentração média & $\%$ & 0,0014 & 0,0038 & 0,0055 & 0,0044 & 0,0060 & 0,0215 \\
\hline \multirow{2}{*}{\multicolumn{2}{|c|}{ Erro total medições( $(\varepsilon)$}} & $\mathrm{P} / \mathrm{m}^{3}$ & $6,41 E+05$ & $5,69 \mathrm{E}+05$ & $5,36 E+05$ & $3,89 \mathrm{E}+05$ & $1,65 E+05$ & $4,14 E+04$ \\
\hline & & Unidade & $1,0-2,0 \mu \mathrm{m}$ & $2,0-3,0 \mu \mathrm{m}$ & $3,0-5,0 \mu \mathrm{m}$ & $5,0-7,0 \mu \mathrm{m}$ & $7,0-10,0 \mu \mathrm{m}$ & $>10,0 \mu \mathrm{m}$ \\
\hline \multirow{8}{*}{ Assento 2E } & \begin{tabular}{|c|}
$\begin{array}{c}\text { Concentração média de } \\
\text { fundo }\end{array}$ \\
\end{tabular} & $\mathrm{P} / \mathrm{m}^{3}$ & $1,03 E+05$ & $3,00 E+04$ & $6,67 \mathrm{E}+03$ & $0,00 E+00$ & $0,00 E+00$ & $0,00 E+00$ \\
\hline & $\begin{array}{c}\begin{array}{c}\text { Número de particulas de } \\
\text { fundo }\end{array} \\
\end{array}$ & $\mathbf{p}$ & 31 & 9 & 2 & 0 & 0 & 0 \\
\hline & $\begin{array}{c}\text { Concentração média } \\
\text { liquida }\end{array}$ & $\mathrm{P} / \mathrm{m}^{3}$ & $9,72 E+07$ & $8,50 E+07$ & $6,85 E+07$ & $3,28 \mathrm{E}+07$ & $5,77 \mathrm{E}+06$ & $3,43 E+05$ \\
\hline & $\begin{array}{l}\text { Número de Particulas } \\
\text { média liquida }\end{array}$ & $\mathbf{P}$ & 29147 & 25515 & 20539 & 9848 & 1732 & 103 \\
\hline & Desvio - Poisson & $\#$ & 170,72 & 159,73 & 143,31 & 99,23 & 41,61 & 10,15 \\
\hline & $\begin{array}{c}\text { Desvio - Poisson - } \\
\text { Relativo } \\
\end{array}$ & $\%$ & 0,6 & 0,6 & 0,7 & 1,0 & 2,4 & 9,9 \\
\hline & $\begin{array}{c}\text { Desvio padrão } \\
\text { Concentração } \\
\end{array}$ & $\mathrm{P} / \mathrm{m}^{3}$ & $1,86 \mathrm{E}+03$ & $2,79 E+03$ & $1,19 E+03$ & $6,20 E+02$ & $1,20 E+02$ & 1,87E+01 \\
\hline & DP/Concentração média & $\%$ & 0,0019 & 0,0033 & 0,0017 & 0,0019 & 0,0021 & 0,0054 \\
\hline \multicolumn{2}{|c|}{ Erro total medições(E) } & $\mathrm{P} / \mathrm{m}^{3}$ & $5,69 \mathrm{E}+05$ & $5,32 E+05$ & $4,78 E+05$ & $3,31 \mathrm{E}+05$ & $1,39 \mathrm{E}+05$ & $3,38 \mathrm{E}+04$ \\
\hline
\end{tabular}




\begin{tabular}{|c|c|c|c|c|c|c|c|c|}
\hline & & |Unidade & $1,0-2,0 \mu \mathrm{m}$ & $2,0-3,0 \mu \mathrm{m}$ & $3,0-5,0 \mu \mathrm{m}$ & $5,0-7,0 \mu \mathrm{m}$ & $|7,0-10,0 \mu \mathrm{m}|$ & $>10,0 \mu \mathrm{m}$ \\
\hline \multirow{8}{*}{ Assento 1D } & $\begin{array}{c}\text { Concentração média de } \\
\text { fundo }\end{array}$ & $\mathrm{P} / \mathrm{m}^{3}$ & $1,87 E+05$ & $8,33 E+04$ & $1,33 E+04$ & $3,33 E+03$ & $0,00 E+00$ & $0,00 E+00$ \\
\hline & $\begin{array}{c}\text { Número de particulas de } \\
\text { fundo }\end{array}$ & $\mathbf{P}$ & 56 & 25 & 4 & 1 & 0 & 0 \\
\hline & $\begin{array}{c}\text { Concentração média } \\
\text { liquida }\end{array}$ & $\mathrm{P} / \mathrm{m}^{3}$ & $1,10 E+08$ & $1,08 E+08$ & $7,71 E+07$ & $3,77 E+07$ & $6,69 E+06$ & $4,18 \mathrm{E}+05$ \\
\hline & $\begin{array}{c}\text { Número de Particulas } \\
\text { média liquida }\end{array}$ & $\mathbf{P}$ & 33036 & 32349 & 23125 & 11300 & 2006 & 126 \\
\hline & Desvio - Poisson & $\#$ & 181,76 & 179,86 & 152,07 & 106,30 & 44,79 & 11,20 \\
\hline & $\begin{array}{c}\text { Desvio - Poisson - } \\
\text { Relativo } \\
\end{array}$ & $\%$ & 0,6 & 0,6 & 0,7 & 0,9 & 2,2 & 8,9 \\
\hline & $\begin{array}{l}\text { Desvio padrão } \\
\text { Concentração }\end{array}$ & $\mathrm{P} / \mathrm{m}^{3}$ & $3,55 \mathrm{E}+03$ & $3,44 \mathrm{E}+03$ & $2,18 \mathrm{E}+03$ & $1,13 \mathrm{E}+03$ & $1,88 \mathrm{E}+02$ & $1,66 \mathrm{E}+01$ \\
\hline & DP/Concentração média & $\%$ & 0,0032 & 0,0032 & 0,0028 & 0,0030 & 0,0028 & 0,0040 \\
\hline \multirow{2}{*}{\multicolumn{2}{|c|}{ Erro total medições(દ) }} & $\mathrm{P} / \mathrm{m}^{3}$ & $6,06 \mathrm{E}+05$ & $6,00 E+05$ & $5,07 E+05$ & $3,54 E+05$ & $1,49 E+05$ & $3,73 E+04$ \\
\hline & & Unidade & $1,0-2,0 \mu \mathrm{m}$ & $2,0-3,0 \mu \mathrm{m}$ & $3,0-5,0 \mu \mathrm{m}$ & $5,0-7,0 \mu \mathrm{m}$ & $7,0-10,0 \mu \mathrm{m}$ & $>10,0 \mu \mathrm{m}$ \\
\hline \multirow{8}{*}{ Assento 1E } & \begin{tabular}{|c|}
$\begin{array}{c}\text { Concentração média de } \\
\text { fundo }\end{array}$ \\
\end{tabular} & $\mathrm{P} / \mathrm{m}^{3}$ & $1,43 E+05$ & $7,67 E+04$ & $6,67 E+03$ & $0,00 E+00$ & $0,00 E+00$ & $0,00 E+00$ \\
\hline & \begin{tabular}{|c|} 
Número de particulas de \\
fundo
\end{tabular} & $\mathbf{P}$ & 43 & 23 & 2 & 0 & 0 & 0 \\
\hline & $\begin{array}{c}\text { Concentração média } \\
\text { liquida }\end{array}$ & $\mathrm{P} / \mathrm{m}^{3}$ & $1,16 \mathrm{E}+08$ & $1,04 \mathrm{E}+08$ & $7,85 \mathrm{E}+07$ & $3,85 \mathrm{E}+07$ & $1,17 \mathrm{E}+07$ & $3,10 E+05$ \\
\hline & $\begin{array}{c}\text { Número de Particulas } \\
\text { média liquida }\end{array}$ & $\mathbf{P}$ & 34653 & 31276 & 23560 & 11540 & 3500 & 93 \\
\hline & Desvio - Poisson & $\#$ & 186,15 & 176,85 & 153,49 & 107,42 & 59,16 & 9,64 \\
\hline & $\begin{array}{c}\text { Desvio - Poisson - } \\
\text { Relativo } \\
\end{array}$ & $\%$ & 0,5 & 0,6 & 0,7 & 0,9 & 1,7 & 10,4 \\
\hline & $\begin{array}{l}\text { Desvio padrão } \\
\text { Concentração }\end{array}$ & $\mathrm{P} / \mathrm{m}^{3}$ & $5,49 E+03$ & $4,70 E+03$ & $3,14 \mathrm{E}+03$ & $2,40 E+03$ & $1,18 \mathrm{E}+03$ & $9,84 E+00$ \\
\hline & DP/Concentração média & $\%$ & 0,0048 & 0,0045 & 0,0040 & 0,0063 & 0,0101 & 0,0032 \\
\hline \multirow{2}{*}{\multicolumn{2}{|c|}{ Erro total medições( $(\varepsilon)$}} & $\mathrm{P} / \mathrm{m}^{3}$ & $6,21 \mathrm{E}+05$ & $5,90 E+05$ & $5,12 E+05$ & $3,58 \mathrm{E}+05$ & $1,97 \mathrm{E}+05$ & $3,21 \mathrm{E}+04$ \\
\hline & & Unidade & $1,0-2,0 \mu \mathrm{m}$ & $2,0-3,0 \mu \mathrm{m}$ & $3,0-5,0 \mu \mathrm{m}$ & $5,0-7,0 \mu \mathrm{m}$ & $7,0-10,0 \mu \mathrm{m}$ & $>10,0 \mu \mathrm{m}$ \\
\hline \multirow{8}{*}{ Assento 1B } & \begin{tabular}{|c|}
$\begin{array}{c}\text { Concentração média de } \\
\text { fundo }\end{array}$ \\
\end{tabular} & $\mathrm{P} / \mathrm{m}^{3}$ & $1,93 \mathrm{E}+05$ & $1,13 \mathrm{E}+05$ & $1,33 E+04$ & $0,00 \mathrm{E}+00$ & $0,00 E+00$ & $0,00 E+00$ \\
\hline & $\begin{array}{c}\begin{array}{c}\text { Número de particulas de } \\
\text { fundo }\end{array} \\
\end{array}$ & $\mathbf{P}$ & 58 & 34 & 4 & 0 & 0 & 0 \\
\hline & $\begin{array}{c}\text { Concentração média } \\
\text { liquida }\end{array}$ & $\mathrm{P} / \mathrm{m}^{3}$ & $8,46 E+07$ & $8,31 E+07$ & $6,19 E+07$ & $2,91 \mathrm{E}+07$ & $5,36 \mathrm{E}+06$ & $3,73 E+05$ \\
\hline & $\begin{array}{c}\text { Número de Particulas } \\
\text { média liquida }\end{array}$ & $\mathbf{P}$ & 25391 & 24939 & 18578 & 8737 & 1608 & 112 \\
\hline & Desvio - Poisson & $\#$ & 159,35 & 157,92 & 136,30 & 93,47 & 40,10 & 10,58 \\
\hline & $\begin{array}{c}\text { Desvio - Poisson - } \\
\text { Relativo } \\
\end{array}$ & $\%$ & 0,6 & 0,6 & 0,7 & 1,1 & 2,5 & 9,4 \\
\hline & $\begin{array}{l}\text { Desvio padrão } \\
\text { Concentração }\end{array}$ & $\mathrm{P} / \mathrm{m}^{3}$ & $4,92 E+03$ & $4,76 \mathrm{E}+03$ & $3,00 E+03$ & $1,35 \mathrm{E}+03$ & $1,84 \mathrm{E}+02$ & $2,88 \mathrm{E}+01$ \\
\hline & DP/Concentração média & $\%$ & 0,0058 & 0,0057 & 0,0048 & 0,0046 & 0,0034 & 0,0077 \\
\hline \multicolumn{2}{|c|}{ Erro total medições $(\varepsilon)$} & $\mathrm{P} / \mathrm{m}^{3}$ & $5,31 E+05$ & $5,26 \mathrm{E}+05$ & $4,54 E+05$ & $3,12 E+05$ & $1,34 \mathrm{E}+05$ & $3,53 \mathrm{E}+04$ \\
\hline
\end{tabular}


Unidade $1,0-2,0 \mu \mathrm{m}|2,0-3,0 \mu \mathrm{m}| 3,0-5,0 \mu \mathrm{m}|5,0-7,0 \mu \mathrm{m}| 7,0-10,0 \mu \mathrm{m} \mid>10,0 \mu \mathrm{m}$

\begin{tabular}{|c|c|c|c|c|c|c|c|c|}
\hline \multirow{8}{*}{ Assento $1 \mathrm{~A}$} & $\begin{array}{c}\text { Concentração média de } \\
\text { fundo }\end{array}$ & $\mathrm{P} / \mathrm{m}^{3}$ & $3,00 E+05$ & $1,13 \mathrm{E}+05$ & $1,00 E+04$ & $0,00 \mathrm{E}+00$ & $0,00 E+00$ & $0,00 \mathrm{E}+00$ \\
\hline & $\begin{array}{c}\begin{array}{c}\text { Número de particulas de } \\
\text { fundo }\end{array} \\
\end{array}$ & $\mathbf{P}$ & 90 & 34 & 3 & 0 & 0 & 0 \\
\hline & $\begin{array}{c}\text { Concentração média } \\
\text { liquida }\end{array}$ & $\mathrm{P} / \mathrm{m}^{3}$ & $7,52 \mathrm{E}+07$ & $7,39 \mathrm{E}+07$ & $5,48 \mathrm{E}+07$ & $2,56 \mathrm{E}+07$ & $4,79 E+06$ & $3,37 \mathrm{E}+05$ \\
\hline & $\begin{array}{c}\text { Número de Particulas } \\
\text { média liquida }\end{array}$ & $\mathbf{p}$ & 22554 & 22169 & 16433 & 7668 & 1436 & 101 \\
\hline & Desvio - Poisson & $\#$ & 150,18 & 148,89 & 128,19 & 87,57 & 37,89 & 10,05 \\
\hline & $\begin{array}{c}\text { Desvio - Poisson - } \\
\text { Relativo }\end{array}$ & $\%$ & 0,7 & 0,7 & 0,8 & 1,1 & 2,6 & 10,0 \\
\hline & $\begin{array}{l}\text { Desvio padrão } \\
\text { Concentração } \\
\end{array}$ & $\mathrm{P} / \mathrm{m}^{3}$ & $1,81 \mathrm{E}+04$ & $1,74 \mathrm{E}+04$ & $1,12 \mathrm{E}+04$ & $6,25 E+03$ & $1,09 \mathrm{E}+03$ & $5,17 E+01$ \\
\hline & DP/Concentração média & $\%$ & 0,0241 & 0,0236 & 0,0205 & 0,0245 & 0,0227 & 0,0154 \\
\hline \multirow{2}{*}{\multicolumn{2}{|c|}{ Erro total medições( $\varepsilon)$}} & $\mathrm{P} / \mathrm{m}^{3}$ & $5,01 \mathrm{E}+05$ & 4,97E+05 & 4,27E+05 & $2,92 \mathrm{E}+05$ & $1,26 \mathrm{E}+05$ & $3,35 E+04$ \\
\hline & & Unidade & $1,0-2,0 \mu \mathrm{m}$ & $2,0-3,0 \mu \mathrm{m}$ & $3,0-5,0 \mu \mathrm{m}$ & $5,0-7,0 \mu \mathrm{m}$ & $7,0-10,0 \mu \mathrm{m}$ & $>10,0 \mu \mathrm{m}$ \\
\hline \multirow{8}{*}{ Assento 2B } & \begin{tabular}{|c|}
$\begin{array}{c}\text { Concentração média de } \\
\text { fundo }\end{array}$ \\
\end{tabular} & $\mathrm{P} / \mathrm{m}^{3}$ & $3,37 E+05$ & $1,83 E+05$ & $1,33 E+04$ & $3,33 E+03$ & $0,00 E+00$ & $0,00 E+00$ \\
\hline & $\begin{array}{c}\text { Número de particulas de } \\
\text { fundo }\end{array}$ & $\mathbf{p}$ & 101 & 55 & 4 & 1 & 0 & 0 \\
\hline & $\begin{array}{c}\text { Concentração média } \\
\text { liquida }\end{array}$ & $\mathrm{P} / \mathrm{m}^{3}$ & $1,49 E+08$ & $1,46 E+08$ & $1,03 E+08$ & $6,00 E+07$ & $1,06 \mathrm{E}+07$ & $6,00 E+05$ \\
\hline & $\begin{array}{c}\text { Número de Particulas } \\
\text { média liquida }\end{array}$ & $\mathbf{P}$ & 44681 & 43661 & 31013 & 17988 & 3177 & 180 \\
\hline & Desvio - Poisson & $\#$ & 211,38 & 208,95 & 176,11 & 134,12 & 56,36 & 13,42 \\
\hline & $\begin{array}{c}\text { Desvio - Poisson - } \\
\text { Relativo } \\
\end{array}$ & $\%$ & 0,5 & 0,5 & 0,6 & 0,7 & 1,8 & 7,5 \\
\hline & $\begin{array}{l}\text { Desvio padrão } \\
\text { Concentração }\end{array}$ & $\mathrm{P} / \mathrm{m}^{3}$ & $9,46 E+03$ & $9,04 E+03$ & $5,49 E+03$ & $2,96 \mathrm{E}+03$ & $7,22 \mathrm{E}+02$ & $4,41 E+01$ \\
\hline & DP/Concentração média & $\%$ & 0,0063 & 0,0062 & 0,0053 & 0,0049 & 0,0068 & 0,0073 \\
\hline \multirow{2}{*}{\multicolumn{2}{|c|}{ Erro total medições $(\varepsilon)$}} & $\mathrm{P} / \mathrm{m}^{3}$ & $7,05 \mathrm{E}+05$ & $6,97 E+05$ & $5,87 E+05$ & $4,47 E+05$ & $1,88 \mathrm{E}+05$ & $4,47 \mathrm{E}+04$ \\
\hline & & Unidade & $1,0-2,0 \mu \mathrm{m}$ & $2,0-3,0 \mu \mathrm{m}$ & $3,0-5,0 \mu \mathrm{m}$ & $5,0-7,0 \mu \mathrm{m}$ & $7,0-10,0 \mu \mathrm{m}$ & $>10,0 \mu \mathrm{m}$ \\
\hline \multirow{8}{*}{ Assento $2 \mathrm{~A}$} & \begin{tabular}{|c|}
$\begin{array}{c}\text { Concentração média de } \\
\text { fundo }\end{array}$ \\
\end{tabular} & $\mathrm{P} / \mathrm{m}^{3}$ & $2,60 E+05$ & $1,47 E+05$ & $2,00 E+04$ & $0,00 E+00$ & $0,00 \mathrm{E}+00$ & $0,00 E+00$ \\
\hline & $\begin{array}{c}\text { Número de particulas de } \\
\text { fundo }\end{array}$ & $\mathbf{P}$ & 78 & 44 & 6 & 0 & 0 & 0 \\
\hline & $\begin{array}{c}\text { Concentração média } \\
\text { liquida }\end{array}$ & $\mathrm{P} / \mathrm{m}^{3}$ & $1,31 \mathrm{E}+08$ & $1,28 \mathrm{E}+08$ & $7,18 \mathrm{E}+07$ & $4,00 E+07$ & $9,71 E+06$ & $5,77 \mathrm{E}+05$ \\
\hline & $\begin{array}{c}\text { Número de Particulas } \\
\text { média liquida }\end{array}$ & $\mathbf{P}$ & 39445 & 38490 & 21550 & 12000 & 2912 & 173 \\
\hline & Desvio - Poisson & $\#$ & 198,61 & 196,19 & 146,80 & 109,54 & 53,96 & 13,15 \\
\hline & $\begin{array}{c}\text { Desvio - Poisson - } \\
\text { Relativo } \\
\end{array}$ & $\%$ & 0,5 & 0,5 & 0,7 & 0,9 & 1,9 & 7,6 \\
\hline & $\begin{array}{l}\text { Desvio padrão } \\
\text { Concentração }\end{array}$ & $\mathrm{P} / \mathrm{m}^{3}$ & $5,02 E+04$ & $4,68 \mathrm{E}+04$ & $3,45 \mathrm{E}+03$ & $1,18 \mathrm{E}+03$ & $6,20 E+03$ & $2,03 E+02$ \\
\hline & DP/Concentração média & $\%$ & 0,0382 & 0,0365 & 0,0048 & 0,0029 & 0,0639 & 0,0352 \\
\hline \multicolumn{2}{|c|}{ Erro total medições(E) } & $\mathrm{P} / \mathrm{m}^{3}$ & $6,64 \mathrm{E}+05$ & $6,56 \mathrm{E}+05$ & $4,89 \mathrm{E}+05$ & $3,65 E+05$ & $1,80 E+05$ & $4,38 \mathrm{E}+0$ \\
\hline
\end{tabular}




\begin{tabular}{|c|c|c|c|c|c|c|c|c|}
\hline & & Unidade & $1,0-2,0 \mu \mathrm{m}$ & $2,0-3,0 \mu \mathrm{m}$ & $3,0-5,0 \mu \mathrm{m}$ & $5,0-7,0 \mu \mathrm{m}$ & $7,0-10,0 \mu \mathrm{m}$ & $>10,0 \mu \mathrm{m}$ \\
\hline \multirow{8}{*}{ Assento 3B } & \begin{tabular}{|c|}
$\begin{array}{c}\text { Concentração média de } \\
\text { fundo }\end{array}$ \\
\end{tabular} & $\mathrm{P} / \mathrm{m}^{3}$ & $1,13 E+05$ & $9,33 E+04$ & $1,00 E+04$ & $0,00 E+00$ & $0,00 E+00$ & $0,00 E+00$ \\
\hline & $\begin{array}{c}\text { Número de particulas de } \\
\text { fundo }\end{array}$ & $\mathbf{P}$ & 34 & 28 & 3 & 0 & 0 & 0 \\
\hline & $\begin{array}{c}\text { Concentração média } \\
\text { liquida }\end{array}$ & $\mathrm{P} / \mathrm{m}^{3}$ & $3,17 E+08$ & $3,02 E+08$ & $1,08 \mathrm{E}+08$ & $5,33 \mathrm{E}+07$ & $3,33 \mathrm{E}+07$ & 4,07E+06 \\
\hline & $\begin{array}{c}\text { Número de Particulas } \\
\text { média liquida }\end{array}$ & $\mathbf{P}$ & 95195 & 90505 & 32520 & 16000 & 10000 & 1222 \\
\hline & Desvio-Poisson & $\#$ & 308,54 & 300,84 & 180,33 & 126,49 & 100,00 & 34,96 \\
\hline & $\begin{array}{l}\text { Desvio - Poisson - } \\
\text { Relativo } \\
\end{array}$ & $\%$ & 0,3 & 0,3 & 0,6 & 0,8 & 1,0 & 2,9 \\
\hline & $\begin{array}{l}\text { Desvio padrão } \\
\text { Concentração }\end{array}$ & $\mathrm{P} / \mathrm{m}^{3}$ & $4,08 E+04$ & $3,83 E+04$ & $1,97 E+03$ & $2,19 E+03$ & $3,10 E+03$ & $6,17 E+02$ \\
\hline & DP/Concentração média & $\%$ & 0,0129 & 0,0127 & 0,0018 & 0,0041 & 0,0093 & 0,0151 \\
\hline \multirow{2}{*}{\multicolumn{2}{|c|}{ Erro total medições(દ) }} & $\mathrm{P} / \mathrm{m}^{3}$ & $1,03 \mathrm{E}+06$ & $1,00 E+06$ & $6,01 \mathrm{E}+05$ & $4,22 E+05$ & $3,33 \mathrm{E}+05$ & $1,17 \mathrm{E}+05$ \\
\hline & & Unidade & $1,0-2,0 \mu \mathrm{m}$ & $2,0-3,0 \mu \mathrm{m}$ & $3,0-5,0 \mu \mathrm{m}$ & $5,0-7,0 \mu \mathrm{m}$ & $7,0-10,0 \mu \mathrm{m}$ & $>10,0 \mu \mathrm{m}$ \\
\hline \multirow{8}{*}{ Assento $3 \mathrm{~A}$} & \begin{tabular}{|c|}
$\begin{array}{c}\text { Concentração média de } \\
\text { fundo }\end{array}$ \\
\end{tabular} & $\mathrm{P} / \mathrm{m}^{3}$ & $1,63 E+05$ & $8,33 E+04$ & $1,00 E+04$ & $0,00 E+00$ & $0,00 E+00$ & $0,00 E+00$ \\
\hline & $\begin{array}{c}\begin{array}{c}\text { Número de particulas de } \\
\text { fundo }\end{array} \\
\end{array}$ & $\mathbf{P}$ & 49 & 25 & 3 & 0 & 0 & 0 \\
\hline & $\begin{array}{c}\text { Concentração média } \\
\text { liquida }\end{array}$ & $\mathrm{P} / \mathrm{m}^{3}$ & $3,47 E+08$ & $3,33 E+08$ & $8,33 E+07$ & $4,75 E+07$ & $3,75 E+07$ & $1,41 E+06$ \\
\hline & $\begin{array}{c}\text { Número de Particulas } \\
\text { média liquida }\end{array}$ & $\mathbf{P}$ & 104057 & 99882 & 25000 & 14250 & 11264 & 423 \\
\hline & Desvio - Poisson & $\#$ & 322,58 & 316,04 & 158,11 & 119,37 & 106,13 & 20,57 \\
\hline & $\begin{array}{c}\text { Desvio - Poisson - } \\
\text { Relativo } \\
\end{array}$ & $\%$ & 0,3 & 0,3 & 0,6 & 0,8 & 0,9 & 4,9 \\
\hline & $\begin{array}{c}\text { Desvio padrão } \\
\text { Concentração }\end{array}$ & $\mathrm{P} / \mathrm{m}^{3}$ & $2,93 E+04$ & $2,76 \mathrm{E}+04$ & $4,94 \mathrm{E}+03$ & $1,37 \mathrm{E}+04$ & $2,08 \mathrm{E}+03$ & $2,80 \mathrm{E}+02$ \\
\hline & DP/Concentração média & $\%$ & 0,0084 & 0,0083 & 0,0059 & 0,0288 & 0,0055 & 0,0199 \\
\hline \multicolumn{2}{|c|}{ Erro total medições( $(\varepsilon)$} & $\mathrm{P} / \mathrm{m}^{3}$ & $1,08 \mathrm{E}+06$ & $1,05 E+06$ & $5,27 E+05$ & $3,98 \mathrm{E}+05$ & $3,54 \mathrm{E}+05$ & $6,86 E+04$ \\
\hline
\end{tabular}


Tabela D-2. Resultados das medições de partículas no assento (Sistema UFAD à $18^{\circ} \mathrm{C}$ - injeção pelo assento $3 \mathrm{D}$ )

\begin{tabular}{|c|c|c|c|c|c|c|c|c|}
\hline & & Unidade & $1,0-2,0 \mu \mathrm{m}$ & $2,0-3,0 \mu \mathrm{m}$ & $3,0-5,0 \mu \mathrm{m}$ & $5,0-7,0 \mu \mathrm{m}$ & $7,0-10,0 \mu \mathrm{m}$ & $>10,0 \mu \mathrm{m}$ \\
\hline \multirow{8}{*}{ Assento 3E } & $\begin{array}{l}\text { Concentração média de } \\
\text { fundo }\end{array}$ & $\mathrm{P} / \mathrm{m}^{3}$ & $8,00 E+04$ & $4,00 E+04$ & $3,33 \mathrm{E}+03$ & $0,00 E+00$ & $0,00 \mathrm{E}+00$ & $0,00 E+00$ \\
\hline & $\begin{array}{l}\text { Número de particulas de } \\
\text { fundo }\end{array}$ & $\mathbf{P}$ & 24 & 12 & 1 & 0 & 0 & 0 \\
\hline & $\begin{array}{l}\text { Concentração média } \\
\text { liquida }\end{array}$ & $\mathrm{P} / \mathrm{m}^{3}$ & $1,04 \mathrm{E}+08$ & $8,87 E+07$ & $7,61 \mathrm{E}+07$ & $5,57 E+07$ & $1,68 \mathrm{E}+07$ & $2,02 E+06$ \\
\hline & $\begin{array}{l}\text { Número de Particulas } \\
\text { média liquida }\end{array}$ & $\mathbf{P}$ & 31257 & 26619 & 22833 & 16719 & 5033 & 607 \\
\hline & Desvio - Poisson & $\#$ & 176,80 & 163,15 & 151,11 & 129,30 & 70,94 & 24,64 \\
\hline & $\begin{array}{l}\text { Desvio - Poisson - } \\
\text { Relativo }\end{array}$ & $\%$ & 0,6 & 0,6 & 0,7 & 0,8 & 1,4 & 4,1 \\
\hline & $\begin{array}{l}\text { Desvio padrão } \\
\text { Concentração }\end{array}$ & $\mathrm{P} / \mathrm{m}^{3}$ & $8,56 \mathrm{E}+03$ & $6,47 E+03$ & $3,98 \mathrm{E}+03$ & $4,06 \mathrm{E}+02$ & $6,18 \mathrm{E}+01$ & $9,72 \mathrm{E}+01$ \\
\hline & DP/Concentração média & $\%$ & 0,0082 & 0,0073 & 0,0052 & 0,0007 & 0,0004 & 0,0048 \\
\hline \multirow{2}{*}{\multicolumn{2}{|c|}{ Erro total medições( $\varepsilon$ ) }} & $\mathrm{P} / \mathrm{m}^{3}$ & $5,89 \mathrm{E}+05$ & $5,44 \mathrm{E}+05$ & $5,04 E+05$ & $4,31 E+05$ & $2,36 \mathrm{E}+05$ & $8,21 E+04$ \\
\hline & & Unidade & $1,0-2,0 \mu \mathrm{m}$ & $2,0-3,0 \mu \mathrm{m}$ & $3,0-5,0 \mu \mathrm{m}$ & $5,0-7,0 \mu \mathrm{m}$ & $7,0-10,0 \mu \mathrm{m}$ & $>10,0 \mu \mathrm{m}$ \\
\hline \multirow{8}{*}{ Assento 2D } & $\begin{array}{l}\text { Concentração média de } \\
\text { fundo }\end{array}$ & $\mathrm{P} / \mathrm{m}^{3}$ & $1,80 E+05$ & $7,33 E+04$ & $1,00 E+04$ & $3,33 E+03$ & $0,00 E+00$ & $0,00 E+00$ \\
\hline & $\begin{array}{l}\text { Número de particulas de } \\
\text { fundo }\end{array}$ & $\mathbf{P}$ & 54 & 22 & 3 & 1 & 0 & 0 \\
\hline & $\begin{array}{c}\text { Concentração média } \\
\text { liquida }\end{array}$ & $\mathrm{P} / \mathrm{m}^{3}$ & $6,36 \mathrm{E}+07$ & $6,29 E+07$ & $5,92 E+07$ & $4,99 \mathrm{E}+07$ & $1,44 E+07$ & $1,71 E+06$ \\
\hline & $\begin{array}{l}\text { Número de Particulas } \\
\text { média liquida }\end{array}$ & $\mathbf{P}$ & 19070 & 18864 & 17769 & 14970 & 4309 & 514 \\
\hline & Desvio - Poisson & $\#$ & 138,09 & 137,35 & 133,30 & 122,35 & 65,64 & 22,67 \\
\hline & $\begin{array}{l}\text { Desvio - Poisson - } \\
\text { Relativo }\end{array}$ & $\%$ & 0,7 & 0,7 & 0,8 & 0,8 & 1,5 & 4,4 \\
\hline & $\begin{array}{l}\text { Desvio padrão } \\
\text { Concentração }\end{array}$ & $\mathrm{P} / \mathrm{m}^{3}$ & $4,13 \mathrm{E}+03$ & $4,05 E+03$ & $2,30 \mathrm{E}+03$ & $2,25 E+03$ & $9,52 E+02$ & $1,29 E+02$ \\
\hline & DP/Concentração média & $\%$ & 0,0065 & 0,0064 & 0,0039 & 0,0045 & 0,0066 & 0,0075 \\
\hline \multirow{2}{*}{\multicolumn{2}{|c|}{ Erro total medições( $\varepsilon$ ) }} & $\mathrm{P} / \mathrm{m}^{3}$ & $4,60 E+05$ & $4,58 \mathrm{E}+05$ & $4,44 E+05$ & $4,08 \mathrm{E}+05$ & $2,19 \mathrm{E}+05$ & $7,56 \mathrm{E}+04$ \\
\hline & & Unidade & $1,0-2,0 \mu \mathrm{m}$ & $2,0-3,0 \mu \mathrm{m}$ & $3,0-5,0 \mu \mathrm{m}$ & $5,0-7,0 \mu \mathrm{m}$ & $7,0-10,0 \mu \mathrm{m}$ & $>10,0 \mu \mathrm{m}$ \\
\hline \multirow{8}{*}{ Assento $2 \mathrm{E}$} & $\begin{array}{l}\text { Concentração média de } \\
\text { fundo }\end{array}$ & $\mathrm{P} / \mathrm{m}^{3}$ & $1,37 \mathrm{E}+05$ & $5,67 E+04$ & $6,67 \mathrm{E}+03$ & $0,00 E+00$ & $0,00 E+00$ & $0,00 E+00$ \\
\hline & $\begin{array}{l}\text { Número de particulas de } \\
\text { fundo }\end{array}$ & $\mathbf{P}$ & 41 & 17 & 2 & 0 & 0 & 0 \\
\hline & $\begin{array}{c}\text { Concentração média } \\
\text { liquida }\end{array}$ & $\mathrm{P} / \mathrm{m}^{3}$ & $5,578 \mathrm{E}+07$ & $5,518 \mathrm{E}+07$ & $4,968 \mathrm{E}+07$ & $4,039 \mathrm{E}+07$ & $1,770 E+07$ & $2,76 E+06$ \\
\hline & $\begin{array}{l}\text { Número de Particulas } \\
\text { média liquida }\end{array}$ & $\mathbf{P}$ & 16734 & 16555 & 14905 & 12118 & 5310 & 827 \\
\hline & Desvio - Poisson & $\#$ & 129,36 & 128,66 & 122,08 & 110,08 & 72,87 & 28,75 \\
\hline & $\begin{array}{l}\text { Desvio - Poisson - } \\
\text { Relativo }\end{array}$ & $\%$ & 0,8 & 0,8 & 0,8 & 0,9 & 1,4 & 3,5 \\
\hline & $\begin{array}{l}\text { Desvio padrão } \\
\text { Concentração }\end{array}$ & $\mathrm{P} / \mathrm{m}^{3}$ & $2,67 E+03$ & $2,63 E+03$ & $2,23 E+03$ & $1,80 \mathrm{E}+03$ & $9,22 E+02$ & $1,86 \mathrm{E}+02$ \\
\hline & DP/Concentração média & $\%$ & 0,0048 & 0,0048 & 0,0045 & 0,0045 & 0,0052 & 0,0067 \\
\hline \multicolumn{2}{|c|}{ Erro total medições(દ) } & $\mathrm{P} / \mathrm{m}^{3}$ & $4,31 \mathrm{E}+05$ & $4,29 E+05$ & $4,07 E+05$ & $3,67 E+05$ & $2,43 E+05$ & $9,58 E+04$ \\
\hline
\end{tabular}




\begin{tabular}{|c|c|c|c|c|c|c|c|c|}
\hline & & Unidade & $1,0-2,0 \mu \mathrm{m}$ & $2,0-3,0 \mu \mathrm{m}$ & $3,0-5,0 \mu \mathrm{m}$ & $5,0-7,0 \mu \mathrm{m}$ & $7,0-10,0 \mu \mathrm{m}$ & $>10,0 \mu \mathrm{m}$ \\
\hline \multirow{8}{*}{ Assento 1D } & $\begin{array}{c}\text { Concentração média de } \\
\text { fundo }\end{array}$ & $\mathrm{P} / \mathrm{m}^{3}$ & $2,20 \mathrm{E}+05$ & $9,67 E+04$ & $1,50 \mathrm{E}+04$ & $1,67 \mathrm{E}+03$ & $0,00 \mathrm{E}+00$ & $0,00 \mathrm{E}+00$ \\
\hline & $\begin{array}{c}\text { Número de particulas de } \\
\text { fundo }\end{array}$ & $\mathbf{P}$ & 66 & 29 & 5 & 1 & 0 & 0 \\
\hline & $\begin{array}{l}\text { Concentração média } \\
\text { liquida }\end{array}$ & $\mathrm{P} / \mathrm{m}^{3}$ & $6,89 \mathrm{E}+07$ & $6,47 \mathrm{E}+07$ & $5,85 E+07$ & $4,51 E+07$ & $1,00 \mathrm{E}+07$ & $1,46 E+06$ \\
\hline & $\begin{array}{l}\text { Número de Particulas } \\
\text { média liquida }\end{array}$ & p & 20657 & 19414 & 17540 & 13520 & 3012 & 437 \\
\hline & Desvio - Poisson & $\#$ & 143,73 & 139,33 & 132,44 & 116,28 & 54,88 & 20,89 \\
\hline & $\begin{array}{l}\text { Desvio - Poisson - } \\
\text { Relativo }\end{array}$ & $\%$ & 0,7 & 0,7 & 0,8 & 0,9 & 1,8 & 4,8 \\
\hline & $\begin{array}{l}\text { Desvio padrão } \\
\text { Concentração }\end{array}$ & $\mathrm{P} / \mathrm{m}^{3}$ & $6,79 E+03$ & $6,67 E+03$ & $5,97 E+03$ & $4,76 \mathrm{E}+03$ & $1,49 \mathrm{E}+03$ & $2,71 E+02$ \\
\hline & DP/Concentração média & $\%$ & 0,0099 & 0,0103 & 0,0102 & 0,0106 & 0,0148 & 0,0186 \\
\hline \multirow{2}{*}{\multicolumn{2}{|c|}{ Erro total medições(દ) }} & $\mathrm{P} / \mathrm{m}^{3}$ & $4,79 E+05$ & $4,64 E+05$ & $4,42 E+05$ & $3,88 \mathrm{E}+05$ & $1,83 E+05$ & $6,96 \mathrm{E}+04$ \\
\hline & & Unidade & $1,0-2,0 \mu \mathrm{m}$ & $2,0-3,0 \mu \mathrm{m}$ & $3,0-5,0 \mu \mathrm{m}$ & $5,0-7,0 \mu \mathrm{m}$ & $7,0-10,0 \mu \mathrm{m}$ & $>10,0 \mu \mathrm{m}$ \\
\hline \multirow{8}{*}{ Assento 1E } & $\begin{array}{c}\text { Concentração média de } \\
\text { fundo }\end{array}$ & $\mathrm{P} / \mathrm{m}^{3}$ & $1,50 \mathrm{E}+05$ & $1,13 E+05$ & $1,33 \mathrm{E}+04$ & $0,00 \mathrm{E}+00$ & $0,00 E+00$ & $0,00 E+00$ \\
\hline & $\begin{array}{c}\text { Número de particulas de } \\
\text { fundo }\end{array}$ & $\mathbf{P}$ & 45 & 34 & 4 & 0 & 0 & 0 \\
\hline & $\begin{array}{l}\text { Concentração média } \\
\text { liquida }\end{array}$ & $\mathrm{P} / \mathrm{m}^{3}$ & $9,36 \mathrm{E}+07$ & $8,46 \mathrm{E}+07$ & $6,33 E+07$ & $5,08 \mathrm{E}+07$ & $1,75 E+07$ & $1,51 \mathrm{E}+06$ \\
\hline & $\begin{array}{l}\text { Número de Particulas } \\
\text { média liquida }\end{array}$ & $\mathbf{P}$ & 28089 & 25381 & 19004 & 15237 & 5247 & 453 \\
\hline & Desvio - Poisson & $\#$ & 167,60 & 159,31 & 137,85 & 123,44 & 72,44 & 21,28 \\
\hline & $\begin{array}{c}\text { Desvio - Poisson - } \\
\text { Relativo } \\
\end{array}$ & $\%$ & 0,6 & 0,6 & 0,7 & 0,8 & 1,4 & 4,7 \\
\hline & $\begin{array}{l}\text { Desvio padrão } \\
\text { Concentração }\end{array}$ & $\mathrm{P} / \mathrm{m}^{3}$ & $5,19 E+03$ & $6,80 E+03$ & $5,64 \mathrm{E}+03$ & $4,04 E+03$ & $1,08 \mathrm{E}+03$ & $1,51 E+02$ \\
\hline & DP/Concentração média & $\%$ & 0,0055 & 0,0080 & 0,0089 & 0,0079 & 0,0062 & 0,0100 \\
\hline \multirow{2}{*}{\multicolumn{2}{|c|}{ Erro total medições(દ) }} & $\mathrm{P} / \mathrm{m}^{3}$ & $5,59 E+05$ & $5,31 E+05$ & $4,60 E+05$ & $4,11 E+05$ & $2,41 E+05$ & $7,09 E+04$ \\
\hline & & Unidade & $1,0-2,0 \mu \mathrm{m}$ & $2,0-3,0 \mu \mathrm{m}$ & $3,0-5,0 \mu \mathrm{m}$ & $5,0-7,0 \mu \mathrm{m}$ & $7,0-10,0 \mu \mathrm{m}$ & $>10,0 \mu \mathrm{m}$ \\
\hline \multirow{8}{*}{ Assento 1B } & $\begin{array}{c}\text { Concentração média de } \\
\text { fundo } \\
\end{array}$ & $\mathrm{P} / \mathrm{m}^{3}$ & $2,50 \mathrm{E}+05$ & $1,20 \mathrm{E}+05$ & $1,00 \mathrm{E}+04$ & $0,00 \mathrm{E}+00$ & $0,00 \mathrm{E}+00$ & $0,00 E+00$ \\
\hline & $\begin{array}{c}\text { Número de particulas de } \\
\text { fundo } \\
\end{array}$ & $\mathbf{P}$ & 75 & 36 & 3 & 0 & 0 & 0 \\
\hline & $\begin{array}{l}\text { Concentração média } \\
\text { liquida }\end{array}$ & $\mathrm{P} / \mathrm{m}^{3}$ & $5,49 \mathrm{E}+07$ & $4,78 \mathrm{E}+07$ & $4,31 E+07$ & $3,05 E+07$ & $7,49 \mathrm{E}+06$ & $1,27 \mathrm{E}+06$ \\
\hline & $\begin{array}{l}\text { Número de Particulas } \\
\text { média liquida }\end{array}$ & $\mathbf{P}$ & 16471 & 14341 & 12925 & 9140 & 2248 & 380 \\
\hline & Desvio - Poisson & $\#$ & 128,34 & 119,75 & 113,69 & 95,60 & 47,41 & 19,49 \\
\hline & $\begin{array}{c}\text { Desvio - Poisson - } \\
\text { Relativo } \\
\end{array}$ & $\%$ & 0,8 & 0,8 & 0,9 & 1,0 & 2,1 & 5,1 \\
\hline & $\begin{array}{l}\text { Desvio padrão } \\
\text { Concentração }\end{array}$ & $\mathrm{P} / \mathrm{m}^{3}$ & $8,24 \mathrm{E}+02$ & $2,03 E+03$ & $1,69 \mathrm{E}+03$ & $1,16 \mathrm{E}+03$ & $3,89 \mathrm{E}+02$ & $8,57 E+01$ \\
\hline & DP/Concentração média & $\%$ & 0,0015 & 0,0042 & 0,0039 & 0,0038 & 0,0052 & 0,0068 \\
\hline \multicolumn{2}{|c|}{ Erro total medições(દ) } & $\mathrm{P} / \mathrm{m}^{3}$ & $4,28 E+05$ & $3,99 E+05$ & $3,79 \mathrm{E}+05$ & $3,19 \mathrm{E}+05$ & $1,58 \mathrm{E}+05$ & $6,50 \mathrm{E}+04$ \\
\hline
\end{tabular}




\begin{tabular}{|c|c|c|c|c|c|c|c|c|}
\hline & & Unidade & $1,0-2,0 \mu \mathrm{m}$ & $2,0-3,0 \mu \mathrm{m}$ & $3,0-5,0 \mu \mathrm{m}$ & $5,0-7,0 \mu \mathrm{m}$ & $7,0-10,0 \mu \mathrm{m}$ & $>10,0 \mu \mathrm{m}$ \\
\hline \multirow{8}{*}{ Assento $1 \mathrm{~A}$} & $\begin{array}{c}\text { Concentração média de } \\
\text { fundo }\end{array}$ & $\mathrm{P} / \mathrm{m}^{3}$ & $3,10 E+05$ & $1,40 E+05$ & 3,33E+03 & $0,00 E+00$ & $0,00 E+00$ & $0,00 E+00$ \\
\hline & $\begin{array}{c}\text { Número de particulas de } \\
\text { fundo }\end{array}$ & $\mathbf{P}$ & 93 & 42 & 1 & 0 & 0 & 0 \\
\hline & $\begin{array}{l}\text { Concentração média } \\
\text { liquida }\end{array}$ & $\mathrm{P} / \mathrm{m}^{3}$ & $4,63 E+07$ & $4,58 E+07$ & $3,51 E+07$ & $2,99 \mathrm{E}+07$ & $5,09 E+06$ & $4,00 E+05$ \\
\hline & $\begin{array}{l}\text { Número de Particulas } \\
\text { média liquida }\end{array}$ & $\mathbf{p}$ & 13881 & 13742 & 10520 & 8961 & 1526 & 120 \\
\hline & Desvio - Poisson & \# & 117,82 & 117,23 & 102,57 & 94,66 & 39,06 & 10,95 \\
\hline & $\begin{array}{l}\text { Desvio - Poisson - } \\
\text { Relativo }\end{array}$ & $\%$ & 0,8 & 0,9 & 1,0 & 1,1 & 2,6 & 9,1 \\
\hline & $\begin{array}{l}\text { Desvio padrão } \\
\text { Concentração }\end{array}$ & $\mathrm{P} / \mathrm{m}^{3}$ & $2,00 E+03$ & $1,98 \mathrm{E}+03$ & $1,45 E+03$ & $1,01 E+03$ & $6,06 \mathrm{E}+02$ & $2,71 E+02$ \\
\hline & DP/Concentração média & $\%$ & 0,0043 & 0,0043 & 0,0041 & 0,0034 & 0,0119 & 0,0678 \\
\hline \multirow{2}{*}{\multicolumn{2}{|c|}{ Erro total medições(દ) }} & $\mathrm{P} / \mathrm{m}^{3}$ & $3,93 E+05$ & $3,91 E+05$ & $3,42 E+05$ & $3,16 \mathrm{E}+05$ & $1,30 E+05$ & $3,65 \mathrm{E}+04$ \\
\hline & & Unidade & $1,0-2,0 \mu \mathrm{m}$ & $2,0-3,0 \mu \mathrm{m}$ & $3,0-5,0 \mu \mathrm{m}$ & $5,0-7,0 \mu \mathrm{m}$ & $7,0-10,0 \mu \mathrm{m}$ & $>10,0 \mu \mathrm{m}$ \\
\hline \multirow{8}{*}{ Assento 2B } & $\begin{array}{c}\text { Concentração média de } \\
\text { fundo }\end{array}$ & $\mathrm{P} / \mathrm{m}^{3}$ & $3,37 E+05$ & $1,83 E+05$ & $1,67 E+04$ & $0,00 E+00$ & $0,00 E+00$ & $0,00 E+00$ \\
\hline & $\begin{array}{c}\text { Número de particulas de } \\
\text { fundo }\end{array}$ & $\mathbf{p}$ & 101 & 55 & 5 & 0 & 0 & 0 \\
\hline & $\begin{array}{l}\text { Concentração média } \\
\text { liquida }\end{array}$ & $\mathrm{p} / \mathrm{m}^{3}$ & $6,78 E+07$ & $6,25 E+07$ & $5,33 E+07$ & $2,67 \mathrm{E}+07$ & $2,17 E+07$ & $1,17 E+06$ \\
\hline & $\begin{array}{l}\text { Número de Particulas } \\
\text { média liquida }\end{array}$ & $\mathbf{p}$ & 20328 & 18742 & 16000 & 8000 & 6520 & 352 \\
\hline & Desvio - Poisson & \# & 142,58 & 136,90 & 126,49 & 89,44 & 80,75 & 18,76 \\
\hline & $\begin{array}{c}\text { Desvio - Poisson - } \\
\text { Relativo } \\
\end{array}$ & $\%$ & 0,7 & 0,7 & 0,8 & 1,1 & 1,2 & 5,3 \\
\hline & $\begin{array}{l}\text { Desvio padrão } \\
\text { Concentração }\end{array}$ & $\mathrm{P} / \mathrm{m}^{3}$ & $5,24 E+03$ & $1,57 \mathrm{E}+03$ & $3,21 E+03$ & $1,07 E+03$ & $2,18 E+03$ & $1,34 \mathrm{E}+02$ \\
\hline & DP/Concentração média & $\%$ & 0,0077 & 0,0025 & 0,0060 & 0,0040 & 0,0100 & 0,0114 \\
\hline \multirow{2}{*}{\multicolumn{2}{|c|}{ Erro total medições(ઘ) }} & $\mathrm{P} / \mathrm{m}^{3}$ & $4,75 E+05$ & $4,56 E+05$ & $4,22 E+05$ & $2,98 E+05$ & $2,69 \mathrm{E}+05$ & $6,25 E+04$ \\
\hline & & Unidade & $1,0-2,0 \mu \mathrm{m}$ & $2,0-3,0 \mu \mathrm{m}$ & $3,0-5,0 \mu \mathrm{m}$ & $5,0-7,0 \mu \mathrm{m}$ & $7,0-10,0 \mu \mathrm{m}$ & $>10,0 \mu \mathrm{m}$ \\
\hline \multirow{9}{*}{ Assento 2A } & $\begin{array}{c}\text { Concentração média de } \\
\text { fundo }\end{array}$ & $\mathrm{p} / \mathrm{m}^{3}$ & $3,23 E+05$ & $1,53 E+05$ & $2,00 E+04$ & $0,00 E+00$ & $0,00 E+00$ & $0,00 E+00$ \\
\hline & $\begin{array}{c}\text { Número de particulas de } \\
\text { fundo }\end{array}$ & $\mathbf{P}$ & 97 & 46 & 6 & 0 & 0 & 0 \\
\hline & $\begin{array}{l}\text { Concentração média } \\
\text { liquida }\end{array}$ & $\mathrm{P} / \mathrm{m}^{3}$ & $5,78 E+07$ & $4,58 E+07$ & $3,50 E+07$ & $2,63 E+07$ & $6,15 E+06$ & $1,08 E+06$ \\
\hline & $\begin{array}{l}\text { Número de Particulas } \\
\text { média liquida }\end{array}$ & $\mathbf{P}$ & 17328 & 13742 & 10500 & 7890 & 1845 & 324 \\
\hline & Desvio - Poisson & $\#$ & 131,64 & 117,23 & 102,47 & 88,83 & 42,95 & 18,00 \\
\hline & $\begin{array}{l}\text { Desvio - Poisson - } \\
\text { Relativo }\end{array}$ & $\%$ & 0,8 & 0,9 & 1,0 & 1,1 & 2,3 & 5,6 \\
\hline & $\begin{array}{l}\text { Desvio padrão } \\
\text { Concentração }\end{array}$ & $\mathrm{p} / \mathrm{m}^{3}$ & $4,44 E+03$ & $1,98 \mathrm{E}+03$ & $2,04 E+03$ & $1,63 E+03$ & $5,17 E+02$ & $1,45 E+02$ \\
\hline & DP/Concentração média & $\%$ & 0,0077 & 0,0043 & 0,0058 & 0,0062 & 0,0084 & 0,0134 \\
\hline & ro total medições(દ) & $\mathrm{p} / \mathrm{m}^{3}$ & $4,39 E+05$ & $3,91 E+05$ & $3,42 E+05$ & $2,96 \mathrm{E}+05$ & $1,43 E+05$ & $6,00 E+04$ \\
\hline
\end{tabular}




\begin{tabular}{|c|c|c|c|c|c|c|c|c|}
\hline & & Unidade & $1,0-2,0 \mu \mathrm{m}$ & $2,0-3,0 \mu \mathrm{m}$ & $3,0-5,0 \mu \mathrm{m}$ & $5,0-7,0 \mu \mathrm{m}$ & $7,0-10,0 \mu \mathrm{m}$ & $>10,0 \mu \mathrm{m}$ \\
\hline \multirow{8}{*}{ Assento 3B } & $\begin{array}{c}\text { Concentração média de } \\
\text { fundo }\end{array}$ & $\mathrm{P} / \mathrm{m}^{3}$ & $1,87 E+05$ & $9,33 E+04$ & $1,00 E+04$ & $0,00 E+00$ & $0,00 E+00$ & $0,00 E+00$ \\
\hline & $\begin{array}{c}\text { Número de particulas de } \\
\text { fundo } \\
\end{array}$ & $\mathbf{P}$ & 56 & 28 & 3 & 0 & 0 & 0 \\
\hline & $\begin{array}{c}\text { Concentração média } \\
\text { liquida }\end{array}$ & $\mathrm{P} / \mathrm{m}^{3}$ & $8,48 \mathrm{E}+07$ & $6,94 \mathrm{E}+07$ & $5,84 \mathrm{E}+07$ & $4,67 E+07$ & $1,39 \mathrm{E}+07$ & $2,53 E+06$ \\
\hline & $\begin{array}{c}\text { Número de Particulas } \\
\text { média liquida }\end{array}$ & $\mathbf{P}$ & 25440 & 20831 & 17520 & 14000 & 4163 & 760 \\
\hline & Desvio - Poisson & $\#$ & 159,50 & 144,33 & 132,36 & 118,32 & 64,52 & 27,57 \\
\hline & $\begin{array}{c}\text { Desvio - Poisson - } \\
\text { Relativo } \\
\end{array}$ & $\%$ & 0,6 & 0,7 & 0,8 & 0,8 & 1,5 & 3,6 \\
\hline & $\begin{array}{l}\text { Desvio padrão } \\
\text { Concentração }\end{array}$ & $\mathrm{P} / \mathrm{m}^{3}$ & $4,56 \mathrm{E}+03$ & $4,14 \mathrm{E}+03$ & $3,04 E+03$ & $3,18 \mathrm{E}+03$ & $3,17 E+02$ & $8,98 \mathrm{E}+01$ \\
\hline & DP/Concentração média & $\%$ & 0,0054 & 0,0060 & 0,0052 & 0,0068 & 0,0023 & 0,0035 \\
\hline \multirow{2}{*}{\multicolumn{2}{|c|}{ Erro total medições( $\varepsilon$ ) }} & $\mathrm{P} / \mathrm{m}^{3}$ & $5,32 \mathrm{E}+05$ & $4,81 E+05$ & $4,41 E+05$ & $3,94 \mathrm{E}+05$ & $2,15 E+05$ & $9,19 \mathrm{E}+04$ \\
\hline & & Unidade & $1,0-2,0 \mu \mathrm{m}$ & $2,0-3,0 \mu \mathrm{m}$ & $3,0-5,0 \mu \mathrm{m}$ & $5,0-7,0 \mu \mathrm{m}$ & $7,0-10,0 \mu \mathrm{m}$ & $>10,0 \mu \mathrm{m}$ \\
\hline \multirow{8}{*}{ Assento $3 \mathrm{~A}$} & $\begin{array}{c}\begin{array}{c}\text { Concentração média de } \\
\text { fundo }\end{array} \\
\end{array}$ & $\mathrm{P} / \mathrm{m}^{3}$ & $1,83 E+05$ & $8,33 E+04$ & $1,00 E+04$ & $0,00 E+00$ & $0,00 E+00$ & $0,00 E+00$ \\
\hline & $\begin{array}{c}\text { Número de particulas de } \\
\text { fundo }\end{array}$ & $\mathbf{P}$ & 55 & 25 & 3 & 0 & 0 & 0 \\
\hline & $\begin{array}{c}\text { Concentração média } \\
\text { liquida }\end{array}$ & $\mathrm{P} / \mathrm{m}^{3}$ & $5,11 \mathrm{E}+07$ & $4,60 E+07$ & $2,71 E+07$ & $3,00 E+07$ & $1,66 \mathrm{E}+07$ & $1,74 \mathrm{E}+06$ \\
\hline & $\begin{array}{c}\text { Número de Particulas } \\
\text { média liquida }\end{array}$ & $\mathbf{P}$ & 15340 & 13796 & 8140 & 9000 & 4980 & 523 \\
\hline & Desvio - Poisson & $\#$ & 123,85 & 117,45 & 90,22 & 94,87 & 70,57 & 22,87 \\
\hline & $\begin{array}{c}\text { Desvio - Poisson - } \\
\text { Relativo } \\
\end{array}$ & $\%$ & 0,8 & 0,9 & 1,1 & 1,1 & 1,4 & 4,4 \\
\hline & $\begin{array}{l}\text { Desvio padrão } \\
\text { Concentração }\end{array}$ & $\mathrm{P} / \mathrm{m}^{3}$ & $1,57 E+03$ & $1,95 E+03$ & $1,16 \mathrm{E}+03$ & $7,95 \mathrm{E}+02$ & $6,17 E+02$ & $1,44 \mathrm{E}+02$ \\
\hline & DP/Concentração média & $\%$ & 0,0031 & 0,0042 & 0,0043 & 0,0027 & 0,0037 & 0,0083 \\
\hline \multicolumn{2}{|c|}{ Erro total medições(छ) } & $\mathrm{P} / \mathrm{m}^{3}$ & $4,13 E+05$ & $3,92 \mathrm{E}+05$ & $3,01 \mathrm{E}+05$ & $3,16 \mathrm{E}+05$ & $2,35 E+05$ & $7,62 \mathrm{E}+04$ \\
\hline
\end{tabular}


Tabela D-3. Resultados das medições de partículas no assento (Sistema UFAD mod. à $18^{\circ} \mathrm{C}-$ injeção pelo assento $3 \mathrm{D}$ )

\begin{tabular}{|c|c|c|c|c|c|c|c|c|}
\hline & & Unidade & $1,0-2,0 \mu \mathrm{m}$ & $2,0-3,0 \mu \mathrm{m}$ & $3,0-5,0 \mu \mathrm{m}$ & $5,0-7,0 \mu \mathrm{m}$ & $7,0-10,0 \mu \mathrm{m}$ & $>10,0 \mu \mathrm{m}$ \\
\hline \multirow{8}{*}{ Assento 3E } & $\begin{array}{c}\text { Concentração média de } \\
\text { fundo }\end{array}$ & $\mathrm{P} / \mathrm{m}^{3}$ & $1,00 E+05$ & $4,33 E+04$ & $3,33 E+03$ & $0,00 \mathrm{E}+00$ & $0,00 E+00$ & $0,00 \mathrm{E}+00$ \\
\hline & $\begin{array}{c}\text { Número de particulas } \\
\text { de fundo }\end{array}$ & $\mathbf{p}$ & 30 & 13 & 1 & 0 & 0 & 0 \\
\hline & $\begin{array}{c}\text { Concentração média } \\
\text { liquida }\end{array}$ & $\mathrm{P} / \mathrm{m}^{3}$ & $4,67 E+08$ & $4,42 E+08$ & $1,07 E+08$ & $9,33 E+07$ & $2,50 \mathrm{E}+07$ & $1,71 \mathrm{E}+06$ \\
\hline & $\begin{array}{l}\text { Número de Particulas } \\
\text { média liquida }\end{array}$ & $\mathbf{P}$ & 140162 & 132609 & 32000 & 28000 & 7500 & 514 \\
\hline & Desvio - Poisson & $\#$ & 374,38 & 364,16 & 178,89 & 167,33 & 86,60 & 22,67 \\
\hline & $\begin{array}{l}\text { Desvio - Poisson - } \\
\text { Relativo }\end{array}$ & $\%$ & 0,3 & 0,3 & 0,6 & 0,6 & 1,2 & 4,4 \\
\hline & $\begin{array}{l}\text { Desvio padrão } \\
\text { Concentração }\end{array}$ & $\mathrm{P} / \mathrm{m}^{3}$ & $2,03 E+04$ & $4,06 \mathrm{E}+04$ & $2,27 E+04$ & $2,11 E+04$ & $1,44 \mathrm{E}+03$ & $2,64 E+03$ \\
\hline & DP/Concentração média & $\%$ & 0,0043 & 0,0092 & 0,0213 & 0,0226 & 0,0057 & 0,1538 \\
\hline \multirow{2}{*}{\multicolumn{2}{|c|}{ Erro total medições $(\varepsilon)$}} & $\mathrm{P} / \mathrm{m}^{3}$ & $1,25 E+06$ & $1,21 \mathrm{E}+06$ & $5,97 \mathrm{E}+05$ & $5,58 \mathrm{E}+05$ & $2,89 E+05$ & $7,56 \mathrm{E}+04$ \\
\hline & & Unidade & $1,0-2,0 \mu \mathrm{m}$ & $2,0-3,0 \mu \mathrm{m}$ & $3,0-5,0 \mu \mathrm{m}$ & $5,0-7,0 \mu \mathrm{m}$ & $7,0-10,0 \mu \mathrm{m}$ & $>10,0 \mu \mathrm{m}$ \\
\hline \multirow{8}{*}{ Assento 2D } & \begin{tabular}{|c|}
$\begin{array}{c}\text { Concentração média de } \\
\text { fundo }\end{array}$ \\
\end{tabular} & $\mathrm{P} / \mathrm{m}^{3}$ & $1,77 \mathrm{E}+05$ & $6,67 E+04$ & $1,00 \mathrm{E}+04$ & $3,33 E+03$ & $0,00 E+00$ & $0,00 E+00$ \\
\hline & $\begin{array}{c}\text { Número de particulas } \\
\text { de fundo }\end{array}$ & $\mathbf{P}$ & 53 & 20 & 3 & 1 & 0 & 0 \\
\hline & $\begin{array}{c}\text { Concentração média } \\
\text { liquida }\end{array}$ & $\mathrm{P} / \mathrm{m}^{3}$ & $1,21 \mathrm{E}+08$ & $1,18 \mathrm{E}+08$ & $9,65 E+07$ & $5,48 E+07$ & $1,89 \mathrm{E}+07$ & $1,48 E+06$ \\
\hline & $\begin{array}{c}\text { Número de Particulas } \\
\text { média liquida }\end{array}$ & $\mathbf{p}$ & 36356 & 35401 & 28960 & 16432 & 5670 & 444 \\
\hline & Desvio - Poisson & $\#$ & 190,67 & 188,15 & 170,18 & 128,19 & 75,30 & 21,07 \\
\hline & $\begin{array}{l}\text { Desvio - Poisson - } \\
\text { Relativo }\end{array}$ & $\%$ & 0,5 & 0,5 & 0,6 & 0,8 & 1,3 & 4,7 \\
\hline & $\begin{array}{c}\text { Desvio padrão } \\
\text { Concentração }\end{array}$ & $\mathrm{P} / \mathrm{m}^{3}$ & $4,90 E+03$ & $4,72 E+03$ & $7,71 E+02$ & $1,63 E+03$ & $1,20 \mathrm{E}+03$ & $4,92 E+01$ \\
\hline & DP/Concentração média & $\%$ & 0,0040 & 0,0040 & 0,0008 & 0,0030 & 0,0063 & 0,0033 \\
\hline \multirow{2}{*}{\multicolumn{2}{|c|}{ Erro total medições( $\varepsilon)$}} & $\mathrm{P} / \mathrm{m}^{3}$ & $6,36 \mathrm{E}+05$ & $6,27 E+05$ & $5,67 E+05$ & $4,27 E+05$ & $2,51 E+05$ & $7,02 E+04$ \\
\hline & & Unidade & $1,0-2,0 \mu \mathrm{m}$ & $2,0-3,0 \mu \mathrm{m}$ & $3,0-5,0 \mu \mathrm{m}$ & $5,0-7,0 \mu \mathrm{m}$ & $7,0-10,0 \mu \mathrm{m}$ & $>10,0 \mu \mathrm{m}$ \\
\hline \multirow{8}{*}{ Assento $2 \mathrm{E}$} & $\begin{array}{c}\text { Concentração média de } \\
\text { fundo }\end{array}$ & $\mathrm{P} / \mathrm{m}^{3}$ & $8,00 E+04$ & $5,67 E+04$ & $6,67 E+03$ & $0,00 \mathrm{E}+00$ & $0,00 \mathrm{E}+00$ & $0,00 E+00$ \\
\hline & $\begin{array}{c}\text { Número de particulas } \\
\text { de fundo }\end{array}$ & $\mathbf{P}$ & 24 & 17 & 2 & 0 & 0 & 0 \\
\hline & $\begin{array}{c}\text { Concentração média } \\
\text { liquida }\end{array}$ & $\mathrm{P} / \mathrm{m}^{3}$ & $1,18 \mathrm{E}+08$ & $1,16 \mathrm{E}+08$ & $6,18 \mathrm{E}+07$ & $2,85 E+07$ & $1,33 \mathrm{E}+07$ & $2,62 E+06$ \\
\hline & $\begin{array}{c}\text { Número de Particulas } \\
\text { média liquida }\end{array}$ & $\mathbf{P}$ & 35536 & 34704 & 18540 & 8560 & 4000 & 785 \\
\hline & Desvio - Poisson & $\#$ & 188,51 & 186,29 & 136,16 & 92,52 & 63,25 & 28,02 \\
\hline & $\begin{array}{l}\text { Desvio - Poisson - } \\
\text { Relativo }\end{array}$ & $\%$ & 0,5 & 0,5 & 0,7 & 1,1 & 1,6 & 3,6 \\
\hline & $\begin{array}{l}\text { Desvio padrão } \\
\text { Concentração } \\
\end{array}$ & $\mathrm{P} / \mathrm{m}^{3}$ & $1,01 E+04$ & $9,80 E+03$ & $5,45 E+03$ & $1,74 \mathrm{E}+03$ & $1,19 \mathrm{E}+03$ & $1,29 E+02$ \\
\hline & DP/Concentração média & $\%$ & 0,0085 & 0,0085 & 0,0088 & 0,0061 & 0,0089 & 0,0049 \\
\hline \multicolumn{2}{|c|}{ Erro total medições $(\varepsilon)$} & $\mathrm{P} / \mathrm{m}^{3}$ & $6,28 \mathrm{E}+05$ & $6,21 E+05$ & $4,54 E+05$ & $3,08 \mathrm{E}+05$ & $2,11 \mathrm{E}+05$ & $9,34 E+04$ \\
\hline
\end{tabular}




\begin{tabular}{|c|c|c|c|c|c|c|c|c|}
\hline & & Unidade & $1,0-2,0 \mu \mathrm{m}$ & $2,0-3,0 \mu \mathrm{m}$ & $3,0-5,0 \mu \mathrm{m}$ & $5,0-7,0 \mu \mathrm{m}$ & $7,0-10,0 \mu \mathrm{m}$ & $>10,0 \mu \mathrm{m}$ \\
\hline \multirow{8}{*}{ Assento 1D } & $\begin{array}{c}\text { Concentração média de } \\
\text { fundo }\end{array}$ & $\mathrm{P} / \mathrm{m}^{3}$ & $1,43 E+05$ & $9,67 E+04$ & $6,67 E+03$ & $0,00 \mathrm{E}+00$ & $0,00 \mathrm{E}+00$ & $0,00 E+00$ \\
\hline & $\begin{array}{c}\text { Número de particulas } \\
\text { de fundo }\end{array}$ & $\mathbf{P}$ & 43 & 29 & 2 & 0 & 0 & 0 \\
\hline & $\begin{array}{c}\text { Concentração média } \\
\text { liquida }\end{array}$ & $\mathrm{P} / \mathrm{m}^{3}$ & $1,37 E+08$ & $1,34 \mathrm{E}+08$ & $9,65 E+07$ & $4,99 \mathrm{E}+07$ & $1,32 E+07$ & $4,90 E+05$ \\
\hline & $\begin{array}{c}\text { Número de Particulas } \\
\text { média liquida }\end{array}$ & $\mathbf{p}$ & 41037 & 40116 & 28952 & 14966 & 3962 & 147 \\
\hline & Desvio - Poisson & $\#$ & 202,58 & 200,29 & 170,15 & 122,34 & 62,94 & 12,12 \\
\hline & $\begin{array}{c}\text { Desvio - Poisson - } \\
\text { Relativo } \\
\end{array}$ & $\%$ & 0,5 & 0,5 & 0,6 & 0,8 & 1,6 & 8,2 \\
\hline & $\begin{array}{l}\text { Desvio padrão } \\
\text { Concentração }\end{array}$ & $\mathrm{P} / \mathrm{m}^{3}$ & $2,83 \mathrm{E}+03$ & $2,78 \mathrm{E}+03$ & $2,10 E+03$ & $1,43 E+03$ & $4,45 E+02$ & $1,61 \mathrm{E}+01$ \\
\hline & DP/Concentração média & $\%$ & 0,0021 & 0,0021 & 0,0022 & 0,0029 & 0,0034 & 0,0033 \\
\hline \multicolumn{2}{|c|}{ Erro total medições(દ) } & $\mathrm{P} / \mathrm{m}^{3}$ & $6,75 E+05$ & $6,68 E+05$ & $5,67 E+05$ & $4,08 E+05$ & $2,10 E+05$ & 4,04E+04 \\
\hline & & Unidade & $1,0-2,0 \mu \mathrm{m}$ & $2,0-3,0 \mu \mathrm{m}$ & $3,0-5,0 \mu \mathrm{m}$ & $5,0-7,0 \mu \mathrm{m}$ & $7,0-10,0 \mu \mathrm{m}$ & $>10,0 \mu \mathrm{m}$ \\
\hline \multirow{8}{*}{ Assento 1E } & $\begin{array}{c}\text { Concentração média de } \\
\text { fundo }\end{array}$ & $\mathrm{P} / \mathrm{m}^{3}$ & $2,23 E+05$ & $8,67 E+04$ & $1,33 E+04$ & $0,00 E+00$ & $0,00 E+00$ & $0,00 E+00$ \\
\hline & $\begin{array}{c}\text { Número de particulas } \\
\text { de fundo }\end{array}$ & $\mathbf{P}$ & 67 & 26 & 4 & 0 & 0 & 0 \\
\hline & $\begin{array}{c}\text { Concentração média } \\
\text { liquida }\end{array}$ & $\mathrm{P} / \mathrm{m}^{3}$ & $9,39 E+07$ & $9,22 E+07$ & $7,01 E+07$ & $5,33 \mathrm{E}+07$ & $2,00 E+07$ & 4,37E+05 \\
\hline & $\begin{array}{c}\text { Número de Particulas } \\
\text { média liquida }\end{array}$ & $\mathbf{p}$ & 28162 & 27660 & 21025 & 16000 & 5987 & 131 \\
\hline & Desvio - Poisson & $\#$ & 167,82 & 166,31 & 145,00 & 126,49 & 77,38 & 11,45 \\
\hline & $\begin{array}{c}\text { Desvio - Poisson - } \\
\text { Relativo } \\
\end{array}$ & $\%$ & 0,6 & 0,6 & 0,7 & 0,8 & 1,3 & 8,7 \\
\hline & $\begin{array}{l}\text { Desvio padrão } \\
\text { Concentração } \\
\end{array}$ & $\mathrm{P} / \mathrm{m}^{3}$ & $5,49 \mathrm{E}+03$ & $5,37 E+03$ & $3,66 \mathrm{E}+03$ & $3,14 \mathrm{E}+03$ & $1,88 \mathrm{E}+03$ & $1,76 \mathrm{E}+01$ \\
\hline & DP/Concentração média & $\%$ & 0,0059 & 0,0058 & 0,0052 & 0,0059 & 0,0094 & 0,0040 \\
\hline \multicolumn{2}{|c|}{ Erro total medições(દ) } & $\mathrm{P} / \mathrm{m}^{3}$ & $5,59 E+05$ & $5,54 E+05$ & $4,83 E+05$ & $4,22 E+05$ & $2,58 \mathrm{E}+05$ & $3,82 \mathrm{E}+04$ \\
\hline & & Unidade & $1,0-2,0 \mu \mathrm{m}$ & $2,0-3,0 \mu \mathrm{m}$ & $3,0-5,0 \mu \mathrm{m}$ & $5,0-7,0 \mu \mathrm{m}$ & $7,0-10,0 \mu \mathrm{m}$ & $>10,0 \mu \mathrm{m}$ \\
\hline \multirow{8}{*}{ Assento 1B } & $\begin{array}{c}\text { Concentração média de } \\
\text { fundo }\end{array}$ & $\mathrm{P} / \mathrm{m}^{3}$ & $2,37 E+05$ & $1,10 E+05$ & $1,00 E+04$ & $0,00 E+00$ & $0,00 E+00$ & $0,00 E+00$ \\
\hline & $\begin{array}{c}\text { Número de particulas } \\
\text { de fundo }\end{array}$ & $\mathbf{p}$ & 71 & 33 & 3 & 0 & 0 & 0 \\
\hline & $\begin{array}{c}\text { Concentração média } \\
\text { liquida } \\
\end{array}$ & $\mathrm{P} / \mathrm{m}^{3}$ & $1,23 E+08$ & $9,71 \mathrm{E}+07$ & $5,84 E+07$ & $3,51 \mathrm{E}+07$ & $6,25 E+06$ & $4,10 E+05$ \\
\hline & $\begin{array}{c}\text { Número de Particulas } \\
\text { média liquida }\end{array}$ & $\mathbf{p}$ & 36903 & 29132 & 17520 & 10520 & 1874 & 123 \\
\hline & Desvio - Poisson & $\#$ & 192,10 & 170,68 & 132,36 & 102,57 & 43,29 & 11,09 \\
\hline & $\begin{array}{c}\text { Desvio - Poisson - } \\
\text { Relativo } \\
\end{array}$ & $\%$ & 0,5 & 0,6 & 0,8 & 1,0 & 2,3 & 9,0 \\
\hline & $\begin{array}{l}\text { Desvio padrão } \\
\text { Concentração } \\
\end{array}$ & $\mathrm{P} / \mathrm{m}^{3}$ & $1,65 \mathrm{E}+04$ & $1,34 \mathrm{E}+04$ & $3,77 \mathrm{E}+03$ & $3,81 E+03$ & $3,83 E+02$ & $3,13 E+01$ \\
\hline & DP/Concentração média & $\%$ & 0,0134 & 0,0138 & 0,0065 & 0,0109 & 0,0061 & 0,0076 \\
\hline \multicolumn{2}{|c|}{ Erro total medições( $\varepsilon)$} & $\mathrm{P} / \mathrm{m}^{3}$ & $6,41 E+05$ & $5,69 \mathrm{E}+05$ & $4,41 E+05$ & $3,42 E+05$ & $1,44 \mathrm{E}+05$ & $3,70 \mathrm{E}+04$ \\
\hline
\end{tabular}




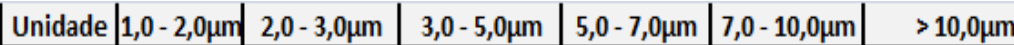

\begin{tabular}{|c|c|c|c|c|c|c|c|c|}
\hline \multirow{8}{*}{ Assento 1A } & $\begin{array}{c}\text { Concentração média de } \\
\text { fundo }\end{array}$ & $\mathrm{P} / \mathrm{m}^{3}$ & $2,07 E+05$ & $1,13 E+05$ & $1,33 E+04$ & $0,00 E+00$ & $0,00 E+00$ & $0,00 E+00$ \\
\hline & \begin{tabular}{c|} 
Número de particulas \\
de fundo
\end{tabular} & $\mathbf{P}$ & 62 & 34 & 4 & 0 & 0 & 0 \\
\hline & $\begin{array}{l}\text { Concentração média } \\
\text { liquida } \\
\end{array}$ & $\mathrm{P} / \mathrm{m}^{3}$ & $\mid 9,91 E+07$ & $9,37 E+07$ & $2,67 E+07$ & $1,96 \mathrm{E}+07$ & $4,90 E+06$ & $3,50 E+05$ \\
\hline & $\begin{array}{c}\text { Número de Particulas } \\
\text { média liquida }\end{array}$ & $\mathbf{P}$ & 29715 & 28121 & 8020 & 5876 & 1471 & 105 \\
\hline & Desvio - Poisson & \# & 172,38 & 167,69 & 89,55 & 76,66 & 38,35 & 10,25 \\
\hline & $\begin{array}{l}\text { Desvio - Poisson - } \\
\text { Relativo } \\
\end{array}$ & $\%$ & 0,6 & 0,6 & 1,1 & 1,3 & 2,6 & 9,8 \\
\hline & $\begin{array}{l}\text { Desvio padrão } \\
\text { Concentração }\end{array}$ & $\mathrm{P} / \mathrm{m}^{3}$ & $3,93 E+03$ & $3,28 E+03$ & $8,43 E+02$ & $1,77 E+03$ & $1,80 E+02$ & $4,22 E+01$ \\
\hline & DP/Concentração média & $\%$ & 0,0040 & 0,0035 & 0,0032 & 0,0091 & 0,0037 & 0,0121 \\
\hline \multirow{2}{*}{\multicolumn{2}{|c|}{ Erro total mediç̧oses(€) }} & $\mathrm{P} / \mathrm{m}^{3}$ & $5,75 E+05$ & $5,59 \mathrm{E}+05$ & $2,99 \mathrm{E}+05$ & $2,56 \mathrm{E}+05$ & $1,28 E+05$ & $3,42 E+04$ \\
\hline & & Unidade & $1,0-2,0 \mu \mathrm{m}$ & $2,0-3,0 \mu \mathrm{m}$ & $3,0-5,0 \mu \mathrm{m}$ & $5,0-7,0 \mu \mathrm{m}$ & $7,0-10,0 \mu \mathrm{m}$ & $>10,0 \mu \mathrm{m}$ \\
\hline \multirow{8}{*}{ Assento 2B } & \begin{tabular}{|c|}
$\begin{array}{c}\text { Concentração média de } \\
\text { fundo }\end{array}$ \\
\end{tabular} & $\mathrm{P} / \mathrm{m}^{3}$ & $1,87 E+05$ & $5,67 E+04$ & $6,67 E+03$ & $0,00 E+00$ & $0,00 E+00$ & $0,00 E+00$ \\
\hline & \begin{tabular}{c|} 
Número de particulas \\
de fundo
\end{tabular} & $\mathbf{p}$ & 56 & 17 & 2 & 0 & 0 & 0 \\
\hline & $\begin{array}{l}\text { Concentração média } \\
\text { liquida }\end{array}$ & $\mathrm{P} / \mathrm{m}^{3}$ & $1,63 \mathrm{E}+08$ & $1,59 E+08$ & $4,52 E+07$ & $2,63 \mathrm{E}+07$ & $1,03 E+07$ & $5,67 E+05$ \\
\hline & $\begin{array}{c}\text { Número de Particulas } \\
\text { média liquida }\end{array}$ & $\mathbf{P}$ & 48805 & 47598 & 13560 & 7891 & 3082 & 170 \\
\hline & Desvio - Poisson & \# & 220,92 & 218,17 & 116,45 & 88,83 & 55,52 & 13,04 \\
\hline & $\begin{array}{c}\text { Desvio - Poisson - } \\
\text { Relativo } \\
\end{array}$ & $\%$ & 0,5 & 0,5 & 0,9 & 1,1 & 1,8 & 7,7 \\
\hline & $\begin{array}{l}\text { Desvio padrão } \\
\text { Concentração }\end{array}$ & $\mathrm{P} / \mathrm{m}^{3}$ & $1,45 E+04$ & $1,40 E+04$ & $4,73 E+03$ & $1,12 E+03$ & $3,92 E+02$ & $3,32 E+01$ \\
\hline & DP/Concentração média & $\%$ & 0,0089 & 0,0088 & 0,0105 & 0,0042 & 0,0038 & 0,0059 \\
\hline \multirow{2}{*}{\multicolumn{2}{|c|}{ Erro total medições(દ) }} & $\mathrm{P} / \mathrm{m}^{3}$ & 7,37E+05 & $7,27 E+05$ & $3,88 E+05$ & $2,96 \mathrm{E}+05$ & $1,85 \mathrm{E}+05$ & $4,35 E+04$ \\
\hline & & Unidade & $1,0-2,0 \mu \mathrm{m}$ & $2,0-3,0 \mu \mathrm{m}$ & $3,0-5,0 \mu \mathrm{m}$ & $5,0-7,0 \mu \mathrm{m}$ & $7,0-10,0 \mu \mathrm{m}$ & $>10,0 \mu \mathrm{m}$ \\
\hline \multirow{8}{*}{ Assento 2A } & \begin{tabular}{|c|}
$\begin{array}{c}\text { Concentração média de } \\
\text { fundo }\end{array}$ \\
\end{tabular} & $\mathrm{P} / \mathrm{m}^{3}$ & $1,80 E+05$ & $1,10 \mathrm{E}+05$ & $1,33 \mathrm{E}+04$ & $0,00 E+00$ & $0,00 E+00$ & $0,00 E+00$ \\
\hline & $\begin{array}{c}\text { Número de particulas } \\
\text { de fundo }\end{array}$ & $\mathbf{p}$ & 54 & 33 & 4 & 0 & 0 & 0 \\
\hline & $\begin{array}{l}\text { Concentração média } \\
\text { liquida }\end{array}$ & $\mathrm{P} / \mathrm{m}^{3}$ & $1,57 E+08$ & $9,71 E+07$ & $5,00 E+07$ & $3,41 E+07$ & $9,68 E+06$ & $6,03 E+05$ \\
\hline & $\begin{array}{c}\text { Número de Particulas } \\
\text { média liquida }\end{array}$ & $\mathbf{P}$ & 47219 & 29137 & 15000 & 10220 & 2903 & 181 \\
\hline & Desvio - Poisson & \# & 217,30 & 170,70 & 122,47 & 101,09 & 53,88 & 13,45 \\
\hline & $\begin{array}{l}\text { Desvio - Poisson - } \\
\text { Relativo }\end{array}$ & $\%$ & 0,5 & 0,6 & 0,8 & 1,0 & 1,9 & 7,4 \\
\hline & $\begin{array}{l}\text { Desvio padrão } \\
\text { Concentração }\end{array}$ & $\mathrm{P} / \mathrm{m}^{3}$ & $2,61 E+04$ & $1,21 E+05$ & $6,08 E+03$ & $1,01 E+03$ & $7,57 E+02$ & $8,05 E+01$ \\
\hline & DP/Concentração média & $\%$ & 0,0166 & 0,1248 & 0,0122 & 0,0030 & 0,0078 & 0,0133 \\
\hline \multicolumn{2}{|c|}{ Erro total medições( $(\varepsilon)$} & $\mathrm{P} / \mathrm{m}^{3}$ & $7,25 E+05$ & $5,82 E+05$ & $4,08 E+05$ & $3,37 E+05$ & $1,80 E+05$ & $4,48 E+04$ \\
\hline
\end{tabular}




\begin{tabular}{|c|c|c|c|c|c|c|c|c|}
\hline & & Unidade & $\mid 1,0-2,0 \mu \mathrm{m}$ & $2,0-3,0 \mu \mathrm{m}$ & $3,0-5,0 \mu \mathrm{m}$ & $5,0-7,0 \mu \mathrm{m}$ & $7,0-10,0 \mu \mathrm{m}$ & $>10,0 \mu \mathrm{m}$ \\
\hline \multirow{8}{*}{ Assento 3B } & \begin{tabular}{|c|}
$\begin{array}{c}\text { Concentração média de } \\
\text { fundo }\end{array}$ \\
\end{tabular} & $\mathrm{P} / \mathrm{m}^{3}$ & $1,30 E+05$ & $7,67 E+04$ & $1,00 \mathrm{E}+04$ & $0,00 E+00$ & $0,00 E+00$ & $0,00 E+00$ \\
\hline & $\begin{array}{c}\text { Número de particulas } \\
\text { de fundo }\end{array}$ & $\mathbf{P}$ & 39 & 23 & 3 & 0 & 0 & 0 \\
\hline & $\begin{array}{c}\begin{array}{c}\text { Concentração média } \\
\text { liquida }\end{array} \\
\end{array}$ & $\mathrm{P} / \mathrm{m}^{3}$ & $1,33 \mathrm{E}+08$ & $1,21 E+08$ & $5,51 \mathrm{E}+07$ & $3,51 E+07$ & $1,83 E+07$ & $8,13 E+05$ \\
\hline & $\begin{array}{c}\text { Número de Particulas } \\
\text { média liquida }\end{array}$ & $\mathbf{P}$ & 39829 & 36292 & 16520 & 10520 & 5492 & 244 \\
\hline & Desvio - Poisson & $\#$ & 199,57 & 190,50 & 128,53 & 102,57 & 74,11 & 15,62 \\
\hline & $\begin{array}{c}\text { Desvio - Poisson - } \\
\text { Relativo } \\
\end{array}$ & $\%$ & 0,5 & 0,5 & 0,8 & 1,0 & 1,3 & 6,4 \\
\hline & $\begin{array}{l}\begin{array}{l}\text { Desvio padrão } \\
\text { Concentração }\end{array} \\
\end{array}$ & $\mathrm{P} / \mathrm{m}^{3}$ & $2,14 \mathrm{E}+03$ & $1,26 \mathrm{E}+03$ & $1,81 \mathrm{E}+04$ & $7,81 \mathrm{E}+03$ & $5,95 \mathrm{E}+02$ & $4,47 E+01$ \\
\hline & DP/Concentração média & $\%$ & 0,0016 & 0,0010 & 0,0329 & 0,0223 & 0,0033 & 0,0055 \\
\hline \multirow{2}{*}{\multicolumn{2}{|c|}{ Erro total medições( $(\varepsilon)$}} & $\mathrm{P} / \mathrm{m}^{3}$ & $6,65 E+05$ & $6,35 E+05$ & $4,29 E+05$ & $3,42 \mathrm{E}+05$ & $2,47 E+05$ & $5,21 \mathrm{E}+04$ \\
\hline & & Unidade & $1,0-2,0 \mu \mathrm{m}$ & $2,0-3,0 \mu \mathrm{m}$ & $3,0-5,0 \mu \mathrm{m}$ & $5,0-7,0 \mu \mathrm{m}$ & $7,0-10,0 \mu \mathrm{m}$ & $>10,0 \mu \mathrm{m}$ \\
\hline \multirow{8}{*}{ Assento 3A } & $\begin{array}{c}\text { Concentração média de } \\
\text { fundo }\end{array}$ & $\mathrm{P} / \mathrm{m}^{3}$ & $7,67 E+04$ & $3,67 E+04$ & $2,33 E+04$ & $0,00 E+00$ & $0,00 E+00$ & $0,00 E+00$ \\
\hline & $\begin{array}{c}\text { Número de particulas } \\
\text { de fundo }\end{array}$ & $\mathbf{P}$ & 23 & 11 & 7 & 0 & 0 & 0 \\
\hline & $\begin{array}{c}\begin{array}{c}\text { Concentração média } \\
\text { liquida }\end{array} \\
\end{array}$ & $\mathrm{P} / \mathrm{m}^{3}$ & $2,84 \mathrm{E}+07$ & $2,05 \mathrm{E}+07$ & $1,33 \mathrm{E}+07$ & $3,15 \mathrm{E}+07$ & $7,56 \mathrm{E}+06$ & $1,26 E+06$ \\
\hline & $\begin{array}{c}\text { Número de Particulas } \\
\text { média liquida }\end{array}$ & $\mathbf{P}$ & 8534 & 6145 & 4000 & 9450 & 2268 & 377 \\
\hline & Desvio - Poisson & $\#$ & 92,38 & 78,39 & 63,25 & 97,21 & 47,62 & 19,42 \\
\hline & $\begin{array}{c}\text { Desvio - Poisson - } \\
\text { Relativo } \\
\end{array}$ & $\%$ & 1,1 & 1,3 & 1,6 & 1,0 & 2,1 & 5,2 \\
\hline & $\begin{array}{l}\begin{array}{l}\text { Desvio padrão } \\
\text { Concentração }\end{array} \\
\end{array}$ & $\mathrm{P} / \mathrm{m}^{3}$ & $2,83 E+04$ & $2,95 E+04$ & $7,92 \mathrm{E}+02$ & $3,36 \mathrm{E}+03$ & $1,71 \mathrm{E}+03$ & $1,04 \mathrm{E}+02$ \\
\hline & DP/Concentração média & $\%$ & 0,0995 & 0,1441 & 0,0059 & 0,0107 & 0,0227 & 0,0083 \\
\hline \multicolumn{2}{|c|}{ Erro total medições( $\varepsilon$ ) } & $\mathrm{P} / \mathrm{m}^{3}$ & $3,09 \mathrm{E}+05$ & $2,63 \mathrm{E}+05$ & $2,11 \mathrm{E}+05$ & $3,24 E+05$ & $1,59 \mathrm{E}+05$ & $6,47 E+04$ \\
\hline
\end{tabular}


Tabela D-4. Resultados das medições de partículas no assento (Sistema $\mathrm{MV}$ à $22^{\circ} \mathrm{C}$ - injeção pelo assento $3 \mathrm{D}$ )

\begin{tabular}{|c|c|c|c|c|c|c|c|c|}
\hline & & Unidade & $1,0-2,0 \mu \mathrm{m}$ & $2,0-3,0 \mu \mathrm{m}$ & $3,0-5,0 \mu \mathrm{m}$ & $5,0-7,0 \mu \mathrm{m}$ & $7,0-10,0 \mu \mathrm{m}$ & $>10,0 \mu \mathrm{m}$ \\
\hline \multirow{8}{*}{ Assento 3E } & $\begin{array}{c}\text { Concentração média de } \\
\text { fundo }\end{array}$ & $\mathrm{P} / \mathrm{m}^{3}$ & $1,67 E+05$ & $1,50 E+05$ & $1,00 E+04$ & $0,00 E+00$ & $0,00 E+00$ & $0,00 E+00$ \\
\hline & $\begin{array}{c}\text { Número de particulas } \\
\text { de fundo }\end{array}$ & $\mathbf{P}$ & 50 & 45 & 3 & 0 & 0 & 0 \\
\hline & $\begin{array}{c}\text { Concentração média } \\
\text { liquida }\end{array}$ & $\mathrm{P} / \mathrm{m}^{3}$ & $2,48 \mathrm{E}+08$ & $2,39 \mathrm{E}+08$ & $1,37 \mathrm{E}+08$ & $1,03 E+08$ & $5,50 \mathrm{E}+07$ & $1,20 E+06$ \\
\hline & $\begin{array}{c}\text { Número de Particulas } \\
\text { média liquida }\end{array}$ & $\mathbf{P}$ & 74332 & 71785,5 & 41000 & 31000 & 16500 & 361 \\
\hline & Desvio - Poisson & $\#$ & 272,64 & 267,93 & 202,48 & 176,07 & 128,45 & 19,00 \\
\hline & $\begin{array}{c}\text { Desvio - Poisson - } \\
\text { Relativo }\end{array}$ & $\%$ & 0,4 & 0,4 & 0,5 & 0,6 & 0,8 & 5,3 \\
\hline & $\begin{array}{l}\text { Desvio padrão } \\
\text { Concentração }\end{array}$ & $\mathrm{P} / \mathrm{m}^{3}$ & $2,79 E+04$ & $2,68 \mathrm{E}+04$ & $1,68 \mathrm{E}+04$ & $1,04 E+04$ & $4,68 \mathrm{E}+03$ & $8,36 \mathrm{E}+01$ \\
\hline & DP/Concentração média & $\%$ & 0,0113 & 0,0112 & 0,0123 & 0,0100 & 0,0085 & 0,0069 \\
\hline \multirow{2}{*}{\multicolumn{2}{|c|}{ Erro total medições(દ) }} & $\mathrm{P} / \mathrm{m}^{3}$ & $9,09 E+05$ & $8,93 E+05$ & $6,75 E+05$ & $5,87 E+05$ & $4,28 \mathrm{E}+05$ & $6,33 E+04$ \\
\hline & & Unidade & $1,0-2,0 \mu \mathrm{m}$ & $2,0-3,0 \mu \mathrm{m}$ & $3,0-5,0 \mu \mathrm{m}$ & $5,0-7,0 \mu \mathrm{m}$ & $7,0-10,0 \mu \mathrm{m}$ & $>10,0 \mu \mathrm{m}$ \\
\hline \multirow{8}{*}{ Assento 2D } & $\begin{array}{c}\text { Concentração média de } \\
\text { fundo }\end{array}$ & $\mathrm{P} / \mathrm{m}^{3}$ & $6,67 E+04$ & $2,33 E+04$ & $3,33 \mathrm{E}+03$ & $0,00 E+00$ & $0,00 E+00$ & $0,00 E+00$ \\
\hline & $\begin{array}{l}\text { Número de particulas } \\
\text { de fundo }\end{array}$ & $\mathbf{P}$ & 20 & 7 & 1 & 0 & 0 & 0 \\
\hline & $\begin{array}{c}\text { Concentração média } \\
\text { liquida }\end{array}$ & $\mathrm{P} / \mathrm{m}^{3}$ & $1,28 \mathrm{E}+08$ & $1,17 E+08$ & $1,05 E+08$ & $4,55 \mathrm{E}+07$ & $8,17 E+06$ & $5,13 E+05$ \\
\hline & $\begin{array}{c}\text { Número de Particulas } \\
\text { média liquida }\end{array}$ & $\mathbf{P}$ & 38535 & 34964 & 31580 & 13650 & 2452 & 154 \\
\hline & Desvio - Poisson & $\#$ & 196,30 & 186,99 & 177,71 & 116,83 & 49,51 & 12,41 \\
\hline & $\begin{array}{c}\text { Desvio - Poisson - } \\
\text { Relativo } \\
\end{array}$ & $\%$ & 0,5 & 0,5 & 0,6 & 0,9 & 2,0 & 8,1 \\
\hline & $\begin{array}{l}\text { Desvio padrão } \\
\text { Concentração }\end{array}$ & $\mathrm{P} / \mathrm{m}^{3}$ & $9,57 \mathrm{E}+03$ & $6,33 E+03$ & $3,42 E+03$ & $9,58 \mathrm{E}+02$ & $1,04 E+03$ & $1,04 \mathrm{E}+02$ \\
\hline & DP/Concentração média & $\%$ & 0,0075 & 0,0054 & 0,0032 & 0,0021 & 0,0127 & 0,0203 \\
\hline \multirow{2}{*}{\multicolumn{2}{|c|}{ Erro total medições(દ) }} & $\mathrm{P} / \mathrm{m}^{3}$ & $6,54 \mathrm{E}+05$ & $6,23 \mathrm{E}+05$ & $5,92 \mathrm{E}+05$ & $3,89 \mathrm{E}+05$ & $1,65 \mathrm{E}+05$ & $4,14 E+04$ \\
\hline & & Unidade & $1,0-2,0 \mu \mathrm{m}$ & $2,0-3,0 \mu \mathrm{m}$ & $3,0-5,0 \mu \mathrm{m}$ & $5,0-7,0 \mu \mathrm{m}$ & $7,0-10,0 \mu \mathrm{m}$ & $>10,0 \mu \mathrm{m}$ \\
\hline \multirow{8}{*}{ Assento 2E } & $\begin{array}{c}\text { Concentração média de } \\
\text { fundo }\end{array}$ & $\mathrm{P} / \mathrm{m}^{3}$ & $1,57 \mathrm{E}+05$ & $7,00 E+04$ & $1,00 E+04$ & $0,00 \mathrm{E}+00$ & $0,00 E+00$ & $0,00 E+00$ \\
\hline & $\begin{array}{c}\text { Número de particulas } \\
\text { de fundo }\end{array}$ & $\mathbf{P}$ & 47 & 21 & 3 & 0 & 0 & 0 \\
\hline & $\begin{array}{c}\text { Concentração média } \\
\text { liquida }\end{array}$ & $\mathrm{P} / \mathrm{m}^{3}$ & $1,43 E+08$ & $1,30 \mathrm{E}+08$ & $1,03 E+08$ & $7,18 \mathrm{E}+07$ & $6,62 E+07$ & $8,33 E+05$ \\
\hline & $\begin{array}{c}\text { Número de Particulas } \\
\text { média liquida }\end{array}$ & $\mathbf{P}$ & 42884,14 & 38985,00 & 31000,00 & 21540,00 & 19871,00 & 250,00 \\
\hline & Desvio - Poisson & $\#$ & 207,08 & 197,45 & 176,07 & 146,77 & 140,96 & 15,81 \\
\hline & $\begin{array}{c}\text { Desvio - Poisson - } \\
\text { Relativo } \\
\end{array}$ & $\%$ & 0,5 & 0,5 & 0,6 & 0,7 & 0,7 & 6,3 \\
\hline & $\begin{array}{l}\text { Desvio padrão } \\
\text { Concentração }\end{array}$ & $\mathrm{P} / \mathrm{m}^{3}$ & $2,39 \mathrm{E}+03$ & $7,24 \mathrm{E}+03$ & $2,15 E+03$ & $1,89 \mathrm{E}+03$ & $1,79 \mathrm{E}+03$ & $5,68 \mathrm{E}+01$ \\
\hline & DP/Concentração média & $\%$ & 0,0017 & 0,0056 & 0,0021 & 0,0026 & 0,0027 & 0,0068 \\
\hline \multicolumn{2}{|c|}{ Erro total medições(દ) } & $\mathrm{P} / \mathrm{m}^{3}$ & $6,90 \mathrm{E}+05$ & $6,58 \mathrm{E}+05$ & $5,87 E+05$ & $4,89 E+05$ & $4,70 E+05$ & $5,27 \mathrm{E}+04$ \\
\hline
\end{tabular}




\begin{tabular}{|c|c|c|c|c|c|c|c|c|}
\hline & & Unidade & $1,0-2,0 \mu \mathrm{m}$ & $2,0-3,0 \mu \mathrm{m}$ & $3,0-5,0 \mu \mathrm{m}$ & $5,0-7,0 \mu \mathrm{m}$ & $7,0-10,0 \mu \mathrm{m}$ & $>10,0 \mu \mathrm{m}$ \\
\hline \multirow{8}{*}{ Assento 1D } & $\begin{array}{c}\text { Concentração média de } \\
\text { fundo }\end{array}$ & $\mathrm{P} / \mathrm{m}^{3}$ & $1,77 E+05$ & $7,00 E+04$ & $1,00 E+04$ & $0,00 E+00$ & $0,00 E+00$ & $0,00 E+00$ \\
\hline & $\begin{array}{c}\text { Número de particulas } \\
\text { de fundo }\end{array}$ & $\mathbf{p}$ & 53 & 21 & 3 & 0 & 0 & 0 \\
\hline & $\begin{array}{l}\text { Concentração média } \\
\text { liquida }\end{array}$ & $\mathrm{P} / \mathrm{m}^{3}$ & $1,40 E+08$ & $1,05 \mathrm{E}+08$ & $9,28 \mathrm{E}+07$ & $5,50 E+07$ & $6,69 \mathrm{E}+06$ & $4,18 \mathrm{E}+05$ \\
\hline & $\begin{array}{c}\text { Número de Particulas } \\
\text { média liquida }\end{array}$ & $\mathbf{P}$ & 42141,833 & 31388 & 27850 & 16500 & 2006 & 125,5 \\
\hline & Desvio - Poisson & $\#$ & 205,28 & 177,17 & 166,88 & 128,45 & 44,79 & 11,20 \\
\hline & $\begin{array}{c}\text { Desvio - Poisson - } \\
\text { Relativo } \\
\end{array}$ & $\%$ & 0,5 & 0,6 & 0,6 & 0,8 & 2,2 & 8,9 \\
\hline & $\begin{array}{l}\text { Desvio padrão } \\
\text { Concentração }\end{array}$ & $\mathrm{P} / \mathrm{m}^{3}$ & $7,58 \mathrm{E}+03$ & $7,53 E+03$ & $1,22 \mathrm{E}+03$ & $3,05 E+03$ & $5,77 E+02$ & $2,23 \mathrm{E}+01$ \\
\hline & DP/Concentração média & $\%$ & 0,0054 & 0,0072 & 0,0013 & 0,0055 & 0,0086 & 0,0053 \\
\hline \multirow{2}{*}{\multicolumn{2}{|c|}{ Erro total medições(દ) }} & $\mathrm{P} / \mathrm{m}^{3}$ & $6,84 E+05$ & $5,91 E+05$ & $5,56 \mathrm{E}+05$ & $4,28 \mathrm{E}+05$ & $1,49 \mathrm{E}+05$ & $3,73 E+04$ \\
\hline & & Unidade & $1,0-2,0 \mu \mathrm{m}$ & $2,0-3,0 \mu \mathrm{m}$ & $3,0-5,0 \mu \mathrm{m}$ & $5,0-7,0 \mu \mathrm{m}$ & $7,0-10,0 \mu \mathrm{m}$ & $>10,0 \mu \mathrm{m}$ \\
\hline \multirow{8}{*}{ Assento $1 \mathrm{E}$} & $\begin{array}{c}\begin{array}{c}\text { Concentração média de } \\
\text { fundo }\end{array} \\
\end{array}$ & $\mathrm{P} / \mathrm{m}^{3}$ & $9,67 E+04$ & $4,67 E+04$ & $1,00 E+04$ & $3,33 E+03$ & $0,00 E+00$ & $0,00 E+00$ \\
\hline & $\begin{array}{c}\text { Número de particulas } \\
\text { de fundo }\end{array}$ & $\mathbf{p}$ & 29 & 14 & 3 & 1 & 0 & 0 \\
\hline & $\begin{array}{l}\text { Concentração média } \\
\text { liquida } \\
\end{array}$ & $\mathrm{P} / \mathrm{m}^{3}$ & $1,27 E+08$ & $1,13 E+08$ & $9,33 \mathrm{E}+07$ & $5,33 \mathrm{E}+07$ & $4,69 \mathrm{E}+06$ & $3,10 \mathrm{E}+05$ \\
\hline & $\begin{array}{c}\text { Número de Particulas } \\
\text { média liquida }\end{array}$ & $\mathbf{P}$ & 38109,375 & 33798,75 & 28000 & 16000 & 1407 & 93 \\
\hline & Desvio - Poisson & $\#$ & 195,22 & 183,84 & 167,33 & 126,49 & 37,51 & 9,64 \\
\hline & $\begin{array}{c}\text { Desvio - Poisson - } \\
\text { Relativo } \\
\end{array}$ & $\%$ & 0,5 & 0,5 & 0,6 & 0,8 & 2,7 & 10,4 \\
\hline & $\begin{array}{l}\text { Desvio padrão } \\
\text { Concentração }\end{array}$ & $\mathrm{P} / \mathrm{m}^{3}$ & $2,40 E+03$ & $7,07 E+03$ & $2,83 \mathrm{E}+03$ & $3,33 E+03$ & $2,50 E+02$ & $4,17 E+01$ \\
\hline & DP/Concentração média & $\%$ & 0,0019 & 0,0063 & 0,0030 & 0,0062 & 0,0053 & 0,0135 \\
\hline \multirow{2}{*}{\multicolumn{2}{|c|}{ Erro total medições $(\varepsilon)$}} & $\mathrm{P} / \mathrm{m}^{3}$ & $6,51 E+05$ & $6,13 E+05$ & $5,58 \mathrm{E}+05$ & $4,22 E+05$ & $1,25 \mathrm{E}+05$ & $3,21 \mathrm{E}+04$ \\
\hline & & Unidade & $1,0-2,0 \mu \mathrm{m}$ & $2,0-3,0 \mu \mathrm{m}$ & $3,0-5,0 \mu \mathrm{m}$ & $5,0-7,0 \mu \mathrm{m}$ & $7,0-10,0 \mu \mathrm{m}$ & $>10,0 \mu \mathrm{m}$ \\
\hline \multirow{8}{*}{ Assento 1B } & \begin{tabular}{|c|}
$\begin{array}{c}\text { Concentração média de } \\
\text { fundo }\end{array}$ \\
\end{tabular} & $\mathrm{P} / \mathrm{m}^{3}$ & $1,10 E+05$ & $6,33 E+04$ & $3,33 \mathrm{E}+03$ & $0,00 \mathrm{E}+00$ & $0,00 \mathrm{E}+00$ & $0,00 \mathrm{E}+00$ \\
\hline & $\begin{array}{c}\text { Número de particulas } \\
\text { de fundo }\end{array}$ & $\mathbf{p}$ & 33 & 19 & 1 & 0 & 0 & 0 \\
\hline & $\begin{array}{c}\text { Concentração média } \\
\text { liquida }\end{array}$ & $\mathrm{P} / \mathrm{m}^{3}$ & $1,18 \mathrm{E}+08$ & $9,86 \mathrm{E}+07$ & $7,52 \mathrm{E}+07$ & $4,67 E+07$ & $5,36 \mathrm{E}+06$ & $3,73 E+05$ \\
\hline & $\begin{array}{c}\text { Número de Particulas } \\
\text { média liquida }\end{array}$ & $\mathbf{p}$ & 35365 & 29586 & 22560 & 14002 & 1608 & 112 \\
\hline & Desvio - Poisson & $\#$ & 188,05 & 172,01 & 150,20 & 118,33 & 40,10 & 10,58 \\
\hline & $\begin{array}{c}\text { Desvio - Poisson - } \\
\text { Relativo } \\
\end{array}$ & $\%$ & 0,5 & 0,6 & 0,7 & 0,8 & 2,5 & 9,4 \\
\hline & $\begin{array}{l}\text { Desvio padrão } \\
\text { Concentração }\end{array}$ & $\mathrm{P} / \mathrm{m}^{3}$ & $1,40 E+03$ & $2,26 \mathrm{E}+03$ & $1,18 \mathrm{E}+03$ & $1,30 \mathrm{E}+03$ & $2,73 E+02$ & $4,52 E+01$ \\
\hline & DP/Concentração média & $\%$ & 0,0012 & 0,0023 & 0,0016 & 0,0028 & 0,0051 & 0,0121 \\
\hline \multicolumn{2}{|c|}{ Erro total medições $(\varepsilon)$} & $\mathrm{P} / \mathrm{m}^{3}$ & $6,27 E+05$ & $5,73 E+05$ & $5,01 E+05$ & $3,94 \mathrm{E}+05$ & $1,34 \mathrm{E}+05$ & $3,53 \mathrm{E}+04$ \\
\hline
\end{tabular}


Unidade $1,0-2,0 \mu \mathrm{m}|2,0-3,0 \mu \mathrm{m}| 3,0-5,0 \mu \mathrm{m}|5,0-7,0 \mu \mathrm{m}| 7,0-10,0 \mu \mathrm{m} \mid>10,0 \mu \mathrm{m}$

\begin{tabular}{|c|c|c|c|c|c|c|c|c|}
\hline \multirow{8}{*}{ Assento 1A } & \begin{tabular}{|c|}
$\begin{array}{c}\text { Concentração média de } \\
\text { fundo }\end{array}$ \\
\end{tabular} & $\mathrm{P} / \mathrm{m}^{3}$ & $1,47 E+05$ & $1,10 \mathrm{E}+05$ & 6,67E+03 & $0,00 \mathrm{E}+00$ & $0,00 E+00$ & $0,00 E+00$ \\
\hline & $\begin{array}{c}\text { Número de particulas } \\
\text { de fundo }\end{array}$ & $\mathbf{P}$ & 44 & 33 & 2 & 0 & 0 & 0 \\
\hline & $\begin{array}{c}\text { Concentração média } \\
\text { liquida }\end{array}$ & $\mathrm{P} / \mathrm{m}^{3}$ & $9,67 E+07$ & $9,10 E+07$ & $6,52 \mathrm{E}+07$ & $2,88 \mathrm{E}+07$ & $1,87 \mathrm{E}+07$ & $3,37 E+05$ \\
\hline & $\begin{array}{c}\text { Número de Particulas } \\
\text { média liquida }\end{array}$ & $\mathbf{p}$ & 29019 & 27308 & 19560 & 8650 & 5620 & 101 \\
\hline & Desvio - Poisson & $\#$ & 170,35 & 165,25 & 139,86 & 93,01 & 74,97 & 10,05 \\
\hline & $\begin{array}{c}\text { Desvio - Poisson - } \\
\text { Relativo }\end{array}$ & $\%$ & 0,6 & 0,6 & 0,7 & 1,1 & 1,3 & 10,0 \\
\hline & $\begin{array}{l}\text { Desvio padrão } \\
\text { Concentração }\end{array}$ & $\mathrm{P} / \mathrm{m}^{3}$ & $1,50 E+04$ & $1,50 E+04$ & $2,33 \mathrm{E}+03$ & $1,49 \mathrm{E}+03$ & $1,19 \mathrm{E}+03$ & $4,41 E+01$ \\
\hline & DP/Concentração média & $\%$ & 0,0155 & 0,0165 & 0,0036 & 0,0052 & 0,0063 & 0,0131 \\
\hline \multirow{2}{*}{\multicolumn{2}{|c|}{ Erro total medições(દ) }} & $\mathrm{P} / \mathrm{m}^{3}$ & $5,68 \mathrm{E}+05$ & $5,51 \mathrm{E}+05$ & $4,66 \mathrm{E}+05$ & $3,10 E+05$ & $2,50 E+05$ & $3,35 E+04$ \\
\hline & & Unidade & $1,0-2,0 \mu \mathrm{m}$ & $2,0-3,0 \mu \mathrm{m}$ & $3,0-5,0 \mu \mathrm{m}$ & $5,0-7,0 \mu \mathrm{m}$ & $7,0-10,0 \mu \mathrm{m}$ & $>10,0 \mu \mathrm{m}$ \\
\hline \multirow{8}{*}{ Assento 2B } & $\begin{array}{c}\text { Concentração média de } \\
\text { fundo }\end{array}$ & $\mathrm{P} / \mathrm{m}^{3}$ & $1,93 E+05$ & $7,00 \mathrm{E}+04$ & $6,67 E+03$ & $0,00 \mathrm{E}+00$ & $0,00 E+00$ & $0,00 E+00$ \\
\hline & $\begin{array}{c}\text { Número de particulas } \\
\text { de fundo }\end{array}$ & $\mathbf{P}$ & 58 & 21 & 2 & 0 & 0 & 0 \\
\hline & $\begin{array}{l}\text { Concentração média } \\
\text { liquida } \\
\end{array}$ & $\mathrm{P} / \mathrm{m}^{3}$ & $1,40 \mathrm{E}+08$ & $1,19 \mathrm{E}+08$ & $8,55 \mathrm{E}+07$ & $6,00 \mathrm{E}+07$ & $2,67 E+07$ & $6,00 E+05$ \\
\hline & $\begin{array}{c}\text { Número de Particulas } \\
\text { média liquida }\end{array}$ & $\mathbf{p}$ & 41989 & 35757 & 25650 & 17988 & 8000 & 180 \\
\hline & Desvio - Poisson & $\#$ & 204,91 & 189,10 & 160,16 & 134,12 & 89,44 & 13,42 \\
\hline & $\begin{array}{c}\text { Desvio - Poisson - } \\
\text { Relativo } \\
\end{array}$ & $\%$ & 0,5 & 0,5 & 0,6 & 0,7 & 1,1 & 7,5 \\
\hline & $\begin{array}{l}\text { Desvio padrão } \\
\text { Concentração }\end{array}$ & $\mathrm{P} / \mathrm{m}^{3}$ & $1,35 E+04$ & $9,36 \mathrm{E}+03$ & $4,76 \mathrm{E}+03$ & $1,30 E+03$ & $8,20 \mathrm{E}+02$ & $2,33 E+01$ \\
\hline & DP/Concentração média & $\%$ & 0,0096 & 0,0079 & 0,0056 & 0,0022 & 0,0031 & 0,0039 \\
\hline \multirow{2}{*}{\multicolumn{2}{|c|}{ Erro total medições(દ) }} & $\mathrm{P} / \mathrm{m}^{3}$ & $6,83 \mathrm{E}+05$ & $6,30 \mathrm{E}+05$ & $5,34 \mathrm{E}+05$ & $4,47 E+05$ & $2,98 \mathrm{E}+05$ & $4,47 E+04$ \\
\hline & & Unidade & $1,0-2,0 \mu \mathrm{m}$ & $2,0-3,0 \mu \mathrm{m}$ & $3,0-5,0 \mu \mathrm{m}$ & $5,0-7,0 \mu \mathrm{m}$ & $7,0-10,0 \mu \mathrm{m}$ & $>10,0 \mu \mathrm{m}$ \\
\hline \multirow{8}{*}{ Assento 2A } & \begin{tabular}{|c|}
$\begin{array}{c}\text { Concentração média de } \\
\text { fundo }\end{array}$ \\
\end{tabular} & $\mathrm{P} / \mathrm{m}^{3}$ & $1,10 E+05$ & 7,33E+04 & $3,33 \mathrm{E}+03$ & $0,00 \mathrm{E}+00$ & $0,00 E+00$ & $0,00 E+00$ \\
\hline & $\begin{array}{c}\text { Número de particulas } \\
\text { de fundo }\end{array}$ & $\mathbf{p}$ & 33 & 22 & 1 & 0 & 0 & 0 \\
\hline & $\begin{array}{l}\text { Concentração média } \\
\text { liquida } \\
\end{array}$ & $\mathrm{P} / \mathrm{m}^{3}$ & $1,49 \mathrm{E}+08$ & $1,31 E+08$ & $9,11 E+07$ & $6,51 E+07$ & $1,77 \mathrm{E}+07$ & $5,77 \mathrm{E}+05$ \\
\hline & $\begin{array}{c}\text { Número de Particulas } \\
\text { média liquida }\end{array}$ & $\mathbf{P}$ & 44781 & 39287 & 27330 & 19520 & 5320 & 173 \\
\hline & Desvio - Poisson & $\#$ & 211,62 & 198,21 & 165,32 & 139,71 & 72,94 & 13,15 \\
\hline & $\begin{array}{c}\text { Desvio - Poisson - } \\
\text { Relativo } \\
\end{array}$ & $\%$ & 0,5 & 0,5 & 0,6 & 0,7 & 1,4 & 7,6 \\
\hline & $\begin{array}{c}\text { Desvio padrão } \\
\text { Concentração } \\
\end{array}$ & $\mathrm{P} / \mathrm{m}^{3}$ & $5,01 E+03$ & $3,90 E+03$ & $1,80 E+03$ & $2,13 E+03$ & $1,50 \mathrm{E}+03$ & $4,11 E+01$ \\
\hline & DP/Concentração média & $\%$ & 0,0034 & 0,0030 & 0,0020 & 0,0033 & 0,0085 & 0,0071 \\
\hline \multicolumn{2}{|c|}{ Erro total medições( $(\varepsilon)$} & $\mathrm{P} / \mathrm{m}^{3}$ & $7,05 E+05$ & $6,61 \mathrm{E}+05$ & $5,51 E+05$ & $4,66 \mathrm{E}+05$ & $2,43 \mathrm{E}+05$ & 4,38E+04 \\
\hline
\end{tabular}


Unidade $1,0-2,0 \mu \mathrm{m}|2,0-3,0 \mu \mathrm{m}| 3,0-5,0 \mu \mathrm{m}|5,0-7,0 \mu \mathrm{m}| 7,0-10,0 \mu \mathrm{m} \mid>10,0 \mu \mathrm{m}$

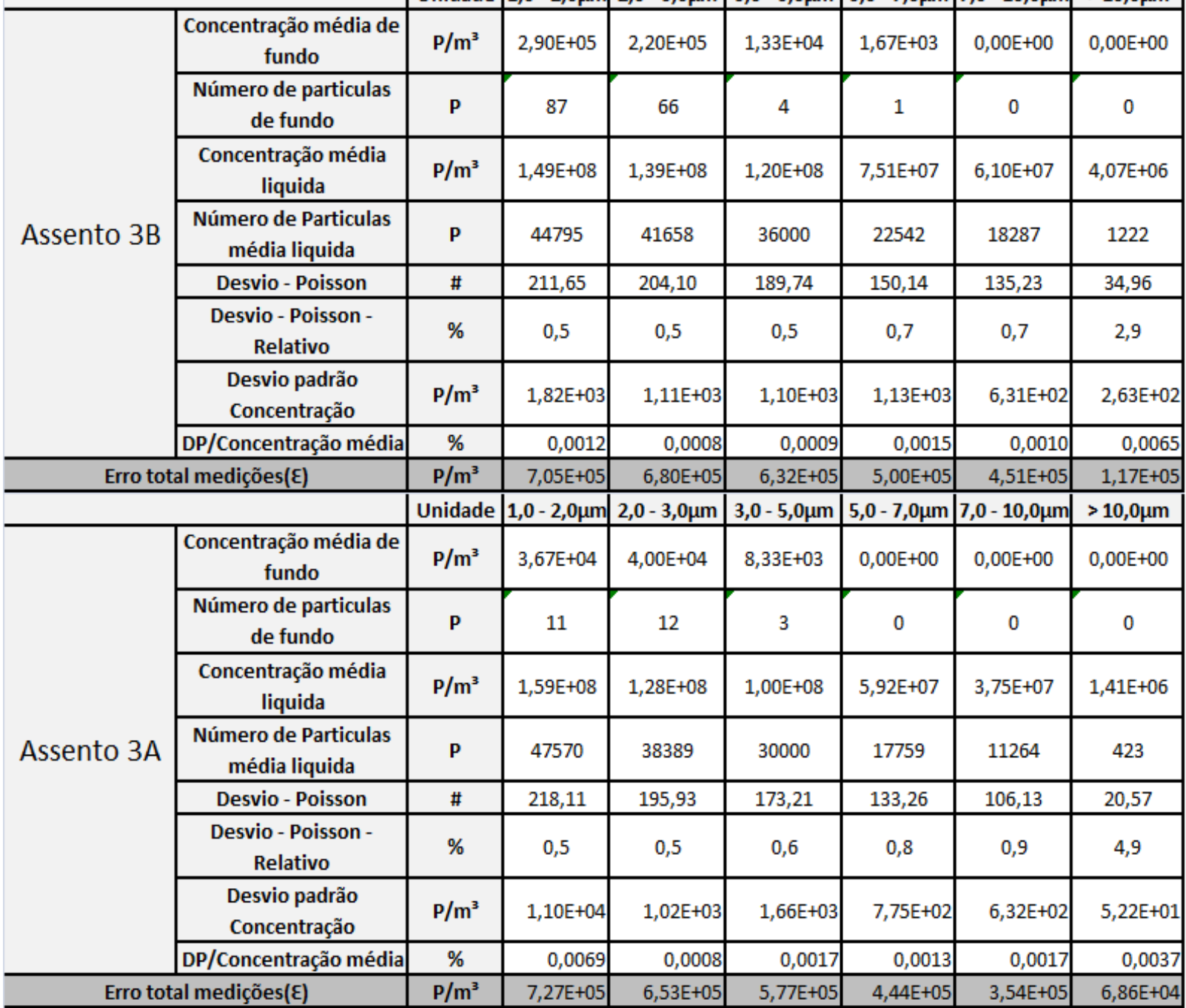


Tabela D-5. Resultados das medições de partículas no assento (Sistema UFAD à $22^{\circ} \mathrm{C}-$ injeção pelo assento $3 \mathrm{D}$ )

\begin{tabular}{|c|c|c|c|c|c|c|c|c|}
\hline & & Unidade & $1,0-2,0 \mu \mathrm{m}$ & $2,0-3,0 \mu \mathrm{m}$ & $3,0-5,0 \mu \mathrm{m}$ & $5,0-7,0 \mu \mathrm{m}$ & $7,0-10,0 \mu \mathrm{m}$ & $>10,0 \mu \mathrm{m}$ \\
\hline \multirow{8}{*}{ Assento 3E } & $\begin{array}{c}\text { Concentração média de } \\
\text { fundo }\end{array}$ & $\mathrm{P} / \mathrm{m}^{3}$ & $1,53 E+05$ & $1,17 E+05$ & $6,67 E+03$ & $0,00 \mathrm{E}+00$ & $0,00 \mathrm{E}+00$ & $0,00 E+00$ \\
\hline & $\begin{array}{c}\text { Número de particulas de } \\
\text { fundo }\end{array}$ & $\mathbf{P}$ & 46 & 35 & 2 & 0 & 0 & 0 \\
\hline & $\begin{array}{c}\text { Concentração média } \\
\text { liquida }\end{array}$ & $\mathrm{P} / \mathrm{m}^{3}$ & $1,55 E+08$ & $1,40 \mathrm{E}+08$ & $9,52 \mathrm{E}+07$ & $9,63 E+07$ & $3,28 \mathrm{E}+07$ & $2,02 E+06$ \\
\hline & $\begin{array}{l}\text { Número de Particulas } \\
\text { média liquida }\end{array}$ & $\mathbf{P}$ & 46458 & 42096 & 28560 & 28880 & 9850 & 607 \\
\hline & Desvio - Poisson & $\#$ & 215,54 & 205,17 & 169,00 & 169,94 & 99,25 & 24,64 \\
\hline & $\begin{array}{c}\text { Desvio - Poisson - } \\
\text { Relativo } \\
\end{array}$ & $\%$ & 0,5 & 0,5 & 0,6 & 0,6 & 1,0 & 4,1 \\
\hline & $\begin{array}{l}\text { Desvio padrão } \\
\text { Concentração }\end{array}$ & $\mathrm{P} / \mathrm{m}^{3}$ & $1,78 \mathrm{E}+04$ & $1,79 E+04$ & $1,07 E+04$ & $1,09 E+04$ & $3,83 \mathrm{E}+03$ & $2,46 \mathrm{E}+02$ \\
\hline & DP/Concentração média & $\%$ & 0,0115 & 0,0127 & 0,0113 & 0,0113 & 0,0117 & 0,0122 \\
\hline \multirow{2}{*}{\multicolumn{2}{|c|}{ Erro total medições(દ) }} & $\mathrm{P} / \mathrm{m}^{3}$ & $7,19 E+05$ & $6,84 E+05$ & $5,63 E+05$ & $5,67 E+05$ & $3,31 E+05$ & $8,21 \mathrm{E}+04$ \\
\hline & & Unidade & $1,0-2,0 \mu \mathrm{m}$ & $2,0-3,0 \mu \mathrm{m}$ & $3,0-5,0 \mu \mathrm{m}$ & $5,0-7,0 \mu \mathrm{m}$ & $7,0-10,0 \mu \mathrm{m}$ & $>10,0 \mu \mathrm{m}$ \\
\hline \multirow{8}{*}{ Assento 2D } & $\begin{array}{c}\begin{array}{c}\text { Concentração média de } \\
\text { fundo }\end{array} \\
\end{array}$ & $\mathrm{P} / \mathrm{m}^{3}$ & $2,53 E+05$ & $7,33 \mathrm{E}+04$ & $2,00 E+04$ & $0,00 \mathrm{E}+00$ & $0,00 E+00$ & $0,00 E+00$ \\
\hline & \begin{tabular}{|c|} 
Número de particulas de \\
fundo
\end{tabular} & $\mathbf{p}$ & 76 & 22 & 6 & 0 & 0 & 0 \\
\hline & $\begin{array}{c}\text { Concentração média } \\
\text { liquida }\end{array}$ & $\mathrm{P} / \mathrm{m}^{3}$ & $1,35 E+08$ & $1,24 E+08$ & $7,85 \mathrm{E}+07$ & $5,19 E+07$ & $1,44 \mathrm{E}+07$ & $1,71 \mathrm{E}+06$ \\
\hline & $\begin{array}{c}\text { Número de Particulas } \\
\text { média liquida }\end{array}$ & $\mathbf{P}$ & 40536 & 37088 & 23560 & 15560 & 4309 & 514 \\
\hline & Desvio - Poisson & $\#$ & 201,34 & 192,58 & 153,49 & 124,74 & 65,64 & 22,67 \\
\hline & $\begin{array}{c}\text { Desvio - Poisson - } \\
\text { Relativo } \\
\end{array}$ & $\%$ & 0,5 & 0,5 & 0,7 & 0,8 & 1,5 & 4,4 \\
\hline & Desvio padrão & $\mathrm{P} / \mathrm{m}^{3}$ & $1,38 E+04$ & $9,11 E+03$ & $6,43 E+03$ & $3,00 E+03$ & $8,30 E+02$ & $1,39 \mathrm{E}+02$ \\
\hline & DP/Concentração média & $\%$ & 0,0102 & 0,0074 & 0,0082 & 0,0058 & 0,0058 & 0,0081 \\
\hline \multirow{2}{*}{\multicolumn{2}{|c|}{ Erro total medições(દ) }} & $\mathrm{P} / \mathrm{m}^{3}$ & $6,71 \mathrm{E}+05$ & $6,42 E+05$ & $5,12 \mathrm{E}+05$ & $4,16 \mathrm{E}+05$ & $2,19 \mathrm{E}+05$ & $7,56 \mathrm{E}+04$ \\
\hline & & Unidade & $1,0-2,0 \mu \mathrm{m}$ & $2,0-3,0 \mu \mathrm{m}$ & $3,0-5,0 \mu \mathrm{m}$ & $5,0-7,0 \mu \mathrm{m}$ & $7,0-10,0 \mu \mathrm{m}$ & $>10,0 \mu \mathrm{m}$ \\
\hline \multirow{8}{*}{ Assento 2E } & $\begin{array}{c}\begin{array}{c}\text { Concentração média de } \\
\text { fundo }\end{array} \\
\end{array}$ & $\mathrm{P} / \mathrm{m}^{3}$ & $1,43 E+05$ & $5,00 \mathrm{E}+04$ & $3,33 E+03$ & $0,00 \mathrm{E}+00$ & $0,00 E+00$ & $0,00 E+00$ \\
\hline & \begin{tabular}{|c|} 
Número de particulas de \\
fundo
\end{tabular} & $\mathbf{p}$ & 43 & 15 & 1 & 0 & 0 & 0 \\
\hline & $\begin{array}{c}\text { Concentração média } \\
\text { liquida }\end{array}$ & $\mathrm{P} / \mathrm{m}^{3}$ & $1,26 \mathrm{E}+08$ & $9,43 E+07$ & $6,31 E+07$ & $3,63 E+07$ & $1,62 \mathrm{E}+07$ & $2,76 \mathrm{E}+06$ \\
\hline & $\begin{array}{c}\text { Número de Particulas } \\
\text { média liquida }\end{array}$ & $\mathbf{P}$ & 37764 & 28281 & 18941 & 10897 & 4870 & 826,5 \\
\hline & Desvio - Poisson & $\#$ & 194,33 & 168,17 & 137,63 & 104,39 & 69,79 & 28,75 \\
\hline & $\begin{array}{c}\text { Desvio - Poisson - } \\
\text { Relativo } \\
\end{array}$ & $\%$ & 0,5 & 0,6 & 0,7 & 1,0 & 1,4 & 3,5 \\
\hline & Desvio padrão & $\mathrm{P} / \mathrm{m}^{3}$ & $9,40 E+03$ & $9,22 \mathrm{E}+03$ & $1,56 \mathrm{E}+03$ & $1,66 \mathrm{E}+03$ & $8,69 \mathrm{E}+02$ & $1,19 \mathrm{E}+02$ \\
\hline & DP/Concentração média & $\%$ & 0,0075 & 0,0098 & 0,0025 & 0,0046 & 0,0054 & 0,0043 \\
\hline \multicolumn{2}{|c|}{ Erro total medições(દ) } & $\mathrm{P} / \mathrm{m}^{3}$ & $6,48 E+05$ & $5,61 \mathrm{E}+05$ & $4,59 E+05$ & $3,48 \mathrm{E}+05$ & $2,33 \mathrm{E}+05$ & $9,58 \mathrm{E}+04$ \\
\hline
\end{tabular}




\begin{tabular}{|c|c|c|c|c|c|c|c|c|}
\hline & & Unidade & $1,0-2,0 \mu \mathrm{m}$ & $2,0-3,0 \mu \mathrm{m}$ & $3,0-5,0 \mu \mathrm{m}$ & $5,0-7,0 \mu \mathrm{m}$ & $7,0-10,0 \mu \mathrm{m}$ & $>10,0 \mu \mathrm{m}$ \\
\hline \multirow{8}{*}{ Assento 1D } & $\begin{array}{c}\text { Concentração média de } \\
\text { fundo }\end{array}$ & $\mathrm{P} / \mathrm{m}^{3}$ & $7,00 E+04$ & $1,47 E+05$ & $6,67 E+03$ & $0,00 E+00$ & $0,00 \mathrm{E}+00$ & $0,00 E+00$ \\
\hline & \begin{tabular}{|c|} 
Número de particulas de \\
fundo
\end{tabular} & $\mathbf{p}$ & 21 & 44 & 2 & 0 & 0 & 0 \\
\hline & $\begin{array}{c}\text { Concentração média } \\
\text { liquida }\end{array}$ & $\mathrm{P} / \mathrm{m}^{3}$ & $1,15 E+08$ & $1,08 \mathrm{E}+08$ & $7,00 \mathrm{E}+07$ & $5,96 \mathrm{E}+07$ & $1,00 \mathrm{E}+07$ & $1,46 E+06$ \\
\hline & $\begin{array}{l}\text { Número de Particulas } \\
\text { média liquida }\end{array}$ & $\mathbf{p}$ & 34459 & 32423,5 & 21000 & 17890 & 3011,5 & 436,5 \\
\hline & Desvio - Poisson & $\#$ & 185,63 & 180,07 & 144,91 & 133,75 & 54,88 & 20,89 \\
\hline & $\begin{array}{c}\text { Desvio - Poisson - } \\
\text { Relativo } \\
\end{array}$ & $\%$ & 0,5 & 0,6 & 0,7 & 0,7 & 1,8 & 4,8 \\
\hline & $\begin{array}{l}\text { Desvio padrão } \\
\text { Concentração }\end{array}$ & $\mathrm{P} / \mathrm{m}^{3}$ & $4,56 E+03$ & $6,16 \mathrm{E}+03$ & $1,40 E+03$ & $1,92 \mathrm{E}+03$ & $8,80 E+02$ & $1,14 \mathrm{E}+02$ \\
\hline & DP/Concentração média & $\%$ & 0,0040 & 0,0057 & 0,0020 & 0,0032 & 0,0088 & 0,0078 \\
\hline \multirow{2}{*}{\multicolumn{2}{|c|}{ Erro total medições(દ) }} & $\mathrm{P} / \mathrm{m}^{3}$ & $6,19 \mathrm{E}+05$ & $6,00 \mathrm{E}+05$ & $4,83 E+05$ & $4,46 \mathrm{E}+05$ & $1,83 E+05$ & $6,96 \mathrm{E}+04$ \\
\hline & & Unidade & $1,0-2,0 \mu \mathrm{m}$ & $2,0-3,0 \mu \mathrm{m}$ & $3,0-5,0 \mu \mathrm{m}$ & $5,0-7,0 \mu \mathrm{m}$ & $7,0-10,0 \mu \mathrm{m}$ & $>10,0 \mu \mathrm{m}$ \\
\hline \multirow{8}{*}{ Assento 1E } & $\begin{array}{c}\text { Concentração média de } \\
\text { fundo }\end{array}$ & $\mathrm{P} / \mathrm{m}^{3}$ & $8,00 E+04$ & $4,33 E+04$ & $1,33 E+04$ & $3,33 E+03$ & $0,00 \mathrm{E}+00$ & $0,00 \mathrm{E}+00$ \\
\hline & \begin{tabular}{|c|} 
Número de particulas de \\
fundo
\end{tabular} & $\mathbf{p}$ & 24 & 13 & 4 & 1 & 0 & 0 \\
\hline & $\begin{array}{c}\text { Concentração média } \\
\text { liquida }\end{array}$ & $\mathrm{P} / \mathrm{m}^{3}$ & $1,16 E+08$ & $1,10 \mathrm{E}+08$ & $6,33 E+07$ & $7,00 \mathrm{E}+07$ & $1,75 \mathrm{E}+07$ & $1,51 E+06$ \\
\hline & $\begin{array}{c}\text { Número de Particulas } \\
\text { média liquida }\end{array}$ & $\mathbf{p}$ & 34821 & 32860 & 19004 & 21000 & 5247 & 453 \\
\hline & Desvio - Poisson & $\#$ & 186,60 & 181,27 & 137,85 & 144,91 & 72,44 & 21,28 \\
\hline & $\begin{array}{c}\text { Desvio - Poisson - } \\
\text { Relativo } \\
\end{array}$ & $\%$ & 0,5 & 0,6 & 0,7 & 0,7 & 1,4 & 4,7 \\
\hline & $\begin{array}{c}\text { Desvio padrão } \\
\text { Concentração } \\
\end{array}$ & $\mathrm{P} / \mathrm{m}^{3}$ & $1,31 E+04$ & $8,65 E+03$ & $1,62 E+03$ & $6,51 E+03$ & $1,81 E+03$ & $1,87 E+02$ \\
\hline & DP/Concentração média & $\%$ & 0,0113 & 0,0079 & 0,0026 & 0,0093 & 0,0104 & 0,0124 \\
\hline \multirow{2}{*}{\multicolumn{2}{|c|}{ Erro total medições(દ) }} & $\mathrm{P} / \mathrm{m}^{3}$ & $6,22 \mathrm{E}+05$ & $6,04 \mathrm{E}+05$ & $4,60 \mathrm{E}+05$ & $4,83 \mathrm{E}+05$ & $2,41 E+05$ & $7,09 \mathrm{E}+04$ \\
\hline & & Unidade & $1,0-2,0 \mu \mathrm{m}$ & $2,0-3,0 \mu \mathrm{m}$ & $3,0-5,0 \mu \mathrm{m}$ & $5,0-7,0 \mu \mathrm{m}$ & $7,0-10,0 \mu \mathrm{m}$ & $>10,0 \mu \mathrm{m}$ \\
\hline \multirow{8}{*}{ Assento 1B } & $\begin{array}{c}\begin{array}{c}\text { Concentração média de } \\
\text { fundo }\end{array} \\
\end{array}$ & $\mathrm{P} / \mathrm{m}^{3}$ & $1,23 E+05$ & $7,00 \mathrm{E}+04$ & $5,00 E+03$ & $0,00 \mathrm{E}+00$ & $0,00 \mathrm{E}+00$ & $0,00 E+00$ \\
\hline & $\begin{array}{c}\text { Número de particulas de } \\
\text { fundo } \\
\end{array}$ & $\mathbf{P}$ & 37 & 21 & 2 & 0 & 0 & 0 \\
\hline & $\begin{array}{c}\text { Concentração média } \\
\text { liquida }\end{array}$ & $\mathrm{P} / \mathrm{m}^{3}$ & $8,34 E+07$ & $7,77 \mathrm{E}+07$ & $5,32 E+07$ & $5,28 E+07$ & $2,18 \mathrm{E}+07$ & $1,27 E+06$ \\
\hline & $\begin{array}{c}\text { Número de Particulas } \\
\text { média liquida }\end{array}$ & $\mathbf{p}$ & 25015 & 23321 & 15960 & 15850 & 6550 & 380 \\
\hline & Desvio - Poisson & $\#$ & 158,16 & 152,71 & 126,33 & 125,90 & 80,93 & 19,49 \\
\hline & $\begin{array}{c}\text { Desvio - Poisson - } \\
\text { Relativo } \\
\end{array}$ & $\%$ & 0,6 & 0,7 & 0,8 & 0,8 & 1,2 & 5,1 \\
\hline & $\begin{array}{l}\text { Desvio padrão } \\
\text { Concentração }\end{array}$ & $\mathrm{P} / \mathrm{m}^{3}$ & $5,54 \mathrm{E}+03$ & $5,42 E+03$ & $2,70 E+03$ & $2,69 E+03$ & $6,79 E+02$ & $1,12 E+02$ \\
\hline & DP/Concentração média & $\%$ & 0,0066 & 0,0070 & 0,0051 & 0,0051 & 0,0031 & 0,0088 \\
\hline \multicolumn{2}{|c|}{ Erro total medições(દ) } & $\mathrm{P} / \mathrm{m}^{3}$ & $5,27 E+05$ & $5,09 \mathrm{E}+05$ & $4,21 E+05$ & $4,20 E+05$ & $2,70 E+05$ & $6,50 E+04$ \\
\hline
\end{tabular}




\begin{tabular}{|c|c|c|c|c|c|c|c|c|}
\hline & & Unidade & $1,0-2,0 \mu \mathrm{m}$ & $2,0-3,0 \mu \mathrm{m}$ & $3,0-5,0 \mu \mathrm{m}$ & $5,0-7,0 \mu \mathrm{m}$ & $7,0-10,0 \mu \mathrm{m}$ & $>10,0 \mu \mathrm{m}$ \\
\hline \multirow{8}{*}{ Assento 1A } & $\begin{array}{c}\text { Concentração média de } \\
\text { fundo }\end{array}$ & $\mathrm{P} / \mathrm{m}^{3}$ & $1,10 E+05$ & $5,67 E+04$ & $6,67 \mathrm{E}+03$ & $0,00 E+00$ & $0,00 \mathrm{E}+00$ & $0,00 E+00$ \\
\hline & $\begin{array}{c}\text { Número de particulas de } \\
\text { fundo }\end{array}$ & P & 33 & 17 & 2 & 0 & 0 & 0 \\
\hline & $\begin{array}{c}\text { Concentração média } \\
\text { liquida }\end{array}$ & $\mathrm{P} / \mathrm{m}^{3}$ & $8,22 E+07$ & $6,96 \mathrm{E}+07$ & $4,57 E+07$ & $3,29 E+07$ & $2,17 E+07$ & $1,50 E+06$ \\
\hline & $\begin{array}{c}\text { Número de Particulas } \\
\text { média liquida }\end{array}$ & $\mathbf{P}$ & 24663 & 20882 & 13697 & 9871 & 6520 & 450 \\
\hline & Desvio - Poisson & $\#$ & 157,04 & 144,51 & 117,03 & 99,35 & 80,75 & 21,21 \\
\hline & $\begin{array}{l}\text { Desvio - Poisson - } \\
\text { Relativo }\end{array}$ & $\%$ & 0,6 & 0,7 & 0,9 & 1,0 & 1,2 & 4,7 \\
\hline & $\begin{array}{l}\text { Desvio padrão } \\
\text { Concentração }\end{array}$ & $\mathrm{P} / \mathrm{m}^{3}$ & $9,44 E+03$ & $5,05 E+03$ & $2,51 E+03$ & $1,76 \mathrm{E}+03$ & $1,84 E+03$ & $6,07 E+01$ \\
\hline & DP/Concentração média & $\%$ & 0,0115 & 0,0072 & 0,0055 & 0,0053 & 0,0085 & 0,0040 \\
\hline \multicolumn{2}{|c|}{ Erro total medições( $(\varepsilon)$} & $\mathrm{P} / \mathrm{m}^{3}$ & $5,24 E+05$ & $4,82 E+05$ & $3,90 \mathrm{E}+05$ & $3,31 \mathrm{E}+05$ & $2,69 \mathrm{E}+05$ & $7,07 E+04$ \\
\hline & & Unidade & $1,0-2,0 \mu \mathrm{m}$ & $2,0-3,0 \mu \mathrm{m}$ & $3,0-5,0 \mu \mathrm{m}$ & $5,0-7,0 \mu \mathrm{m}$ & $7,0-10,0 \mu \mathrm{m}$ & $>10,0 \mu \mathrm{m}$ \\
\hline \multirow{8}{*}{ Assento 2B } & $\begin{array}{c}\text { Concentração média de } \\
\text { fundo } \\
\end{array}$ & $\mathrm{P} / \mathrm{m}^{3}$ & $5,33 E+04$ & $3,00 E+04$ & $6,67 \mathrm{E}+03$ & $0,00 E+00$ & $0,00 E+00$ & $0,00 E+00$ \\
\hline & \begin{tabular}{|c|} 
Número de particulas de \\
fundo \\
\end{tabular} & p & 16 & 9 & 2 & 0 & 0 & 0 \\
\hline & $\begin{array}{c}\text { Concentração média } \\
\text { liquida }\end{array}$ & $\mathrm{P} / \mathrm{m}^{3}$ & $1,05 E+08$ & $9,18 \mathrm{E}+07$ & $6,67 \mathrm{E}+07$ & $4,33 E+07$ & $2,67 \mathrm{E}+07$ & $1,07 E+06$ \\
\hline & $\begin{array}{l}\text { Número de Particulas } \\
\text { média liquida }\end{array}$ & P & 31635 & 27547 & 20000 & 13002 & 8000 & 320 \\
\hline & Desvio - Poisson & $\#$ & 177,86 & 165,97 & 141,42 & 114,03 & 89,44 & 17,89 \\
\hline & $\begin{array}{c}\text { Desvio - Poisson - } \\
\text { Relativo } \\
\end{array}$ & $\%$ & 0,6 & 0,6 & 0,7 & 0,9 & 1,1 & 5,6 \\
\hline & $\begin{array}{l}\text { Desvio padrão } \\
\text { Concentração } \\
\end{array}$ & $\mathrm{P} / \mathrm{m}^{3}$ & $4,66 \mathrm{E}+03$ & $1,12 E+04$ & $2,78 \mathrm{E}+03$ & $2,14 E+03$ & $1,70 \mathrm{E}+03$ & $1,11 E+02$ \\
\hline & DP/Concentração média & $\%$ & 0,0044 & 0,0121 & 0,0042 & 0,0049 & 0,0064 & 0,0104 \\
\hline \multirow{2}{*}{\multicolumn{2}{|c|}{ Erro total medições(દ) }} & $\mathrm{P} / \mathrm{m}^{3}$ & $5,93 \mathrm{E}+05$ & $5,53 E+05$ & $4,71 E+05$ & $3,80 \mathrm{E}+05$ & $2,98 \mathrm{E}+05$ & $5,96 \mathrm{E}+04$ \\
\hline & & Unidade & $1,0-2,0 \mu \mathrm{m}$ & $2,0-3,0 \mu \mathrm{m}$ & $3,0-5,0 \mu \mathrm{m}$ & $5,0-7,0 \mu \mathrm{m}$ & $7,0-10,0 \mu \mathrm{m}$ & $>10,0 \mu \mathrm{m}$ \\
\hline \multirow{8}{*}{ Assento 2A } & $\begin{array}{c}\begin{array}{c}\text { Concentração média de } \\
\text { fundo }\end{array} \\
\end{array}$ & $\mathrm{P} / \mathrm{m}^{3}$ & $1,00 E+05$ & $4,33 \mathrm{E}+04$ & $3,33 \mathrm{E}+03$ & $0,00 E+00$ & $0,00 \mathrm{E}+00$ & $0,00 E+00$ \\
\hline & $\begin{array}{c}\text { Número de particulas de } \\
\text { fundo } \\
\end{array}$ & P & 30 & 13 & 1 & 0 & 0 & 0 \\
\hline & $\begin{array}{c}\text { Concentração média } \\
\text { liquida } \\
\end{array}$ & $\mathrm{P} / \mathrm{m}^{3}$ & $6,42 E+07$ & $5,50 \mathrm{E}+07$ & $3,34 \mathrm{E}+07$ & $2,29 E+07$ & $6,15 E+06$ & $1,08 E+06$ \\
\hline & $\begin{array}{c}\text { Número de Particulas } \\
\text { média liquida }\end{array}$ & P & 19248 & 16513 & 10005 & 6866 & 1845 & 324 \\
\hline & Desvio - Poisson & $\#$ & 138,74 & 128,50 & 100,02 & 82,86 & 42,95 & 18,00 \\
\hline & $\begin{array}{c}\text { Desvio - Poisson - } \\
\text { Relativo } \\
\end{array}$ & $\%$ & 0,7 & 0,8 & 1,0 & 1,2 & 2,3 & 5,6 \\
\hline & $\begin{array}{l}\text { Desvio padrão } \\
\text { Concentração } \\
\end{array}$ & $\mathrm{P} / \mathrm{m}^{3}$ & $4,54 \mathrm{E}+03$ & $4,30 E+03$ & $7,63 E+02$ & $6,90 \mathrm{E}+02$ & $3,27 E+02$ & $1,20 E+02$ \\
\hline & DP/Concentração média & $\%$ & 0,0071 & 0,0078 & 0,0023 & 0,0030 & 0,0053 & 0,0111 \\
\hline \multicolumn{2}{|c|}{ Erro total medições(દ) } & $\mathrm{P} / \mathrm{m}^{3}$ & $4,62 E+05$ & $4,28 E+05$ & $3,33 \mathrm{E}+05$ & $2,76 E+05$ & $1,43 E+05$ & $6,00 \mathrm{E}+04$ \\
\hline
\end{tabular}


Unidade $1,0-2,0 \mu \mathrm{m}|2,0-3,0 \mu \mathrm{m}| 3,0-5,0 \mu \mathrm{m}|5,0-7,0 \mu \mathrm{m}| 7,0-10,0 \mu \mathrm{m} \mid>10,0 \mu \mathrm{m}$

\begin{tabular}{|c|c|c|c|c|c|c|c|c|}
\hline \multirow{8}{*}{ Assento 3B } & $\begin{array}{c}\text { Concentração média de } \\
\text { fundo }\end{array}$ & $\mathrm{P} / \mathrm{m}^{3}$ & $1,10 \mathrm{E}+05$ & $5,00 E+04$ & $1,00 E+04$ & $1,67 \mathrm{E}+03$ & $0,00 E+00$ & $0,00 E+00$ \\
\hline & $\begin{array}{c}\text { Número de particulas de } \\
\text { fundo } \\
\end{array}$ & $\mathbf{P}$ & 33 & 15 & 3 & 1 & 0 & 0 \\
\hline & $\begin{array}{c}\text { Concentração média } \\
\text { liquida }\end{array}$ & $\mathrm{P} / \mathrm{m}^{3}$ & $1,06 E+08$ & $9,14 \mathrm{E}+07$ & $7,53 \mathrm{E}+07$ & $5,21 \mathrm{E}+07$ & $1,39 \mathrm{E}+07$ & $2,53 E+06$ \\
\hline & $\begin{array}{c}\text { Número de Particulas } \\
\text { média liquida }\end{array}$ & $\mathbf{P}$ & 31778 & 27426 & 22580 & 15620 & 4163 & 760 \\
\hline & Desvio - Poisson & $\#$ & 178,26 & 165,61 & 150,27 & 124,98 & 64,52 & 27,57 \\
\hline & $\begin{array}{l}\text { Desvio - Poisson - } \\
\text { Relativo }\end{array}$ & $\%$ & 0,6 & 0,6 & 0,7 & 0,8 & 1,5 & 3,6 \\
\hline & $\begin{array}{l}\text { Desvio padrão } \\
\text { Concentração }\end{array}$ & $\mathrm{P} / \mathrm{m}^{3}$ & $6,06 E+03$ & $8,52 E+03$ & $1,75 \mathrm{E}+03$ & $1,03 E+03$ & $9,16 \mathrm{E}+02$ & $6,22 E+01$ \\
\hline & DP/Concentração média & $\%$ & 0,0057 & 0,0093 & 0,0023 & 0,0020 & 0,0066 & 0,0025 \\
\hline \multirow{2}{*}{\multicolumn{2}{|c|}{ Erro total medições $(\varepsilon)$}} & $\mathrm{P} / \mathrm{m}^{3}$ & $5,94 \mathrm{E}+05$ & $5,52 E+05$ & $5,01 \mathrm{E}+05$ & $4,17 E+05$ & $2,15 E+05$ & $9,19 \mathrm{E}+04$ \\
\hline & & Unidade & $1,0-2,0 \mu \mathrm{m}$ & $2,0-3,0 \mu \mathrm{m}$ & $3,0-5,0 \mu \mathrm{m}$ & $5,0-7,0 \mu \mathrm{m}$ & $7,0-10,0 \mu \mathrm{m}$ & $>10,0 \mu \mathrm{m}$ \\
\hline \multirow{8}{*}{ Assento 3A } & \begin{tabular}{|c|}
$\begin{array}{c}\text { Concentração média de } \\
\text { fundo }\end{array}$ \\
\end{tabular} & $\mathrm{P} / \mathrm{m}^{3}$ & $2,23 E+05$ & $1,20 E+05$ & $6,67 E+03$ & $0,00 E+00$ & $0,00 E+00$ & $0,00 E+00$ \\
\hline & $\begin{array}{c}\text { Número de particulas de } \\
\text { fundo } \\
\end{array}$ & $\mathbf{P}$ & 67 & 36 & 2 & 0 & 0 & 0 \\
\hline & $\begin{array}{c}\text { Concentração média } \\
\text { liquida }\end{array}$ & $\mathrm{P} / \mathrm{m}^{3}$ & $6,39 \mathrm{E}+07$ & $6,31 E+07$ & $5,07 E+07$ & $2,88 \mathrm{E}+07$ & $6,83 E+06$ & $5,00 E+05$ \\
\hline & $\begin{array}{c}\text { Número de Particulas } \\
\text { média liquida }\end{array}$ & $\mathbf{P}$ & 19183 & 18926 & 15210 & 8652 & 2050 & 150 \\
\hline & Desvio - Poisson & $\#$ & 138,50 & 137,57 & 123,33 & 93,02 & 45,28 & 12,25 \\
\hline & $\begin{array}{l}\text { Desvio - Poisson - } \\
\text { Relativo } \\
\end{array}$ & $\%$ & 0,7 & 0,7 & 0,8 & 1,1 & 2,2 & 8,2 \\
\hline & $\begin{array}{l}\text { Desvio padrão } \\
\text { Concentração }\end{array}$ & $\mathrm{P} / \mathrm{m}^{3}$ & $4,48 E+03$ & $4,43 E+03$ & $3,78 \mathrm{E}+03$ & $9,94 E+02$ & $9,41 E+01$ & $6,62 E+01$ \\
\hline & DP/Concentração média & $\%$ & 0,0070 & 0,0070 & 0,0075 & 0,0034 & 0,0014 & 0,0132 \\
\hline \multicolumn{2}{|c|}{ Erro total medições(દ) } & $\mathrm{P} / \mathrm{m}^{3}$ & $4,62 E+05$ & $4,59 E+05$ & $4,11 E+05$ & $3,10 \mathrm{E}+05$ & $1,51 \mathrm{E}+05$ & $4,08 E+04$ \\
\hline
\end{tabular}


Tabela D-6. Resultados das medições de partículas no assento (Sistema UFAD mod. à $22^{\circ} \mathrm{C}-$ injeção pelo assento $3 \mathrm{D}$ )

\begin{tabular}{|c|c|c|c|c|c|c|c|c|}
\hline & & Unidade & $1,0-2,0 \mu \mathrm{m}$ & $2,0-3,0 \mu \mathrm{m}$ & $3,0-5,0 \mu \mathrm{m}$ & $5,0-7,0 \mu \mathrm{m}$ & $7,0-10,0 \mu \mathrm{m}$ & $>10,0 \mu \mathrm{m}$ \\
\hline \multirow{8}{*}{ Assento 3E } & $\begin{array}{c}\begin{array}{c}\text { Concentração média de } \\
\text { fundo }\end{array} \\
\end{array}$ & $\mathrm{P} / \mathrm{m}^{3}$ & $1,00 E+05$ & $4,50 E+04$ & $1,67 \mathrm{E}+03$ & $0,00 E+00$ & $0,00 E+00$ & $0,00 E+00$ \\
\hline & $\begin{array}{c}\text { Número de particulas } \\
\text { de fundo }\end{array}$ & $\mathbf{P}$ & 30 & 13,5 & 0,5 & 0 & 0 & 0 \\
\hline & $\begin{array}{c}\text { Concentração média } \\
\text { liquida } \\
\end{array}$ & $\mathrm{P} / \mathrm{m}^{3}$ & $1,48 \mathrm{E}+08$ & $1,37 E+08$ & $1,03 E+08$ & $1,33 \mathrm{E}+08$ & $8,33 \mathrm{E}+07$ & $1,97 \mathrm{E}+07$ \\
\hline & $\begin{array}{c}\text { Número de Particulas } \\
\text { média liquida }\end{array}$ & $\mathbf{P}$ & 44330 & 40969 & 31000 & 39860 & 25000 & 5897 \\
\hline & Desvio - Poisson & $\#$ & 210,55 & 202,41 & 176,07 & 199,65 & 158,11 & 76,79 \\
\hline & $\begin{array}{c}\text { Desvio - Poisson - } \\
\text { Relativo } \\
\end{array}$ & $\%$ & 0,5 & 0,5 & 0,6 & 0,5 & 0,6 & 1,3 \\
\hline & $\begin{array}{c}\text { Desvio padrão } \\
\text { Concentração }\end{array}$ & $\mathrm{P} / \mathrm{m}^{3}$ & $1,29 \mathrm{E}+03$ & $1,05 E+03$ & $1,75 E+03$ & $1,80 \mathrm{E}+03$ & $2,02 E+03$ & $6,49 E+02$ \\
\hline & DP/Concentração média & $\%$ & 0,0009 & 0,0008 & 0,0017 & 0,0014 & 0,0024 & 0,0033 \\
\hline \multirow{2}{*}{\multicolumn{2}{|c|}{ Erro total medições( $\varepsilon)$}} & $\mathrm{P} / \mathrm{m}^{3}$ & $7,02 \mathrm{E}+05$ & $6,75 E+05$ & $5,87 E+05$ & $6,66 \mathrm{E}+05$ & $5,27 E+05$ & $2,56 \mathrm{E}+05$ \\
\hline & & Unidade & $1,0-2,0 \mu \mathrm{m}$ & $2,0-3,0 \mu \mathrm{m}$ & $3,0-5,0 \mu \mathrm{m}$ & $5,0-7,0 \mu \mathrm{m}$ & $7,0-10,0 \mu \mathrm{m}$ & $>10,0 \mu \mathrm{m}$ \\
\hline \multirow{8}{*}{ Assento 2D } & $\begin{array}{c}\text { Concentração média de } \\
\text { fundo }\end{array}$ & $\mathrm{P} / \mathrm{m}^{3}$ & $1,75 E+05$ & $7,17 E+04$ & $1,00 \mathrm{E}+04$ & $1,67 \mathrm{E}+03$ & $0,00 \mathrm{E}+00$ & $0,00 E+00$ \\
\hline & $\begin{array}{c}\text { Número de particulas } \\
\text { de fundo }\end{array}$ & $\mathbf{P}$ & 52,5 & 21,5 & 3 & 0,5 & 0 & 0 \\
\hline & $\begin{array}{c}\text { Concentração média } \\
\text { liquida }\end{array}$ & $\mathrm{P} / \mathrm{m}^{3}$ & $1,31 \mathrm{E}+08$ & $1,28 \mathrm{E}+08$ & $1,12 \mathrm{E}+08$ & $7,00 E+07$ & $3,35 E+07$ & $1,48 \mathrm{E}+06$ \\
\hline & $\begin{array}{c}\text { Número de Particulas } \\
\text { média liquida }\end{array}$ & $\mathbf{P}$ & 39275 & 38473 & 33560 & 21000 & 10050 & 444 \\
\hline & Desvio - Poisson & $\#$ & 198,18 & 196,15 & 183,19 & 144,91 & 100,25 & 21,07 \\
\hline & $\begin{array}{c}\text { Desvio - Poisson - } \\
\text { Relativo } \\
\end{array}$ & $\%$ & 0,5 & 0,5 & 0,5 & 0,7 & 1,0 & 4,7 \\
\hline & $\begin{array}{l}\text { Desvio padrão } \\
\text { Concentração }\end{array}$ & $\mathrm{P} / \mathrm{m}^{3}$ & $1,14 \mathrm{E}+04$ & $1,11 \mathrm{E}+04$ & $1,85 \mathrm{E}+03$ & $1,14 \mathrm{E}+03$ & $9,59 \mathrm{E}+02$ & $1,26 \mathrm{E}+02$ \\
\hline & DP/Concentração média & $\%$ & 0,0087 & 0,0087 & 0,0017 & 0,0016 & 0,0029 & 0,0085 \\
\hline \multirow{2}{*}{\multicolumn{2}{|c|}{ Erro total medições $(\varepsilon)$}} & $\mathrm{P} / \mathrm{m}^{3}$ & $6,61 \mathrm{E}+05$ & $6,54 \mathrm{E}+05$ & $6,11 \mathrm{E}+05$ & $4,83 \mathrm{E}+05$ & $3,34 \mathrm{E}+05$ & $7,02 \mathrm{E}+04$ \\
\hline & & Unidade & $1,0-2,0 \mu \mathrm{m}$ & $2,0-3,0 \mu \mathrm{m}$ & $3,0-5,0 \mu \mathrm{m}$ & $5,0-7,0 \mu \mathrm{m}$ & $7,0-10,0 \mu \mathrm{m}$ & $>10,0 \mu \mathrm{m}$ \\
\hline \multirow{8}{*}{ Assento 2E } & $\begin{array}{c}\text { Concentração média de } \\
\text { fundo }\end{array}$ & $\mathrm{P} / \mathrm{m}^{3}$ & $1,73 E+05$ & $5,67 E+04$ & $6,67 E+03$ & $0,00 \mathrm{E}+00$ & $0,00 \mathrm{E}+00$ & $0,00 \mathrm{E}+00$ \\
\hline & $\begin{array}{c}\text { Número de particulas } \\
\text { de fundo }\end{array}$ & $\mathbf{P}$ & 52 & 17 & 2 & 0 & 0 & 0 \\
\hline & $\begin{array}{c}\begin{array}{c}\text { Concentração média } \\
\text { liquida }\end{array} \\
\end{array}$ & $\mathrm{P} / \mathrm{m}^{3}$ & $1,53 \mathrm{E}+08$ & $1,50 \mathrm{E}+08$ & $8,47 E+07$ & $5,16 \mathrm{E}+07$ & $1,54 \mathrm{E}+07$ & $1,43 \mathrm{E}+06$ \\
\hline & $\begin{array}{c}\text { Número de Particulas } \\
\text { média liquida }\end{array}$ & $\mathbf{P}$ & 45824 & 45003 & 25414 & 15480 & 4613 & 428 \\
\hline & Desvio - Poisson & $\#$ & 214,07 & 212,14 & 159,42 & 124,42 & 67,92 & 20,68 \\
\hline & $\begin{array}{c}\text { Desvio - Poisson - } \\
\text { Relativo } \\
\end{array}$ & $\%$ & 0,5 & 0,5 & 0,6 & 0,8 & 1,5 & 4,8 \\
\hline & $\begin{array}{l}\text { Desvio padrão } \\
\text { Concentração } \\
\end{array}$ & $\mathrm{P} / \mathrm{m}^{3}$ & $1,06 \mathrm{E}+04$ & $1,03 E+04$ & $4,78 \mathrm{E}+03$ & $1,59 \mathrm{E}+03$ & $7,40 E+02$ & $1,01 \mathrm{E}+02$ \\
\hline & DP/Concentração média & $\%$ & 0,0070 & 0,0069 & 0,0056 & 0,0031 & 0,0048 & 0,0071 \\
\hline \multicolumn{2}{|c|}{ Erro total medições( $(\varepsilon)$} & $\mathrm{P} / \mathrm{m}^{3}$ & $7,14 \mathrm{E}+05$ & $7,07 E+05$ & $5,31 E+05$ & $4,15 E+05$ & $2,26 \mathrm{E}+05$ & $6,89 \mathrm{E}+04$ \\
\hline
\end{tabular}




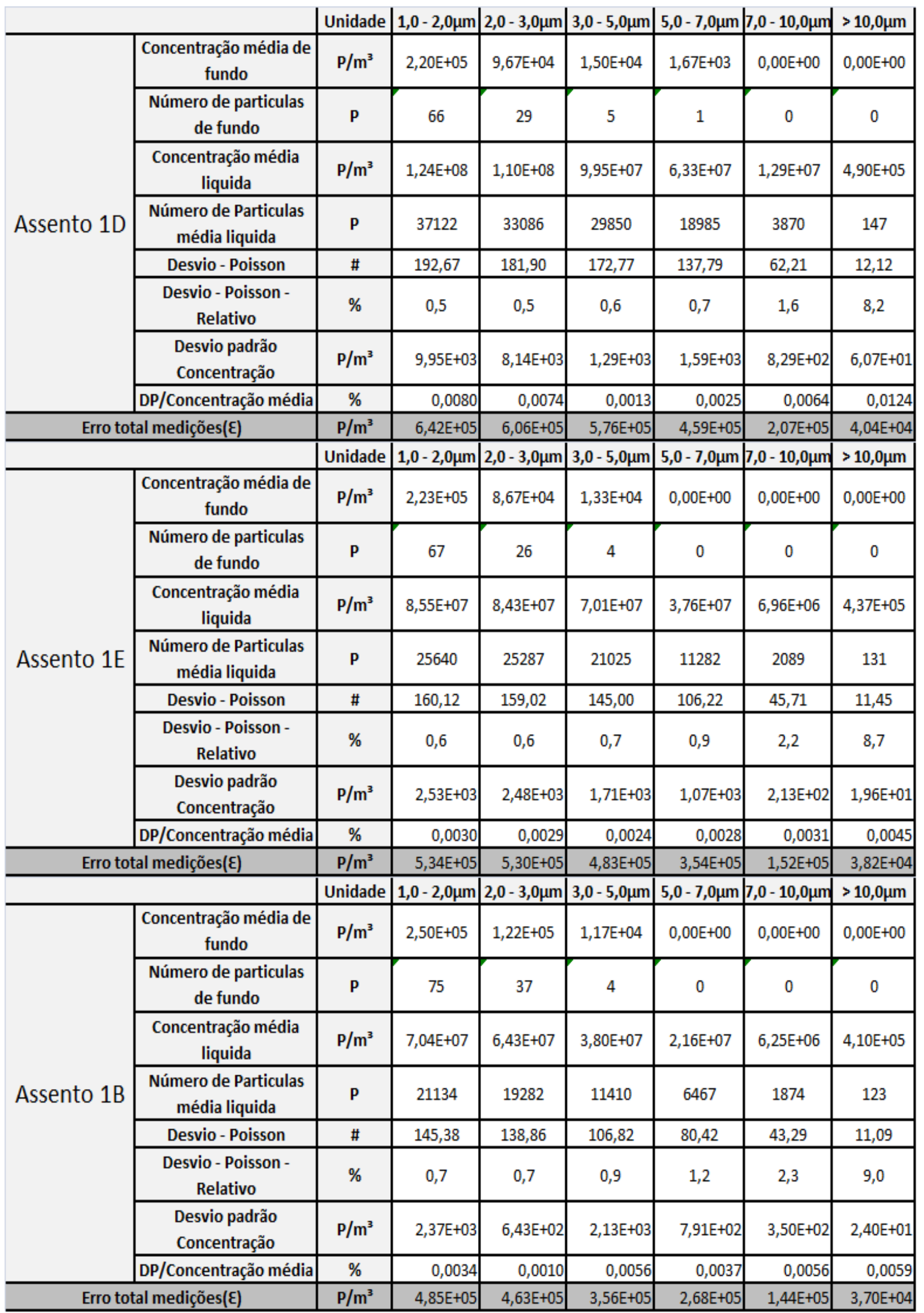




\begin{tabular}{|c|c|c|c|c|c|c|c|c|}
\hline & & Unidade & $1,0-2,0 \mu \mathrm{m}$ & $2,0-3,0 \mu \mathrm{m}$ & $3,0-5,0 \mu \mathrm{m}$ & $5,0-7,0 \mu \mathrm{m}$ & $7,0-10,0 \mu \mathrm{m}$ & $>10,0 \mu \mathrm{m}$ \\
\hline \multirow{8}{*}{ Assento 1A } & $\begin{array}{c}\text { Concentração média de } \\
\text { fundo }\end{array}$ & $\mathrm{P} / \mathrm{m}^{3}$ & $3,03 E+05$ & $1,30 E+05$ & $1,67 \mathrm{E}+04$ & $0,00 E+00$ & $0,00 E+00$ & $0,00 E+00$ \\
\hline & $\begin{array}{c}\text { Número de particulas } \\
\text { de fundo }\end{array}$ & $\mathbf{p}$ & 91 & 39 & 5 & 0 & 0 & 0 \\
\hline & $\begin{array}{c}\text { Concentração média } \\
\text { liquida } \\
\end{array}$ & $\mathrm{P} / \mathrm{m}^{3}$ & $5,30 \mathrm{E}+07$ & $5,25 \mathrm{E}+07$ & $2,88 \mathrm{E}+07$ & $3,11 \mathrm{E}+07$ & $4,90 \mathrm{E}+06$ & $2,57 \mathrm{E}+05$ \\
\hline & $\begin{array}{c}\text { Número de Particulas } \\
\text { média liquida }\end{array}$ & $\mathbf{p}$ & 15894 & 15742 & 8650 & 9341 & 1471 & 77 \\
\hline & Desvio - Poisson & $\#$ & 126,07 & 125,47 & 93,01 & 96,65 & 38,35 & 8,77 \\
\hline & $\begin{array}{c}\text { Desvio - Poisson - } \\
\text { Relativo } \\
\end{array}$ & $\%$ & 0,8 & 0,8 & 1,1 & 1,0 & 2,6 & 11,4 \\
\hline & $\begin{array}{l}\text { Desvio padrão } \\
\text { Concentração }\end{array}$ & $\mathrm{P} / \mathrm{m}^{3}$ & $1,13 E+03$ & $8,32 E+02$ & $7,78 \mathrm{E}+02$ & $1,41 E+03$ & $1,18 \mathrm{E}+02$ & $1,12 \mathrm{E}+01$ \\
\hline & DP/Concentração média & $\%$ & 0,0021 & 0,0016 & 0,0027 & 0,0045 & 0,0024 & 0,0044 \\
\hline \multirow{2}{*}{\multicolumn{2}{|c|}{ Erro total medições( $(\varepsilon)$}} & $\mathrm{P} / \mathrm{m}^{3}$ & $4,20 E+05$ & $4,18 E+05$ & $3,10 E+05$ & $3,22 \mathrm{E}+05$ & $1,28 \mathrm{E}+05$ & $2,92 \mathrm{E}+04$ \\
\hline & & Unidade & $1,0-2,0 \mu \mathrm{m}$ & $2,0-3,0 \mu \mathrm{m}$ & $3,0-5,0 \mu \mathrm{m}$ & $5,0-7,0 \mu \mathrm{m}$ & $7,0-10,0 \mu \mathrm{m}$ & $>10,0 \mu \mathrm{m}$ \\
\hline \multirow{8}{*}{ Assento 2B } & $\begin{array}{c}\text { Concentração média de } \\
\text { fundo }\end{array}$ & $\mathrm{P} / \mathrm{m}^{3}$ & $3,37 \mathrm{E}+05$ & $1,83 \mathrm{E}+05$ & $1,67 \mathrm{E}+04$ & $0,00 \mathrm{E}+00$ & $0,00 E+00$ & $0,00 E+00$ \\
\hline & $\begin{array}{c}\text { Número de particulas } \\
\text { de fundo }\end{array}$ & $\mathbf{p}$ & 101 & 55 & 5 & 0 & 0 & 0 \\
\hline & $\begin{array}{l}\text { Concentração média } \\
\text { liquida }\end{array}$ & $\mathrm{P} / \mathrm{m}^{3}$ & $1,04 \mathrm{E}+08$ & $8,37 E+07$ & $5,53 \mathrm{E}+07$ & $3,75 \mathrm{E}+07$ & $1,03 E+07$ & $5,67 E+05$ \\
\hline & $\begin{array}{c}\text { Número de Particulas } \\
\text { média liquida }\end{array}$ & $\mathbf{p}$ & 31117 & 25105 & 16589 & 11250 & 3082 & 170 \\
\hline & Desvio - Poisson & $\#$ & 176,40 & 158,44 & 128,80 & 106,07 & 55,52 & 13,04 \\
\hline & $\begin{array}{c}\text { Desvio - Poisson - } \\
\text { Relativo } \\
\end{array}$ & $\%$ & 0,6 & 0,6 & 0,8 & 0,9 & 1,8 & 7,7 \\
\hline & $\begin{array}{l}\text { Desvio padrão } \\
\text { Concentração }\end{array}$ & $\mathrm{P} / \mathrm{m}^{3}$ & $9,09 \mathrm{E}+03$ & $1,05 E+03$ & $1,15 \mathrm{E}+03$ & $3,86 \mathrm{E}+03$ & $5,68 \mathrm{E}+02$ & $6,62 E+01$ \\
\hline & DP/Concentração média & $\%$ & 0,0088 & 0,0013 & 0,0021 & 0,0103 & 0,0055 & 0,0117 \\
\hline \multirow{2}{*}{\multicolumn{2}{|c|}{ Erro total medições( $(\varepsilon)$}} & $\mathrm{P} / \mathrm{m}^{3}$ & $5,88 \mathrm{E}+05$ & $5,28 \mathrm{E}+05$ & $4,29 E+05$ & $3,54 \mathrm{E}+05$ & $1,85 \mathrm{E}+05$ & $4,35 \mathrm{E}+04$ \\
\hline & & Unidade & $1,0-2,0 \mu \mathrm{m}$ & $2,0-3,0 \mu \mathrm{m}$ & $3,0-5,0 \mu \mathrm{m}$ & $5,0-7,0 \mu \mathrm{m}$ & $7,0-10,0 \mu \mathrm{m}$ & $>10,0 \mu \mathrm{m}$ \\
\hline \multirow{8}{*}{ Assento 2A } & \begin{tabular}{|c|}
$\begin{array}{c}\text { Concentração média de } \\
\text { fundo }\end{array}$ \\
\end{tabular} & $\mathrm{P} / \mathrm{m}^{3}$ & $3,23 E+05$ & $1,53 \mathrm{E}+05$ & $2,00 E+04$ & $0,00 E+00$ & $0,00 E+00$ & $0,00 E+00$ \\
\hline & $\begin{array}{c}\text { Número de particulas } \\
\text { de fundo }\end{array}$ & $\mathbf{P}$ & 97 & 46 & 6 & 0 & 0 & 0 \\
\hline & $\begin{array}{l}\text { Concentração média } \\
\text { liquida } \\
\end{array}$ & $\mathrm{P} / \mathrm{m}^{3}$ & $2,56 \mathrm{E}+07$ & $2,19 \mathrm{E}+07$ & $7,83 \mathrm{E}+06$ & $5,07 E+06$ & $1,87 E+06$ & $6,03 E+05$ \\
\hline & $\begin{array}{c}\text { Número de Particulas } \\
\text { média liquida }\end{array}$ & $\mathbf{p}$ & 7684 & 6564 & 2350 & 1520 & 560 & 181 \\
\hline & Desvio - Poisson & $\#$ & 87,66 & 81,02 & 48,48 & 38,99 & 23,66 & 13,45 \\
\hline & $\begin{array}{c}\text { Desvio - Poisson - } \\
\text { Relativo } \\
\end{array}$ & $\%$ & 1,1 & 1,2 & 2,1 & 2,6 & 4,2 & 7,4 \\
\hline & $\begin{array}{l}\text { Desvio padrão } \\
\text { Concentração }\end{array}$ & $\mathrm{P} / \mathrm{m}^{3}$ & $8,47 E+02$ & $2,65 \mathrm{E}+02$ & $3,49 \mathrm{E}+02$ & $9,53 \mathrm{E}+01$ & $1,11 \mathrm{E}+02$ & $3,11 \mathrm{E}+01$ \\
\hline & DP/Concentração média & $\%$ & 0,0033 & 0,0012 & 0,0045 & 0,0019 & 0,0060 & 0,0052 \\
\hline \multicolumn{2}{|c|}{ Erro total medições(દ) } & $\mathrm{P} / \mathrm{m}^{3}$ & $2,92 \mathrm{E}+05$ & $2,70 E+05$ & $1,62 \mathrm{E}+05$ & $1,30 \mathrm{E}+05$ & $7,89 \mathrm{E}+04$ & $4,48 \mathrm{E}+04$ \\
\hline
\end{tabular}


Unidade $1,0-2,0 \mu \mathrm{m}|2,0-3,0 \mu \mathrm{m}| 3,0-5,0 \mu \mathrm{m}|5,0-7,0 \mu \mathrm{m}| 7,0-10,0 \mu \mathrm{m} \mid>10,0 \mu \mathrm{m}$

\begin{tabular}{|c|c|c|c|c|c|c|c|c|}
\hline & \\
\hline \multirow{8}{*}{ Assento 3B } & \begin{tabular}{|c|}
$\begin{array}{c}\text { Concentração média de } \\
\text { fundo }\end{array}$ \\
\end{tabular} & $\mathrm{P} / \mathrm{m}^{3}$ & $1,87 E+05$ & $9,33 E+04$ & $1,00 E+04$ & $0,00 E+00$ & $0,00 E+00$ & $0,00 E+00$ \\
\hline & $\begin{array}{c}\text { Número de particulas } \\
\text { de fundo }\end{array}$ & $\mathbf{P}$ & 56 & 28 & 3 & 0 & 0 & 0 \\
\hline & $\begin{array}{c}\text { Concentração média } \\
\text { liquida }\end{array}$ & $\mathrm{P} / \mathrm{m}^{3}$ & $9,41 E+07$ & $6,86 \mathrm{E}+07$ & $5,20 E+07$ & $3,42 E+07$ & $1,83 E+07$ & $8,13 E+05$ \\
\hline & $\begin{array}{l}\text { Número de Particulas } \\
\text { média liquida }\end{array}$ & $\mathbf{P}$ & 28235 & 20586 & 15600 & 10250 & 5492 & 244 \\
\hline & Desvio - Poisson & $\#$ & 168,03 & 143,48 & 124,90 & 101,24 & 74,11 & 15,62 \\
\hline & $\begin{array}{l}\text { Desvio - Poisson - } \\
\text { Relativo }\end{array}$ & $\%$ & 0,6 & 0,7 & 0,8 & 1,0 & 1,3 & 6,4 \\
\hline & $\begin{array}{l}\text { Desvio padrão } \\
\text { Concentração }\end{array}$ & $\mathrm{P} / \mathrm{m}^{3}$ & $8,00 E+03$ & $7,14 \mathrm{E}+02$ & $7,91 \mathrm{E}+02$ & $7,43 E+02$ & $4,75 E+02$ & $3,94 \mathrm{E}+$ \\
\hline & DP/Concentração média & $\%$ & 0,0085 & 0,0010 & 0,0015 & 0,0022 & 0,0026 & 0,0048 \\
\hline \multirow{2}{*}{\multicolumn{2}{|c|}{ Erro total medições(દ) }} & $\mathrm{P} / \mathrm{m}^{3}$ & $5,60 \mathrm{E}+05$ & $4,78 \mathrm{E}+05$ & $4,16 \mathrm{E}+05$ & $3,37 E+05$ & $2,47 E+05$ & $5,21 E+04$ \\
\hline & & Unidade & $1,0-2,0 \mu \mathrm{m}$ & $2,0-3,0 \mu \mathrm{m}$ & $3,0-5,0 \mu \mathrm{m}$ & $5,0-7,0 \mu \mathrm{m}$ & $7,0-10,0 \mu \mathrm{m}$ & $>10,0 \mu \mathrm{m}$ \\
\hline \multirow{8}{*}{ Assento 3A } & $\begin{array}{c}\begin{array}{c}\text { Concentração média de } \\
\text { fundo }\end{array} \\
\end{array}$ & $\mathrm{P} / \mathrm{m}^{3}$ & $1,83 E+05$ & $8,33 E+04$ & $1,00 E+04$ & $0,00 \mathrm{E}+00$ & $0,00 \mathrm{E}+00$ & $0,00 E+00$ \\
\hline & $\begin{array}{c}\text { Número de particulas } \\
\text { de fundo }\end{array}$ & $\mathbf{P}$ & 55 & 25 & 3 & 0 & 0 & 0 \\
\hline & $\begin{array}{c}\text { Concentração média } \\
\text { liquida } \\
\end{array}$ & $\mathrm{P} / \mathrm{m}^{3}$ & $4,06 \mathrm{E}+07$ & $3,16 \mathrm{E}+07$ & $1,72 \mathrm{E}+07$ & $1,37 E+07$ & $7,56 \mathrm{E}+06$ & $1,26 \mathrm{E}+06$ \\
\hline & $\begin{array}{c}\text { Número de Particulas } \\
\text { média liquida }\end{array}$ & $\mathbf{P}$ & 12169 & 9492 & 5157 & 4096 & 2268 & 377 \\
\hline & Desvio - Poisson & $\#$ & 110,31 & 97,43 & 71,81 & 64,00 & 47,62 & 19,42 \\
\hline & $\begin{array}{c}\text { Desvio - Poisson - } \\
\text { Relativo } \\
\end{array}$ & $\%$ & 0,9 & 1,0 & 1,4 & 1,6 & 2,1 & 5,2 \\
\hline & $\begin{array}{l}\text { Desvio padrão } \\
\text { Concentração }\end{array}$ & $\mathrm{P} / \mathrm{m}^{3}$ & $5,12 E+02$ & $5,38 E+02$ & $5,46 \mathrm{E}+02$ & $3,43 E+01$ & $1,04 \mathrm{E}+02$ & $1,67 E+02$ \\
\hline & DP/Concentração média & $\%$ & 0,0013 & 0,0017 & 0,0032 & 0,0003 & 0,0014 & 0,0133 \\
\hline \multicolumn{2}{|c|}{ Erro total medições $(\varepsilon)$} & $\mathrm{P} / \mathrm{m}^{3}$ & $3,68 \mathrm{E}+05$ & $3,25 \mathrm{E}+05$ & $2,39 \mathrm{E}+05$ & $2,13 \mathrm{E}+05$ & $1,59 \mathrm{E}+05$ & $6,47 E+04$ \\
\hline
\end{tabular}


Tabela D-7. Resultados das medições de partículas no assento (Sistema MV à $18^{\circ} \mathrm{C}$ - injeção pelo assento $3 \mathrm{E}$ )

\begin{tabular}{|c|c|c|c|c|c|c|c|c|}
\hline & & Unidade & $1,0-2,0 \mu \mathrm{m}$ & $2,0-3,0 \mu \mathrm{m}$ & $3,0-5,0 \mu \mathrm{m}$ & $5,0-7,0 \mu \mathrm{m}$ & $7,0-10,0 \mu \mathrm{m}$ & $>10,0 \mu \mathrm{m}$ \\
\hline \multirow{8}{*}{ Assento 3D } & $\begin{array}{c}\text { Concentração média de } \\
\text { fundo }\end{array}$ & $\mathrm{P} / \mathrm{m}^{3}$ & $1,07 E+05$ & $4,83 E+04$ & $6,67 \mathrm{E}+03$ & $0,00 E+00$ & $0,00 E+00$ & $0,00 \mathrm{E}+00$ \\
\hline & $\begin{array}{c}\text { Número de particulas de } \\
\text { fundo }\end{array}$ & $\mathbf{P}$ & 32 & 14,5 & 2 & 0 & 0 & 0 \\
\hline & $\begin{array}{c}\text { Concentração média } \\
\text { liquida }\end{array}$ & $\mathrm{P} / \mathrm{m}^{3}$ & $9,25 \mathrm{E}+00$ & $7,11 \mathrm{E}+00$ & $6,60 \mathrm{E}+00$ & $5,95 \mathrm{E}+07$ & $5,40 \mathrm{E}+07$ & $1,93 \mathrm{E}+06$ \\
\hline & $\begin{array}{l}\text { Número de Particulas } \\
\text { média liquida }\end{array}$ & $\mathbf{P}$ & 41372,5 & 31797,5 & 29540 & 17849 & 16198 & 579,5 \\
\hline & Desvio - Poisson & $\#$ & 203,40 & 178,32 & 171,87 & 133,60 & 127,27 & 24,07 \\
\hline & $\begin{array}{l}\text { Desvio - Poisson - } \\
\text { Relativo }\end{array}$ & $\%$ & 0,5 & 0,6 & 0,6 & 0,7 & 0,8 & 4,2 \\
\hline & $\begin{array}{l}\text { Desvio padrão } \\
\text { Concentração }\end{array}$ & $\mathrm{P} / \mathrm{m}^{3}$ & $1,58 \mathrm{E}+03$ & $9,79 E+02$ & $1,33 E+03$ & $7,35 \mathrm{E}+02$ & $2,70 E+03$ & $1,28 \mathrm{E}+02$ \\
\hline & DP/Concentração média & $\%$ & 17105,5782 & 13783,2214 & 20088,5693 & 0,0012 & 0,0050 & 0,0066 \\
\hline \multirow{2}{*}{\multicolumn{2}{|c|}{ Erro total medições( $(\varepsilon)$}} & $\mathrm{P} / \mathrm{m}^{3}$ & $6,78 \mathrm{E}+05$ & $5,94 \mathrm{E}+05$ & $5,73 \mathrm{E}+05$ & $4,45 E+05$ & $4,24 E+05$ & $8,02 E+04$ \\
\hline & & Unidade & $1,0-2,0 \mu \mathrm{m}$ & $2,0-3,0 \mu \mathrm{m}$ & $3,0-5,0 \mu \mathrm{m}$ & $5,0-7,0 \mu \mathrm{m}$ & $7,0-10,0 \mu \mathrm{m}$ & $>10,0 \mu \mathrm{m}$ \\
\hline \multirow{8}{*}{ Assento 2D } & $\begin{array}{c}\text { Concentração média de } \\
\text { fundo }\end{array}$ & $\mathrm{P} / \mathrm{m}^{3}$ & $1,07 E+05$ & $4,83 E+04$ & $6,67 E+03$ & $0,00 \mathrm{E}+00$ & $0,00 E+00$ & $0,00 E+00$ \\
\hline & $\begin{array}{c}\text { Número de particulas de } \\
\text { fundo }\end{array}$ & $\mathbf{P}$ & 32 & 15 & 2 & 0 & 0 & 0 \\
\hline & $\begin{array}{c}\text { Concentração média } \\
\text { liquida }\end{array}$ & $\mathrm{P} / \mathrm{m}^{3}$ & $1,15 \mathrm{E}+08$ & $1,05 \mathrm{E}+08$ & $8,00 E+07$ & $6,07 E+07$ & $2,20 E+07$ & $1,60 \mathrm{E}+05$ \\
\hline & $\begin{array}{c}\text { Número de Particulas } \\
\text { média liquida }\end{array}$ & $\mathbf{P}$ & 34517,5 & 31571,5 & 24000 & 18220 & 6589 & 48 \\
\hline & Desvio - Poisson & $\#$ & 185,79 & 177,68 & 154,92 & 134,98 & 81,17 & 6,93 \\
\hline & $\begin{array}{c}\text { Desvio - Poisson - } \\
\text { Relativo }\end{array}$ & $\%$ & 0,5 & 0,6 & 0,6 & 0,7 & 1,2 & 14,4 \\
\hline & $\begin{array}{l}\text { Desvio padrão } \\
\text { Concentração }\end{array}$ & $\mathrm{P} / \mathrm{m}^{3}$ & $1,12 \mathrm{E}+03$ & $4,99 \mathrm{E}+03$ & $1,04 \mathrm{E}+03$ & $5,40 E+02$ & $9,26 E+02$ & $9,07 E+00$ \\
\hline & DP/Concentração média & $\%$ & 0,0010 & 0,0047 & 0,0013 & 0,0009 & 0,0042 & 0,0057 \\
\hline \multirow{2}{*}{\multicolumn{2}{|c|}{ Erro total medições( $(\varepsilon)$}} & $\mathrm{P} / \mathrm{m}^{3}$ & $6,19 \mathrm{E}+05$ & $5,92 \mathrm{E}+05$ & $5,16 \mathrm{E}+05$ & $4,50 \mathrm{E}+05$ & $2,71 \mathrm{E}+05$ & $2,31 \mathrm{E}+04$ \\
\hline & & Unidade & $1,0-2,0 \mu \mathrm{m}$ & $2,0-3,0 \mu \mathrm{m}$ & $3,0-5,0 \mu \mathrm{m}$ & $5,0-7,0 \mu \mathrm{m}$ & $7,0-10,0 \mu \mathrm{m}$ & $>10,0 \mu \mathrm{m}$ \\
\hline \multirow{8}{*}{ Assento $2 \mathrm{E}$} & $\begin{array}{c}\text { Concentração média de } \\
\text { fundo }\end{array}$ & $\mathrm{P} / \mathrm{m}^{3}$ & $1,10 \mathrm{E}+05$ & $5,33 E+04$ & $6,67 \mathrm{E}+03$ & $3,33 \mathrm{E}+03$ & $3,33 E+03$ & $0,00 E+00$ \\
\hline & $\begin{array}{c}\text { Número de particulas de } \\
\text { fundo }\end{array}$ & $\mathbf{P}$ & 33 & 16 & 2 & 1 & 1 & 0 \\
\hline & $\begin{array}{c}\text { Concentração média } \\
\text { liquida } \\
\end{array}$ & $\mathrm{P} / \mathrm{m}^{3}$ & $9,78 \mathrm{E}+07$ & $9,14 E+07$ & $7,52 E+07$ & $5,51 \mathrm{E}+07$ & $2,98 \mathrm{E}+07$ & $8,33 \mathrm{E}+04$ \\
\hline & $\begin{array}{c}\text { Número de Particulas } \\
\text { média liquida }\end{array}$ & $\mathbf{P}$ & 29336,5 & 27420 & 22546 & 16520 & 8954 & 25 \\
\hline & Desvio - Poisson & $\#$ & 171,28 & 165,59 & 150,15 & 128,53 & 94,63 & 5,00 \\
\hline & $\begin{array}{c}\text { Desvio - Poisson - } \\
\text { Relativo } \\
\end{array}$ & $\%$ & 0,6 & 0,6 & 0,7 & 0,8 & 1,1 & 20,0 \\
\hline & $\begin{array}{c}\text { Desvio padrão } \\
\text { Concentração }\end{array}$ & $\mathrm{P} / \mathrm{m}^{3}$ & $8,65 E+02$ & $1,83 \mathrm{E}+02$ & $5,86 \mathrm{E}+02$ & $6,78 \mathrm{E}+02$ & $7,76 \mathrm{E}+02$ & $1,01 \mathrm{E}+01$ \\
\hline & DP/Concentração média & $\%$ & 0,0009 & 0,0002 & 0,0008 & 0,0012 & 0,0026 & 0,0122 \\
\hline \multicolumn{2}{|c|}{ Erro total medições( $(\varepsilon)$} & $\mathrm{P} / \mathrm{m}^{3}$ & $5,71 \mathrm{E}+05$ & $5,52 \mathrm{E}+05$ & $5,01 E+05$ & $4,28 \mathrm{E}+05$ & $3,15 \mathrm{E}+05$ & $1,67 \mathrm{E}+04$ \\
\hline
\end{tabular}




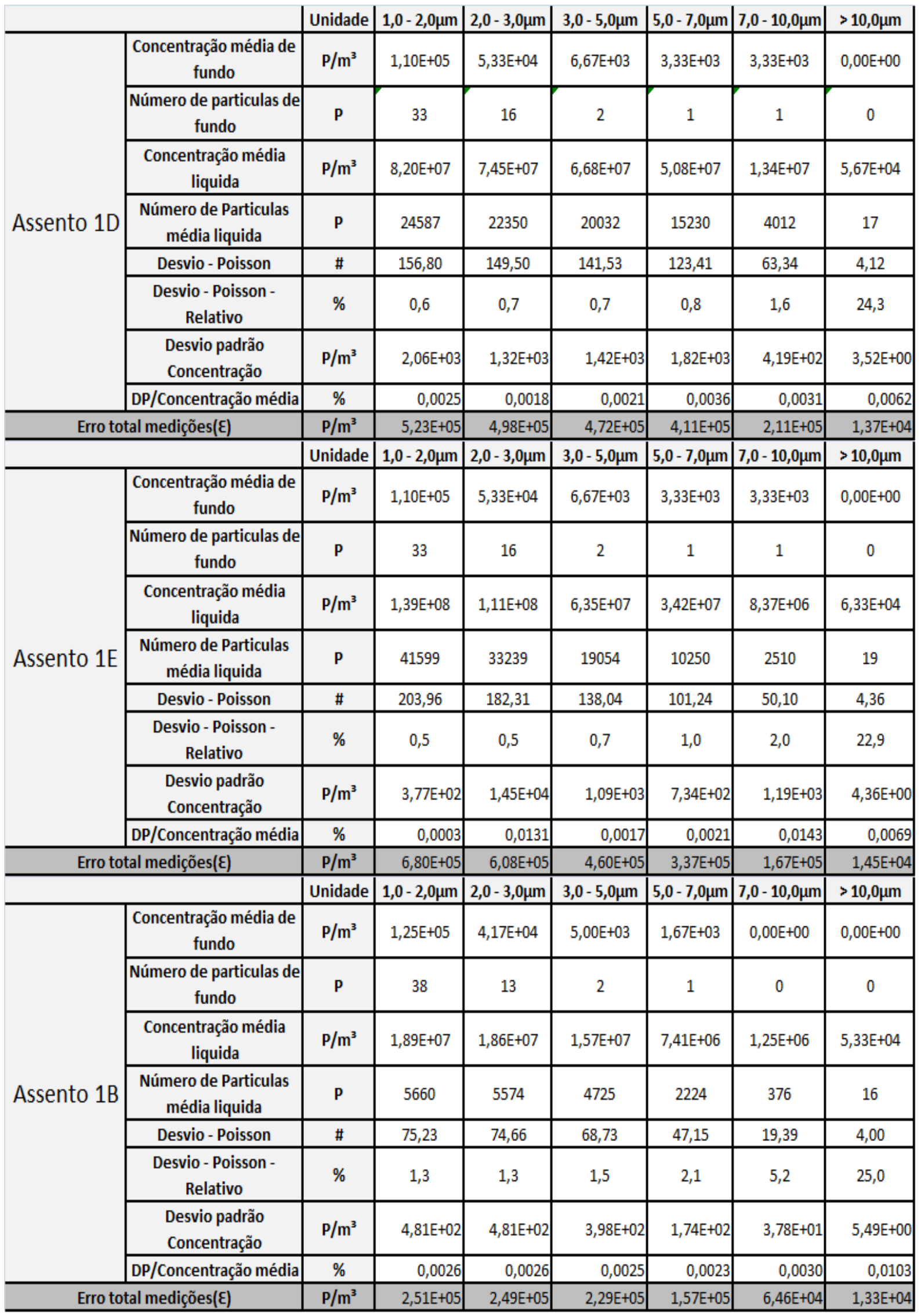




\begin{tabular}{|c|c|c|c|c|c|c|c|c|}
\hline & & Unidade & $1,0-2,0 \mu \mathrm{m}$ & $2,0-3,0 \mu \mathrm{m}$ & $3,0-5,0 \mu \mathrm{m}$ & $5,0-7,0 \mu \mathrm{m}$ & $7,0-10,0 \mu \mathrm{m}$ & $>10,0 \mu \mathrm{m}$ \\
\hline \multirow{8}{*}{ Assento 1A } & $\begin{array}{c}\text { Concentração média de } \\
\text { fundo }\end{array}$ & $\mathrm{P} / \mathrm{m}^{3}$ & $1,60 \mathrm{E}+05$ & $5,67 E+04$ & $6,67 E+03$ & $0,00 E+00$ & $0,00 \mathrm{E}+00$ & $0,00 \mathrm{E}+00$ \\
\hline & $\begin{array}{c}\text { Número de particulas de } \\
\text { fundo }\end{array}$ & $\mathbf{p}$ & 48 & 17 & 2 & 0 & 0 & 0 \\
\hline & $\begin{array}{c}\text { Concentração média } \\
\text { liquida }\end{array}$ & $\mathrm{P} / \mathrm{m}^{3}$ & $5,78 \mathrm{E}+07$ & $5,08 \mathrm{E}+07$ & $3,85 E+07$ & $2,92 \mathrm{E}+07$ & $6,85 E+06$ & $7,00 E+04$ \\
\hline & $\begin{array}{c}\text { Número de Particulas } \\
\text { média liquida }\end{array}$ & $\mathbf{p}$ & 17340 & 15241 & 11562 & 8756 & 2056 & 21 \\
\hline & Desvio - Poisson & $\#$ & 131,68 & 123,45 & 107,53 & 93,57 & 45,34 & 4,58 \\
\hline & $\begin{array}{c}\text { Desvio - Poisson - } \\
\text { Relativo } \\
\end{array}$ & $\%$ & 0,8 & 0,8 & 0,9 & 1,1 & 2,2 & 21,8 \\
\hline & $\begin{array}{l}\text { Desvio padrão } \\
\text { Concentração }\end{array}$ & $\mathrm{P} / \mathrm{m}^{3}$ & $1,17 E+03$ & $1,35 E+02$ & $8,90 E+02$ & $8,70 E+02$ & $7,98 \mathrm{E}+01$ & $1,38 \mathrm{E}+01$ \\
\hline & DP/Concentração média & $\%$ & 0,0020 & 0,0003 & 0,0023 & 0,0030 & 0,0012 & 0,0198 \\
\hline \multirow{2}{*}{\multicolumn{2}{|c|}{ Erro total medições $(\varepsilon)$}} & $\mathrm{P} / \mathrm{m}^{3}$ & $4,39 E+05$ & $4,12 E+05$ & $3,58 \mathrm{E}+05$ & $3,12 E+05$ & $1,51 E+05$ & $1,53 \mathrm{E}+04$ \\
\hline & & Unidade & $1,0-2,0 \mu \mathrm{m}$ & $2,0-3,0 \mu \mathrm{m}$ & $3,0-5,0 \mu \mathrm{m}$ & $5,0-7,0 \mu \mathrm{m}$ & $7,0-10,0 \mu \mathrm{m}$ & $>10,0 \mu \mathrm{m}$ \\
\hline \multirow{8}{*}{ Assento 2B } & $\begin{array}{c}\text { Concentração média de } \\
\text { fundo }\end{array}$ & $\mathrm{P} / \mathrm{m}^{3}$ & $1,93 E+05$ & $7,67 E+04$ & $1,00 E+04$ & $0,00 E+00$ & $0,00 E+00$ & $0,00 E+00$ \\
\hline & $\begin{array}{c}\text { Número de particulas de } \\
\text { fundo }\end{array}$ & $\mathbf{P}$ & 58 & 23 & 3 & 0 & 0 & 0 \\
\hline & $\begin{array}{c}\text { Concentração média } \\
\text { liquida }\end{array}$ & $\mathrm{P} / \mathrm{m}^{3}$ & $9,11 E+07$ & $8,40 E+07$ & $7,53 E+07$ & $5,15 E+07$ & $2,85 E+07$ & $1,27 E+05$ \\
\hline & $\begin{array}{c}\text { Número de Particulas } \\
\text { média liquida }\end{array}$ & $\mathbf{P}$ & 27331 & 25213 & 22587 & 15444 & 8560 & 38 \\
\hline & Desvio - Poisson & $\#$ & 165,32 & 158,79 & 150,29 & 124,27 & 92,52 & 6,16 \\
\hline & $\begin{array}{c}\text { Desvio - Poisson - } \\
\text { Relativo } \\
\end{array}$ & $\%$ & 0,6 & 0,6 & 0,7 & 0,8 & 1,1 & 16,2 \\
\hline & $\begin{array}{l}\text { Desvio padrão } \\
\text { Concentração } \\
\end{array}$ & $\mathrm{P} / \mathrm{m}^{3}$ & $5,92 E+03$ & $1,02 E+03$ & $9,95 E+02$ & $9,07 E+02$ & $7,57 \mathrm{E}+02$ & $4,07 E+01$ \\
\hline & DP/Concentração média & $\%$ & 0,0065 & 0,0012 & 0,0013 & 0,0018 & 0,0027 & 0,0321 \\
\hline \multirow{2}{*}{\multicolumn{2}{|c|}{ Erro total medições(દ) }} & $\mathrm{P} / \mathrm{m}^{3}$ & $5,51 \mathrm{E}+05$ & $5,29 E+05$ & $5,01 \mathrm{E}+05$ & $4,14 \mathrm{E}+05$ & $3,08 \mathrm{E}+05$ & $2,05 \mathrm{E}+04$ \\
\hline & & Unidade & $1,0-2,0 \mu \mathrm{m}$ & $2,0-3,0 \mu \mathrm{m}$ & $3,0-5,0 \mu \mathrm{m}$ & $5,0-7,0 \mu \mathrm{m}$ & $7,0-10,0 \mu \mathrm{m}$ & $>10,0 \mu \mathrm{m}$ \\
\hline \multirow{8}{*}{ Assento 2A } & $\begin{array}{c}\text { Concentração média de } \\
\text { fundo } \\
\end{array}$ & $\mathrm{P} / \mathrm{m}^{3}$ & $1,68 \mathrm{E}+05$ & $7,50 E+04$ & $5,00 E+03$ & $0,00 E+00$ & $0,00 E+00$ & $0,00 E+00$ \\
\hline & \begin{tabular}{|c|} 
Número de particulas de \\
fundo
\end{tabular} & $\mathbf{P}$ & 51 & 23 & 2 & 0 & 0 & 0 \\
\hline & $\begin{array}{c}\text { Concentração média } \\
\text { liquida } \\
\end{array}$ & $\mathrm{P} / \mathrm{m}^{3}$ & $7,45 E+07$ & $6,86 \mathrm{E}+07$ & $6,08 \mathrm{E}+07$ & $2,85 E+07$ & $1,75 E+07$ & $1,07 E+05$ \\
\hline & $\begin{array}{c}\text { Número de Particulas } \\
\text { média liquida }\end{array}$ & $\mathbf{p}$ & 22359 & 20573 & 18250 & 8547 & 5260 & 32 \\
\hline & Desvio - Poisson & $\#$ & 149,53 & 143,43 & 135,09 & 92,45 & 72,53 & 5,66 \\
\hline & $\begin{array}{c}\text { Desvio - Poisson - } \\
\text { Relativo }\end{array}$ & $\%$ & 0,7 & 0,7 & 0,7 & 1,1 & 1,4 & 17,7 \\
\hline & $\begin{array}{l}\text { Desvio padrão } \\
\text { Concentração } \\
\end{array}$ & $\mathrm{P} / \mathrm{m}^{3}$ & $5,79 E+03$ & $9,69 E+02$ & $7,38 \mathrm{E}+02$ & $2,36 \mathrm{E}+03$ & $6,89 \mathrm{E}+01$ & $6,46 E+00$ \\
\hline & DP/Concentração média & $\%$ & 0,0078 & 0,0014 & 0,0012 & 0,0083 & 0,0004 & 0,0061 \\
\hline \multicolumn{2}{|c|}{ Erro total medições(દ) } & $\mathrm{P} / \mathrm{m}^{3}$ & $4,98 \mathrm{E}+05$ & $4,78 \mathrm{E}+05$ & $4,50 E+05$ & $3,08 \mathrm{E}+05$ & $2,42 E+05$ & $1,89 \mathrm{E}+04$ \\
\hline
\end{tabular}




\begin{tabular}{|c|c|c|c|c|c|c|c|c|}
\hline & & Unidade & $1,0-2,0 \mu \mathrm{m}$ & $2,0-3,0 \mu \mathrm{m}$ & $3,0-5,0 \mu \mathrm{m}$ & $5,0-7,0 \mu \mathrm{m}$ & $7,0-10,0 \mu \mathrm{m}$ & $>10,0 \mu \mathrm{m}$ \\
\hline \multirow{8}{*}{ Assento 3B } & \begin{tabular}{|c|}
$\begin{array}{c}\text { Concentração média de } \\
\text { fundo }\end{array}$ \\
\end{tabular} & $\mathrm{P} / \mathrm{m}^{3}$ & $1,95 E+05$ & $8,33 E+04$ & $6,67 E+03$ & $0,00 E+00$ & $0,00 E+00$ & $0,00 E+00$ \\
\hline & $\begin{array}{c}\text { Número de particulas de } \\
\text { fundo } \\
\end{array}$ & $\mathbf{P}$ & 59 & 25 & 2 & 0 & 0 & 0 \\
\hline & $\begin{array}{c}\text { Concentração média } \\
\text { liquida }\end{array}$ & $\mathrm{P} / \mathrm{m}^{3}$ & $1,18 \mathrm{E}+08$ & $1,09 E+08$ & $8,19 E+07$ & $5,00 E+07$ & $2,13 E+07$ & $3,27 E+05$ \\
\hline & $\begin{array}{c}\text { Número de Particulas } \\
\text { média liquida }\end{array}$ & $\mathbf{P}$ & 35270 & 32558 & 24560 & 14999 & 6380 & 98 \\
\hline & Desvio - Poisson & $\#$ & 187,80 & 180,44 & 156,72 & 122,47 & 79,87 & 9,90 \\
\hline & $\begin{array}{l}\text { Desvio - Poisson - } \\
\text { Relativo } \\
\end{array}$ & $\%$ & 0,5 & 0,6 & 0,6 & 0,8 & 1,3 & 10,1 \\
\hline & $\begin{array}{l}\text { Desvio padrão } \\
\text { Concentração }\end{array}$ & $\mathrm{P} / \mathrm{m}^{3}$ & $6,97 E+03$ & $6,59 \mathrm{E}+03$ & $1,85 \mathrm{E}+03$ & $9,82 E+02$ & $1,83 E+03$ & $1,15 \mathrm{E}+01$ \\
\hline & DP/Concentração média & $\%$ & 0,0059 & 0,0061 & 0,0023 & 0,0020 & 0,0086 & 0,0035 \\
\hline \multirow{2}{*}{\multicolumn{2}{|c|}{ Erro total medições $(\varepsilon)$}} & $\mathrm{P} / \mathrm{m}^{3}$ & $6,26 \mathrm{E}+05$ & $6,01 \mathrm{E}+05$ & $5,22 \mathrm{E}+05$ & $4,08 E+05$ & $2,66 \mathrm{E}+05$ & $3,30 E+04$ \\
\hline & & Unidade & $1,0-2,0 \mu \mathrm{m}$ & $2,0-3,0 \mu \mathrm{m}$ & $3,0-5,0 \mu \mathrm{m}$ & $5,0-7,0 \mu \mathrm{m}$ & $7,0-10,0 \mu \mathrm{m}$ & $>10,0 \mu \mathrm{m}$ \\
\hline \multirow{8}{*}{ Assento $3 \mathrm{~A}$} & \begin{tabular}{|c|}
$\begin{array}{c}\text { Concentração média de } \\
\text { fundo }\end{array}$ \\
\end{tabular} & $\mathrm{P} / \mathrm{m}^{3}$ & $1,93 E+05$ & $6,67 E+04$ & $1,00 E+04$ & $3,33 E+03$ & $3,33 E+03$ & $0,00 E+00$ \\
\hline & $\begin{array}{c}\text { Número de particulas de } \\
\text { fundo } \\
\end{array}$ & $\mathbf{P}$ & 58 & 20 & 3 & 1 & 1 & 0 \\
\hline & $\begin{array}{c}\text { Concentração média } \\
\text { liquida }\end{array}$ & $\mathrm{P} / \mathrm{m}^{3}$ & $7,78 E+07$ & $7,12 \mathrm{E}+07$ & $6,52 E+07$ & $4,00 E+07$ & $1,74 \mathrm{E}+07$ & $3,10 E+05$ \\
\hline & $\begin{array}{c}\text { Número de Particulas } \\
\text { média liquida }\end{array}$ & $\mathbf{P}$ & 23331 & 21361 & 19547 & 12003 & 5210 & 93 \\
\hline & Desvio - Poisson & $\#$ & 152,74 & 146,15 & 139,81 & 109,56 & 72,18 & 9,64 \\
\hline & $\begin{array}{l}\text { Desvio - Poisson - } \\
\text { Relativo } \\
\end{array}$ & $\%$ & 0,7 & 0,7 & 0,7 & 0,9 & 1,4 & 10,4 \\
\hline & $\begin{array}{l}\text { Desvio padrão } \\
\text { Concentração } \\
\end{array}$ & $\mathrm{P} / \mathrm{m}^{3}$ & $2,84 E+03$ & $1,08 \mathrm{E}+03$ & $1,28 \mathrm{E}+03$ & $2,01 E+03$ & $1,65 \mathrm{E}+03$ & $3,34 \mathrm{E}+01$ \\
\hline & DP/Concentração média & $\%$ & 0,0036 & 0,0015 & 0,0020 & 0,0050 & 0,0095 & 0,0108 \\
\hline \multicolumn{2}{|c|}{ Erro total medições(દ) } & $\mathrm{P} / \mathrm{m}^{3}$ & $5,09 E+05$ & $4,87 E+05$ & $4,66 \mathrm{E}+05$ & $3,65 E+05$ & $2,41 \mathrm{E}+05$ & $3,21 \mathrm{E}+04$ \\
\hline
\end{tabular}


Tabela D-8. Resultados das medições de partículas no assento (Sistema UFAD à $18^{\circ} \mathrm{C}$ - injeção pelo assento $3 \mathrm{E}$ )

\begin{tabular}{|c|c|c|c|c|c|c|c|c|}
\hline & & Unidade & $1,0-2,0 \mu \mathrm{m}$ & $2,0-3,0 \mu \mathrm{m}$ & $3,0-5,0 \mu \mathrm{m}$ & $5,0-7,0 \mu \mathrm{m}$ & $7,0-10,0 \mu \mathrm{m}$ & $>10,0 \mu \mathrm{m}$ \\
\hline \multirow{8}{*}{ Assento 3D } & $\begin{array}{l}\text { Concentração média de } \\
\text { fundo }\end{array}$ & $\mathrm{P} / \mathrm{m}^{3}$ & $1,93 \mathrm{E}+05$ & $1,50 \mathrm{E}+05$ & $1,00 \mathrm{E}+04$ & $0,00 \mathrm{E}+00$ & $0,00 \mathrm{E}+00$ & $0,00 E+00$ \\
\hline & $\begin{array}{l}\text { Número de particulas de } \\
\text { fundo }\end{array}$ & P & 58 & 45 & 3 & 0 & 0 & 0 \\
\hline & Concentração média liquida & $\mathrm{P} / \mathrm{m}^{3}$ & $1,12 E+08$ & $8,25 \mathrm{E}+07$ & $6,33 E+07$ & $4,54 E+07$ & 2,07E+07 & $2,02 E+06$ \\
\hline & \begin{tabular}{|c|} 
Número de Particulas média \\
liquida
\end{tabular} & $\mathbf{p}$ & 33583,5 & 24738,5 & 18997 & 13620 & 6206,5 & 606,5 \\
\hline & Desvio - Poisson & $\#$ & 183,26 & 157,28 & 137,83 & 116,70 & 78,78 & 24,63 \\
\hline & Desvio - Poisson - Relativo & $\%$ & 0,5 & 0,6 & 0,7 & 0,9 & 1,3 & 4,1 \\
\hline & Desvio padrão Concentração & $\mathrm{P} / \mathrm{m}^{3}$ & $2,06 \mathrm{E}+03$ & $1,30 \mathrm{E}+03$ & $2,49 E+03$ & $2,34 E+03$ & $7,40 E+02$ & $5,55 E+01$ \\
\hline & DP/Concentração média & $\%$ & 0,0018 & 0,0016 & 0,0039 & 0,0051 & 0,0036 & 0,0027 \\
\hline \multirow{2}{*}{\multicolumn{2}{|c|}{ Erro total medições(દ) }} & $\mathrm{P} / \mathrm{m}^{3}$ & $6,11 E+05$ & $5,24 \mathrm{E}+05$ & $4,59 E+05$ & $3,89 \mathrm{E}+05$ & $2,63 E+05$ & $8,21 E+04$ \\
\hline & & Unidade & $1,0-2,0 \mu \mathrm{m}$ & $2,0-3,0 \mu \mathrm{m}$ & $3,0-5,0 \mu \mathrm{m}$ & $5,0-7,0 \mu \mathrm{m}$ & $7,0-10,0 \mu \mathrm{m}$ & $>10,0 \mu \mathrm{m}$ \\
\hline \multirow{8}{*}{ Assento 2D } & $\begin{array}{l}\text { Concentração média de } \\
\text { fundo }\end{array}$ & $\mathrm{P} / \mathrm{m}^{3}$ & $1,10 \mathrm{E}+05$ & $4,00 E+04$ & $3,33 \mathrm{E}+03$ & $0,00 \mathrm{E}+00$ & $0,00 \mathrm{E}+00$ & $0,00 E+00$ \\
\hline & $\begin{array}{c}\text { Número de particulas de } \\
\text { fundo }\end{array}$ & P & 33 & 12 & 1 & 0 & 0 & 0 \\
\hline & Concentração média liquida & $\mathrm{P} / \mathrm{m}^{3}$ & $6,35 \mathrm{E}+07$ & $6,29 \mathrm{E}+07$ & $5,51 E+07$ & $3,81 \mathrm{E}+07$ & $9,82 E+06$ & $1,13 E+06$ \\
\hline & \begin{tabular}{|c|}
$\begin{array}{c}\text { Número de Particulas média } \\
\text { liquida }\end{array}$ \\
\end{tabular} & $\mathbf{p}$ & 19047 & 18883,5 & 16522,5 & 11418,5 & 2945,5 & 339,5 \\
\hline & Desvio - Poisson & $\#$ & 138,01 & 137,42 & 128,54 & 106,86 & 54,27 & 18,43 \\
\hline & Desvio - Poisson - Relativo & $\%$ & 0,7 & 0,7 & 0,8 & 0,9 & 1,8 & 5,4 \\
\hline & Desvio padrão Concentração & $\mathrm{P} / \mathrm{m}^{3}$ & $3,39 \mathrm{E}+03$ & $3,34 \mathrm{E}+03$ & $2,70 E+03$ & $1,96 \mathrm{E}+03$ & $5,16 E+02$ & $6,05 \mathrm{E}+01$ \\
\hline & DP/Concentração média & $\%$ & 0,0053 & 0,0053 & 0,0049 & 0,0052 & 0,0053 & 0,0053 \\
\hline \multirow{2}{*}{\multicolumn{2}{|c|}{ Erro total medições( $(\varepsilon)$}} & $\mathrm{P} / \mathrm{m}^{3}$ & $4,60 \mathrm{E}+05$ & $4,58 \mathrm{E}+05$ & $4,28 \mathrm{E}+05$ & $3,56 \mathrm{E}+05$ & $1,81 \mathrm{E}+05$ & $6,14 E+04$ \\
\hline & & Unidade & $1,0-2,0 \mu \mathrm{m}$ & $2,0-3,0 \mu \mathrm{m}$ & $3,0-5,0 \mu \mathrm{m}$ & $5,0-7,0 \mu \mathrm{m}$ & $7,0-10,0 \mu \mathrm{m}$ & $>10,0 \mu \mathrm{m}$ \\
\hline \multirow{8}{*}{ Assento 2E } & $\begin{array}{l}\text { Concentração média de } \\
\text { fundo } \\
\end{array}$ & $\mathrm{P} / \mathrm{m}^{3}$ & $7,00 E+04$ & $3,00 E+04$ & $3,33 \mathrm{E}+03$ & $0,00 E+00$ & $0,00 E+00$ & $0,00 \mathrm{E}+00$ \\
\hline & $\begin{array}{l}\text { Número de particulas de } \\
\text { fundo }\end{array}$ & p & 21 & 9 & 1 & 0 & 0 & 0 \\
\hline & Concentração média liquida & $\mathrm{P} / \mathrm{m}^{3}$ & $7,24 \mathrm{E}+07$ & $7,38 \mathrm{E}+07$ & $6,23 \mathrm{E}+07$ & $4,65 E+07$ & $1,96 \mathrm{E}+07$ & $3,08 E+06$ \\
\hline & \begin{tabular}{|c|} 
Número de Particulas média \\
liquida
\end{tabular} & $\mathbf{P}$ & 21706 & 22135 & 18694 & 13945 & 5879 & 924 \\
\hline & Desvio - Poisson & $\#$ & 147,33 & 148,78 & 136,73 & 118,09 & 76,67 & 30,40 \\
\hline & Desvio - Poisson - Relativo & $\%$ & 0,7 & 0,7 & 0,7 & 0,8 & 1,3 & 3,3 \\
\hline & Desvio padrão Concentração & $\mathrm{P} / \mathrm{m}^{3}$ & $9,43 E+02$ & $3,24 \mathrm{E}+02$ & $2,71 E+03$ & $8,08 \mathrm{E}+02$ & $8,35 E+02$ & $7,09 \mathrm{E}+01$ \\
\hline & DP/Concentração média & $\%$ & 0,0013 & 0,0004 & 0,0043 & 0,0017 & 0,0043 & 0,0023 \\
\hline \multicolumn{2}{|c|}{ Erro total medições(દ) } & $\mathrm{P} / \mathrm{m}^{3}$ & $4,91 E+05$ & $4,96 \mathrm{E}+05$ & $4,56 E+05$ & $3,94 E+05$ & $2,56 \mathrm{E}+05$ & $1,01 E+05$ \\
\hline
\end{tabular}




\begin{tabular}{|c|c|c|c|c|c|c|c|c|}
\hline & & Unidade & $1,0-2,0 \mu \mathrm{m}$ & $2,0-3,0 \mu \mathrm{m}$ & $3,0-5,0 \mu \mathrm{m}$ & $5,0-7,0 \mu \mathrm{m}$ & $7,0-10,0 \mu \mathrm{m}$ & $>10,0 \mu \mathrm{m}$ \\
\hline \multirow{8}{*}{ Assento 1D } & $\begin{array}{l}\text { Concentração média de } \\
\text { fundo }\end{array}$ & $\mathrm{P} / \mathrm{m}^{3}$ & $1,47 E+05$ & $1,20 \mathrm{E}+05$ & $6,67 E+03$ & $0,00 E+00$ & $0,00 E+00$ & $0,00 E+00$ \\
\hline & $\begin{array}{l}\text { Número de particulas de } \\
\text { fundo }\end{array}$ & $\mathbf{p}$ & 44 & 36 & 2 & 0 & 0 & 0 \\
\hline & Concentração média liquida & $\mathrm{P} / \mathrm{m}^{3}$ & $7,72 \mathrm{E}+07$ & $7,58 \mathrm{E}+07$ & $4,13 E+07$ & $3,19 \mathrm{E}+07$ & $6,62 E+06$ & $1,78 \mathrm{E}+06$ \\
\hline & \begin{tabular}{|c|} 
Número de Particulas média \\
liquida
\end{tabular} & $\mathbf{P}$ & 23148 & 22746 & 12399 & 9578 & 1985 & 534 \\
\hline & Desvio - Poisson & $\#$ & 152,14 & 150,82 & 111,35 & 97,87 & 44,55 & 23,11 \\
\hline & Desvio - Poisson - Relativo & $\%$ & 0,7 & 0,7 & 0,9 & 1,0 & 2,2 & 4,3 \\
\hline & Desvio padrão Concentração & $\mathrm{P} / \mathrm{m}^{3}$ & $1,54 \mathrm{E}+03$ & $2,41 E+03$ & $7,06 \mathrm{E}+02$ & $1,95 \mathrm{E}+03$ & $2,07 E+02$ & $9,77 E+01$ \\
\hline & DP/Concentração média & $\%$ & 0,0020 & 0,0032 & 0,0017 & 0,0061 & 0,0031 & 0,0055 \\
\hline \multirow{2}{*}{\multicolumn{2}{|c|}{ Erro total medições $(\varepsilon)$}} & $\mathrm{P} / \mathrm{m}^{3}$ & $5,07 E+05$ & $5,03 E+05$ & $3,71 \mathrm{E}+05$ & $3,26 \mathrm{E}+05$ & $1,49 \mathrm{E}+05$ & $7,70 E+04$ \\
\hline & & Unidade & $1,0-2,0 \mu \mathrm{m}$ & $2,0-3,0 \mu \mathrm{m}$ & $3,0-5,0 \mu \mathrm{m}$ & $5,0-7,0 \mu \mathrm{m}$ & $7,0-10,0 \mu \mathrm{m}$ & $>10,0 \mu \mathrm{m}$ \\
\hline \multirow{8}{*}{ Assento $1 \mathrm{E}$} & $\begin{array}{c}\text { Concentração média de } \\
\text { fundo }\end{array}$ & $\mathrm{P} / \mathrm{m}^{3}$ & $1,87 E+05$ & $9,33 E+04$ & $0,00 E+00$ & $0,00 E+00$ & $0,00 E+00$ & $0,00 E+00$ \\
\hline & $\begin{array}{l}\text { Número de particulas de } \\
\text { fundo }\end{array}$ & $\mathbf{p}$ & 56 & 28 & 0 & 0 & 0 & 0 \\
\hline & Concentração média liquida & $\mathrm{P} / \mathrm{m}^{3}$ & $7,62 \mathrm{E}+07$ & $7,69 \mathrm{E}+07$ & $3,75 E+07$ & $2,18 \mathrm{E}+07$ & $4,18 \mathrm{E}+06$ & $1,84 \mathrm{E}+06$ \\
\hline & $\begin{array}{c}\text { Número de Particulas média } \\
\text { liquida }\end{array}$ & $\mathbf{P}$ & 22846 & 23071 & 11250 & 6542 & 1254 & 551 \\
\hline & Desvio - Poisson & $\#$ & 151,15 & 151,89 & 106,07 & 80,88 & 35,41 & 23,46 \\
\hline & Desvio - Poisson - Relativo & $\%$ & 0,7 & 0,7 & 0,9 & 1,2 & 2,8 & 4,3 \\
\hline & Desvio padrão Concentração & $\mathrm{P} / \mathrm{m}^{3}$ & $2,10 E+03$ & $2,12 E+03$ & $6,39 \mathrm{E}+02$ & $2,95 \mathrm{E}+02$ & $1,38 \mathrm{E}+02$ & $4,06 E+01$ \\
\hline & DP/Concentração média & $\%$ & 0,0028 & 0,0028 & 0,0017 & 0,0014 & 0,0033 & 0,0022 \\
\hline \multirow{2}{*}{\multicolumn{2}{|c|}{ Erro total medições( $(\varepsilon)$}} & $\mathrm{P} / \mathrm{m}^{3}$ & $5,04 E+05$ & $5,06 E+05$ & $3,54 \mathrm{E}+05$ & $2,70 E+05$ & $1,18 E+05$ & $7,82 E+04$ \\
\hline & & Unidade & $1,0-2,0 \mu \mathrm{m}$ & $2,0-3,0 \mu \mathrm{m}$ & $3,0-5,0 \mu \mathrm{m}$ & $5,0-7,0 \mu \mathrm{m}$ & $7,0-10,0 \mu \mathrm{m}$ & $>10,0 \mu \mathrm{m}$ \\
\hline \multirow{8}{*}{ Assento $1 \mathrm{~B}$} & $\begin{array}{l}\text { Concentração média de } \\
\text { fundo }\end{array}$ & $\mathrm{P} / \mathrm{m}^{3}$ & $1,57 E+05$ & $5,33 E+04$ & $1,00 E+04$ & $0,00 E+00$ & $0,00 E+00$ & $0,00 E+00$ \\
\hline & $\begin{array}{l}\text { Número de particulas de } \\
\text { fundo }\end{array}$ & $\mathbf{P}$ & 47 & 16 & 3 & 0 & 0 & 0 \\
\hline & Concentração média liquida & $\mathrm{P} / \mathrm{m}^{3}$ & $6,20 \mathrm{E}+07$ & $6,29 E+07$ & $3,94 E+07$ & $3,17 E+07$ & $6,05 E+06$ & $8,58 E+05$ \\
\hline & $\begin{array}{c}\text { Número de Particulas média } \\
\text { liquida }\end{array}$ & $\mathbf{p}$ & 18587 & 18860 & 11817 & 9520 & 1816 & 258 \\
\hline & Desvio - Poisson & $\#$ & 136,33 & 137,33 & 108,70 & 97,57 & 42,61 & 16,05 \\
\hline & Desvio - Poisson - Relativo & $\%$ & 0,7 & 0,7 & 0,9 & 1,0 & 2,3 & 6,2 \\
\hline & Desvio padrão Concentração & $\mathrm{P} / \mathrm{m}^{3}$ & $2,73 E+03$ & $2,06 \mathrm{E}+03$ & $1,02 \mathrm{E}+03$ & $1,28 \mathrm{E}+03$ & $8,41 E+01$ & $3,11 E+01$ \\
\hline & DP/Concentração média & $\%$ & 0,0044 & 0,0033 & 0,0026 & 0,0040 & 0,0014 & 0,0036 \\
\hline \multicolumn{2}{|c|}{ Erro total medições( $(\varepsilon)$} & $\mathrm{P} / \mathrm{m}^{3}$ & $4,54 E+05$ & $4,58 E+05$ & $3,62 E+05$ & $3,25 E+05$ & $1,42 E+05$ & $5,35 E+04$ \\
\hline
\end{tabular}




\begin{tabular}{|c|c|c|c|c|c|c|c|c|}
\hline & & Unidade & $1,0-2,0 \mu \mathrm{m}$ & $2,0-3,0 \mu \mathrm{m}$ & $3,0-5,0 \mu \mathrm{m}$ & $5,0-7,0 \mu \mathrm{m}$ & $7,0-10,0 \mu \mathrm{m}$ & $>10,0 \mu \mathrm{m}$ \\
\hline \multirow{8}{*}{ Assento 1A } & $\begin{array}{l}\text { Concentração média de } \\
\text { fundo }\end{array}$ & $\mathrm{P} / \mathrm{m}^{3}$ & $2,23 E+05$ & $8,00 E+04$ & $6,67 E+03$ & $0,00 E+00$ & $0,00 E+00$ & $0,00 E+00$ \\
\hline & $\begin{array}{l}\text { Número de particulas de } \\
\text { fundo }\end{array}$ & $\mathbf{p}$ & 67 & 24 & 2 & 0 & 0 & 0 \\
\hline & Concentração média liquida & $\mathrm{P} / \mathrm{m}^{3}$ & $3,13 E+07$ & $2,67 E+07$ & $2,65 E+07$ & $1,53 \mathrm{E}+07$ & $3,28 \mathrm{E}+06$ & $7,00 E+05$ \\
\hline & \begin{tabular}{|c|}
$\begin{array}{c}\text { Número de Particulas média } \\
\text { liquida }\end{array}$ \\
\end{tabular} & $\mathbf{p}$ & 9377 & 8022 & 7954 & 4585 & 985 & 210 \\
\hline & Desvio - Poisson & $\#$ & 96,83 & 89,57 & 89,19 & 67,71 & 31,38 & 14,49 \\
\hline & Desvio - Poisson - Relativo & $\%$ & 1,0 & 1,1 & 1,1 & 1,5 & 3,2 & 6,9 \\
\hline & Desvio padrão Concentração & $\mathrm{P} / \mathrm{m}^{3}$ & $3,73 \mathrm{E}+03$ & $1,36 E+03$ & $1,18 \mathrm{E}+03$ & $7,64 E+02$ & $9,78 E+01$ & $8,63 E+01$ \\
\hline & DP/Concentração média & $\%$ & 0,0119 & 0,0051 & 0,0045 & 0,0050 & 0,0030 & 0,0123 \\
\hline \multirow{2}{*}{\multicolumn{2}{|c|}{ Erro total medições(ઘ) }} & $\mathrm{P} / \mathrm{m}^{3}$ & $3,23 E+05$ & $2,99 \mathrm{E}+05$ & $2,97 E+05$ & $2,26 \mathrm{E}+05$ & $1,05 E+05$ & $4,83 E+04$ \\
\hline & & Unidade & $1,0-2,0 \mu \mathrm{m}$ & $2,0-3,0 \mu \mathrm{m}$ & $3,0-5,0 \mu \mathrm{m}$ & $5,0-7,0 \mu \mathrm{m}$ & $7,0-10,0 \mu \mathrm{m}$ & $>10,0 \mu \mathrm{m}$ \\
\hline \multirow{8}{*}{ Assento 2B } & $\begin{array}{l}\text { Concentração média de } \\
\text { fundo }\end{array}$ & $\mathrm{P} / \mathrm{m}^{3}$ & $1,37 E+05$ & $1,13 E+05$ & $3,33 E+03$ & $0,00 E+00$ & $0,00 E+00$ & $0,00 E+00$ \\
\hline & $\begin{array}{l}\text { Número de particulas de } \\
\text { fundo }\end{array}$ & $\mathbf{p}$ & 41 & 34 & 1 & 0 & 0 & 0 \\
\hline & Concentração média liquida & $\mathrm{P} / \mathrm{m}^{3}$ & $6,29 \mathrm{E}+07$ & $6,68 \mathrm{E}+07$ & $5,97 E+07$ & $4,42 E+07$ & $2,15 E+07$ & $1,06 \mathrm{E}+06$ \\
\hline & \begin{tabular}{|c|} 
Número de Particulas média \\
liquida
\end{tabular} & $\mathbf{P}$ & 18877 & 20033 & 17899 & 13258 & 6452 & 318 \\
\hline & Desvio - Poisson & $\#$ & 137,39 & 141,54 & 133,79 & 115,14 & 80,32 & 17,83 \\
\hline & Desvio - Poisson - Relativo & $\%$ & 0,7 & 0,7 & 0,7 & 0,9 & 1,2 & 5,6 \\
\hline & Desvio padrão Concentração & $\mathrm{P} / \mathrm{m}^{3}$ & $3,35 E+03$ & $4,55 E+03$ & $1,12 \mathrm{E}+03$ & $1,21 E+03$ & $9,12 E+02$ & $7,61 \mathrm{E}+01$ \\
\hline & DP/Concentração média & $\%$ & 0,0053 & 0,0068 & 0,0019 & 0,0027 & 0,0042 & 0,0072 \\
\hline \multirow{2}{*}{\multicolumn{2}{|c|}{ Erro total medições( $(\varepsilon)$}} & $\mathrm{P} / \mathrm{m}^{3}$ & $4,58 \mathrm{E}+05$ & $4,72 E+05$ & $4,46 E+05$ & $3,84 E+05$ & $2,68 E+05$ & $5,94 E+04$ \\
\hline & & Unidade & $1,0-2,0 \mu \mathrm{m}$ & $2,0-3,0 \mu \mathrm{m}$ & $3,0-5,0 \mu \mathrm{m}$ & $5,0-7,0 \mu \mathrm{m}$ & $7,0-10,0 \mu \mathrm{m}$ & $>10,0 \mu \mathrm{m}$ \\
\hline \multirow{8}{*}{ Assento 2A } & $\begin{array}{l}\text { Concentração média de } \\
\text { fundo }\end{array}$ & $\mathrm{P} / \mathrm{m}^{3}$ & $4,33 E+04$ & $2,00 E+04$ & $0,00 E+00$ & $0,00 E+00$ & $0,00 E+00$ & $0,00 E+00$ \\
\hline & $\begin{array}{l}\text { Número de particulas de } \\
\text { fundo }\end{array}$ & $\mathbf{P}$ & 13 & 6 & 0 & 0 & 0 & 0 \\
\hline & Concentração média liquida & $\mathrm{P} / \mathrm{m}^{3}$ & $5,03 E+07$ & $4,35 E+07$ & $3,51 \mathrm{E}+07$ & $1,68 \mathrm{E}+07$ & $6,74 E+06$ & $1,34 \mathrm{E}+06$ \\
\hline & \begin{tabular}{|c|}
$\begin{array}{c}\text { Número de Particulas média } \\
\text { liquida }\end{array}$ \\
\end{tabular} & $\mathbf{p}$ & 15094 & 13038 & 10520 & 5040 & 2023 & 402 \\
\hline & Desvio - Poisson & $\#$ & 122,86 & 114,18 & 102,57 & 70,99 & 44,98 & 20,05 \\
\hline & Desvio - Poisson - Relativo & $\%$ & 0,8 & 0,9 & 1,0 & 1,4 & 2,2 & 5,0 \\
\hline & Desvio padrão Concentração & $\mathrm{P} / \mathrm{m}^{3}$ & $3,18 \mathrm{E}+03$ & $3,16 \mathrm{E}+03$ & $1,93 \mathrm{E}+03$ & $8,75 E+02$ & $4,96 \mathrm{E}+02$ & $1,45 \mathrm{E}+01$ \\
\hline & DP/Concentração média & $\%$ & 0,0063 & 0,0073 & 0,0055 & 0,0052 & 0,0073 & 0,0011 \\
\hline \multicolumn{2}{|c|}{ Erro total medições $(\varepsilon)$} & $\mathrm{P} / \mathrm{m}^{3}$ & $4,10 E+05$ & $3,81 E+05$ & $3,42 E+05$ & $2,37 E+05$ & $1,50 E+05$ & $6,68 E+04$ \\
\hline
\end{tabular}




\begin{tabular}{|c|c|c|c|c|c|c|c|c|}
\hline & & Unidade & $1,0-2,0 \mu \mathrm{m}$ & $2,0-3,0 \mu \mathrm{m}$ & $3,0-5,0 \mu \mathrm{m}$ & $5,0-7,0 \mu \mathrm{m}$ & $7,0-10,0 \mu \mathrm{m}$ & $>10,0 \mu \mathrm{m}$ \\
\hline \multirow{8}{*}{ Assento 3B } & $\begin{array}{l}\text { Concentração média de } \\
\text { fundo }\end{array}$ & $\mathrm{P} / \mathrm{m}^{3}$ & $2,23 E+05$ & $1,13 E+05$ & $6,67 E+03$ & $0,00 E+00$ & $0,00 E+00$ & $0,00 E+00$ \\
\hline & $\begin{array}{l}\text { Número de particulas de } \\
\text { fundo }\end{array}$ & $\mathbf{P}$ & 67 & 34 & 2 & 0 & 0 & 0 \\
\hline & Concentração média liquida & $\mathrm{P} / \mathrm{m}^{3}$ & $1,00 \mathrm{E}+08$ & $9,90 E+07$ & $3,92 \mathrm{E}+07$ & $3,12 \mathrm{E}+07$ & $1,46 \mathrm{E}+07$ & $1,16 \mathrm{E}+06$ \\
\hline & \begin{tabular}{|c|} 
Número de Particulas média \\
liquida
\end{tabular} & $\mathbf{P}$ & 30125 & 29688 & 11765 & 9345 & 4372 & 348 \\
\hline & Desvio - Poisson & $\#$ & 173,56 & 172,30 & 108,46 & 96,67 & 66,12 & 18,65 \\
\hline & Desvio - Poisson - Relativo & $\%$ & 0,6 & 0,6 & 0,9 & 1,0 & 1,5 & 5,4 \\
\hline & Desvio padrão Concentração & $\mathrm{P} / \mathrm{m}^{3}$ & $1,95 \mathrm{E}+03$ & $1,90 \mathrm{E}+03$ & $4,73 E+02$ & $9,11 E+02$ & $2,22 E+02$ & $2,04 \mathrm{E}+01$ \\
\hline & DP/Concentração média & $\%$ & 0,0019 & 0,0019 & 0,0012 & 0,0029 & 0,0015 & 0,0018 \\
\hline \multirow{2}{*}{\multicolumn{2}{|c|}{ Erro total medições $(\varepsilon)$}} & $\mathrm{P} / \mathrm{m}^{3}$ & $5,79 E+05$ & $5,74 \mathrm{E}+05$ & $3,62 \mathrm{E}+05$ & $3,22 \mathrm{E}+05$ & $2,20 E+05$ & $6,22 \mathrm{E}+04$ \\
\hline & & Unidade & $1,0-2,0 \mu \mathrm{m}$ & $2,0-3,0 \mu \mathrm{m}$ & $3,0-5,0 \mu \mathrm{m}$ & $5,0-7,0 \mu \mathrm{m}$ & $7,0-10,0 \mu \mathrm{m}$ & $>10,0 \mu \mathrm{m}$ \\
\hline \multirow{8}{*}{ Assento $3 \mathrm{~A}$} & $\begin{array}{l}\text { Concentração média de } \\
\text { fundo }\end{array}$ & $\mathrm{P} / \mathrm{m}^{3}$ & $1,30 E+05$ & $5,00 E+04$ & $3,33 E+03$ & $0,00 E+00$ & $0,00 E+00$ & $0,00 E+00$ \\
\hline & $\begin{array}{c}\text { Número de particulas de } \\
\text { fundo }\end{array}$ & $\mathbf{P}$ & 39 & 15 & 1 & 0 & 0 & 0 \\
\hline & Concentração média liquida & $\mathrm{P} / \mathrm{m}^{3}$ & $1,00 E+08$ & $9,90 \mathrm{E}+07$ & $6,13 \mathrm{E}+07$ & $4,30 E+07$ & $2,01 E+07$ & $1,00 E+06$ \\
\hline & \begin{tabular}{|c|} 
Número de Particulas média \\
liquida \\
\end{tabular} & $\mathbf{P}$ & 30125 & 29688 & 18400 & 12890 & 6042 & 300 \\
\hline & Desvio - Poisson & $\#$ & 173,56 & 172,30 & 135,65 & 113,53 & 77,73 & 17,32 \\
\hline & Desvio - Poisson - Relativo & $\%$ & 0,6 & 0,6 & 0,7 & 0,9 & 1,3 & 5,8 \\
\hline & Desvio padrão Concentração & $\mathrm{P} / \mathrm{m}^{3}$ & $1,95 \mathrm{E}+03$ & $1,90 \mathrm{E}+03$ & $1,46 \mathrm{E}+03$ & $7,36 \mathrm{E}+02$ & $1,36 \mathrm{E}+03$ & $1,54 \mathrm{E}+01$ \\
\hline & DP/Concentração média & $\%$ & 0,0019 & 0,0019 & 0,0024 & 0,0017 & 0,0067 & 0,0015 \\
\hline \multicolumn{2}{|c|}{ Erro total medições(E) } & $\mathrm{P} / \mathrm{m}^{3}$ & $5,79 E+05$ & $5,74 \mathrm{E}+05$ & $4,52 \mathrm{E}+05$ & $3,78 E+05$ & $2,59 \mathrm{E}+05$ & $5,77 \mathrm{E}+04$ \\
\hline
\end{tabular}


Tabela D-9. Resultados das medições de partículas no assento (Sistema UFAD mod. à $18^{\circ} \mathrm{C}-$ injeção pelo assento $3 \mathrm{E}$ )

\begin{tabular}{|c|c|c|c|c|c|c|c|c|}
\hline & & Unidade & $1,0-2,0 \mu \mathrm{m}$ & $2,0-3,0 \mu \mathrm{m}$ & $3,0-5,0 \mu \mathrm{m}$ & $5,0-7,0 \mu \mathrm{m}$ & $7,0-10,0 \mu \mathrm{m}$ & $>10,0 \mu \mathrm{m}$ \\
\hline \multirow{8}{*}{ Assento 3D } & $\begin{array}{c}\text { Concentração média de } \\
\text { fundo }\end{array}$ & $\mathrm{P} / \mathrm{m}^{3}$ & $1,17 \mathrm{E}+05$ & $3,67 E+04$ & $3,33 \mathrm{E}+03$ & $0,00 E+00$ & $0,00 E+00$ & $0,00 E+00$ \\
\hline & \begin{tabular}{|c|} 
Número de particulas de \\
fundo
\end{tabular} & $\mathbf{P}$ & 35 & 11 & 1 & 0 & 0 & 0 \\
\hline & $\begin{array}{l}\text { Concentração média } \\
\text { liquida }\end{array}$ & $\mathrm{P} / \mathrm{m}^{3}$ & $1,20 E+08$ & $1,03 E+08$ & $8,00 E+07$ & $6,67 E+07$ & $3,33 E+07$ & $5,97 E+06$ \\
\hline & $\begin{array}{l}\text { Número de Particulas } \\
\text { média liquida }\end{array}$ & $\mathbf{P}$ & 36118 & 30815 & 24000 & 20000 & 10000 & 1791 \\
\hline & Desvio - Poisson & $\#$ & 190,05 & 175,54 & 154,92 & 141,42 & 100,00 & 42,32 \\
\hline & $\begin{array}{c}\text { Desvio - Poisson - } \\
\text { Relativo } \\
\end{array}$ & $\%$ & 0,5 & 0,6 & 0,6 & 0,7 & 1,0 & 2,4 \\
\hline & $\begin{array}{l}\text { Desvio padrão } \\
\text { Concentração }\end{array}$ & $\mathrm{P} / \mathrm{m}^{3}$ & $5,26 \mathrm{E}+02$ & $9,35 E+02$ & $3,13 E+03$ & $7,05 E+02$ & $7,68 \mathrm{E}+02$ & $2,98 \mathrm{E}+02$ \\
\hline & DP/Concentração média & $\%$ & 0,0004 & 0,0009 & 0,0039 & 0,0011 & 0,0023 & 0,0050 \\
\hline \multirow{2}{*}{\multicolumn{2}{|c|}{ Erro total medições( $\varepsilon$ ) }} & $\mathrm{P} / \mathrm{m}^{3}$ & $6,33 \mathrm{E}+05$ & $5,85 E+05$ & $5,16 \mathrm{E}+05$ & $4,71 \mathrm{E}+05$ & $3,33 \mathrm{E}+05$ & $1,41 E+05$ \\
\hline & & Unidade & $1,0-2,0 \mu \mathrm{m}$ & $2,0-3,0 \mu \mathrm{m}$ & $3,0-5,0 \mu \mathrm{m}$ & $5,0-7,0 \mu \mathrm{m}$ & $7,0-10,0 \mu \mathrm{m}$ & $>10,0 \mu \mathrm{m}$ \\
\hline \multirow{8}{*}{ Assento 2D } & \begin{tabular}{|c|}
$\begin{array}{c}\text { Concentração média de } \\
\text { fundo }\end{array}$ \\
\end{tabular} & $\mathrm{P} / \mathrm{m}^{3}$ & $1,87 E+05$ & $1,10 \mathrm{E}+05$ & $6,67 E+03$ & $3,33 E+03$ & $0,00 E+00$ & $0,00 E+00$ \\
\hline & $\begin{array}{c}\text { Número de particulas de } \\
\text { fundo }\end{array}$ & $\mathbf{P}$ & 56 & 33 & 2 & 1 & 0 & 0 \\
\hline & $\begin{array}{c}\text { Concentração média } \\
\text { liquida } \\
\end{array}$ & $\mathrm{P} / \mathrm{m}^{3}$ & $9,38 E+07$ & $8,16 \mathrm{E}+07$ & $6,33 E+07$ & $4,53 E+07$ & $1,50 E+07$ & $7,42 E+05$ \\
\hline & $\begin{array}{c}\text { Número de Particulas } \\
\text { média liquida }\end{array}$ & P & 28130 & 24483 & 19000 & 13580 & 4500 & 223 \\
\hline & Desvio - Poisson & $\#$ & 167,72 & 156,47 & 137,84 & 116,53 & 67,08 & 14,92 \\
\hline & $\begin{array}{c}\text { Desvio - Poisson - } \\
\text { Relativo } \\
\end{array}$ & $\%$ & 0,6 & 0,6 & 0,7 & 0,9 & 1,5 & 6,7 \\
\hline & $\begin{array}{l}\text { Desvio padrão } \\
\text { Concentração }\end{array}$ & $\mathrm{P} / \mathrm{m}^{3}$ & $1,25 \mathrm{E}+03$ & $1,00 E+03$ & $9,08 \mathrm{E}+02$ & $7,17 \mathrm{E}+02$ & $5,78 E+02$ & $2,37 E+01$ \\
\hline & DP/Concentração média & $\%$ & 0,0013 & 0,0012 & 0,0014 & 0,0016 & 0,0039 & 0,0032 \\
\hline \multirow{2}{*}{\multicolumn{2}{|c|}{ Erro total medições( $(\varepsilon)$}} & $\mathrm{P} / \mathrm{m}^{3}$ & $5,59 \mathrm{E}+05$ & $5,22 \mathrm{E}+05$ & $4,59 \mathrm{E}+05$ & $3,88 \mathrm{E}+05$ & $2,24 E+05$ & 4,97E+04 \\
\hline & & Unidade & $1,0-2,0 \mu \mathrm{m}$ & $2,0-3,0 \mu \mathrm{m}$ & $3,0-5,0 \mu \mathrm{m}$ & $5,0-7,0 \mu \mathrm{m}$ & $7,0-10,0 \mu \mathrm{m}$ & $>10,0 \mu \mathrm{m}$ \\
\hline \multirow{8}{*}{ Assento 2E } & \begin{tabular}{|c|}
$\begin{array}{c}\text { Concentração média de } \\
\text { fundo }\end{array}$ \\
\end{tabular} & $\mathrm{P} / \mathrm{m}^{3}$ & $2,53 E+05$ & $9,00 E+04$ & $3,33 E+03$ & $0,00 E+00$ & $0,00 E+00$ & $0,00 E+00$ \\
\hline & \begin{tabular}{|c|}
$\begin{array}{c}\text { Número de particulas de } \\
\text { fundo }\end{array}$ \\
\end{tabular} & P & 76 & 27 & 1 & 0 & 0 & 0 \\
\hline & $\begin{array}{c}\text { Concentração média } \\
\text { liquida }\end{array}$ & $\mathrm{P} / \mathrm{m}^{3}$ & $1,04 \mathrm{E}+08$ & $8,89 \mathrm{E}+07$ & $6,42 \mathrm{E}+07$ & $5,29 \mathrm{E}+07$ & $2,28 \mathrm{E}+07$ & $6,87 E+05$ \\
\hline & $\begin{array}{l}\text { Número de Particulas } \\
\text { média liquida }\end{array}$ & $\mathbf{P}$ & 31213 & 26684 & 19250 & 15870 & 6854 & 206 \\
\hline & Desvio - Poisson & $\#$ & 176,67 & 163,35 & 138,74 & 125,98 & 82,79 & 14,35 \\
\hline & $\begin{array}{c}\text { Desvio - Poisson - } \\
\text { Relativo } \\
\end{array}$ & $\%$ & 0,6 & 0,6 & 0,7 & 0,8 & 1,2 & 7,0 \\
\hline & $\begin{array}{l}\text { Desvio padrão } \\
\text { Concentração }\end{array}$ & $\mathrm{P} / \mathrm{m}^{3}$ & $4,06 \mathrm{E}+02$ & $2,37 E+03$ & $1,13 \mathrm{E}+03$ & $9,11 E+02$ & $1,22 \mathrm{E}+03$ & $3,89 \mathrm{E}+01$ \\
\hline & DP/Concentração média & $\%$ & 0,0004 & 0,0027 & 0,0018 & 0,0017 & 0,0054 & 0,0057 \\
\hline \multicolumn{2}{|c|}{ Erro total medições( $(\varepsilon)$} & $\mathrm{P} / \mathrm{m}^{3}$ & $5,89 \mathrm{E}+05$ & $5,45 E+05$ & $4,62 E+05$ & $4,20 \mathrm{E}+05$ & $2,76 \mathrm{E}+05$ & $4,78 \mathrm{E}+04$ \\
\hline
\end{tabular}




\begin{tabular}{|c|c|c|c|c|c|c|c|c|}
\hline & & Unidade & $1,0-2,0 \mu \mathrm{m}$ & $2,0-3,0 \mu \mathrm{m}$ & $3,0-5,0 \mu \mathrm{m}$ & $5,0-7,0 \mu \mathrm{m}$ & $7,0-10,0 \mu \mathrm{m}$ & $>10,0 \mu \mathrm{m}$ \\
\hline \multirow{8}{*}{ Assento 1D } & $\begin{array}{c}\text { Concentração média de } \\
\text { fundo }\end{array}$ & $\mathrm{P} / \mathrm{m}^{3}$ & $7,67 E+04$ & $2,00 E+04$ & $3,33 \mathrm{E}+03$ & $0,00 \mathrm{E}+00$ & $0,00 \mathrm{E}+00$ & $0,00 \mathrm{E}+00$ \\
\hline & $\begin{array}{c}\text { Número de particulas de } \\
\text { fundo }\end{array}$ & $\mathbf{p}$ & 23 & 6 & 1 & 0 & 0 & 0 \\
\hline & $\begin{array}{c}\text { Concentração média } \\
\text { liquida }\end{array}$ & $\mathrm{P} / \mathrm{m}^{3}$ & $1,02 E+08$ & $7,38 \mathrm{E}+07$ & $5,85 \mathrm{E}+07$ & $3,53 \mathrm{E}+07$ & $1,00 \mathrm{E}+07$ & $4,12 E+05$ \\
\hline & $\begin{array}{l}\text { Número de Particulas } \\
\text { média liquida }\end{array}$ & $\mathbf{p}$ & 30516 & 22128 & 17560 & 10584 & 2999 & 124 \\
\hline & Desvio - Poisson & $\#$ & 174,687885 & 148,756272 & 132,5141502 & 102,8785692 & 54,7631263 & 11,1130554 \\
\hline & $\begin{array}{l}\text { Desvio - Poisson - } \\
\text { Relativo }\end{array}$ & $\%$ & 0,6 & 0,7 & 0,8 & 1,0 & 1,8 & 9,0 \\
\hline & $\begin{array}{l}\text { Desvio padrão } \\
\text { Concentração }\end{array}$ & $\mathrm{P} / \mathrm{m}^{3}$ & $2,31 E+02$ & $1,72 E+03$ & $9,73 E+02$ & $6,13 E+02$ & $5,15 E+02$ & $1,27 \mathrm{E}+01$ \\
\hline & DP/Concentração média & $\%$ & 0,0002 & 0,0023 & 0,0017 & 0,0017 & 0,0052 & 0,0031 \\
\hline \multirow{2}{*}{\multicolumn{2}{|c|}{ Erro total medições $(\varepsilon)$}} & $\mathrm{P} / \mathrm{m}^{3}$ & $5,82 \mathrm{E}+05$ & $4,96 \mathrm{E}+05$ & $4,42 E+05$ & $3,43 E+05$ & $1,83 \mathrm{E}+05$ & $3,70 E+04$ \\
\hline & & Unidade & $1,0-2,0 \mu \mathrm{m}$ & $2,0-3,0 \mu \mathrm{m}$ & $3,0-5,0 \mu \mathrm{m}$ & $5,0-7,0 \mu \mathrm{m}$ & $7,0-10,0 \mu \mathrm{m}$ & $>10,0 \mu \mathrm{m}$ \\
\hline \multirow{8}{*}{ Assento $1 \mathrm{E}$} & $\begin{array}{c}\text { Concentração média de } \\
\text { fundo }\end{array}$ & $\mathrm{P} / \mathrm{m}^{3}$ & $9,67 E+04$ & $3,67 E+04$ & $3,33 \mathrm{E}+03$ & $0,00 \mathrm{E}+00$ & $0,00 E+00$ & $0,00 \mathrm{E}+00$ \\
\hline & $\begin{array}{c}\text { Número de particulas de } \\
\text { fundo }\end{array}$ & $\mathbf{p}$ & 29 & 11 & 1 & 0 & 0 & 0 \\
\hline & $\begin{array}{c}\text { Concentração média } \\
\text { liquida }\end{array}$ & $\mathrm{P} / \mathrm{m}^{3}$ & $1,09 \mathrm{E}+08$ & $1,07 E+08$ & $5,30 \mathrm{E}+07$ & $2,66 \mathrm{E}+07$ & $1,87 E+06$ & $3,40 \mathrm{E}+05$ \\
\hline & $\begin{array}{c}\text { Número de Particulas } \\
\text { média liquida }\end{array}$ & $\mathbf{P}$ & 32744 & 32037 & 15890 & 7985 & 560 & 102 \\
\hline & Desvio - Poisson & $\#$ & 180,95 & 178,99 & 126,06 & 89,36 & 23,66 & 10,10 \\
\hline & $\begin{array}{c}\text { Desvio - Poisson - } \\
\text { Relativo } \\
\end{array}$ & $\%$ & 0,6 & 0,6 & 0,8 & 1,1 & 4,2 & 9,9 \\
\hline & $\begin{array}{l}\text { Desvio padrão } \\
\text { Concentração }\end{array}$ & $\mathrm{P} / \mathrm{m}^{3}$ & $1,51 E+03$ & $1,46 \mathrm{E}+03$ & $1,25 E+03$ & $1,17 \mathrm{E}+03$ & $3,85 E+01$ & $1,06 \mathrm{E}+01$ \\
\hline & DP/Concentração média & $\%$ & 0,0014 & 0,0014 & 0,0024 & 0,0044 & 0,0021 & 0,0031 \\
\hline \multirow{2}{*}{\multicolumn{2}{|c|}{ Erro total medições(દ) }} & $\mathrm{P} / \mathrm{m}^{3}$ & $6,03 E+05$ & $5,97 E+05$ & $4,20 E+05$ & $2,98 \mathrm{E}+05$ & $7,89 \mathrm{E}+04$ & $3,37 E+04$ \\
\hline & & Unidade & $1,0-2,0 \mu \mathrm{m}$ & $2,0-3,0 \mu \mathrm{m}$ & $3,0-5,0 \mu \mathrm{m}$ & $5,0-7,0 \mu \mathrm{m}$ & $7,0-10,0 \mu \mathrm{m}$ & $>10,0 \mu \mathrm{m}$ \\
\hline \multirow{8}{*}{ Assento 1B } & \begin{tabular}{|c|}
$\begin{array}{c}\text { Concentração média de } \\
\text { fundo }\end{array}$ \\
\end{tabular} & $\mathrm{P} / \mathrm{m}^{3}$ & $1,47 E+05$ & $5,00 E+04$ & $5,00 \mathrm{E}+03$ & $0,00 \mathrm{E}+00$ & $0,00 \mathrm{E}+00$ & $0,00 \mathrm{E}+00$ \\
\hline & $\begin{array}{c}\text { Número de particulas de } \\
\text { fundo }\end{array}$ & $\mathbf{p}$ & 44 & 15 & 2 & 0 & 0 & 0 \\
\hline & $\begin{array}{l}\text { Concentração média } \\
\text { liquida }\end{array}$ & $\mathrm{P} / \mathrm{m}^{3}$ & $9,51 E+07$ & $9,33 E+07$ & $6,98 \mathrm{E}+07$ & $3,31 E+07$ & $5,33 E+06$ & $2,87 E+05$ \\
\hline & $\begin{array}{c}\text { Número de Particulas } \\
\text { média liquida }\end{array}$ & $\mathbf{p}$ & 28526 & 28001 & 20931 & 9931 & 1599 & 86 \\
\hline & Desvio - Poisson & $\#$ & 168,90 & 167,33 & 144,68 & 99,65 & 39,99 & 9,27 \\
\hline & $\begin{array}{c}\text { Desvio - Poisson - } \\
\text { Relativo } \\
\end{array}$ & $\%$ & 0,6 & 0,6 & 0,7 & 1,0 & 2,5 & 10,8 \\
\hline & $\begin{array}{l}\text { Desvio padrão } \\
\text { Concentração }\end{array}$ & $\mathrm{P} / \mathrm{m}^{3}$ & $8,91 E+02$ & $8,54 \mathrm{E}+02$ & $5,93 E+02$ & $4,91 E+02$ & $9,41 E+01$ & $1,01 E+01$ \\
\hline & DP/Concentração média & $\%$ & 0,0009 & 0,0009 & 0,0008 & 0,0015 & 0,0018 & 0,0035 \\
\hline \multicolumn{2}{|c|}{ Erro total medições(દ) } & $\mathrm{P} / \mathrm{m}^{3}$ & $5,63 E+05$ & $5,58 \mathrm{E}+05$ & $4,82 E+05$ & $3,32 E+05$ & $1,33 \mathrm{E}+05$ & $3,09 E+04$ \\
\hline
\end{tabular}




\begin{tabular}{|c|c|c|c|c|c|c|c|c|}
\hline & & Unidade & $1,0-2,0 \mu \mathrm{m}$ & $2,0-3,0 \mu \mathrm{m}$ & $3,0-5,0 \mu \mathrm{m}$ & $5,0-7,0 \mu \mathrm{m}$ & $7,0-10,0 \mu \mathrm{m}$ & $>10,0 \mu \mathrm{m}$ \\
\hline \multirow{8}{*}{ Assento $1 \mathrm{~A}$} & $\begin{array}{c}\begin{array}{c}\text { Concentração média de } \\
\text { fundo }\end{array} \\
\end{array}$ & $\mathrm{P} / \mathrm{m}^{3}$ & $1,70 E+05$ & $7,67 E+04$ & $8,33 E+03$ & $0,00 E+00$ & $0,00 E+00$ & $0,00 \mathrm{E}+00$ \\
\hline & $\begin{array}{c}\text { Número de particulas de } \\
\text { fundo }\end{array}$ & $\mathbf{P}$ & 51 & 23 & 3 & 0 & 0 & 0 \\
\hline & $\begin{array}{c}\text { Concentração média } \\
\text { liquida }\end{array}$ & $\mathrm{P} / \mathrm{m}^{3}$ & $3,93 E+07$ & $2,39 \mathrm{E}+07$ & $1,62 \mathrm{E}+07$ & $8,49 E+06$ & $1,75 E+06$ & $3,45 E+05$ \\
\hline & $\begin{array}{c}\text { Número de Particulas } \\
\text { média liquida }\end{array}$ & $\mathbf{p}$ & 11801 & 7169 & 4852 & 2546 & 526 & 104 \\
\hline & Desvio - Poisson & $\#$ & 108,63 & 84,67 & 69,66 & 50,46 & 22,93 & 10,17 \\
\hline & $\begin{array}{c}\text { Desvio - Poisson - } \\
\text { Relativo } \\
\end{array}$ & $\%$ & 0,9 & 1,2 & 1,4 & 2,0 & 4,4 & 9,8 \\
\hline & $\begin{array}{l}\text { Desvio padrão } \\
\text { Concentração }\end{array}$ & $\mathrm{P} / \mathrm{m}^{3}$ & $4,28 \mathrm{E}+02$ & $5,52 E+02$ & $5,17 E+02$ & $6,92 E+01$ & $8,98 \mathrm{E}+01$ & $3,75 E+01$ \\
\hline & DP/Concentração média & $\%$ & 0,0011 & 0,0023 & 0,0032 & 0,0008 & 0,0051 & 0,0109 \\
\hline \multirow{2}{*}{\multicolumn{2}{|c|}{ Erro total medições(દ) }} & $\mathrm{P} / \mathrm{m}^{3}$ & $3,62 E+05$ & $2,82 E+05$ & $2,32 E+05$ & $1,68 E+05$ & $7,64 \mathrm{E}+04$ & $3,39 E+04$ \\
\hline & & Unidade & $1,0-2,0 \mu \mathrm{m}$ & $2,0-3,0 \mu \mathrm{m}$ & $3,0-5,0 \mu \mathrm{m}$ & $5,0-7,0 \mu \mathrm{m}$ & $7,0-10,0 \mu \mathrm{m}$ & $>10,0 \mu \mathrm{m}$ \\
\hline \multirow{8}{*}{ Assento 2B } & $\begin{array}{c}\text { Concentração média de } \\
\text { fundo }\end{array}$ & $\mathrm{P} / \mathrm{m}^{3}$ & $1,13 E+05$ & $2,33 E+04$ & $8,33 E+03$ & $0,00 E+00$ & $0,00 E+00$ & $0,00 E+00$ \\
\hline & \begin{tabular}{|c|}
$\begin{array}{c}\text { Número de particulas de } \\
\text { fundo }\end{array}$ \\
\end{tabular} & $\mathbf{P}$ & 34 & 7 & 3 & 0 & 0 & 0 \\
\hline & $\begin{array}{l}\text { Concentração média } \\
\text { liquida }\end{array}$ & $\mathrm{P} / \mathrm{m}^{3}$ & $6,78 \mathrm{E}+07$ & $4,79 E+07$ & $3,36 \mathrm{E}+07$ & $1,96 \mathrm{E}+07$ & $1,45 E+07$ & $6,18 \mathrm{E}+05$ \\
\hline & $\begin{array}{c}\text { Número de Particulas } \\
\text { média liquida }\end{array}$ & $\mathbf{P}$ & 20354 & 14370 & 10078 & 5870 & 4350 & 186 \\
\hline & Desvio - Poisson & $\#$ & 142,67 & 119,87 & 100,39 & 76,62 & 65,95 & 13,62 \\
\hline & $\begin{array}{l}\text { Desvio - Poisson - } \\
\text { Relativo }\end{array}$ & $\%$ & 0,7 & 0,8 & 1,0 & 1,3 & 1,5 & 7,3 \\
\hline & $\begin{array}{l}\text { Desvio padrão } \\
\text { Concentração }\end{array}$ & $\mathrm{P} / \mathrm{m}^{3}$ & $8,67 E+02$ & $8,43 E+02$ & $7,23 E+02$ & $5,75 E+02$ & $9,19 E+02$ & $3,02 E+01$ \\
\hline & DP/Concentração média & $\%$ & 0,0013 & 0,0018 & 0,0022 & 0,0029 & 0,0063 & 0,0049 \\
\hline \multirow{2}{*}{\multicolumn{2}{|c|}{ Erro total medições( $\varepsilon)$}} & $\mathrm{P} / \mathrm{m}^{3}$ & $4,76 E+05$ & $4,00 E+05$ & $3,35 E+05$ & $2,55 E+05$ & $2,20 E+05$ & $4,54 \mathrm{E}+04$ \\
\hline & & Unidade & $1,0-2,0 \mu \mathrm{m}$ & $2,0-3,0 \mu \mathrm{m}$ & $3,0-5,0 \mu \mathrm{m}$ & $5,0-7,0 \mu \mathrm{m}$ & $7,0-10,0 \mu \mathrm{m}$ & $>10,0 \mu \mathrm{m}$ \\
\hline \multirow{8}{*}{ Assento $2 \mathrm{~A}$} & $\begin{array}{c}\begin{array}{c}\text { Concentração média de } \\
\text { fundo }\end{array} \\
\end{array}$ & $\mathrm{P} / \mathrm{m}^{3}$ & $1,03 E+05$ & $5,67 E+04$ & $8,33 E+03$ & $0,00 E+00$ & $0,00 E+00$ & $0,00 E+00$ \\
\hline & \begin{tabular}{|c|} 
Número de particulas de \\
fundo
\end{tabular} & $\mathbf{P}$ & 31 & 17 & 3 & 0 & 0 & 0 \\
\hline & $\begin{array}{c}\text { Concentração média } \\
\text { liquida }\end{array}$ & $\mathrm{P} / \mathrm{m}^{3}$ & $3,22 \mathrm{E}+07$ & $2,06 \mathrm{E}+07$ & $1,20 E+07$ & $8,49 E+06$ & $2,82 E+06$ & $6,15 E+05$ \\
\hline & $\begin{array}{l}\text { Número de Particulas } \\
\text { média liquida }\end{array}$ & $\mathbf{P}$ & 9670 & 6183 & 3589 & 2548 & 847 & 185 \\
\hline & Desvio - Poisson & $\#$ & 98,34 & 78,63 & 59,91 & 50,48 & 29,10 & 13,58 \\
\hline & $\begin{array}{l}\text { Desvio - Poisson - } \\
\text { Relativo }\end{array}$ & $\%$ & 1,0 & 1,3 & 1,7 & 2,0 & 3,4 & 7,4 \\
\hline & $\begin{array}{l}\text { Desvio padrão } \\
\text { Concentração }\end{array}$ & $\mathrm{P} / \mathrm{m}^{3}$ & $8,12 \mathrm{E}+02$ & $5,62 E+02$ & $6,95 \mathrm{E}+02$ & $2,66 \mathrm{E}+02$ & $1,07 E+02$ & $3,91 \mathrm{E}+01$ \\
\hline & DP/Concentração média & $\%$ & 0,0025 & 0,0027 & 0,0058 & 0,0031 & 0,0038 & 0,0064 \\
\hline \multicolumn{2}{|c|}{ Erro total medições(દ) } & $\mathrm{P} / \mathrm{m}^{3}$ & $3,28 \mathrm{E}+05$ & $2,62 E+05$ & $2,00 E+05$ & $1,68 \mathrm{E}+05$ & $9,70 E+04$ & $4,53 E+04$ \\
\hline
\end{tabular}




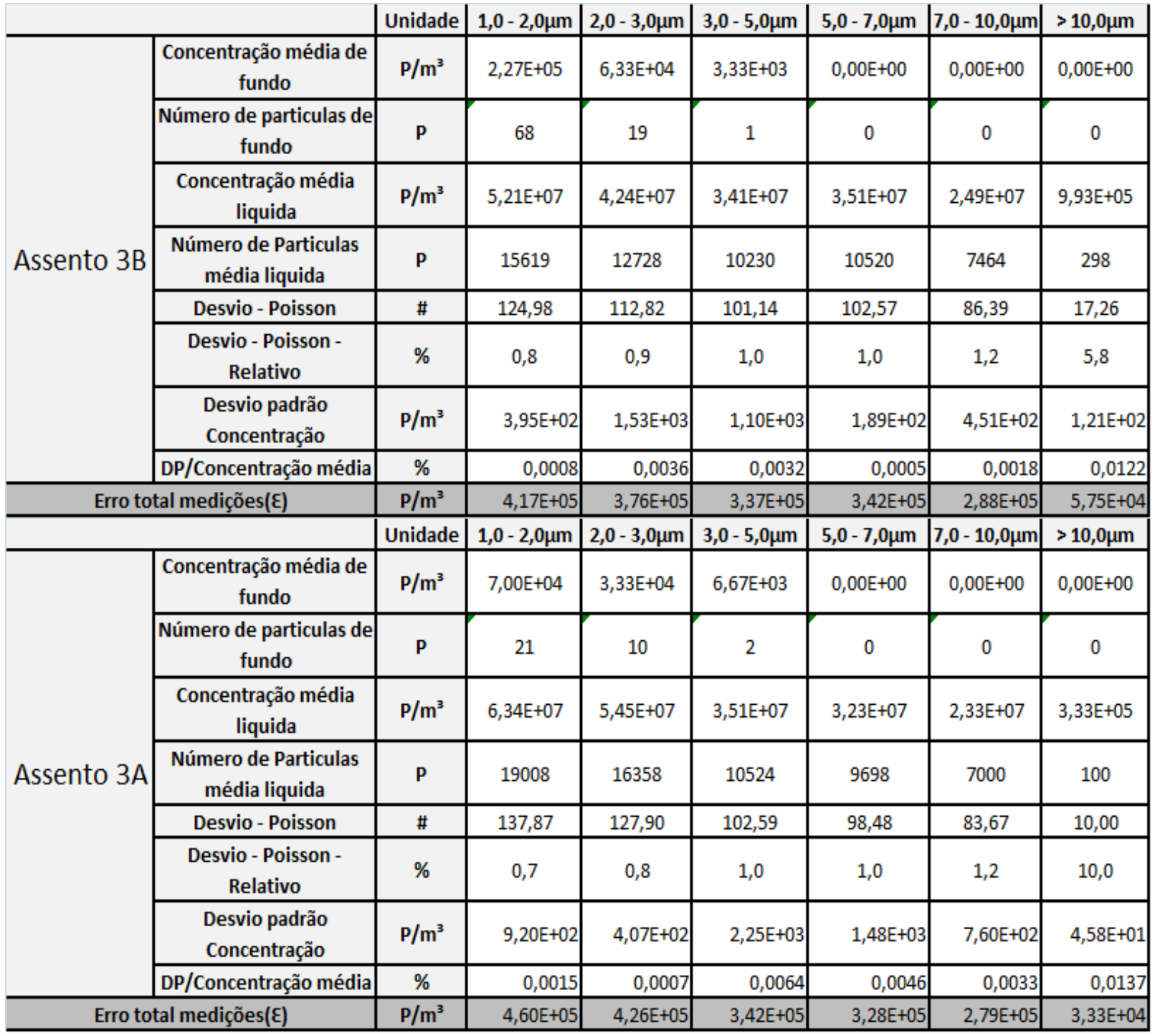


Tabela D-10. Resultados das medições de partículas no assento (Sistema MV à $22^{\circ} \mathrm{C}$ - injeção pelo assento $3 \mathrm{E}$ )

\begin{tabular}{|c|c|c|c|c|c|c|c|c|}
\hline & & | Unidade & $1,0-2,0 \mu \mathrm{m}$ & $2,0-3,0 \mu \mathrm{m}$ & $3,0-5,0 \mu \mathrm{m}$ & $5,0-7,0 \mu \mathrm{m}$ & $7,0-10,0 \mu \mathrm{m}$ & $>10,0 \mu \mathrm{m}$ \\
\hline \multirow{8}{*}{ Assento 3D } & $\begin{array}{c}\text { Concentração média de } \\
\text { fundo }\end{array}$ & $\mathrm{P} / \mathrm{m}^{3}$ & $1,50 E+05$ & $4,00 E+04$ & $3,33 E+03$ & $0,00 \mathrm{E}+00$ & $0,00 \mathrm{E}+00$ & $0,00 E+00$ \\
\hline & $\begin{array}{c}\text { Número de particulas de } \\
\text { fundo }\end{array}$ & $\mathbf{p}$ & 45 & 12 & 1 & 0 & 0 & 0 \\
\hline & $\begin{array}{c}\text { Concentração média } \\
\text { liquida }\end{array}$ & $\mathrm{P} / \mathrm{m}^{3}$ & $8,87 E+00$ & $8,06 \mathrm{E}+00$ & $6,27 E+00$ & $8,37 \mathrm{E}+07$ & $3,68 \mathrm{E}+07$ & $1,38 E+06$ \\
\hline & $\begin{array}{l}\text { Número de Particulas } \\
\text { média liquida }\end{array}$ & $\mathbf{P}$ & 45244 & 41065 & 31985 & 25120 & 11052 & 414 \\
\hline & Desvio - Poisson & $\#$ & 212,71 & 202,65 & 178,84 & 158,49 & 105,13 & 20,35 \\
\hline & $\begin{array}{l}\text { Desvio - Poisson - } \\
\text { Relativo }\end{array}$ & $\%$ & 0,5 & 0,5 & 0,6 & 0,6 & 1,0 & 4,9 \\
\hline & $\begin{array}{l}\text { Desvio padrão } \\
\text { Concentração }\end{array}$ & $\mathrm{P} / \mathrm{m}^{3}$ & $9,78 \mathrm{E}+03$ & $1,18 \mathrm{E}+03$ & $1,29 \mathrm{E}+03$ & $1,75 \mathrm{E}+03$ & $4,56 \mathrm{E}+03$ & $1,20 E+02$ \\
\hline & DP/Concentração média & $\%$ & 110184,8687 & 14638,7377 & 20577,4685 & 0,0021 & 0,0124 & 0,0087 \\
\hline \multirow{2}{*}{\multicolumn{2}{|c|}{ Erro total medições(E) }} & $\mathrm{P} / \mathrm{m}^{3}$ & $7,09 E+05$ & $6,75 \mathrm{E}+05$ & $5,96 \mathrm{E}+05$ & $5,28 \mathrm{E}+05$ & $3,50 \mathrm{E}+05$ & $6,78 E+04$ \\
\hline & & Unidade & $1,0-2,0 \mu \mathrm{m}$ & $2,0-3,0 \mu \mathrm{m}$ & $3,0-5,0 \mu \mathrm{m}$ & $5,0-7,0 \mu \mathrm{m}$ & $7,0-10,0 \mu \mathrm{m}$ & $>10,0 \mu \mathrm{m}$ \\
\hline \multirow{8}{*}{ Assento 2D } & $\begin{array}{c}\text { Concentração média de } \\
\text { fundo }\end{array}$ & $\mathrm{P} / \mathrm{m}^{3}$ & $1,10 \mathrm{E}+05$ & $3,33 \mathrm{E}+04$ & $6,67 E+03$ & $0,00 \mathrm{E}+00$ & $0,00 E+00$ & $0,00 E+00$ \\
\hline & $\begin{array}{c}\text { Número de particulas de } \\
\text { fundo }\end{array}$ & $\mathbf{P}$ & 33 & 10 & 2 & 0 & 0 & 0 \\
\hline & $\begin{array}{c}\text { Concentração média } \\
\text { liquida }\end{array}$ & $\mathrm{P} / \mathrm{m}^{3}$ & $1,04 E+08$ & $9,80 E+07$ & $8,30 E+07$ & $4,80 E+07$ & $1,85 E+07$ & 1,17E+05 \\
\hline & $\begin{array}{l}\text { Número de Particulas } \\
\text { média liquida }\end{array}$ & $\mathbf{p}$ & 31244 & 29412 & 24899 & 14396 & 5541 & 35 \\
\hline & Desvio - Poisson & $\#$ & 176,76 & 171,50 & 157,79 & 119,98 & 74,44 & 5,92 \\
\hline & $\begin{array}{l}\text { Desvio - Poisson - } \\
\text { Relativo }\end{array}$ & $\%$ & 0,6 & 0,6 & 0,6 & 0,8 & 1,3 & 16,9 \\
\hline & $\begin{array}{l}\text { Desvio padrão } \\
\text { Concentração }\end{array}$ & $\mathrm{P} / \mathrm{m}^{3}$ & $4,77 \mathrm{E}+03$ & $6,58 \mathrm{E}+03$ & $2,49 E+03$ & $1,08 \mathrm{E}+03$ & $2,04 \mathrm{E}+03$ & $6,99 \mathrm{E}+00$ \\
\hline & DP/Concentração média & $\%$ & 0,0046 & 0,0067 & 0,0030 & 0,0023 & 0,0110 & 0,0060 \\
\hline \multirow{2}{*}{\multicolumn{2}{|c|}{ Erro total medições( $\varepsilon$ ) }} & $\mathrm{P} / \mathrm{m}^{3}$ & $5,89 E+05$ & $5,72 E+05$ & $5,26 E+05$ & $4,00 E+05$ & $2,48 \mathrm{E}+05$ & $1,97 E+04$ \\
\hline & & Unidade & $1,0-2,0 \mu \mathrm{m}$ & $2,0-3,0 \mu \mathrm{m}$ & $3,0-5,0 \mu \mathrm{m}$ & $5,0-7,0 \mu \mathrm{m}$ & $7,0-10,0 \mu \mathrm{m}$ & $>10,0 \mu \mathrm{m}$ \\
\hline \multirow{8}{*}{ Assento 2E } & \begin{tabular}{|c|} 
Concentração média de \\
fundo \\
\end{tabular} & $\mathrm{P} / \mathrm{m}^{3}$ & $1,87 E+05$ & $1,13 \mathrm{E}+05$ & $6,67 E+03$ & $0,00 E+00$ & $0,00 E+00$ & $0,00 E+00$ \\
\hline & $\begin{array}{c}\text { Número de particulas de } \\
\text { fundo }\end{array}$ & $\mathbf{p}$ & 56 & 34 & 2 & 0 & 0 & 0 \\
\hline & $\begin{array}{c}\text { Concentração média } \\
\text { liquida }\end{array}$ & $\mathrm{P} / \mathrm{m}^{3}$ & $1,09 E+08$ & $1,03 E+08$ & $8,80 E+07$ & $7,19 E+07$ & $3,75 E+07$ & $3,73 E+05$ \\
\hline & $\begin{array}{l}\text { Número de Particulas } \\
\text { média liquida }\end{array}$ & $\mathbf{p}$ & 32587 & 30759 & 26410 & 21558 & 11250 & 112 \\
\hline & Desvio - Poisson & $\#$ & 180,52 & 175,38 & 162,51 & 146,83 & 106,07 & 10,58 \\
\hline & $\begin{array}{l}\text { Desvio - Poisson - } \\
\text { Relativo }\end{array}$ & $\%$ & 0,6 & 0,6 & 0,6 & 0,7 & 0,9 & 9,4 \\
\hline & $\begin{array}{l}\text { Desvio padrão } \\
\text { Concentração }\end{array}$ & $\mathrm{P} / \mathrm{m}^{3}$ & $6,70 \mathrm{E}+03$ & $1,05 \mathrm{E}+04$ & $1,93 \mathrm{E}+03$ & $3,15 \mathrm{E}+03$ & $1,96 \mathrm{E}+03$ & $4,18 \mathrm{E}+01$ \\
\hline & DP/Concentração média & $\%$ & 0,0062 & 0,0103 & 0,0022 & 0,0044 & 0,0052 & 0,0112 \\
\hline \multicolumn{2}{|c|}{ Erro total medições(દ) } & $\mathrm{P} / \mathrm{m}^{3}$ & $6,02 E+05$ & $5,85 E+05$ & $5,42 E+05$ & $4,89 \mathrm{E}+05$ & $3,54 \mathrm{E}+05$ & $3,53 \mathrm{E}+04$ \\
\hline
\end{tabular}




\begin{tabular}{|c|c|c|c|c|c|c|c|c|}
\hline & & Unidade & $1,0-2,0 \mu \mathrm{m}$ & $2,0-3,0 \mu \mathrm{m}$ & $3,0-5,0 \mu \mathrm{m}$ & $5,0-7,0 \mu \mathrm{m}$ & $7,0-10,0 \mu \mathrm{m}$ & $>10,0 \mu \mathrm{m}$ \\
\hline \multirow{8}{*}{ Assento 1D } & $\begin{array}{c}\text { Concentração média de } \\
\text { fundo }\end{array}$ & $\mathrm{P} / \mathrm{m}^{3}$ & $2,23 E+05$ & $1,07 E+05$ & $3,33 E+03$ & $0,00 E+00$ & $0,00 E+00$ & $0,00 E+00$ \\
\hline & $\begin{array}{c}\text { Número de particulas de } \\
\text { fundo }\end{array}$ & $\mathbf{P}$ & 67 & 32 & 1 & 0 & 0 & 0 \\
\hline & $\begin{array}{c}\text { Concentração média } \\
\text { liquida }\end{array}$ & $\mathrm{P} / \mathrm{m}^{3}$ & $9,83 \mathrm{E}+07$ & $8,85 E+07$ & $7,85 E+07$ & $3,84 \mathrm{E}+07$ & $2,34 \mathrm{E}+07$ & $6,00 \mathrm{E}+04$ \\
\hline & $\begin{array}{l}\text { Número de Particulas } \\
\text { média liquida }\end{array}$ & $\mathbf{P}$ & 29491 & 26552 & 23560 & 11520 & 7012 & 18 \\
\hline & Desvio - Poisson & $\#$ & 171,73 & 162,95 & 153,49 & 107,33 & 83,74 & 4,24 \\
\hline & $\begin{array}{c}\text { Desvio - Poisson - } \\
\text { Relativo } \\
\end{array}$ & $\%$ & 0,6 & 0,6 & 0,7 & 0,9 & 1,2 & 23,6 \\
\hline & $\begin{array}{l}\text { Desvio padrão } \\
\text { Concentração }\end{array}$ & $\mathrm{P} / \mathrm{m}^{3}$ & $8,86 \mathrm{E}+03$ & $1,53 E+03$ & $2,28 E+03$ & $8,99 \mathrm{E}+02$ & $7,53 \mathrm{E}+02$ & $3,10 \mathrm{E}+00$ \\
\hline & DP/Concentração média & $\%$ & 0,0090 & 0,0017 & 0,0029 & 0,0023 & 0,0032 & 0,0052 \\
\hline \multirow{2}{*}{\multicolumn{2}{|c|}{ Erro total medições(દ) }} & $\mathrm{P} / \mathrm{m}^{3}$ & $5,73 E+05$ & $5,43 E+05$ & $5,12 \mathrm{E}+05$ & $3,58 \mathrm{E}+05$ & $2,79 E+05$ & $1,41 \mathrm{E}+04$ \\
\hline & & Unidade & $1,0-2,0 \mu \mathrm{m}$ & $2,0-3,0 \mu \mathrm{m}$ & $3,0-5,0 \mu \mathrm{m}$ & $5,0-7,0 \mu \mathrm{m}$ & $7,0-10,0 \mu \mathrm{m}$ & $>10,0 \mu \mathrm{m}$ \\
\hline \multirow{8}{*}{ Assento $1 \mathrm{E}$} & \begin{tabular}{|c|}
$\begin{array}{c}\text { Concentração média de } \\
\text { fundo }\end{array}$ \\
\end{tabular} & $\mathrm{P} / \mathrm{m}^{3}$ & $1,37 E+05$ & $7,33 \mathrm{E}+04$ & $6,67 E+03$ & $0,00 E+00$ & $0,00 E+00$ & $0,00 E+00$ \\
\hline & $\begin{array}{c}\text { Número de particulas de } \\
\text { fundo }\end{array}$ & $\mathbf{P}$ & 41 & 22 & 2 & 0 & 0 & 0 \\
\hline & $\begin{array}{l}\text { Concentração média } \\
\text { liquida }\end{array}$ & $\mathrm{P} / \mathrm{m}^{3}$ & $9,52 E+07$ & $8,69 \mathrm{E}+07$ & $7,52 E+07$ & $5,51 E+07$ & $1,81 \mathrm{E}+07$ & $5,33 E+04$ \\
\hline & $\begin{array}{l}\text { Número de Particulas } \\
\text { média liquida }\end{array}$ & $\mathbf{P}$ & 28554 & 26078 & 22560 & 16542 & 5420 & 16 \\
\hline & Desvio - Poisson & $\#$ & 168,98 & 161,49 & 150,20 & 128,62 & 73,62 & 4,00 \\
\hline & $\begin{array}{c}\text { Desvio - Poisson - } \\
\text { Relativo } \\
\end{array}$ & $\%$ & 0,6 & 0,6 & 0,7 & 0,8 & 1,4 & 25,0 \\
\hline & $\begin{array}{l}\text { Desvio padrão } \\
\text { Concentração }\end{array}$ & $\mathrm{P} / \mathrm{m}^{3}$ & $1,03 E+03$ & $1,16 \mathrm{E}+03$ & $6,75 E+03$ & $2,30 E+03$ & $1,94 \mathrm{E}+03$ & $4,24 E+00$ \\
\hline & DP/Concentração média & $\%$ & 0,0011 & 0,0013 & 0,0090 & 0,0042 & 0,0107 & 0,0080 \\
\hline \multirow{2}{*}{\multicolumn{2}{|c|}{ Erro total medições( $(\varepsilon)$}} & $\mathrm{P} / \mathrm{m}^{3}$ & $5,63 E+05$ & $5,38 \mathrm{E}+05$ & $5,01 E+05$ & $4,29 E+05$ & $2,45 E+05$ & $1,33 \mathrm{E}+04$ \\
\hline & & Unidade & $1,0-2,0 \mu \mathrm{m}$ & $2,0-3,0 \mu \mathrm{m}$ & $3,0-5,0 \mu \mathrm{m}$ & $5,0-7,0 \mu \mathrm{m}$ & $7,0-10,0 \mu \mathrm{m}$ & $>10,0 \mu \mathrm{m}$ \\
\hline \multirow{8}{*}{ Assento 1B } & $\begin{array}{c}\begin{array}{c}\text { Concentração média de } \\
\text { fundo }\end{array} \\
\end{array}$ & $\mathrm{P} / \mathrm{m}^{3}$ & $1,87 E+05$ & $1,20 \mathrm{E}+05$ & $6,67 E+03$ & $0,00 E+00$ & $0,00 E+00$ & $0,00 \mathrm{E}+00$ \\
\hline & $\begin{array}{c}\text { Número de particulas de } \\
\text { fundo } \\
\end{array}$ & $\mathbf{P}$ & 56 & 36 & 2 & 0 & 0 & 0 \\
\hline & $\begin{array}{l}\text { Concentração média } \\
\text { liquida }\end{array}$ & $\mathrm{P} / \mathrm{m}^{3}$ & $7,16 \mathrm{E}+07$ & $6,47 E+07$ & $5,52 E+07$ & $2,35 E+07$ & $7,85 E+06$ & $4,33 E+04$ \\
\hline & $\begin{array}{l}\text { Número de Particulas } \\
\text { média liquida }\end{array}$ & $\mathbf{p}$ & 21489 & 19395 & 16547 & 7052 & 2356 & 13 \\
\hline & Desvio - Poisson & $\#$ & 146,59 & 139,27 & 128,64 & 83,98 & 48,54 & 3,61 \\
\hline & $\begin{array}{c}\text { Desvio - Poisson - } \\
\text { Relativo } \\
\end{array}$ & $\%$ & 0,7 & 0,7 & 0,8 & 1,2 & 2,1 & 27,7 \\
\hline & $\begin{array}{l}\text { Desvio padrão } \\
\text { Concentração }\end{array}$ & $\mathrm{P} / \mathrm{m}^{3}$ & $2,45 E+02$ & $4,52 E+02$ & $1,82 \mathrm{E}+03$ & $9,83 E+02$ & $3,58 \mathrm{E}+02$ & $4,14 \mathrm{E}+00$ \\
\hline & DP/Concentração média & $\%$ & 0,0003 & 0,0007 & 0,0033 & 0,0042 & 0,0046 & 0,0095 \\
\hline \multicolumn{2}{|c|}{ Erro total medições( $(\varepsilon)$} & $\mathrm{P} / \mathrm{m}^{3}$ & $4,89 E+05$ & $4,64 E+05$ & $4,29 E+05$ & $2,80 E+05$ & $1,62 \mathrm{E}+05$ & $1,20 \mathrm{E}+04$ \\
\hline
\end{tabular}




\begin{tabular}{|c|c|c|c|c|c|c|c|c|}
\hline & & Unidade & $1,0-2,0 \mu \mathrm{m}$ & $2,0-3,0 \mu \mathrm{m}$ & $3,0-5,0 \mu \mathrm{m}$ & $5,0-7,0 \mu \mathrm{m}$ & $7,0-10,0 \mu \mathrm{m}$ & $>10,0 \mu \mathrm{m}$ \\
\hline \multirow{8}{*}{ Assento $1 \mathrm{~A}$} & $\begin{array}{c}\text { Concentração média de } \\
\text { fundo }\end{array}$ & $\mathrm{P} / \mathrm{m}^{3}$ & $1,60 \mathrm{E}+05$ & $5,67 \mathrm{E}+04$ & $6,67 \mathrm{E}+03$ & $0,00 E+00$ & $0,00 E+00$ & $0,00 E+00$ \\
\hline & $\begin{array}{c}\text { Número de particulas de } \\
\text { fundo }\end{array}$ & $\mathbf{P}$ & 48 & 17 & 2 & 0 & 0 & 0 \\
\hline & $\begin{array}{c}\text { Concentração média } \\
\text { liquida }\end{array}$ & $\mathrm{P} / \mathrm{m}^{3}$ & $6,57 E+07$ & $5,81 E+07$ & $4,83 E+07$ & $3,17 \mathrm{E}+07$ & $8,45 E+06$ & $6,83 E+05$ \\
\hline & $\begin{array}{l}\text { Número de Particulas } \\
\text { média liquida }\end{array}$ & $\mathbf{P}$ & 19700 & 17436 & 14503 & 9513 & 2536 & 205 \\
\hline & Desvio - Poisson & \# & 140,36 & 132,05 & 120,43 & 97,53 & 50,36 & 14,32 \\
\hline & $\begin{array}{l}\text { Desvio - Poisson - } \\
\text { Relativo }\end{array}$ & $\%$ & 0,7 & 0,8 & 0,8 & 1,0 & 2,0 & 7,0 \\
\hline & $\begin{array}{l}\text { Desvio padrão } \\
\text { Concentração }\end{array}$ & $\mathrm{P} / \mathrm{m}^{3}$ & $2,17 E+03$ & $1,50 E+03$ & $9,91 E+02$ & $7,94 \mathrm{E}+02$ & $5,81 E+02$ & $4,10 E+01$ \\
\hline & DP/Concentração média & $\%$ & 0,0033 & 0,0026 & 0,0021 & 0,0025 & 0,0069 & 0,0060 \\
\hline \multirow{2}{*}{\multicolumn{2}{|c|}{ Erro total medições(દ) }} & $\mathrm{P} / \mathrm{m}^{3}$ & $4,68 E+05$ & $4,40 E+05$ & $4,01 E+05$ & $3,25 E+05$ & $1,68 \mathrm{E}+05$ & $4,77 E+04$ \\
\hline & & Unidade & $1,0-2,0 \mu \mathrm{m}$ & $2,0-3,0 \mu \mathrm{m}$ & $3,0-5,0 \mu \mathrm{m}$ & $5,0-7,0 \mu \mathrm{m}$ & $7,0-10,0 \mu \mathrm{m}$ & $>10,0 \mu \mathrm{m}$ \\
\hline \multirow{8}{*}{ Assento 2B } & $\begin{array}{c}\text { Concentração média de } \\
\text { fundo }\end{array}$ & $\mathrm{P} / \mathrm{m}^{3}$ & $7,00 E+04$ & $4,00 E+04$ & $6,67 \mathrm{E}+03$ & $0,00 E+00$ & $0,00 E+00$ & $0,00 E+00$ \\
\hline & $\begin{array}{c}\text { Número de particulas de } \\
\text { fundo }\end{array}$ & $\mathbf{p}$ & 21 & 12 & 2 & 0 & 0 & 0 \\
\hline & $\begin{array}{c}\text { Concentração média } \\
\text { liquida }\end{array}$ & $\mathrm{P} / \mathrm{m}^{3}$ & $1,13 \mathrm{E}+08$ & $9,57 E+07$ & $8,84 E+07$ & $6,52 E+07$ & $2,98 \mathrm{E}+07$ & $1,27 E+05$ \\
\hline & $\begin{array}{c}\text { Número de Particulas } \\
\text { média liquida }\end{array}$ & $\mathbf{P}$ & 33880 & 28713 & 26530 & 19560 & 8952 & 38 \\
\hline & Desvio - Poisson & $\#$ & 184,07 & 169,45 & 162,88 & 139,86 & 94,62 & 6,16 \\
\hline & $\begin{array}{l}\text { Desvio - Poisson - } \\
\text { Relativo }\end{array}$ & $\%$ & 0,5 & 0,6 & 0,6 & 0,7 & 1,1 & 16,2 \\
\hline & $\begin{array}{l}\text { Desvio padrão } \\
\text { Concentração }\end{array}$ & $\mathrm{P} / \mathrm{m}^{3}$ & $2,19 E+03$ & $8,17 E+03$ & $8,78 \mathrm{E}+02$ & $1,98 \mathrm{E}+03$ & $8,09 E+02$ & $8,76 E+00$ \\
\hline & DP/Concentração média & $\%$ & 0,0019 & 0,0085 & 0,0010 & 0,0030 & 0,0027 & 0,0069 \\
\hline \multirow{2}{*}{\multicolumn{2}{|c|}{ Erro total medições(દ) }} & $\mathrm{P} / \mathrm{m}^{3}$ & $6,14 E+05$ & $5,65 E+05$ & $5,43 E+05$ & $4,66 \mathrm{E}+05$ & $3,15 \mathrm{E}+05$ & $2,05 E+04$ \\
\hline & & Unidade & $1,0-2,0 \mu \mathrm{m}$ & $2,0-3,0 \mu \mathrm{m}$ & $3,0-5,0 \mu \mathrm{m}$ & $5,0-7,0 \mu \mathrm{m}$ & $7,0-10,0 \mu \mathrm{m}$ & $>10,0 \mu \mathrm{m}$ \\
\hline \multirow{8}{*}{ Assento $2 \mathrm{~A}$} & $\begin{array}{c}\text { Concentração média de } \\
\text { fundo } \\
\end{array}$ & $\mathrm{P} / \mathrm{m}^{3}$ & $1,70 \mathrm{E}+05$ & $7,50 E+04$ & $3,33 \mathrm{E}+03$ & $0,00 E+00$ & $0,00 E+00$ & $0,00 E+00$ \\
\hline & $\begin{array}{c}\text { Número de particulas de } \\
\text { fundo }\end{array}$ & $\mathbf{P}$ & 51 & 23 & 1 & 0 & 0 & 0 \\
\hline & $\begin{array}{c}\text { Concentração média } \\
\text { liquida }\end{array}$ & $\mathrm{P} / \mathrm{m}^{3}$ & $8,20 E+07$ & $7,84 \mathrm{E}+07$ & $6,19 \mathrm{E}+07$ & $4,17 E+07$ & $1,20 E+07$ & $4,60 E+05$ \\
\hline & $\begin{array}{c}\text { Número de Particulas } \\
\text { média liquida }\end{array}$ & $\mathbf{p}$ & 24615 & 23522 & 18560 & 12520 & 3589 & 138 \\
\hline & Desvio - Poisson & $\#$ & 156,89 & 153,37 & 136,24 & 111,89 & 59,91 & 11,75 \\
\hline & $\begin{array}{l}\text { Desvio - Poisson - } \\
\text { Relativo } \\
\end{array}$ & $\%$ & 0,6 & 0,7 & 0,7 & 0,9 & 1,7 & 8,5 \\
\hline & $\begin{array}{l}\text { Desvio padrão } \\
\text { Concentração }\end{array}$ & $\mathrm{P} / \mathrm{m}^{3}$ & $1,02 E+04$ & $2,98 \mathrm{E}+03$ & $3,20 E+03$ & $9,81 E+02$ & $3,55 \mathrm{E}+02$ & $3,69 E+01$ \\
\hline & DP/Concentração média & $\%$ & 0,0124 & 0,0038 & 0,0052 & 0,0024 & 0,0030 & 0,0080 \\
\hline \multicolumn{2}{|c|}{ Erro total medições(દ) } & $\mathrm{P} / \mathrm{m}^{3}$ & $5,23 E+05$ & $5,11 \mathrm{E}+05$ & $4,54 \mathrm{E}+05$ & $3,73 E+05$ & $2,00 \mathrm{E}+05$ & $3,92 \mathrm{E}+04$ \\
\hline
\end{tabular}




\begin{tabular}{|c|c|c|c|c|c|c|c|c|}
\hline & & Unidade & $1,0-2,0 \mu \mathrm{m}$ & $2,0-3,0 \mu \mathrm{m}$ & $3,0-5,0 \mu \mathrm{m}$ & $5,0-7,0 \mu \mathrm{m}$ & $7,0-10,0 \mu \mathrm{m}$ & $>10,0 \mu \mathrm{m}$ \\
\hline \multirow{8}{*}{ Assento 3B } & \begin{tabular}{|c|}
$\begin{array}{c}\text { Concentração média de } \\
\text { fundo }\end{array}$ \\
\end{tabular} & $\mathrm{P} / \mathrm{m}^{3}$ & $9,33 E+04$ & $4,00 E+04$ & $3,33 E+03$ & $0,00 E+00$ & $0,00 E+00$ & $0,00 E+00$ \\
\hline & \begin{tabular}{|c|}
$\begin{array}{c}\text { Número de particulas de } \\
\text { fundo }\end{array}$ \\
\end{tabular} & $\mathbf{P}$ & 28 & 12 & 1 & 0 & 0 & 0 \\
\hline & $\begin{array}{c}\text { Concentração média } \\
\text { liquida }\end{array}$ & $\mathrm{P} / \mathrm{m}^{3}$ & $9,78 \mathrm{E}+07$ & $9,22 \mathrm{E}+07$ & $8,84 E+07$ & $6,02 \mathrm{E}+07$ & $2,82 \mathrm{E}+07$ & $6,40 E+05$ \\
\hline & $\begin{array}{c}\text { Número de Particulas } \\
\text { média liquida }\end{array}$ & $\mathbf{P}$ & 29339 & 27653 & 26530 & 18052 & 8452 & 192 \\
\hline & Desvio - Poisson & $\#$ & 171,29 & 166,29 & 162,88 & 134,36 & 91,93 & 13,86 \\
\hline & $\begin{array}{l}\text { Desvio - Poisson - } \\
\text { Relativo } \\
\end{array}$ & $\%$ & 0,6 & 0,6 & 0,6 & 0,7 & 1,1 & 7,2 \\
\hline & $\begin{array}{l}\text { Desvio padrão } \\
\text { Concentração }\end{array}$ & $\mathrm{P} / \mathrm{m}^{3}$ & $5,71 E+03$ & $3,50 \mathrm{E}+03$ & $3,68 \mathrm{E}+03$ & $2,02 E+03$ & $2,03 E+03$ & $8,35 \mathrm{E}+01$ \\
\hline & DP/Concentração média & $\%$ & 0,0058 & 0,0038 & 0,0042 & 0,0033 & 0,0072 & 0,0130 \\
\hline \multirow{2}{*}{\multicolumn{2}{|c|}{ Erro total medições( $(\varepsilon)$}} & $\mathrm{P} / \mathrm{m}^{3}$ & $5,71 E+05$ & $5,54 \mathrm{E}+05$ & $5,43 E+05$ & $4,48 E+05$ & $3,06 \mathrm{E}+05$ & $4,62 \mathrm{E}+04$ \\
\hline & & Unidade & $1,0-2,0 \mu \mathrm{m}$ & $2,0-3,0 \mu \mathrm{m}$ & $3,0-5,0 \mu \mathrm{m}$ & $5,0-7,0 \mu \mathrm{m}$ & $7,0-10,0 \mu \mathrm{m}$ & $>10,0 \mu \mathrm{m}$ \\
\hline \multirow{8}{*}{ Assento 3A } & $\begin{array}{c}\text { Concentração média de } \\
\text { fundo }\end{array}$ & $\mathrm{P} / \mathrm{m}^{3}$ & $1,30 \mathrm{E}+05$ & $8,00 E+04$ & $3,33 E+03$ & $0,00 E+00$ & $0,00 E+00$ & $0,00 E+00$ \\
\hline & \begin{tabular}{|c|}
$\begin{array}{c}\text { Número de particulas de } \\
\text { fundo }\end{array}$ \\
\end{tabular} & $\mathbf{P}$ & 39 & 24 & 1 & 0 & 0 & 0 \\
\hline & $\begin{array}{c}\text { Concentração média } \\
\text { liquida }\end{array}$ & $\mathrm{P} / \mathrm{m}^{3}$ & $9,43 E+07$ & $8,74 \mathrm{E}+07$ & $6,85 E+07$ & $4,51 \mathrm{E}+07$ & $2,65 E+07$ & $4,50 E+05$ \\
\hline & $\begin{array}{c}\text { Número de Particulas } \\
\text { média liquida }\end{array}$ & $\mathbf{P}$ & 28297 & 26234 & 20560 & 13520 & 7952 & 135 \\
\hline & Desvio - Poisson & $\#$ & 168,22 & 161,97 & 143,39 & 116,28 & 89,17 & 11,62 \\
\hline & $\begin{array}{l}\text { Desvio - Poisson - } \\
\text { Relativo } \\
\end{array}$ & $\%$ & 0,6 & 0,6 & 0,7 & 0,9 & 1,1 & 8,6 \\
\hline & $\begin{array}{c}\text { Desvio padrão } \\
\text { Concentração }\end{array}$ & $\mathrm{P} / \mathrm{m}^{3}$ & $6,92 \mathrm{E}+03$ & $1,92 \mathrm{E}+03$ & $3,37 \mathrm{E}+03$ & $2,74 \mathrm{E}+03$ & $2,51 E+03$ & $2,13 E+01$ \\
\hline & DP/Concentração média & $\%$ & 0,0073 & 0,0022 & 0,0049 & 0,0061 & 0,0095 & 0,0047 \\
\hline \multicolumn{2}{|c|}{ Erro total medições( $\varepsilon$ ) } & $\mathrm{P} / \mathrm{m}^{3}$ & $5,61 \mathrm{E}+05$ & $5,40 \mathrm{E}+05$ & $4,78 \mathrm{E}+05$ & $3,88 \mathrm{E}+05$ & $2,97 \mathrm{E}+05$ & $3,87 \mathrm{E}+04$ \\
\hline
\end{tabular}


Tabela D-11. Resultados das medições de partículas no assento (Sistema UFAD à $22^{\circ} \mathrm{C}$ - injeção pelo assento $3 \mathrm{E}$ )

\begin{tabular}{|c|c|c|c|c|c|c|c|c|}
\hline & & Unidade & $1,0-2,0 \mu \mathrm{m}$ & $2,0-3,0 \mu \mathrm{m}$ & $3,0-5,0 \mu \mathrm{m}$ & $5,0-7,0 \mu \mathrm{m}$ & $7,0-10,0 \mu \mathrm{m}$ & $>10,0 \mu \mathrm{m}$ \\
\hline \multirow{8}{*}{ Assento 3D } & $\begin{array}{c}\text { Concentração média de } \\
\text { fundo }\end{array}$ & $\mathrm{P} / \mathrm{m}^{3}$ & $7,67 \mathrm{E}+04$ & $3,67 E+04$ & $6,67 \mathrm{E}+03$ & $0,00 \mathrm{E}+00$ & $0,00 E+00$ & $0,00 E+00$ \\
\hline & $\begin{array}{c}\text { Número de particulas de } \\
\text { fundo }\end{array}$ & $\mathbf{P}$ & 23 & 11 & 2 & 0 & 0 & 0 \\
\hline & $\begin{array}{c}\text { Concentração média } \\
\text { liquida }\end{array}$ & $\mathrm{P} / \mathrm{m}^{3}$ & $9,20 \mathrm{E}+07$ & $9,47 E+07$ & $7,68 \mathrm{E}+07$ & $5,44 \mathrm{E}+07$ & $1,51 \mathrm{E}+07$ & $1,65 \mathrm{E}+06$ \\
\hline & $\begin{array}{c}\text { Número de Particulas } \\
\text { média liquida }\end{array}$ & $\mathbf{P}$ & 27611 & 28423 & 23048 & 16309 & 4524 & 495 \\
\hline & Desvio - Poisson & $\#$ & 166,16 & 168,59 & 151,81 & 127,71 & 67,26 & 22,25 \\
\hline & $\begin{array}{c}\text { Desvio - Poisson - } \\
\text { Relative } \\
\end{array}$ & $\%$ & 0,6 & 0,6 & 0,7 & 0,8 & 1,5 & 4,5 \\
\hline & $\begin{array}{l}\text { Desvio padrão } \\
\text { Concentração }\end{array}$ & $\mathrm{P} / \mathrm{m}^{3}$ & $3,77 \mathrm{E}+03$ & $3,09 \mathrm{E}+03$ & $1,27 E+03$ & $2,59 \mathrm{E}+03$ & $7,59 \mathrm{E}+02$ & $6,11 \mathrm{E}+01$ \\
\hline & DP/Concentração média & $\%$ & 0,0041 & 0,0033 & 0,0017 & 0,0048 & 0,0050 & 0,0037 \\
\hline \multirow{2}{*}{\multicolumn{2}{|c|}{ Erro total medições(દ) }} & $\mathrm{P} / \mathrm{m}^{3}$ & $5,54 \mathrm{E}+05$ & $5,62 E+05$ & $5,06 \mathrm{E}+05$ & $4,26 E+05$ & $2,24 \mathrm{E}+05$ & $7,42 E+04$ \\
\hline & & Unidade & $1,0-2,0 \mu \mathrm{m}$ & $2,0-3,0 \mu \mathrm{m}$ & $3,0-5,0 \mu \mathrm{m}$ & $5,0-7,0 \mu \mathrm{m}$ & $7,0-10,0 \mu \mathrm{m}$ & $>10,0 \mu \mathrm{m}$ \\
\hline \multirow{8}{*}{ Assento 2D } & $\begin{array}{c}\text { Concentração média de } \\
\text { fundo }\end{array}$ & $\mathrm{P} / \mathrm{m}^{3}$ & $1,87 E+05$ & $1,10 E+05$ & $3,33 \mathrm{E}+03$ & $0,00 \mathrm{E}+00$ & $0,00 E+00$ & $0,00 \mathrm{E}+00$ \\
\hline & $\begin{array}{c}\text { Número de particulas de } \\
\text { fundo }\end{array}$ & $\mathbf{P}$ & 56 & 33 & 1 & 0 & 0 & 0 \\
\hline & $\begin{array}{c}\text { Concentração média } \\
\text { liquida }\end{array}$ & $\mathrm{P} / \mathrm{m}^{3}$ & $9,20 \mathrm{E}+07$ & $9,08 E+07$ & $6,26 \mathrm{E}+07$ & $5,46 \mathrm{E}+07$ & $2,18 \mathrm{E}+07$ & $1,68 \mathrm{E}+06$ \\
\hline & $\begin{array}{c}\text { Número de Particulas } \\
\text { média liquida }\end{array}$ & $\mathbf{P}$ & 27607 & 27235 & 18785 & 16394 & 6542 & 504 \\
\hline & Desvio - Poisson & $\#$ & 166,15 & 165,03 & 137,06 & 128,04 & 80,88 & 22,45 \\
\hline & $\begin{array}{c}\text { Desvio - Poisson - } \\
\text { Relativo } \\
\end{array}$ & $\%$ & 0,6 & 0,6 & 0,7 & 0,8 & 1,2 & 4,5 \\
\hline & $\begin{array}{l}\text { Desvio padrão } \\
\text { Concentração }\end{array}$ & $\mathrm{P} / \mathrm{m}^{3}$ & $6,44 \mathrm{E}+03$ & $6,31 E+03$ & $4,03 E+03$ & $2,58 \mathrm{E}+03$ & $9,24 \mathrm{E}+02$ & $1,20 E+02$ \\
\hline & DP/Concentração média & $\%$ & 0,0070 & 0,0070 & 0,0064 & 0,0047 & 0,0042 & 0,0072 \\
\hline \multirow{2}{*}{\multicolumn{2}{|c|}{ Erro total medições(દ) }} & $\mathrm{P} / \mathrm{m}^{3}$ & $5,54 \mathrm{E}+05$ & $5,50 \mathrm{E}+05$ & $4,57 E+05$ & $4,27 E+05$ & $2,70 E+05$ & $7,48 \mathrm{E}+04$ \\
\hline & & Unidade & $1,0-2,0 \mu \mathrm{m}$ & $2,0-3,0 \mu \mathrm{m}$ & $3,0-5,0 \mu \mathrm{m}$ & $5,0-7,0 \mu \mathrm{m}$ & $7,0-10,0 \mu \mathrm{m}$ & $>10,0 \mu \mathrm{m}$ \\
\hline \multirow{8}{*}{ Assento 2E } & $\begin{array}{c}\text { Concentração média de } \\
\text { fundo }\end{array}$ & $\mathrm{P} / \mathrm{m}^{3}$ & $7,33 E+04$ & $3,33 \mathrm{E}+04$ & $3,33 \mathrm{E}+03$ & $0,00 E+00$ & $0,00 E+00$ & $0,00 \mathrm{E}+00$ \\
\hline & \begin{tabular}{|c|} 
Número de particulas de \\
fundo \\
\end{tabular} & $\mathbf{P}$ & 22 & 10 & 1 & 0 & 0 & 0 \\
\hline & $\begin{array}{c}\text { Concentração média } \\
\text { liquida }\end{array}$ & $\mathrm{P} / \mathrm{m}^{3}$ & $9,05 E+07$ & $7,97 \mathrm{E}+07$ & $7,47 E+07$ & $5,11 \mathrm{E}+07$ & $1,97 E+07$ & $1,67 \mathrm{E}+06$ \\
\hline & $\begin{array}{l}\text { Número de Particulas } \\
\text { média liquida }\end{array}$ & $\mathbf{P}$ & 27163 & 23920 & 22411 & 15316 & 5908 & 500 \\
\hline & Desvio - Poisson & $\#$ & 164,81 & 154,66 & 149,70 & 123,76 & 76,86 & 22,36 \\
\hline & $\begin{array}{c}\text { Desvio - Poisson - } \\
\text { Relativo } \\
\end{array}$ & $\%$ & 0,6 & 0,6 & 0,7 & 0,8 & 1,3 & 4,5 \\
\hline & $\begin{array}{l}\text { Desvio padrão } \\
\text { Concentração }\end{array}$ & $\mathrm{P} / \mathrm{m}^{3}$ & $4,28 \mathrm{E}+03$ & $3,10 \mathrm{E}+03$ & $2,35 E+03$ & $8,71 E+02$ & $9,53 \mathrm{E}+02$ & $1,04 \mathrm{E}+02$ \\
\hline & DP/Concentração média & $\%$ & 0,0047 & 0,0039 & 0,0031 & 0,0017 & 0,0048 & 0,0062 \\
\hline \multicolumn{2}{|c|}{ Erro total medições $(\varepsilon)$} & $\mathrm{P} / \mathrm{m}^{3}$ & $5,49 E+05$ & $5,16 \mathrm{E}+05$ & $4,99 \mathrm{E}+05$ & $4,13 E+05$ & $2,56 \mathrm{E}+05$ & $7,45 E+04$ \\
\hline
\end{tabular}


Unidade $1,0-2,0 \mu \mathrm{m}|2,0-3,0 \mu \mathrm{m}| 3,0-5,0 \mu \mathrm{m}|5,0-7,0 \mu \mathrm{m}| 7,0-10,0 \mu \mathrm{m} \mid>10,0 \mu \mathrm{m}$

\begin{tabular}{|c|c|c|c|c|c|c|c|c|}
\hline \multirow{8}{*}{ Assento 1D } & $\begin{array}{c}\text { Concentração média de } \\
\text { fundo }\end{array}$ & $\mathrm{P} / \mathrm{m}^{3}$ & $2,53 E+05$ & $1,87 E+05$ & $1,00 E+04$ & $0,00 \mathrm{E}+00$ & $0,00 \mathrm{E}+00$ & $0,00 \mathrm{E}+00$ \\
\hline & $\begin{array}{c}\text { Número de particulas de } \\
\text { fundo }\end{array}$ & $\mathbf{P}$ & 76 & 56 & 3 & 0 & 0 & 0 \\
\hline & $\begin{array}{c}\text { Concentração média } \\
\text { liquida } \\
\end{array}$ & $\mathrm{P} / \mathrm{m}^{3}$ & $9,68 \mathrm{E}+07$ & $9,54 \mathrm{E}+07$ & $5,47 E+07$ & $4,00 E+07$ & $1,63 \mathrm{E}+07$ & $1,71 \mathrm{E}+06$ \\
\hline & $\begin{array}{l}\text { Número de Particulas } \\
\text { média liquida }\end{array}$ & $\mathbf{P}$ & 29030 & 28626 & 16410 & 11987 & 4882 & 513 \\
\hline & Desvio - Poisson & $\#$ & 170,38 & 169,19 & 128,10 & 109,49 & 69,87 & 22,64 \\
\hline & $\begin{array}{c}\text { Desvio - Poisson - } \\
\text { Relativo }\end{array}$ & $\%$ & 0,6 & 0,6 & 0,8 & 0,9 & 1,4 & 4,4 \\
\hline & $\begin{array}{l}\text { Desvio padrão } \\
\text { Concentração }\end{array}$ & $\mathrm{P} / \mathrm{m}^{3}$ & $5,17 E+03$ & $5,06 \mathrm{E}+03$ & $2,84 E+03$ & $1,53 E+03$ & $8,92 E+02$ & $1,31 \mathrm{E}+02$ \\
\hline & DP/Concentração média & $\%$ & 0,0053 & 0,0053 & 0,0052 & 0,0038 & 0,0055 & 0,0077 \\
\hline \multirow{2}{*}{\multicolumn{2}{|c|}{ Erro total medições(દ) }} & $\mathrm{P} / \mathrm{m}^{3}$ & $5,68 \mathrm{E}+05$ & $5,64 E+05$ & $4,27 E+05$ & $3,65 E+05$ & $2,33 E+05$ & $7,55 \mathrm{E}+04$ \\
\hline & & Unidade & $1,0-2,0 \mu \mathrm{m}$ & $2,0-3,0 \mu \mathrm{m}$ & $3,0-5,0 \mu \mathrm{m}$ & $5,0-7,0 \mu \mathrm{m}$ & $7,0-10,0 \mu \mathrm{m}$ & $>10,0 \mu \mathrm{m}$ \\
\hline \multirow{8}{*}{ Assento $1 \mathrm{E}$} & $\begin{array}{c}\text { Concentração média de } \\
\text { fundo }\end{array}$ & $\mathrm{P} / \mathrm{m}^{3}$ & $1,87 E+05$ & $7,67 E+04$ & $3,33 E+03$ & $0,00 \mathrm{E}+00$ & $1,67 E+03$ & $0,00 \mathrm{E}+00$ \\
\hline & $\begin{array}{c}\text { Número de particulas de } \\
\text { fundo }\end{array}$ & $\mathbf{p}$ & 56 & 23 & 1 & 0 & 1 & 0 \\
\hline & $\begin{array}{c}\text { Concentração média } \\
\text { liquida } \\
\end{array}$ & $\mathrm{P} / \mathrm{m}^{3}$ & $1,02 E+08$ & $9,08 E+07$ & $6,07 E+07$ & $4,19 \mathrm{E}+07$ & $2,85 E+07$ & $2,40 E+06$ \\
\hline & $\begin{array}{c}\text { Número de Particulas } \\
\text { média liquida } \\
\end{array}$ & $\mathbf{P}$ & 30567 & 27233 & 18205 & 12558 & 8537 & 721 \\
\hline & Desvio - Poisson & $\#$ & 174,83 & 165,02 & 134,93 & 112,06 & 92,39 & 26,84 \\
\hline & $\begin{array}{c}\text { Desvio - Poisson - } \\
\text { Relativo }\end{array}$ & $\%$ & 0,6 & 0,6 & 0,7 & 0,9 & 1,1 & 3,7 \\
\hline & $\begin{array}{l}\text { Desvio padrão } \\
\text { Concentração }\end{array}$ & $\mathrm{P} / \mathrm{m}^{3}$ & $5,22 \mathrm{E}+03$ & $5,71 E+03$ & $8,87 E+02$ & $9,35 E+02$ & $1,34 \mathrm{E}+03$ & $1,03 E+02$ \\
\hline & DP/Concentração média & $\%$ & 0,0051 & 0,0063 & 0,0015 & 0,0022 & 0,0047 & 0,0043 \\
\hline \multirow{2}{*}{\multicolumn{2}{|c|}{ Erro total medições(દ) }} & $\mathrm{P} / \mathrm{m}^{3}$ & $5,83 \mathrm{E}+05$ & $5,50 \mathrm{E}+05$ & $4,50 E+05$ & $3,74 \mathrm{E}+05$ & $3,08 \mathrm{E}+05$ & $8,95 \mathrm{E}+04$ \\
\hline & & Unidade & $1,0-2,0 \mu \mathrm{m}$ & $2,0-3,0 \mu \mathrm{m}$ & $3,0-5,0 \mu \mathrm{m}$ & $5,0-7,0 \mu \mathrm{m}$ & $7,0-10,0 \mu \mathrm{m}$ & $>10,0 \mu \mathrm{m}$ \\
\hline \multirow{8}{*}{ Assento 1B } & $\begin{array}{c}\text { Concentração média de } \\
\text { fundo }\end{array}$ & $\mathrm{P} / \mathrm{m}^{3}$ & $2,23 E+05$ & $1,10 \mathrm{E}+05$ & $3,33 \mathrm{E}+03$ & $0,00 \mathrm{E}+00$ & $0,00 \mathrm{E}+00$ & $0,00 \mathrm{E}+00$ \\
\hline & $\begin{array}{c}\text { Número de particulas de } \\
\text { fundo } \\
\end{array}$ & $\mathbf{P}$ & 67 & 33 & 1 & 0 & 0 & 0 \\
\hline & $\begin{array}{l}\text { Concentração média } \\
\text { liquida } \\
\end{array}$ & $\mathrm{P} / \mathrm{m}^{3}$ & $7,10 \mathrm{E}+07$ & $6,99 \mathrm{E}+07$ & $5,01 \mathrm{E}+07$ & $3,52 \mathrm{E}+07$ & $8,03 E+06$ & $1,69 \mathrm{E}+06$ \\
\hline & $\begin{array}{c}\text { Número de Particulas } \\
\text { média liquida }\end{array}$ & $\mathbf{P}$ & 21295 & 20983 & 15031 & 10547 & 2409 & 507 \\
\hline & Desvio - Poisson & $\#$ & 145,93 & 144,86 & 122,60 & 102,70 & 49,08 & 22,52 \\
\hline & $\begin{array}{c}\text { Desvio - Poisson - } \\
\text { Relativo } \\
\end{array}$ & $\%$ & 0,7 & 0,7 & 0,8 & 1,0 & 2,0 & 4,4 \\
\hline & $\begin{array}{l}\text { Desvio padrão } \\
\text { Concentração } \\
\end{array}$ & $\mathrm{P} / \mathrm{m}^{3}$ & $5,32 E+03$ & $5,24 \mathrm{E}+03$ & $4,08 E+03$ & $2,72 E+03$ & $7,30 \mathrm{E}+02$ & $1,23 E+02$ \\
\hline & DP/Concentração média & $\%$ & 0,0075 & 0,0075 & 0,0081 & 0,0077 & 0,0091 & 0,0073 \\
\hline \multicolumn{2}{|c|}{ Erro total medições(દ) } & $\mathrm{P} / \mathrm{m}^{3}$ & $4,86 \mathrm{E}+05$ & $4,83 \mathrm{E}+05$ & $4,09 E+05$ & $3,42 \mathrm{E}+05$ & $1,64 E+05$ & $7,51 \mathrm{E}+04$ \\
\hline
\end{tabular}




\begin{tabular}{|c|c|c|c|c|c|c|c|c|}
\hline & & Unidade & $1,0-2,0 \mu \mathrm{m}$ & $2,0-3,0 \mu \mathrm{m}$ & $3,0-5,0 \mu \mathrm{m}$ & $5,0-7,0 \mu \mathrm{m}$ & $7,0-10,0 \mu \mathrm{m}$ & $>10,0 \mu \mathrm{m}$ \\
\hline \multirow{8}{*}{ Assento 1A } & $\begin{array}{c}\text { Concentração média de } \\
\text { fundo }\end{array}$ & $\mathrm{P} / \mathrm{m}^{3}$ & $1,70 E+05$ & $5,67 \mathrm{E}+04$ & $6,67 E+03$ & $0,00 E+00$ & $0,00 E+00$ & $0,00 \mathrm{E}+00$ \\
\hline & $\begin{array}{c}\text { Número de particulas de } \\
\text { fundo }\end{array}$ & $\mathbf{P}$ & 51 & 17 & 2 & 0 & 0 & 0 \\
\hline & $\begin{array}{l}\text { Concentração média } \\
\text { liquida }\end{array}$ & $\mathrm{P} / \mathrm{m}^{3}$ & $7,11 \mathrm{E}+07$ & $7,01 \mathrm{E}+07$ & $3,81 \mathrm{E}+07$ & $2,85 \mathrm{E}+07$ & $1,17 \mathrm{E}+07$ & $1,26 \mathrm{E}+06$ \\
\hline & $\begin{array}{l}\text { Número de Particulas } \\
\text { média liquida }\end{array}$ & $\mathbf{P}$ & 21340 & 21042 & 11420 & 8563 & 3510 & 378 \\
\hline & Desvio - Poisson & $\#$ & 146,08 & 145,06 & 106,86 & 92,54 & 59,25 & 19,44 \\
\hline & $\begin{array}{c}\text { Desvio - Poisson - } \\
\text { Relativo }\end{array}$ & $\%$ & 0,7 & 0,7 & 0,9 & 1,1 & 1,7 & 5,1 \\
\hline & $\begin{array}{l}\text { Desvio padrão } \\
\text { Concentração }\end{array}$ & $\mathrm{P} / \mathrm{m}^{3}$ & $4,56 \mathrm{E}+03$ & $4,47 E+03$ & $1,78 \mathrm{E}+03$ & $1,23 \mathrm{E}+03$ & $5,72 \mathrm{E}+02$ & $1,12 \mathrm{E}+02$ \\
\hline & DP/Concentração média & $\%$ & 0,0064 & 0,0064 & 0,0047 & 0,0043 & 0,0049 & 0,0089 \\
\hline \multirow{2}{*}{\multicolumn{2}{|c|}{ Erro total medições(દ) }} & $\mathrm{P} / \mathrm{m}^{3}$ & $4,87 E+05$ & $4,84 E+05$ & $3,56 \mathrm{E}+05$ & $3,08 \mathrm{E}+05$ & $1,97 E+05$ & $6,48 \mathrm{E}+04$ \\
\hline & & Unidade & $1,0-2,0 \mu \mathrm{m}$ & $2,0-3,0 \mu \mathrm{m}$ & $3,0-5,0 \mu \mathrm{m}$ & $5,0-7,0 \mu \mathrm{m}$ & $7,0-10,0 \mu \mathrm{m}$ & $>10,0 \mu \mathrm{m}$ \\
\hline \multirow{8}{*}{ Assento 2B } & $\begin{array}{c}\text { Concentração média de } \\
\text { fundo }\end{array}$ & $\mathrm{P} / \mathrm{m}^{3}$ & $2,03 E+05$ & $7,00 E+04$ & $6,67 E+03$ & $0,00 \mathrm{E}+00$ & $0,00 E+00$ & $0,00 E+00$ \\
\hline & \begin{tabular}{|c|}
$\begin{array}{c}\text { Número de particulas de } \\
\text { fundo }\end{array}$ \\
\end{tabular} & $\mathbf{P}$ & 61 & 21 & 2 & 0 & 0 & 0 \\
\hline & $\begin{array}{c}\text { Concentração média } \\
\text { liquida } \\
\end{array}$ & $\mathrm{P} / \mathrm{m}^{3}$ & $7,11 \mathrm{E}+07$ & $6,18 \mathrm{E}+07$ & $6,32 \mathrm{E}+07$ & $5,51 \mathrm{E}+07$ & $1,19 \mathrm{E}+07$ & $1,19 \mathrm{E}+06$ \\
\hline & $\begin{array}{c}\text { Número de Particulas } \\
\text { média liquida }\end{array}$ & $\mathbf{P}$ & 21340 & 18542 & 18960 & 16520 & 3562 & 356 \\
\hline & Desvio - Poisson & $\#$ & 146,08 & 136,17 & 137,70 & 128,53 & 59,68 & 18,87 \\
\hline & $\begin{array}{c}\text { Desvio - Poisson - } \\
\text { Relativo } \\
\end{array}$ & $\%$ & 0,7 & 0,7 & 0,7 & 0,8 & 1,7 & 5,3 \\
\hline & $\begin{array}{l}\text { Desvio padrão } \\
\text { Concentração }\end{array}$ & $\mathrm{P} / \mathrm{m}^{3}$ & $4,56 \mathrm{E}+03$ & $4,57 E+03$ & $3,63 E+03$ & $9,41 E+02$ & $7,09 \mathrm{E}+02$ & $8,37 E+01$ \\
\hline & DP/Concentração média & $\%$ & 0,0064 & 0,0074 & 0,0057 & 0,0017 & 0,0060 & 0,0071 \\
\hline \multirow{2}{*}{\multicolumn{2}{|c|}{ Erro total medições(દ) }} & $\mathrm{P} / \mathrm{m}^{3}$ & $4,87 E+05$ & $4,54 \mathrm{E}+05$ & $4,59 \mathrm{E}+05$ & $4,28 E+05$ & $1,99 \mathrm{E}+05$ & $6,29 E+04$ \\
\hline & & Unidade & $1,0-2,0 \mu \mathrm{m}$ & $2,0-3,0 \mu \mathrm{m}$ & $3,0-5,0 \mu \mathrm{m}$ & $5,0-7,0 \mu \mathrm{m}$ & $7,0-10,0 \mu \mathrm{m}$ & $>10,0 \mu \mathrm{m}$ \\
\hline \multirow{8}{*}{ Assento 2A } & $\begin{array}{c}\text { Concentração média de } \\
\text { fundo }\end{array}$ & $\mathrm{P} / \mathrm{m}^{3}$ & $1,13 \mathrm{E}+05$ & $3,67 \mathrm{E}+04$ & $1,00 E+04$ & $0,00 \mathrm{E}+00$ & $0,00 \mathrm{E}+00$ & $0,00 E+00$ \\
\hline & \begin{tabular}{|c|}
$\begin{array}{c}\text { Número de particulas de } \\
\text { fundo }\end{array}$ \\
\end{tabular} & $\mathbf{P}$ & 34 & 11 & 3 & 0 & 0 & 0 \\
\hline & $\begin{array}{c}\text { Concentração média } \\
\text { liquida } \\
\end{array}$ & $\mathrm{P} / \mathrm{m}^{3}$ & $7,11 \mathrm{E}+07$ & $5,48 E+07$ & $4,18 \mathrm{E}+07$ & $2,63 E+07$ & $1,01 \mathrm{E}+07$ & $1,34 \mathrm{E}+06$ \\
\hline & $\begin{array}{c}\text { Número de Particulas } \\
\text { média liquida }\end{array}$ & $\mathbf{P}$ & 21340 & 16439 & 12528 & 7895 & 3039 & 402 \\
\hline & Desvio - Poisson & $\#$ & 146,08 & 128,21 & 111,93 & 88,85 & 55,13 & 20,04 \\
\hline & $\begin{array}{c}\text { Desvio - Poisson - } \\
\text { Relativo } \\
\end{array}$ & $\%$ & 0,7 & 0,8 & 0,9 & 1,1 & 1,8 & 5,0 \\
\hline & $\begin{array}{l}\text { Desvio padrão } \\
\text { Concentração }\end{array}$ & $\mathrm{P} / \mathrm{m}^{3}$ & $4,56 \mathrm{E}+03$ & $1,68 \mathrm{E}+03$ & $7,17 E+02$ & $1,15 \mathrm{E}+03$ & $8,26 \mathrm{E}+02$ & $1,16 \mathrm{E}+02$ \\
\hline & DP/Concentração média & $\%$ & 0,0064 & 0,0031 & 0,0017 & 0,0044 & 0,0082 & 0,0087 \\
\hline \multicolumn{2}{|c|}{ Erro total medições(દ) } & $\mathrm{P} / \mathrm{m}^{3}$ & $4,87 E+05$ & $4,27 E+05$ & $3,73 \mathrm{E}+05$ & $2,96 \mathrm{E}+05$ & $1,84 \mathrm{E}+05$ & $6,68 \mathrm{E}+04$ \\
\hline
\end{tabular}




\begin{tabular}{|c|c|c|c|c|c|c|c|c|}
\hline & & Unidade & $1,0-2,0 \mu \mathrm{m}$ & $2,0-3,0 \mu \mathrm{m}$ & $3,0-5,0 \mu \mathrm{m}$ & $5,0-7,0 \mu \mathrm{m}$ & $7,0-10,0 \mu \mathrm{m}$ & $>10,0 \mu \mathrm{m}$ \\
\hline \multirow{8}{*}{ Assento 3B } & \begin{tabular}{|c|}
$\begin{array}{c}\text { Concentração média de } \\
\text { fundo }\end{array}$ \\
\end{tabular} & $\mathrm{P} / \mathrm{m}^{3}$ & $2,23 E+05$ & $6,50 E+04$ & $6,67 E+03$ & $0,00 E+00$ & $0,00 E+00$ & $0,00 E+00$ \\
\hline & \begin{tabular}{|c|}
$\begin{array}{c}\text { Número de particulas de } \\
\text { fundo }\end{array}$ \\
\end{tabular} & $\mathbf{P}$ & 67 & 20 & 2 & 0 & 0 & 0 \\
\hline & $\begin{array}{c}\text { Concentração média } \\
\text { liquida }\end{array}$ & $\mathrm{P} / \mathrm{m}^{3}$ & $8,81 E+07$ & $8,67 E+07$ & $5,95 \mathrm{E}+07$ & $4,51 \mathrm{E}+07$ & $1,19 \mathrm{E}+07$ & $1,29 E+06$ \\
\hline & $\begin{array}{c}\text { Número de Particulas } \\
\text { média liquida }\end{array}$ & $\mathbf{P}$ & 26425 & 26016 & 17842 & 13520 & 3563 & 387 \\
\hline & Desvio - Poisson & $\#$ & 162,56 & 161,29 & 133,57 & 116,28 & 59,69 & 19,67 \\
\hline & $\begin{array}{c}\text { Desvio - Poisson - } \\
\text { Relativo } \\
\end{array}$ & $\%$ & 0,6 & 0,6 & 0,7 & 0,9 & 1,7 & 5,1 \\
\hline & $\begin{array}{c}\text { Desvio padrão } \\
\text { Concentração }\end{array}$ & $\mathrm{P} / \mathrm{m}^{3}$ & $4,34 \mathrm{E}+03$ & $4,24 E+03$ & $7,68 \mathrm{E}+02$ & $1,36 \mathrm{E}+03$ & $8,87 E+02$ & $4,64 E+01$ \\
\hline & DP/Concentração média & $\%$ & 0,0049 & 0,0049 & 0,0013 & 0,0030 & 0,0075 & 0,0036 \\
\hline \multirow{2}{*}{\multicolumn{2}{|c|}{ Erro total medições(દ) }} & $\mathrm{P} / \mathrm{m}^{3}$ & $5,42 \mathrm{E}+05$ & $5,38 \mathrm{E}+05$ & $4,45 E+05$ & $3,88 \mathrm{E}+05$ & $1,99 \mathrm{E}+05$ & $6,56 \mathrm{E}+04$ \\
\hline & & Unidade & $1,0-2,0 \mu \mathrm{m}$ & $2,0-3,0 \mu \mathrm{m}$ & $3,0-5,0 \mu \mathrm{m}$ & $5,0-7,0 \mu \mathrm{m}$ & $7,0-10,0 \mu \mathrm{m}$ & $>10,0 \mu \mathrm{m}$ \\
\hline \multirow{8}{*}{ Assento 3A } & \begin{tabular}{|c|}
$\begin{array}{c}\text { Concentração média de } \\
\text { fundo }\end{array}$ \\
\end{tabular} & $\mathrm{P} / \mathrm{m}^{3}$ & $1,37 \mathrm{E}+05$ & $7,00 E+04$ & $3,33 E+03$ & $0,00 E+00$ & $0,00 E+00$ & $0,00 E+00$ \\
\hline & \begin{tabular}{|c|}
$\begin{array}{c}\text { Número de particulas de } \\
\text { fundo }\end{array}$ \\
\end{tabular} & $\mathbf{P}$ & 41 & 21 & 1 & 0 & 0 & 0 \\
\hline & $\begin{array}{c}\text { Concentração média } \\
\text { liquida }\end{array}$ & $\mathrm{P} / \mathrm{m}^{3}$ & $6,30 E+07$ & $5,45 E+07$ & $5,12 E+07$ & $2,62 \mathrm{E}+07$ & $1,17 \mathrm{E}+07$ & $2,10 E+06$ \\
\hline & $\begin{array}{c}\text { Número de Particulas } \\
\text { média liquida }\end{array}$ & $\mathbf{P}$ & 18886 & 16360 & 15350 & 7852 & 3520 & 630 \\
\hline & Desvio - Poisson & $\#$ & 137,43 & 127,91 & 123,90 & 88,61 & 59,33 & 25,10 \\
\hline & $\begin{array}{c}\text { Desvio - Poisson - } \\
\text { Relativo } \\
\end{array}$ & $\%$ & 0,7 & 0,8 & 0,8 & 1,1 & 1,7 & 4,0 \\
\hline & $\begin{array}{c}\text { Desvio padrão } \\
\text { Concentração }\end{array}$ & $\mathrm{P} / \mathrm{m}^{3}$ & $9,17 E+02$ & $2,93 \mathrm{E}+02$ & $4,90 E+02$ & $8,17 E+02$ & $1,83 E+02$ & $1,24 \mathrm{E}+02$ \\
\hline & DP/Concentração média & $\%$ & 0,0015 & 0,0005 & 0,0010 & 0,0031 & 0,0016 & 0,0059 \\
\hline \multicolumn{2}{|c|}{ Erro total medições $(\varepsilon)$} & $\mathrm{P} / \mathrm{m}^{3}$ & $4,58 \mathrm{E}+05$ & $4,26 \mathrm{E}+05$ & $4,13 E+05$ & $2,95 E+05$ & $1,98 \mathrm{E}+05$ & $8,37 \mathrm{E}+04$ \\
\hline
\end{tabular}


Tabela D-12. Resultados das medições de partículas no assento (Sistema UFAD mod. à $22^{\circ} \mathrm{C}-$ injeção pelo assento $3 \mathrm{E}$ )

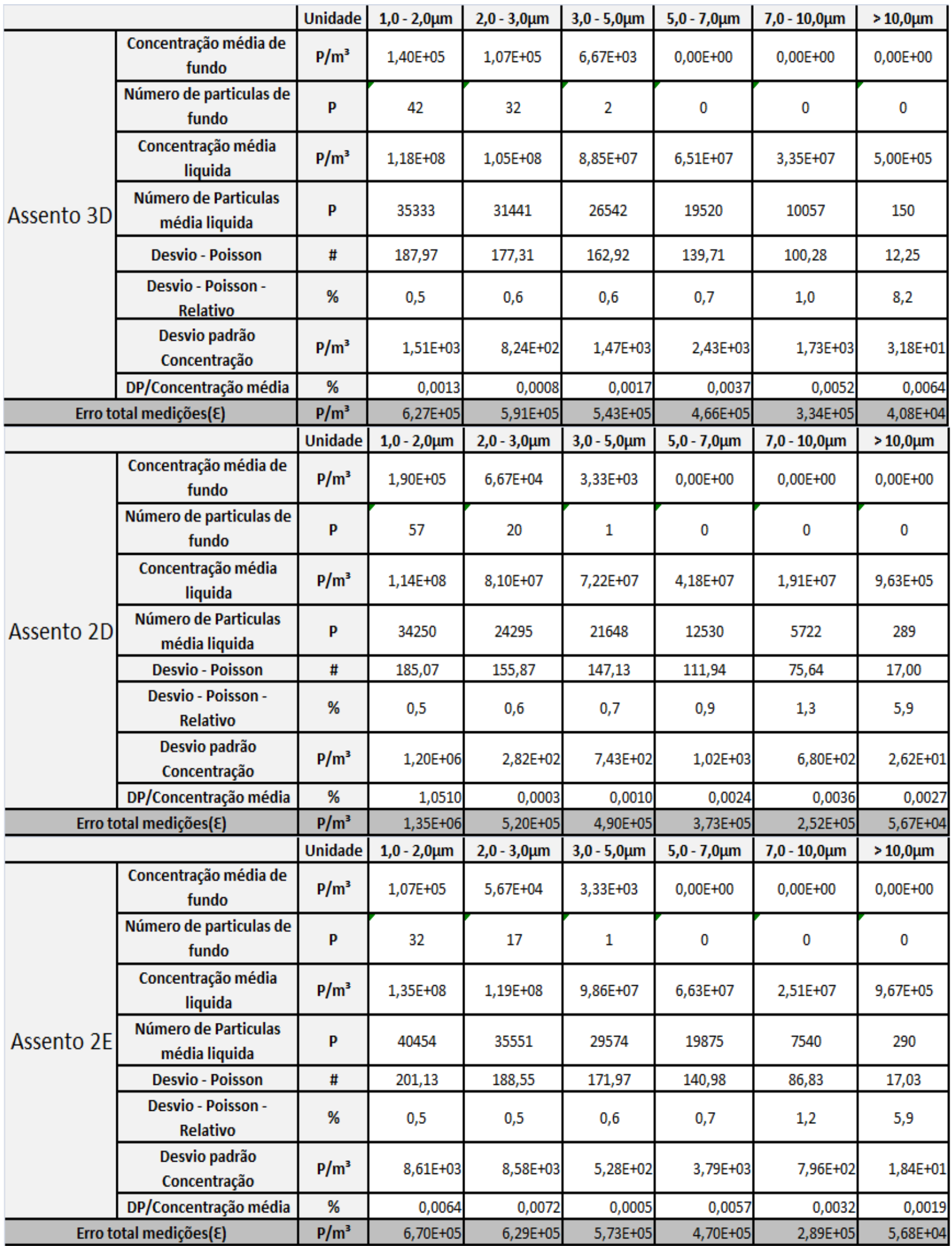




\begin{tabular}{|c|c|c|c|c|c|c|c|c|}
\hline & & Unidade & $1,0-2,0 \mu \mathrm{m}$ & $2,0-3,0 \mu \mathrm{m}$ & $3,0-5,0 \mu \mathrm{m}$ & $5,0-7,0 \mu \mathrm{m}$ & $7,0-10,0 \mu \mathrm{m}$ & $>10,0 \mu \mathrm{m}$ \\
\hline \multirow{8}{*}{ Assento 1D } & $\begin{array}{c}\text { Concentração média de } \\
\text { fundo }\end{array}$ & $\mathrm{P} / \mathrm{m}^{3}$ & $2,23 \mathrm{E}+05$ & $1,13 \mathrm{E}+05$ & $6,67 E+03$ & $0,00 E+00$ & $0,00 \mathrm{E}+00$ & $0,00 E+00$ \\
\hline & $\begin{array}{c}\text { Número de particulas de } \\
\text { fundo }\end{array}$ & $\mathbf{p}$ & 67 & 34 & 2 & 0 & 0 & 0 \\
\hline & $\begin{array}{c}\text { Concentração média } \\
\text { liquida } \\
\end{array}$ & $\mathrm{P} / \mathrm{m}^{3}$ & $1,07 E+08$ & $1,05 E+08$ & $5,97 \mathrm{E}+07$ & $5,08 \mathrm{E}+07$ & $9,42 E+06$ & $5,90 \mathrm{E}+05$ \\
\hline & $\begin{array}{l}\text { Número de Particulas } \\
\text { média liquida }\end{array}$ & $\mathbf{P}$ & 32158 & 31601 & 17899 & 15235 & 2826 & 177 \\
\hline & Desvio - Poisson & $\#$ & 179,33 & 177,77 & 133,79 & 123,43 & 53,16 & 13,30 \\
\hline & $\begin{array}{l}\text { Desvio - Poisson - } \\
\text { Relativo }\end{array}$ & $\%$ & 0,6 & 0,6 & 0,7 & 0,8 & 1,9 & 7,5 \\
\hline & $\begin{array}{l}\text { Desvio padrão } \\
\text { Concentração } \\
\end{array}$ & $\mathrm{P} / \mathrm{m}^{3}$ & $2,72 E+03$ & $2,67 E+03$ & $1,09 \mathrm{E}+03$ & $1,41 \mathrm{E}+03$ & $2,56 \mathrm{E}+02$ & $1,31 \mathrm{E}+01$ \\
\hline & DP/Concentração média & $\%$ & 0,0025 & 0,0025 & 0,0018 & 0,0028 & 0,0027 & 0,0022 \\
\hline \multirow{2}{*}{\multicolumn{2}{|c|}{ Erro total medições(દ) }} & $\mathrm{P} / \mathrm{m}^{3}$ & $5,98 E+05$ & $5,93 E+05$ & $4,46 E+05$ & $4,11 E+05$ & $1,77 E+05$ & $4,43 E+04$ \\
\hline & & Unidade & $1,0-2,0 \mu \mathrm{m}$ & $2,0-3,0 \mu \mathrm{m}$ & $3,0-5,0 \mu \mathrm{m}$ & $5,0-7,0 \mu \mathrm{m}$ & $7,0-10,0 \mu \mathrm{m}$ & $>10,0 \mu \mathrm{m}$ \\
\hline \multirow{8}{*}{ Assento $1 \mathrm{E}$} & $\begin{array}{c}\text { Concentração média de } \\
\text { fundo }\end{array}$ & $\mathrm{P} / \mathrm{m}^{3}$ & $1,47 E+05$ & $1,13 E+05$ & $1,00 \mathrm{E}+04$ & $0,00 \mathrm{E}+00$ & $0,00 E+00$ & $0,00 E+00$ \\
\hline & $\begin{array}{c}\text { Número de particulas de } \\
\text { fundo }\end{array}$ & $\mathbf{p}$ & 44 & 34 & 3 & 0 & 0 & 0 \\
\hline & $\begin{array}{c}\text { Concentração média } \\
\text { liquida }\end{array}$ & $\mathrm{P} / \mathrm{m}^{3}$ & $9,66 \mathrm{E}+07$ & $9,51 E+07$ & $7,51 \mathrm{E}+07$ & $4,40 E+07$ & $8,58 \mathrm{E}+06$ & $5,70 E+05$ \\
\hline & $\begin{array}{c}\text { Número de Particulas } \\
\text { média liquida }\end{array}$ & $\mathbf{P}$ & 28983 & 28545 & 22538 & 13187 & 2575 & 171 \\
\hline & Desvio - Poisson & $\#$ & 170,24 & 168,95 & 150,12 & 114,83 & 50,74 & 13,08 \\
\hline & $\begin{array}{c}\text { Desvio - Poisson - } \\
\text { Relativo } \\
\end{array}$ & $\%$ & 0,6 & 0,6 & 0,7 & 0,9 & 2,0 & 7,6 \\
\hline & $\begin{array}{l}\text { Desvio padrão } \\
\text { Concentração }\end{array}$ & $\mathrm{P} / \mathrm{m}^{3}$ & $3,20 E+03$ & $3,11 E+03$ & $1,40 \mathrm{E}+03$ & $1,11 \mathrm{E}+03$ & $2,02 E+02$ & $1,19 \mathrm{E}+01$ \\
\hline & DP/Concentração média & $\%$ & 0,0033 & 0,0033 & 0,0019 & 0,0025 & 0,0024 & 0,0021 \\
\hline \multirow{2}{*}{\multicolumn{2}{|c|}{ Erro total medições(દ) }} & $\mathrm{P} / \mathrm{m}^{3}$ & $5,67 E+05$ & $5,63 E+05$ & $5,00 E+05$ & $3,83 E+05$ & $1,69 \mathrm{E}+05$ & $4,36 \mathrm{E}+04$ \\
\hline & & Unidade & $1,0-2,0 \mu \mathrm{m}$ & $2,0-3,0 \mu \mathrm{m}$ & $3,0-5,0 \mu \mathrm{m}$ & $5,0-7,0 \mu \mathrm{m}$ & $7,0-10,0 \mu \mathrm{m}$ & $>10,0 \mu \mathrm{m}$ \\
\hline \multirow{8}{*}{ Assento $1 \mathrm{~B}$} & $\begin{array}{c}\text { Concentração média de } \\
\text { fundo }\end{array}$ & $\mathrm{P} / \mathrm{m}^{3}$ & $7,00 \mathrm{E}+04$ & $3,33 \mathrm{E}+04$ & $3,33 \mathrm{E}+03$ & $0,00 \mathrm{E}+00$ & $0,00 E+00$ & $0,00 E+00$ \\
\hline & $\begin{array}{c}\text { Número de particulas de } \\
\text { fundo } \\
\end{array}$ & $\mathbf{p}$ & 21 & 10 & 1 & 0 & 0 & 0 \\
\hline & $\begin{array}{c}\text { Concentração média } \\
\text { liquida }\end{array}$ & $\mathrm{P} / \mathrm{m}^{3}$ & $6,58 \mathrm{E}+07$ & $6,51 E+07$ & $5,26 \mathrm{E}+07$ & $2,89 \mathrm{E}+07$ & $5,34 E+06$ & $3,53 E+05$ \\
\hline & $\begin{array}{c}\text { Número de Particulas } \\
\text { média liquida }\end{array}$ & $\mathbf{P}$ & 19745 & 19530 & 15790 & 8677 & 1602 & 106 \\
\hline & Desvio - Poisson & $\#$ & 140,5169029 & 139,7497764 & 125,6582667 & 93,15 & 40,02 & 10,30 \\
\hline & $\begin{array}{l}\text { Desvio - Poisson - } \\
\text { Relativo }\end{array}$ & $\%$ & 0,7 & 0,7 & 0,8 & 1,1 & 2,5 & 9,7 \\
\hline & $\begin{array}{l}\text { Desvio padrão } \\
\text { Concentração }\end{array}$ & $\mathrm{P} / \mathrm{m}^{3}$ & $2,56 \mathrm{E}+03$ & $2,50 E+03$ & $1,74 \mathrm{E}+03$ & $1,15 \mathrm{E}+03$ & $2,65 E+02$ & $2,35 \mathrm{E}+01$ \\
\hline & DP/Concentração média & $\%$ & 0,0039 & 0,0038 & 0,0033 & 0,0040 & 0,0050 & 0,0066 \\
\hline \multicolumn{2}{|c|}{ Erro total medições(દ) } & $\mathrm{P} / \mathrm{m}^{3}$ & $4,68 \mathrm{E}+05$ & $4,66 E+05$ & $4,19 \mathrm{E}+05$ & $3,11 E+05$ & $1,33 E+05$ & $3,43 \mathrm{E}+04$ \\
\hline
\end{tabular}




\begin{tabular}{|c|c|c|c|c|c|c|c|c|}
\hline & & Unidade & $1,0-2,0 \mu \mathrm{m}$ & $2,0-3,0 \mu \mathrm{m}$ & $3,0-5,0 \mu \mathrm{m}$ & $5,0-7,0 \mu \mathrm{m}$ & $7,0-10,0 \mu \mathrm{m}$ & $>10,0 \mu \mathrm{m}$ \\
\hline \multirow{8}{*}{ Assento 1A } & $\begin{array}{c}\text { Concentração média de } \\
\text { fundo }\end{array}$ & $\mathrm{P} / \mathrm{m}^{3}$ & $1,50 E+05$ & $5,00 E+04$ & $3,33 \mathrm{E}+03$ & $0,00 E+00$ & $0,00 E+00$ & $0,00 E+00$ \\
\hline & $\begin{array}{c}\text { Número de particulas de } \\
\text { fundo }\end{array}$ & $\mathbf{P}$ & 45 & 15 & 1 & 0 & 0 & 0 \\
\hline & $\begin{array}{c}\text { Concentração média } \\
\text { liquida } \\
\end{array}$ & $\mathrm{P} / \mathrm{m}^{3}$ & $6,20 E+07$ & $6,15 \mathrm{E}+07$ & $1,40 \mathrm{E}+07$ & $7,83 E+06$ & $1,95 E+06$ & $3,10 \mathrm{E}+05$ \\
\hline & $\begin{array}{l}\text { Número de Particulas } \\
\text { média liquida }\end{array}$ & $\mathbf{p}$ & 18603 & 18461 & 4200 & 2350 & 586 & 93 \\
\hline & Desvio - Poisson & $\#$ & 136,39 & 135,87 & 64,81 & 48,48 & 24,21 & 9,64 \\
\hline & $\begin{array}{c}\text { Desvio - Poisson - } \\
\text { Relativo } \\
\end{array}$ & $\%$ & 0,7 & 0,7 & 1,5 & 2,1 & 4,1 & 10,4 \\
\hline & $\begin{array}{l}\text { Desvio padrão } \\
\text { Concentração }\end{array}$ & $\mathrm{P} / \mathrm{m}^{3}$ & $1,17 E+03$ & $1,36 \mathrm{E}+03$ & $5,08 \mathrm{E}+02$ & $8,57 E+01$ & $1,23 E+02$ & $8,54 E+00$ \\
\hline & DP/Concentração média & $\%$ & 0,0019 & 0,0022 & 0,0036 & 0,0011 & 0,0063 & 0,0028 \\
\hline \multirow{2}{*}{\multicolumn{2}{|c|}{ Erro total medições(દ) }} & $\mathrm{P} / \mathrm{m}^{3}$ & $4,55 E+05$ & $4,53 E+05$ & $2,16 \mathrm{E}+05$ & $1,62 \mathrm{E}+05$ & $8,07 E+04$ & $3,21 \mathrm{E}+04$ \\
\hline & & Unidade & $1,0-2,0 \mu \mathrm{m}$ & $2,0-3,0 \mu \mathrm{m}$ & $3,0-5,0 \mu \mathrm{m}$ & $5,0-7,0 \mu \mathrm{m}$ & $7,0-10,0 \mu \mathrm{m}$ & $>10,0 \mu \mathrm{m}$ \\
\hline \multirow{8}{*}{ Assento 2B } & $\begin{array}{c}\text { Concentração média de } \\
\text { fundo }\end{array}$ & $\mathrm{P} / \mathrm{m}^{3}$ & $1,77 \mathrm{E}+05$ & $8,17 E+04$ & $1,33 E+04$ & $0,00 \mathrm{E}+00$ & $0,00 \mathrm{E}+00$ & $0,00 E+00$ \\
\hline & $\begin{array}{c}\text { Número de particulas de } \\
\text { fundo }\end{array}$ & $\mathbf{p}$ & 53 & 25 & 4 & 0 & 0 & 0 \\
\hline & $\begin{array}{c}\text { Concentração média } \\
\text { liquida } \\
\end{array}$ & $\mathrm{P} / \mathrm{m}^{3}$ & $6,18 \mathrm{E}+07$ & $6,07 E+07$ & $5,21 E+07$ & $3,36 \mathrm{E}+07$ & $9,82 E+06$ & $1,50 E+06$ \\
\hline & $\begin{array}{c}\text { Número de Particulas } \\
\text { média liquida }\end{array}$ & $\mathbf{P}$ & 18554 & 18205 & 15644 & 10067 & 2945 & 450 \\
\hline & Desvio - Poisson & $\#$ & 136,21 & 134,93 & 125,08 & 100,33 & 54,27 & 21,21 \\
\hline & $\begin{array}{c}\text { Desvio - Poisson - } \\
\text { Relativo } \\
\end{array}$ & $\%$ & 0,7 & 0,7 & 0,8 & 1,0 & 1,8 & 4,7 \\
\hline & $\begin{array}{l}\text { Desvio padrão } \\
\text { Concentração }\end{array}$ & $\mathrm{P} / \mathrm{m}^{3}$ & $1,12 E+04$ & $1,10 E+04$ & $7,00 E+03$ & $3,22 \mathrm{E}+03$ & $5,69 \mathrm{E}+02$ & $1,30 E+02$ \\
\hline & DP/Concentração média & $\%$ & 0,0181 & 0,0181 & 0,0134 & 0,0096 & 0,0058 & 0,0086 \\
\hline \multirow{2}{*}{\multicolumn{2}{|c|}{ Erro total medições $(\varepsilon)$}} & $\mathrm{P} / \mathrm{m}^{3}$ & $4,54 E+05$ & $4,50 \mathrm{E}+05$ & $4,17 E+05$ & $3,34 E+05$ & $1,81 E+05$ & $7,07 E+04$ \\
\hline & & Unidade & $1,0-2,0 \mu \mathrm{m}$ & $2,0-3,0 \mu \mathrm{m}$ & $3,0-5,0 \mu \mathrm{m}$ & $5,0-7,0 \mu \mathrm{m}$ & $7,0-10,0 \mu \mathrm{m}$ & $>10,0 \mu \mathrm{m}$ \\
\hline \multirow{8}{*}{ Assento 2A } & $\begin{array}{c}\text { Concentração média de } \\
\text { fundo } \\
\end{array}$ & $\mathrm{P} / \mathrm{m}^{3}$ & $9,00 E+04$ & $1,03 E+05$ & $6,67 \mathrm{E}+03$ & $0,00 \mathrm{E}+00$ & $0,00 \mathrm{E}+00$ & $0,00 E+00$ \\
\hline & $\begin{array}{c}\text { Número de particulas de } \\
\text { fundo }\end{array}$ & $\mathbf{p}$ & 27 & 31 & 2 & 0 & 0 & 0 \\
\hline & $\begin{array}{c}\text { Concentração média } \\
\text { liquida }\end{array}$ & $\mathrm{P} / \mathrm{m}^{3}$ & $4,05 E+07$ & $2,77 \mathrm{E}+07$ & $2,19 \mathrm{E}+07$ & $1,51 E+07$ & $4,10 E+06$ & $8,93 E+05$ \\
\hline & $\begin{array}{c}\text { Número de Particulas } \\
\text { média liquida }\end{array}$ & $\mathbf{p}$ & 12141 & 8313 & 6582 & 4520 & 1230 & 268 \\
\hline & Desvio - Poisson & $\#$ & 110,19 & 91,18 & 81,13 & 67,23 & 35,07 & 16,37 \\
\hline & $\begin{array}{c}\text { Desvio - Poisson - } \\
\text { Relativo } \\
\end{array}$ & $\%$ & 0,9 & 1,1 & 1,2 & 1,5 & 2,9 & 6,1 \\
\hline & $\begin{array}{l}\text { Desvio padrão } \\
\text { Concentração }\end{array}$ & $\mathrm{P} / \mathrm{m}^{3}$ & $1,05 E+03$ & $7,43 E+02$ & $7,72 \mathrm{E}+01$ & $8,78 \mathrm{E}+01$ & $1,03 \mathrm{E}+02$ & $1,13 E+02$ \\
\hline & DP/Concentração média & $\%$ & 0,0026 & 0,0027 & 0,0004 & 0,0006 & 0,0025 & 0,0126 \\
\hline \multicolumn{2}{|c|}{ Erro total medições( $(\varepsilon)$} & $\mathrm{P} / \mathrm{m}^{3}$ & $3,67 E+05$ & $3,04 E+05$ & $2,70 E+05$ & $2,24 E+05$ & $1,17 E+05$ & $5,46 E+04$ \\
\hline
\end{tabular}




\begin{tabular}{|c|c|c|c|c|c|c|c|c|}
\hline & & Unidade & $1,0-2,0 \mu \mathrm{m}$ & $2,0-3,0 \mu \mathrm{m}$ & $3,0-5,0 \mu \mathrm{m}$ & $5,0-7,0 \mu \mathrm{m}$ & $7,0-10,0 \mu \mathrm{m}$ & $>10,0 \mu \mathrm{m}$ \\
\hline \multirow{8}{*}{ Assento $3 \mathrm{~B}$} & $\begin{array}{c}\text { Concentração média de } \\
\text { fundo }\end{array}$ & $\mathrm{P} / \mathrm{m}^{3}$ & $2,97 E+05$ & $1,87 E+05$ & $3,33 E+03$ & $0,00 E+00$ & $0,00 E+00$ & $0,00 E+00$ \\
\hline & $\begin{array}{c}\text { Número de particulas de } \\
\text { fundo }\end{array}$ & $\mathbf{P}$ & 89 & 56 & 1 & 0 & 0 & 0 \\
\hline & $\begin{array}{c}\text { Concentração média } \\
\text { liquida }\end{array}$ & $\mathrm{P} / \mathrm{m}^{3}$ & $8,89 \mathrm{E}+07$ & $8,15 \mathrm{E}+07$ & $5,23 \mathrm{E}+07$ & $1,81 \mathrm{E}+07$ & $7,96 \mathrm{E}+06$ & $1,16 \mathrm{E}+06$ \\
\hline & $\begin{array}{c}\text { Número de Particulas } \\
\text { média liquida }\end{array}$ & $\mathbf{p}$ & 26671 & 24437 & 15682 & 5423 & 2389 & 348 \\
\hline & Desvio - Poisson & $\#$ & 163,31 & 156,32 & 125,23 & 73,64 & 48,88 & 18,65 \\
\hline & $\begin{array}{c}\text { Desvio - Poisson - } \\
\text { Relativo } \\
\end{array}$ & $\%$ & 0,6 & 0,6 & 0,8 & 1,4 & 2,0 & 5,4 \\
\hline & $\begin{array}{l}\text { Desvio padrão } \\
\text { Concentração }\end{array}$ & $\mathrm{P} / \mathrm{m}^{3}$ & $1,43 E+03$ & $2,08 E+04$ & $8,80 E+02$ & $3,94 E+01$ & $2,02 E+02$ & $1,79 \mathrm{E}+01$ \\
\hline & DP/Concentração média & $\%$ & 0,0016 & 0,0256 & 0,0017 & 0,0002 & 0,0025 & 0,0015 \\
\hline \multirow{2}{*}{\multicolumn{2}{|c|}{ Erro total medições( $(\varepsilon)$}} & $\mathrm{P} / \mathrm{m}^{3}$ & $5,44 \mathrm{E}+05$ & $5,21 E+05$ & 4,17E+05 & $2,45 E+05$ & $1,63 \mathrm{E}+05$ & $6,22 E+04$ \\
\hline & & Unidade & $1,0-2,0 \mu \mathrm{m}$ & $2,0-3,0 \mu \mathrm{m}$ & $3,0-5,0 \mu \mathrm{m}$ & $5,0-7,0 \mu \mathrm{m}$ & $7,0-10,0 \mu \mathrm{m}$ & $>10,0 \mu \mathrm{m}$ \\
\hline \multirow{8}{*}{ Assento $3 \mathrm{~A}$} & $\begin{array}{c}\text { Concentração média de } \\
\text { fundo } \\
\end{array}$ & $\mathrm{P} / \mathrm{m}^{3}$ & $1,23 \mathrm{E}+05$ & $5,33 E+04$ & $6,67 E+03$ & $0,00 \mathrm{E}+00$ & $0,00 E+00$ & $0,00 E+00$ \\
\hline & $\begin{array}{c}\text { Número de particulas de } \\
\text { fundo }\end{array}$ & $\mathbf{P}$ & 37 & 16 & 2 & 0 & 0 & 0 \\
\hline & $\begin{array}{c}\text { Concentração média } \\
\text { liquida } \\
\end{array}$ & $\mathrm{P} / \mathrm{m}^{3}$ & $1,05 E+08$ & $8,42 E+07$ & $3,29 \mathrm{E}+07$ & $1,52 E+07$ & $5,08 \mathrm{E}+06$ & $5,07 E+05$ \\
\hline & $\begin{array}{c}\text { Número de Particulas } \\
\text { média liquida }\end{array}$ & $\mathbf{P}$ & 31617 & 25249 & 9875 & 4560 & 1524 & 152 \\
\hline & Desvio - Poisson & $\#$ & 177,81 & 158,90 & 99,37 & 67,53 & 39,04 & 12,33 \\
\hline & $\begin{array}{c}\text { Desvio - Poisson - } \\
\text { Relativo } \\
\end{array}$ & $\%$ & 0,6 & 0,6 & 1,0 & 1,5 & 2,6 & 8,1 \\
\hline & $\begin{array}{l}\text { Desvio padrão } \\
\text { Concentração }\end{array}$ & $\mathrm{P} / \mathrm{m}^{3}$ & $1,81 \mathrm{E}+04$ & $4,74 E+02$ & $2,97 \mathrm{E}+00$ & $1,07 E+00$ & $2,36 \mathrm{E}+00$ & $2,13 \mathrm{E}+00$ \\
\hline & DP/Concentração média & $\%$ & 0,0172 & 0,0006 & 0,0000 & 0,0000 & 0,0000 & 0,0004 \\
\hline \multicolumn{2}{|c|}{ Erro total medições( $(\varepsilon)$} & $\mathrm{P} / \mathrm{m}^{3}$ & $5,93 E+05$ & $5,30 E+05$ & $3,31 \mathrm{E}+05$ & $2,25 E+05$ & $1,30 \mathrm{E}+05$ & $4,11 \mathrm{E}+04$ \\
\hline
\end{tabular}

